\title{
Managing Migrant Workers - moral economies of temporary labour in the Swedish IT and wild berry industries
}

Karin Krifors

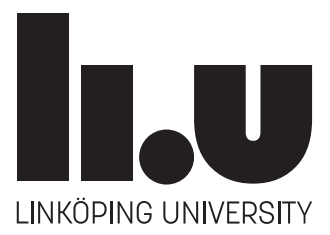

Linköping Studies in Arts and Science No. 717

Faculty of Arts and Sciences

Linköping 2017 
At the Faculty of Arts and Sciences at Linköping University, research and doctoral studies are carried out within broad problem areas. Research is organized in interdisciplinary research environments and doctoral studies mainly in graduate schools. Jointly, they publish the series Linköping Studies in Arts and Science. This thesis comes from Institute for Research on Migration, Ethnicity and Society (REMESO) at the Department of Social and Welfare Studies.

Distributed by:

Department of Social and Welfare Studies Linköping University

58183 Linköping

Karin Krifors

Managing Migrant Workers

- moral economies of temporary labour in the Swedish IT and wild berry industries

Edition 1:1

ISBN 978-91-7685-513-3

ISSN 0282-9800

(c) Karin Krifors

Department of Social and Welfare Studies 2017

Cover Illustration by Nevena Cvijetić

Cover Photo by Nedžad Mešić

Printed by: LiU-Tryck, Linköping 2017 


\section{Acknowledgements}

Although writing this thesis was at times very hard, it has also been fun and hopeful, and it has given me the privilege of being inspired and guided by many people without whom I could never have finished this project. Of course, this project would have been impossible without the people who generously gave of their time and participated in the interviews, and to whom I am very grateful.

During these years I have been part of the inspiring and dynamic research environment at REMESO, Linköping University. I am grateful for how this has influenced my research and especially for all the help from my main supervisor, Anders Neergaard. Thank you Anders for giving me confidence and depth in my research, for always speaking your mind (even at times when I know that you have held back), for all the important discussions on theory and politics, for supporting me in all aspects of academic life and for patiently reading and commenting so thoroughly on everything that I have written. Thank you to my supervisors Sofie Tornhill and Anna Gavanas. Sofie, thank you for your theoretical depth and for all your insightful readings of the endless versions of chapters that I have sent you these past two years. You have made all my texts (and thoughts) better. Anna, thank you for listening and guiding me through all the bumps of the fieldwork with your enthusiastic discussions and encouragement.

Anna Bredström has been indispensable to this project on many levels. My deepest thanks for being an inspiration when it comes to theory and activism; thank you for your crucial friendship, patient mentoring, important research, babysitting, and for everything else. I have also been blessed with incredible PhD colleagues during these years. You all contributed with your warmth and friendly support, and most of you have assisted this thesis in very direct ways with comments on my drafts: Sara Ahlstedt, Christophe Foultier, Jennie K Larsson, Nedžad Mešić, Viktor Vesterberg, Indre Genelyte, Xolani Tshabalala, Julia Willén, Olav Nygård, Andrey Tibajev, and Lisa Karlsson Blom. A special thank you to Jennie and Sara for your integrity, feminism, and for being my most important allies. Also, thank you to Nedžad and Viktor for always adding colour to my day -Nedžad also for helping me out with all the details about the book design and lists; to Julia and Lisa for all your energy and generosity in life and in intellectual matters; to Andrey and Olav for your support during the most hectic last period of writing up this thesis. 
Many people have also read and commented on my work. Thank you Katarina Mattsson, Åsa-Karin Engstand, and Fredrik Hertzberg for your comments on my $60 \%$ text, and in particular Katarina for your thorough reading that gave me a new perspective on my project. Thank you Aina Tollefsen and Peo Hansen whose essential contributions made me take important decisions after my 90\% seminar. Thank you Peo for continuing to give me comments and ideas. At REMESO, all my colleagues have contributed to my work in innumerable ways -thank you! Carl-Ulrich Schierup, who supported and inspired my ideas when I started as a $\mathrm{PhD}$ student, deserves a special mention, and so does Anita Andersson, for patiently guiding me through the terrain of teaching. Eva Rehnholm and Bitte Palmqvist have helped me with all kinds of administrative problems. I also want to thank John Revington for his patient and detailed editing of my manuscript. Needless to say, the responsibility for any shortcomings in the text is mine alone. Nevena Cvijetić has been a (creative) rock when it comes to talking book covers. Charlotta Hedberg, Mats Wingborg and Charles Woolfson have helped me navigate my research in the wild berry industry and I am grateful for that.

I owe great gratitude to Forte (FAS) for supporting my $\mathrm{PhD}$ project, to the Helge Ax:son Jonsson Foundation for generous contributions to my fieldwork and studies abroad, and to the Lars Hierta Foundation. I also want to thank Fulbright Sweden and the Fulbright Commission for the scholarship and indispensible help when I had the opportunity to spend six months in the US as a visiting PhD student. At the University of Southern California I had the privilege of meeting Pierrette Hondagneu-Sotelo. Thank you Pierrette for your incredible generosity, mentoring, and for the academic inspiration during my time in LA. I am also grateful to members of faculty and the graduate students at the Department of Sociology, USC, for sharing your research, commenting on my texts, and making me feel very welcome. A special thank you to Jennifer Candipan for all your thoughts and ideas and generous ways, and to Kristie Beltran Hernandez for showing me around and taking care of me.

Many other people have made a difference to my research process. Thank you Diana Mulinari for your encouragement, comments and for how your analyses and solidarity have influenced many others that mean much to me in the academy, Aleksandra Allund for paving the way, Helma Lutz for support and helping me with my applications, Marianne Winther Jørgensen for conversations and all your work when I was buried in the dissertation during crucial application periods, and Sabine Gruber and Josefina Syssner for listening and for giving me advice. Thank you Maja Sager and Paula Mulinari who have inspired me with their research and their perspectives on citizenship, racism, and work. I am in many ways 
indebted to other friends who were also $\mathrm{PhD}$ candidates, and whose research has been important to me. My deepest thank you to Linnéa Bodén, Veronica Ekström, Sofia Lindström, and Hanna Sjögren for providing a safe place to resist academic conventions, to Anna Siverskog for great moments of activism, food and writing, to Anna Kaijser for always sharing your wisdom and for commenting on my thesis during this last intense period of writing, and to Vanna Nordling - talking to you about theories and methods, about babies, injustices, life, and about making sense of a PhD project, has been fundamental! Also thank you to Minna Seikkula and Ayşegül Kayagil for your helpful comments on my recent texts.

I am grateful to my extended family for all their support, babysitting and dog sitting: Petter Krifors, Erik Krifors, Eva-Lena Samuelsson, LarsGöran Thorell, Eva Krifors and Per Silfwerin, Lilian and Sven-Erik Edman, Birgitta Petersson and Christer Rönneholm - thank you! Also my friends have been invaluable during these years. Thank you for taking care of me in Norrköping: Malin Ringqvist, Tobias Fälth, and Ylva Persson; for living with me in Malmö: Anna Johansson, Manne Palm, and Oscar Kjell; for sharing laughs and your wisdom with me for more years than I can count; Sara Aarnivaara, Fernando Arias, David Pekovic, Kiki Granath Schmidt, Joanna Johnson, Mirjana Westermark, Moa Sjögärd and Jenny Frank. I am also grateful for the beautiful partners and children that you have brought into my life! Thank you also Malin, Kiki and Love Arinell for all your help with my manuscript, Oscar for sharing research experiences, and Joanna and Mirjana for being my first anti-racist role models at the University. My wonderful friend and fellow researcher Andréa Wiszmeg has been important in all dimensions of my life during these years - thank you for all your strength and integrity and for watching out for me.

Two people have contributed with more hours and more loving support than reasonably possible: Yvonne Thorell and Ola Aronsson. Thank you for everything mum - it is impossible to list it all. Ola, all my love and millions of thank yous for always encouraging me, and for being funny, caring, and passionate about the most unexpected aspects of life. I dedicate this book to Sami, because laughing, talking, and thinking big thoughts with you is my favourite thing and gives me energy to pull off all the rest. 



\section{Contents}

Studying the selection of migrants.................................................................. 1

Managers and the global economy of migration...........................................................

The moral economy of migration management.......................................................4

Labour migration contested - moral debates..................................................................... 5

Research aim and research questions ..............................................................................

Outline of the chapters ......................................................................................................

Labour in regimes of managed migration................................................... 11

Migrant exclusion from citizenship and precarious workers ............................... 12

Managed migration and employer interests.............................................................. 14

Labour migration: discourse and policy in Sweden ......................................................... 15

National and transnational memberships .................................................................. 16

Circular migration - spontaneous migration flows? .......................................................... 18

Continuities and discontinuities of analysing guest-worker regimes................19

Temporary labour migration - two cases .................................................................21

Theorising the moral economy of international production ..................25

Migration: being mobile in a global economy .............................................................26

Production in global chains - locating the actors .....................................................2

The nation and the transnational - institutions and identities ...................................... 30

Locating the worker in theories of production...........................................................

Differences between workers ................................................................................................... 33

Moral economy - grand theory and situated management discourse ............35

Morality as normativity and discourse ................................................................................ 39

Talking to managers - reflections on method............................................ 45

Lingering around the 'buzz of migration talk'

- and engaging with other theories ................................................................................. 45

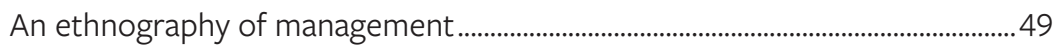

Studying 'up' - access to managers ........................................................................................... 50

Interviewing managers - the informants, ethics and complicity............................... 54

The interview as discourse ...............................................................................................5

Analytical strategies ......................................................................................................... 61

Analysing discourse and interpretative repertoires................................................... 62 
The wild berry industry - seasonal work

and its reliance on foreign labour.

Explaining supply chain relations

- the development of a wild berry industry. .68

A northern business .................................................................................................................. 72

Bargaining over berries - distributors in Sweden .......................................................75

Down the supply chain - working on the

relations with partners in Thailand.

The other side of the industry - madams, Bulgarians, and tourist pickers .. 81

\section{Representations of labour - legitimising}

conditions in the wild berry industry

Speaking back - responsibility as a defence

against discourses of exploitation

Picking berries - the natural law of risks and freedom...........................................8 88

Negotiating the morals of competition........................................................................... 92

Discourses of economy - pricing, valuation, and moral evaluations...............94

Is the price right? Nature and supply chain compromise ..........................................95

Migrants' bargaining power and transnational practices .............................................97

Management constructions of migrants and their morals............................... 100

Respectability and fortune............................................................................................100

Hard work as disposition ......................................................................................................104

Thai culture in the camps........................................................................................................108

Migration control and circularity - constructing the perfect match ............. 110

What migrants do - continuity of farming ...............................................................110

The boundaries of temporary migration ...........................................................................112

The moral economy and public opinion....................................................................... 116

Talking to the media ......................................................................................................116

Knowing the migrants and sharing their interests ......................................................119

Summarising the case for the wild berry industry .............................................. 121

Swedish management discourse in an international IT industry ......123

Studying highly skilled mobility: temporary

workers and expatriate privilege .............................................................................. 124

Indian workers in Sweden - or services performed in India? .......................... 125

Management work - supplying Indian labour .......................................................... 128

Selling workers - management talk as marketing practice .........................................130

Internationalising Swedish industry - a management task........................................134

The abstract language about labour - workers as bodies and resources .. 136

The identity of workplace and employment ...............................................................139

Speaking through globalisation discourse - silencing the role of labour.... 141 
Constructions of cultural differences from a supply-chain perspective ..... 147 Production of management knowledge - mapping cultures and nationalities....151 Discourses of the nation and Indian culture as 'Other' .................................................153 Cultural difference and constructions of race .............................................................155 Those who overcome difference - being cosmopolitan................................................157

Mobility and careers - explaining the social context of Indian workers ...... 159 Mediating intimacy, and the discipline of mobility ........................................................161

Indian labour in economic terms ............................................................................. 162

Economic spaces - negotiating the differences between Sweden and India.......165

Analysing absences - anxiety and the circulation of emotions.......................... 168

Managing emotions and navigating anxiety in the New Economy.............................171

Moral economies of temporary migration - concluding discussion .177

The moral economy of managing temporary migrant workers ....................... 178

Supply chains as the economic setting ..................................................................... 179

Constructions of mobility: circulation and possibilities of moving 'up'....... 181

Constitutive diversity: culture, race, gender and nations ................................. 183

Precarity as the normal condition ........................................................................... 186

The absence of discussions about citizenship ....................................................... 188

Epilogue: Employer arguments in the migration debate .................................... 192

Bibliography ................................................................................................ 195 



\section{Studying the selection of migrants}

National borders as well as citizenship boundaries are regulated, conditioned, and selectively opened or closed to different groups of migrants. There is no single principle that guides migration policy in Europe, but rather a continuous negotiation of different interests and different realities. These negotiations rest upon arguments that highlight humanitarian ideals, economic interests, geopolitics, and history. The management of migration mediates between a multitude of discourses on migration in politics and everyday life in Europe. We hear advocates of humanitarian ideals protest against current migration policies; in other arenas nationalist narratives are voiced and voted through; regional security is strengthened by increased border controls, and, what this thesis primarily focuses on, economic arguments in favour of increased migration and mobility are raised. The economic benefits of migration to Europe are often emphasised by politicians and policymakers in relation to specific types of labour migration, for example temporary migrants who make no citizenship claims, or those who have a highly valued education and high-paying jobs. In this 'economic discourse', employers and businesses are assumed to desire these particular migrants.

This thesis investigates the management of migration and the mediation of mobility, both of citizenship and of economic opportunities, through a focus on practices performed by actors within Swedish industry. By concentrating on the management of one particular migrant group, temporary labour migrants, I will discuss how migrant selection is made legitimate, and how it can be contested within the currently dominant migration regime in Sweden. The politics of migrant management and selection requires accountability and transparency of the categories and definitions that are used. This accountability is important for the management practices to be understood as being legitimate, and to establish why some groups of migrants are favoured over others. This thesis deals with how managers in the private sector define and evaluate migrant workers in interaction with current migration regimes, and how legitimacy around these processes is constituted. Here, I am particularly interested in how language constructs these migrant categories by naming, describing, and arguing for specific definitions, boundaries, and 
differences rather than others. The thesis studies the discourse of labour migration in specific economic, social, and organisational settings.

The material that my analysis rests on was collected mainly between 2011 and 2014 and this thesis was written during a time when European societies and the social sciences were increasingly occupied with issues of migration. The study was carried out in Sweden; a country that is part of the European Union (EU) and that shares many political and legal features with other EU member states. Sweden is however also a country that is portrayed as different because of its Nordic welfare state model and its profile as an open and liberal country regarding migration, both asylum migration and, more recently, labour migration. In 2008, Sweden introduced a policy reform on labour migration that made it easier for employers to apply for work permits for people from countries outside the EU. ${ }^{1}$ The policy reform initiated a debate on the conditions under which workers could, or should, be granted work permits. The design of regulations, standards and administrative routines that needed to be worked out contributed to a focus on diversity among workers, such as different access to social rights and temporary residence permits. ${ }^{2}$ Central to the design of the new labour migration regulation was the role it gave employers in terms of defining their needs for foreign labour, with much less involvement by trade unions than previously (Frank 2014; Neergaard 2015).

State practices of regulating citizenship and entry for different groups of migrants has been relatively well documented in recent years, as the academic field of migration research has expanded and has contributed to a deep and detailed understanding of the changing regimes of migration and citizenship (Castles and Miller 2003; Schierup et al. 2006). This thesis, instead, approaches the study of migration management by centring the role of employers, the involvement of capital interest, and management discourse in the regulation of migrant categories. This perspective contributes to the knowledge about these actors who are given a central role in current migration policy in terms of applying for work permits for foreign workers, as well as designing employment and mobility structures that align with these regimes. Employers and managers of corporations

1 Within the Schengen cooperation area the principle of free movement is central, which means that European Union citizens are exempt from work permit requirements in Sweden.

2 For a longer discussion of all these aspects of labour migration to Sweden see the governmental reports that preceded the reform (SOU 2005:50, 2006:87), as well as governmental reports on circular migration (SOU 2010:40, 2011:28). 
that employ foreign labour therefore play a role in how migration management is justified.

\section{Managers and the global economy of migration}

Employers have not been sufficiently included in studies on migration processes, although they can be assumed to have a large influence on the structures of migration, as well as on migration politics. One implication of this research gap is a lack of systematic theorisation of economic discourses and arguments that concern migration with respect to business, capital, and employers. An intervention in relation to this research is important in order to understand the alliances and political trends in terms of migration attitudes in European societies. In this thesis, I have carried out ethnographic research in two very different industries that dominate the statistics of work permits in Sweden: the wild forest berry industry and the IT services industry. During my research I talked to managers in Swedish industries who are engaged in what they refer to as an 'advancing internationalisation' of the production processes of both wild berries and IT services. Already, the terminology of the 'labour migrant' meets with opposition because to the managers it is not the migration of the workers or the regulation of their citizenship that is necessarily the most interesting or important issue; but the location of labour in the production process.

Labour migrants, in all the disorderly contours of the social world of migration policy and labour market desires, can be understood in relation to two different contexts: their exclusion from citizenship, and their integration in a global economy. In this thesis I will therefore propose theories that take the social position of migrants seriously in dialogue with theories of the internationalisation of production. Specifically, I will discuss the role of supply-chain capitalism (Tsing 2012) and outsourcing in these processes. This dialogue between two research traditions involves thinking critically about the concepts that are being used; for example, defining when people are considered to be labour migrants and when they are part of a temporary foreign labour workforce; when they are considered to be migrant workers and when they constitute transnational labour. 'Labour' signifies a role in the production process, in contrast to the conceptualisation of the 'worker', which communicates a reference to the position of someone performing work in the global economy. 'Migrant' can signify an administrative category, for example a definition that springs from situations in which berry pickers or IT workers are subject to migration control and the administration of work permits. A migrant 
can also refer to someone who has moved to Sweden from India or Thailand, for example, or to someone displaced from their home. In contrast, 'transnational' or 'temporary', as prefixes, describe this movement as neither one-directional nor part of a permanent situation, perhaps indicating that the movement itself is not important at all.

Different concepts are used in the text because of the twin interests of this research project to discuss how managers mediate the migration of people who are also workers, and how migrant labour is situated in relation to Swedish citizenship and Swedish labour. The continuous conceptual discussion that this requires illustrates a tension between the theories of economic globalisation and citizenship, and migrant exclusion; a tension that this thesis will address.

\section{The moral economy of migration management}

In most European countries, the policy area of immigration was one of the least politicised until the mid-1980s. Historically, Sweden has also been characterised by a consensus among most of the political parties in relation to migration politics (Hammar 1985). Today, as right-wing parties attract large numbers of votes on anti-immigration agendas in most European countries, the importance of nationalism in European migration politics is conspicuous. However, the moral legitimacy of migration policies navigates complex issues of membership, including economic membership and the labour market inclusion that is managed by employers.

This thesis maintains a focus on management discourse among managers and employer representatives in Swedish industries who mobilise temporary migrant labour in Swedish industries. ${ }^{3}$ The focus centres on the economy of capitalist production as a field that has implications on the selection and management of migrants. ${ }^{4}$ Managers can be viewed as actors within this economic field of production and labour, in contrast to other actors in migration management who, for instance, perform border controls with reference to national security, or mediate social welfare in line with dominant notions of citizenship. Yet these fields and practices

3 In the IT industry some of the informants are employer representatives who recruit Indian labour to their companies. Others do not recruit foreign labour but are responsible for intracorporate transfers. The informants in the wild berry industry are sometimes entrepreneurs, and sometimes managers, and the majority work in companies that are not the formal employers of temporary migrant labour. Instead they mobilise labour through agreements with suppliers in Thailand.

4 In references to production, I also include production of services. 
are not separate. In order to analyse the economic discourses that frame the work that managers in the Swedish wild berry industry and the IT services industry perform, I make use of the concept of a 'moral economy'. The analytical foundation that a moral economy offers is the perspective on economic relations, as well as cultural, social and moral relations (Sayer 2005a). Economic logic and discourses are not more rationalistic, and do not represent more neatly delimited interests than, for instance, discourses that centre on national belonging. Instead, the managers who provided information for this thesis should be understood as actors who are also situated in national, social, cultural, and economic contexts; contexts that need to be analysed in order to make sense of how they construct the legitimacy of their management practices.

\section{Labour migration contested - moral debates}

Two scenes from my early fieldwork can help to illustrate what I understand as current discussions and contestations of legitimacy when specific aspects of Swedish migration management are discussed.

Two years into my graduate studies I presented a paper at a conference organised within a broad trade union network. Most speakers addressed the exploitation of migrant workers in Sweden, and the discussions that followed about labour rights were engaging and enthusiastic. I gave a presentation that partly brought up some current challenges to labour movement arguments on migration. After my talk a trade union activist commented: 'Just make a note that we are not at all talking about stopping anyone from working here in Sweden. We just want to make sure that Swedish agreements apply in Sweden'. The following week, the same trade union published a report that concluded how more controls on employers were necessary in order to ensure Swedish labour standards (LO 2013). No arguments to stop labour migration, like the activist had pointed out at the conference, were presented in this report. The report received wide criticism that mainly argued that the consequence of trade union logic would be closed borders to hard-working foreign workers. The trade union was accused of being protectionist and of 'disguising their power play into care' (Sydsvenskan, 2013) for migrant workers.

We have come to recognise the positions that some actors take in the debates about labour migration, for example the political opposition between trade unions and employer organisations. In this particular context, which is also a dramaturgy of the debate that many of us recognise, notions about the nation and nationalism emerged as central aspects that contested the legitimacy of certain positions. Avoiding addressing the issue of migrant workers explicitly, the trade union argued for the moral 
legitimacy of maintaining coherent rights and citizenship within Sweden. However, because the trade union argument invoked notions about the nation, the argument was also framed as being protectionist against migrants, and was therefore called out as morally illegitimate. In addition, small adjustments and practices within migration management construct moral positions of, for instance, solidarity within nations or across borders.

Later, during my PhD studies, I was asked to moderate a panel discussion on the topic of what to do about the situation of Asian berry pickers in Sweden. The discussion was organised by students with an interest in the political potential of labour laws and human rights. The public debate in Sweden had been characterised by descriptions of severe exploitation of this migrant group, and several panel members argued that the new regulations on labour migration had caused an erosion of labour rights in Sweden. An employer representative in the panel, however, explained that apart from some exceptions among criminal employers, Thai berry pickers chose to be in Sweden year after year, and that many of them came home with more money than they would otherwise have been able to make in a year. When this was not contested by other members in the panel, a student in the audience asked; 'But what is the problem then? Why are we here talking about this if this is what they [the migrant workers] want?' None of the panel members answered the question, except for the employer representative who confirmed the intervention.

In this situation, the nation did not constitute the central aspect of moral evaluation. Instead, the audience expected detailed knowledge of migrant experiences in order to make a moral judgement on what should be done about their situation - and whether or not it was right to do anything at all. The moral issue was centred on the wellbeing of the berry pickers, and the phrase 'why are we here' challenged the legitimacy of a discussion that concerned anything but the choice of the migrant workers. Although the talk was framed around rights and legal frameworks, the discussion about migration seemed to require a common moral position in order to legitimise any interventions in the mobilisation of migrant workers. Moral evaluations of the panel discussion I have described depend on complex notions about which people are the subjects of national law, labour standards, and human rights, and they also depend on our understanding of the transnational spaces of migrants who are trying to navigate a global economy.

Moral economy is a central theoretical concept in this thesis. It highlights both the normative evaluations and justifications implicit in the design of migrant labour policy and regulations, as well as the moral negotiations of working conditions and compensation for migrant workers. 
The focus is on how these discourses of right and wrong, and the moral justifications that are made by those who recruit migrant labour, employ or manage the work of these migrants in Sweden.

\section{Research aim and research questions}

While migration research has asked valuable questions concerning changing citizenship and migrant inclusion in relation to the Swedish nation, this thesis discusses the effects of how actors within capitalist production and Swedish industries manage migrant work and migration discourse. The aim of this thesis is to explore how managers give meaning to, justify, and negotiate their reliance on temporary migrant workers in two sectors in Sweden with radically different positions within globalised orders of production. More specifically, I analyse how managers in the wild berry industry and the IT services industry talk about, and explain the working conditions of, Thai and Indian temporary migrant workers: the two nationalities that acquire the majority of work permits in Sweden. Using this analysis, my objective is to understand the ways in which managers and employers become directly involved in the regulation of transnational migration, mobility, and labour-market differentiation.

This research aim translates into several research questions:

In what ways do managers describe labour mobility and migrant work in the berry-picking and IT services industries? How do they talk about economic interests in relation to different actors in the global economy?

How do managers produce, or relate to, discourses of transnational and national belonging as they administer working conditions, supervise labour, or control temporary migrant workers?

In what ways do managers evaluate and morally justify arrangements of temporary migrant labour in the two named industries that represent different cases; the wild berry industry, which is characterised by work that is generally classified as unskilled seasonal labour, and the IT services industry, which is assumed to employ high-skilled labour and represent privileged migration?

How can we understand the managers' construction of temporary migrant workers within economic globalisation, and what are the implications for theories of global economic restructuring and theories of migration? 


\section{Outline of the chapters}

This thesis takes as its starting point the recent shifts in migration discourse and policy that introduce complex practices of managing migration, both in terms of entry and border crossing, and in terms of citizenship and access to social rights. In the second chapter of this thesis I will present theories that explain how changing migration regimes correspond to changing notions of a European and Swedish citizenship. In particular, I will focus on how the role of employers has been conceptualised in previous research on labour migration. I will discuss research on social exclusion of migrants and connect these to discussions about national or transnational membership, especially referencing current debates about circular migration and historic debates about guest worker regimes. By the end of this chapter I will shortly introduce the two case studies of temporary migration that this thesis analyses, the management of Thai berry pickers and Indian computer specialists, and provide a brief context on how these cases relate to the regulatory framework of labour migration in Sweden.

In chapter 3 I will present the theoretical framework of this thesis and the central concepts that I will use in the analysis. The theoretical chapter explains why I work with the theoretical framework of moral economy, and how I define different aspects of moral economy to be able to analyse both management discourse and its relations to temporary labour migration. First, I conceptualise global economy with a particular focus on chains and networks in production. I explain why supply chain capitalism (Tsing 2012) represents a particularly useful concept, in light of how both the wild berry industry and the IT industry are characterised by substantial outsourcing. Second, I discuss the centrality of analysing how labour and workers are represented in relation to global economy. During the last part of the theoretical chapter I discuss how the moral dimensions of economy can be conceptualised (Sayer 2005b) and how these dimensions can be productively analysed using tools from discourse psychology (Wetherell and Potter 1992).

Chapter 4 deals with the ethnography of this thesis and presents the choices that I made and how I collected the material on which I base my analyses. I discuss how the timing of my research was characterised by an intense interest in issues of labour migration, which presented me with both opportunities, for instance in terms of access to informants, and obstacles related to expectations on what different cases would represent. I describe my material and how I found the main informants, managers in different supplying companies in the wild berry industry and the IT industry, as well as what was characteristic about the interviews. I discuss 
whether interviewing managers represents a case of studying 'up' and the ethical considerations of this research. I finish the chapter by presenting, in more detail, the analytical strategies and analytical tools that discourse psychology provides and that centres the active use of language and the interpretative repertoires through which managers construct the role of foreign workers in Swedish industries.

The first case that I analyse regards the wild berry industry in the Northern parts of Sweden where thousands of workers from Thailand pick berries during a short season every summer. In chapters 5 and $6 \mathrm{I}$ analyse how managers in so called berry companies talk about the supply chain relations and the role of Thai workers in the industry. In chapter 5 I pay particular attention to the interpretative repertoires around constructions of the industry and its legitimacy in relation to the wider Swedish society. In chapter 6 I analyse how the managers talk about Thai berry pickers in relation to constructions of Thai culture, circular mobility and notions of the Thai body and its ability to perform hard labour. I also discuss the management perspective on how berry picking can be evaluated and how the economic arrangements can be justified. In chapters 7 and 8 I present the analyses of interviews with managers in the Swedish IT industry. In chapter 7 I mainly discuss how managers talked about internationalisation of the industry, which constituted a dominant theme in the interviews. I analyse the role of supplying companies when IT services are 'offshored' to India, and how managers describe the role of Indian workers in Sweden in relation to these processes. In chapter 8, I analyse how Indian workers are situated in relation to the Swedish labour market as managers talk about cultural differences and public feelings of suspicion and fear of loosing jobs. In the final chapter I discuss the similarities and tensions between the analyses of the two case studies. I situate the management of temporary labour migration in relation to debates about global differentiation of workers, mobility and citizenship. 



\section{Labour in regimes of managed migration}

Migration theories explain the movement of people and how boundaries are drawn between different categories of citizens and non-citizens. These theoretical frameworks are central for studying the moral negotiations that regimes of managed migration give rise to. The migration theories presented in this chapter explain a recent upturn of economic discourse around the desire to select certain migrants, partly by connecting these trends to the changing social citizenship of the European welfare states (Schierup et al. 2006). This background puts the managers and employers that I interviewed during my fieldwork in a specific context of time - when migrants were described and talked about in relation to their value as workers and citizens - and in a specific place (Sweden) - where labour migration is on the agenda in relation to newly introduced regimes for managed migration.

The review of migration literature on labour migration in this chapter also discusses how the economy has been relatively absent from theories of social citizenship, and how the practices and desires of employers have not been sufficiently investigated in studies on migration since the 1970s. These current research gaps can be addressed by paying attention to the historic context of labour migration, and by questioning the novelty of some arrangements in European regimes of managed migration. By consulting studies of earlier labour migration, for example the extensive labour immigration to post-war Sweden, we can see patterns of why and how foreign workers were recruited, and how this has been justified historically. In this way the important roles of management and employers are brought into focus.

This chapter ends with a discussion about how changing migration regimes have affected the composition of the workforce, and especially the presence of temporary migrant workers, in the two case industries that this thesis studies: the wild berry industry and the IT services industry. 


\section{Migrant exclusion from citizenship and precarious workers}

It is through the complex politics of citizenship and diversity that the events of people moving from one place to another has become charged with meaning and controversies. In her book Us \& Them - The Dangerous Politics of Immigration Control, Bridget Anderson (2013) takes on the task of conceptually framing the 'messy business' of the complex processes of exclusion and tolerance that target migrants, by asking how immigration politics not only shapes citizenship for them but also for those who are formal citizens. Anderson argues that citizenship is defined in relation to a 'community of value', which assigns the right and morally valued citizen-subjects. The boundaries of a community of value are dependent on definitions of failed citizens within - for instance those who are seen as economic burdens - and non-citizens outside, such as various categories of migrants. Immigration politics constructs competition between failed citizens and non-citizens regarding membership and the privileges that come with it. This results in strikingly disparate phenomena within the current migration regimes, such as the management of tiers for different categories of migrants, labour market protectionism, deportation of undocumented migrants, and anti-immigration politics. This messy business, in which the position of migrants is not static and not aligned to a single principle or social relationship, is how I also perceive the context of labour migration to Sweden.

Citizenship is often talked about in terms of social inclusion and social exclusion along a continuum (Lister 2003) in which the everyday life of some migrants is defined almost completely by their lack of social and economic rights, while other migrants go to work or raise families relatively unhampered by their lack of formal citizenship. As a concept in migration studies, citizenship often seems to take on different meanings, depending on which migrant group these theories address. This thesis does not address the value, or lack thereof, that is ascribed to the unemployed migrant (Larsson 2015; Vesterberg 2016), the refugee (Fryklund and Lundberg 2010; Johannesson 2017), the unaccompanied child (Wernesjö 2014), the failed asylum seeker, or the undocumented migrant (Holgersson 2011; Khosravi 2010; Nielsen 2016; Nordling forthcoming; Sager 2011) in Sweden.

The conceptualisation of the labour migrant necessarily centres notions of labour, and evokes an altogether different context to that of an asylum seeker who enters a state apparatus of social investigations, or of an irregular migrant whose circumstances may appear diffuse and unsta- 
ble. The non-citizenship of labour migrants needs to be studied in relation to their employment, work situation, employer, and overall career trajectories. In this sense, the focus on citizenship as the central defining aspect of the labour migrant's life conflicts with the conceptualisation of the category of 'labour migrant'.

Migration scholars increasingly use the concept of precarity to describe the interrelations of exclusion from citizenship, which apply mainly to migrants, and the flexibilisation of the labour market with its growing segments of low-paid, dead-end jobs. Precarity conceptually encompasses the vulnerabile condition of migrant workers but also the heterogeneity of experiences that neoliberal economy gives rise to (Bak Jørgensen 2016). Precarisation, further, reaches beyond notions of poverty and social exclusion to 'encapsulate political, economic and social processes that generate an existence characterised by risk, insecurity, threats, uncertainty and chance' (Schierup et al. 2015: 43). Researchers of migration and labour have argued that state practices of migration control are interrelated with the capital interests of cheap labour, and that migrant workers are 'valuable because they are vulnerable' (Bauder 2006: 26). Judy Fudge, professor of law, states that:

\footnotetext{
Almost all countries use immigration law to create a variety of different migration statuses, some of which are highly precarious, which in turn generate a differentiated supply of labour that, together with migratory processes, produces precarious workers and precarious employment norms. (Fudge 2014: 30)
}

Besides a focus on the changing labour markets, the conceptual work on precarity also examines austerity and the changing welfare regimes. It is argued that the ideals of solidarity within the European welfare state have been increasingly replaced with notions of state responsibility to support individuals as they adapt to globalisation, to 'the market', and to an increasingly flexible labour market (Levitas 1998; Jessop 2007; Peck 2001; Schierup et al. 2006). While these social transformations of the state do not only affect migrants, labour migration policies or temporary foreign worker programmes that emphasise the value of people's employability or employment formalise and institutionalise the precarity of some workers - namely, migrants. Temporary work permits, for instance, illustrate the decoupling of citizenship and labour that is characteristic of this development. 


\section{Managed migration and employer interests}

So how can we make sense of the upswing of economic discourses that seem to drive Swedish migration policies? Political scientists have argued that it is not so much the withdrawal of states that is central to the recent transformation of welfare regimes in which citizenship and labour are decoupled. Rather than losing its influence as a powerful actor in globalisation when the economy becomes increasingly transnational, the role of the state has shifted to that of providing favourable conditions for capital as a site of investment. Marketisation is increasingly promoted in order to increase the attractiveness of economic activities within the nation-state, marking an emergence of a 'competition state' (Cerny 1995, 1997). It is in this context that the transnational importation of labour leads to a separation of labour from citizenship rights, and a re-commodification of labour.

By relating the competition state to migration politics, Georg Menz describes a double construction of migrant subjects:

\footnotetext{
The new paradigm of managed migration, mastering (maitriser), and guiding (steuern or gestire) migration flows, entails the active solicitation and encouragement of human resource potentials on the one hand, perceived as a scarce commodity, access to which is subject to fierce competition from other European destinations alongside the more established countries of emigration, and more restrictive procedures and administration of humanitarian migration channels on the other. (Menz 2008:257).
}

In arguments that advocate the reform of Swedish migration policy, the notion of labour as a scarce resource over which there is international competition has indeed been prominent. Menz (2008) argues that although 'trade unions and especially employer associations have been pivotal actors in lobbying, shaping, and in some instances even coadministering economic migration policy' (2008: 258) these interest groups have largely been ignored in migration research. Research into Sweden's recent approach to labour migration has started to reconstruct an understanding of how social actors such as trade unions (Neergaard 2015) and state authorities (Emilsson 2016; Frank 2014) have been positioned in relation to these developments. Specific research on employers or employer organisations is however largely missing from the literature; a knowledge gap this study aims to address.

Swedish employer organisations have mainly proposed a thorough liberalisation of Swedish labour migration policy (Krifors 2013). Such a position is not self-evident in an international perspective. Employers may 
for example have strong interests in lobbying for restricted work permits, limited to one employer or perhaps to one sector, if this would allow for greater control of foreign workers and less competition in terms of wages and working conditions. Against this background it is therefore interesting to study the ways in which managers from specific firms express and define their economic interests in labour migrants. The reform of labour migration in Sweden has been criticised for embracing employer and capital interests (Frank 2010). Schierup and Allund (2011) argue that the reform, illustrative of a larger marketisation, contributes to the end of Swedish exceptionalism that was previously represented internationally as a state model of tolerance, egalitarianism, and multiculturalism. This liberal legislation has also been taken as a sign that the state has withdrawn from the responsibility of protecting standards of work and wages, which mirrors a more general development (Woolfson et al. 2014). The 2008 reform has furthermore inspired a new refugee legislation, enacted in 2016, which emphasises employment and economic self-sufficiency over permanent residence and family unification.

\section{Labour migration: discourse and policy in Sweden}

Migration scholars have specifically linked the changing politics of the welfare state to a new design of migration regimes in which discourse around the economic value of migration is highlighted. Since the beginning of the millennium there has been increased political interest and encouragement in facilitating the mobility of labour also from countries external to the EU. The most apparent reason for this is the economic need for migrants to work in European countries with an ageing population and a 'demographic deficit' (Schierup et al. 2006).

Most European states have, however, been reluctant to change any fundamental liberalisation of their migration legislation (Hansen 2016). In contrast, Sweden has introduced a reform of labour immigration regulations, and since 2008 there have been no caps on entries and no restrictions regarding skill requirements for third country citizens who wish to seek employment in Sweden. This absence of restricted programs, or 'tiers', that have been introduced for different migrant groups in many other countries, led the OECD to name the Swedish regime one of the most liberal among high-income countries (2011). This label also signals a break from the previous 'Swedish model' of corporatist economic policies and strong trade unions with de facto veto on questions regarding labour import (Calleman and Herzfeld Olsson 2015; Frank 2010; Krifors 2013).

Within the current Swedish framework there is no formal division between different groups of migrant workers with work permits; for exam- 
ple divisions based on which sectors of the national labour market have a high demand for labour, or regarding the educational background of migrants. Pre-reform regulations required a control of labour shortages and a union statement that was usually treated as binding. Following the reform, labour market tests were replaced by a compulsory advertisement period of ten days directed at potential Swedish or EU applicants before work permits could be issued to third country nationals. There are, however, no obligations on the employer to interview other applicants. Management practices among employers may be particularly interesting to study in a Swedish context because of the relative autonomy of employers to name and define their need for foreign workers within the Swedish legal framework.

\section{National and transnational memberships}

In the introduction to this thesis I illustrated how debates on labour migration navigated notions of national and transnational membership, and how this affected the moral evaluations within these debates. References to the specific context of labour in Sweden valued unity, for instance, while references to the transnational space of migrants valued freedom of mobility.

Within the theories of migration and citizenship, the potential of national and transnational membership has been extensively debated. Arguing that the state has been given too much influence in social studies of inclusion, the sociologist Yasemin Soysal claims that migrants have been incorporated as members of European states, and have received extensive social rights despite their lack of formal citizenship (Soysal 1994). Soysal also argues that membership of an international community, and discourses of universal personhood, reconfigure the national order of inclusion:

The nation-state becomes an implementer of a multitude of, at times conflicting, functions and responsibilities, derived from world-level discourses rather than from its territorialized identity. And the link between the individual and the state becomes more and more instrumental and routine rather than charismatic and sentimental (Soysal 1994: 165).

Soysal's argument references both the observation of transnational membership, as well as the critique of academic theories that do not value the effects of transnational membership. Soysal further argues that transnational memberships are institutional as well as discursive aspects of peo- 
ples' orientation and require theoretical frameworks beyond a focus on social exclusion and national citizenship. Soysal's perspective favours a politics of post-national membership, which lends legitimacy with reference to 'universal personhood' rather than 'national belonging'.

Transnational theories claim to challenge taken-for-granted concepts and methodological assumptions of the nation or nation-state as the natural border of research objects. The critique of methodological nationalism (Beck 2000; Chernilo 2006) has also been used to illustrate how social theory itself constitutes mobility, movement, and migration as automatically problematic (see e.g. Glick-Schiller et al. 2011; Portes 1989). According to this perspective, the 'transmigrant' (Glick-Schiller et al. 1995) makes visible those migrant practices that are not determined by assimilationist politics and that creatively navigate national policies on both production and reproduction. Although transnationalist theories do not always engage explicitly in political aspects of migration, their perspectives often have consequences for political arguments, and, in some debates, also for the moral evaluation of political strategies of membership. A focus on transnational inclusion has partly influenced the academic debate about a European community. Scholars such as the sociologist Ulrich Beck have supported a notion of European cosmopolitan citizenship that transcends what is seen as a rigid protectionism of nation-states and their inability to deal with migration in democratic and fair ways (Beck 2007). Critiquing this view of cosmopolitan citizenship, migration scholar Peo Hansen argues that European trajectories and harmonisation of migration policies in the EU could in fact be associated with greater protectionism (Hansen 2009). A European politics of decreasing social citizenship and increasing border controls provides a contact point for anti-immigrant politics of individual nation-states. Therefore, political initiatives based on such political agendas can merge into policy located outside the individual nation-state allowing restrictions to be implemented with less accountability (ibid.).

In this thesis I understand the debates about national and transnational spaces, and the discursive construction of these spaces as free or restrictive, as being about belonging and I use these debates as a platform from which to analyse moral arguments in management discourses. Therefore, the separation of national and transnational membership generates empirical questions with regard to the case studies of this thesis. These questions concern how the dominance of temporary or short-term labour within both the IT services industry and the wild berry industry affects notions of membership. Some of these aspects are also dealt with in recent academic and political discussions on circular migration. 


\section{Circular migration - spontaneous migration flows?}

Related to the discussions of national and transnational perspectives are debates within policy and migration scholarship that address whether migration calls for social inclusion and national citizenship for migrants. The different ways in which migrants are allowed to enter a country on the basis of employment is managed through state policy, but migration policies are also affected by the ways in which migrants' settlement is perceived (Castles and Miller 2003). Researchers have for instance critiqued the simplistic understanding of migration as something that happens once, happens in one direction, and includes permanent settlement and progressive integration in a new host country (Ong 2003). Such notions of migrant settlement dominated migration politics during the last decades of the 2oth century. Current policy trends, however, seem to be partly moving towards a re-emphasis on migrant return and an interest in what is called circular migration.

Steven Vertovec (2007) argues that the conceptualisation of circular migration, which has been launched as a concept in policy and research, constitutes attempts to capture migration patterns of diaspora and transnational migrants that are far from new. The emphasis on non-permanent migration counters notions of migration as a process that necessarily drains developing countries of labour and skills. Instead, processes of circular migration are framed through development discourses as win-winwin situations that benefit the sending country, the hosting countries, as well as the migrants and their families (ibid.). In Sweden, governmental reports (SOU 2010:40, SOU 2011:28) on the topic of circular migration and policy reform, discussed diverse topics such as family relations, dual-citizenship, and the portability of social insurance. The report also included an academic discourse on migration, especially on transnationalist notions of migration and mobility. The committee that published the report advocated what it described as 'spontaneous circular migration, i.e. a system where the individual decides when he or she migrates, and where the employer decides if labour from third countries should be hired' (SOU 2011:28: 12). There is, however, a tension with regard to the notion of the spontaneity of circular migration, since it does not take into account the potential discrepancy between institutional and structural contexts of the decisions made by migrants and employers. This tension addresses the difficulties of navigating judgements of what constitutes 'freedom' and what constitutes 'force' in a context of transnational migration, and therefore provides a background against which managers' moral evaluations can be analysed. The analytical chapters will address the effects of employer practice and management discourse in terms of 
structuring a migration that is sometimes defined as spontaneous and sometimes understood as managed through policy.

\section{Continuities and discontinuities of analysing guest-worker regimes}

The policy focus on labour migration in Europe has gained more influence since the early 2000s, and therefore the academic notion of managed migration has mainly been used in order to capture these later trends. There is however a northern European history of extensive labour immigration by guest workers that characterised the post-war period. These guest workers were thought to fill temporary needs for labour, though we now know that they have come to represent a large part of a permanent 'immigrant community'. These types of historic labour migration regimes are by no means specific to Europe; they are part of a 'global history of deportable labour' (Hahamovitch 2011).

Compared to the fields of research on migration that has emerged in the last decades, when the role of employers was largely neglected, Marxist analyses of post-war labour migration in the 1970 s exemplifies migration research that did pay attention to employers and capital (see e.g. Castles and Kosack 1972). These theories have however also been critiqued for their conceptualisation of labour migrants as cheap labour for capital, and for simplistic analyses of migrant workers' distinct roles in class conflicts and economic functions for hegemonic social relations. In his critique, Burawoy (1976) for instance argues that understanding labour migration as an increased supply of cheap labour fails to address the central questions: 'cheap for whom? in respect to what? under which circumstances?' (ibid: 1055ff).

Yet it is not only the Marxist theoretical focus that allows for the analyses of employer interests. The central role of employers emerges also in historic accounts of post-war labour migration, such as that of Hahamovitch (2011), or in a Swedish context Frank (2005). In her introduction and historical overview on guest worker systems, Hahamovitch illustrates the recurring conflict between capital interest in guest workers and public oppositions to the presence of foreign labour (Hahamovitch 2011: 15) and brings light to some of the lobbying work of employers in Germany and Australia at the turn of the last century. She describes how the German state did not primarily become involved in regulating the mobility and settlement of Polish farm workers in order to facilitate the import of labour. The main reason was rather to satisfy public opinion and ensure that guest workers were not integrated into German society. 
These political strategies were later acknowledged and adopted by the employers. 'Recognising the power of anti-Polish forces, growers petitioned not for an open border but for the right to import agricultural labour on a temporary basis' (ibid.).

In 1946 a governmental investigation in Sweden initiated discussions to meet the demand for labour through migration, and in the 1950 s agreements for the collective transfer of labour were signed with Finland, Hungary, and Italy. From having been mainly an emigrant country Sweden turned into a country of immigration, and entered a new period marked by several shifts in policy and changing public opinion (Hammar 1985). The post-war labour immigration policies in Sweden were designed with more liberal views on settlement and the naturalisation of migrants than, for instance, the German guest worker programs (ibid.). This legislation changed over several phases from the mid-196os onwards towards a stricter regulation of migration. These changes reinforced the legal protection of migrant workers, but their mobility also became more rigidly regulated as migrants were required to have found both employment and accommodation before entering Sweden (Frank 2005: 18). The authorities introduced a requirement of a labour shortage of potential immigrant workers from the Nordic countries before allowing work permits to be issued to migrants from other parts of Europe. Furthermore, working conditions and salaries needed to correspond to Swedish collective agreements or praxis within the sector or the occupation in which the migrant worker was employed.

There was widespread concern about a deficit of labour in Sweden during the first years of this relatively unregulated policy. The labour unions initially supported the liberal policies, but became increasingly worried that immigration would result in a low-wage immigrant workforce, leading to social dumping, since migrant workers were almost exclusively recruited for low-skilled jobs (SOU 2006: 86-87). The unions insisted on making full employment of the native population a priority. The historically strong position of trade unions in Sweden, and the fact that workplaces were to a large extent subject to collective agreements, affected the migration legislation. Most migrants did however also become members of the unions (Kjellberg 2010: 84).

One of the reasons for more restrictive rules during the 1960s was the social situation of many migrant workers from southern Europe who arrived in Sweden without either work permits or housing. Many foreign workers and their accompanying families needed assistance from the Swedish authorities, and their situations became a public concern. Also, the unions reacted against the exploitation of migrant workers and identified the need for better initial controls of social conditions for migrant 
workers (Frank 2005: 91). Hence, the moral negotiations of labour migration not only referenced economic values of capital and native workers, but also mirrored social values of 'decency' that worked to shift policy and attitudes.

The system for importing labour during the 1960s and the early 1970 s was not comparable to the guest worker system implemented, for example, in Germany. In Sweden, work permits were generally routinely extended after their initial approval, which strengthened the migrant workers' position in the Swedish labour market. Many labour migrants also settled in Sweden, and naturalisation within this group was relatively high (SOU 2006: 85-7). Furthermore, although employers often preferred to recruit unmarried migrant labour, workers were allowed to bring their families (Frank 2005: 205). Labour immigration to Sweden was also different from that in the other countries of southern and central Europe, and although ethnic segmentation was visible in the labour market, migrants had full access to the social welfare system, and most gained permanent residence permits (Schierup et al. 2006: 196). In practice, the trade unions came to exercise a de facto veto on work permits, and their stricter approach to work permit applications in the early 1970s contributed to a dramatic decrease of labour migration; a practice which largely remained until 2008 (OECD 2011: 57).

This overview illustrates the development and far-from-linear transformation of the regulation and implementation of foreign labour recruitment, both by the state and by employers. The moral dimensions raised in public debates seem to have had an impact on how employers argued, and on which discourses on belonging, permanency, and settlement were invoked in these arguments. Historic accounts of the recruitment of foreign workers partly describe employers' arguments and desires. However, the research that I have presented here does not systematically analyse how employers relate to notions of the national population and their fears, privileges, or empathy, as they affect and intervene in migration processes. This provides an analytic interest for the following chapters of this thesis.

\section{Temporary labour migration - two cases}

So far, I have discussed how the reform of labour migration regulations in Sweden represents a new migration regime in terms of policy. Several researchers have also begun to study the effects of the reform (for instance Calleman et al. 2015). One of the most significant changes the reform has delivered is the increase of migrant labour to the service industry. The 
pre-reform requirements of the labour shortage in Sweden and the EU had previously made it difficult to hire workers from third countries to work in restaurants or hotels (Calleman et al. 2015). Yet more generally, the reform has not led to a dramatic increase of labour immigration to Sweden.

Two other sectors, which together are the focus of this thesis, stand out in the statistics on work visas granted in Sweden: the IT services industry and the agricultural sector. Computer specialists from India represent the second largest and most rapidly growing group, while Thai seasonal workers constitute the largest group. Before the reform, these sectors already recruited foreign workers due to exceptions for experts and seasonal workers in the previous regulatory framework. While the administrative practices of recruitment in these sectors have been affected by the reforms (Emilsson 2016), the numbers have not increased as markedly as it may appear in the statistics on labour migration.

A majority of the work permits in the IT industry are granted to Indian nationals. In the agricultural sector, the migrant work especially concerns seasonal workers in the wild berry industry, and mostly employs Thai nationals. To some extent, these two groups have been symbolically important for how labour migration in Sweden is perceived and discussed. The IT workers represent the desirable work force that is the target in competitive states' migration agendas, and the berry pickers represent vulnerable migrant workers who suffer from a lack of legal protection. The importance of these debates in relation to how managers talk about migrant labour in the two industries is analysed in the following chapters.

In general, however, labour immigration policy in high-income countries almost always implies a trade-off between migrant rights and the admission of migrants (Ruhs 2013). After the reform of labour migration regulations, and following reports of the denial of decent conditions and wages and the failure to follow up on employers who have been approved as sponsors of work permits, the debates in Sweden have been particularly focused on labour rights. Actors such as the Swedish Migration Agency and several trade unions publicly renounced the main responsibility for workplace and employer controls at the time of the reform. Although stricter controls have since been implemented, there is a division in the debate concerning employer organisations that have requested administrative procedures to be as simple as possible and those who argue that employers need to be further monitored (Calleman et al. 2015; Krifors 2013). Migrants' rights remain important in the political debates about the reform, but the initial debates about the dangers of lower overall wage levels in Sweden have not persisted, considering the rather small scale of labour immigration (Calleman et al. 2015). 
The two case studies in this dissertation concern migrant workers who are considered to be highly skilled and attractive, as well as migrant workers who are categorised as low-skilled seasonal workers. The difference between the two groups in terms of which moral dimensions the employers address will inform the analytical chapters in this thesis. Similar in both these industries is the dominance of temporary labour migration where migrant workers do not normally apply for permanent residence permits (the Migration Swedish Agency 2016). In fact, short-term stays of less than one year, at workplaces where there are many other labour migrants, represent the most common situation for migrant workers in Sweden (OECD 2011: 91). These two Swedish case studies have the potential of contributing to the research on the mechanisms of managing temporary labour migration, rather than long-term migration that has constituted the main focus of recent migration theories (Parreñas 2010).

Swedish migration policy does not block long-term work permits for agricultural work and IT work if employers claim such a need for labour in the long term. The short-term character of work permits, however, is related to the ways in which production is organised within these industries. Swedish companies are often not the formal employers of temporary foreign labour; the workers' mobility and migration is instead organised by networks of international suppliers. The short-term work in Sweden therefore cannot be understood only in relation to migration regimes and state regulations.

In the next chapter I discuss how actors within the economy can be identified for the purpose of this thesis. I will also develop a theoretical framework that provides a structure for the analysis of management discourse in the two case industries. By 'develop', I mean that the dialogue between migration perspectives and the global economy requires several small steps of interpretation. The interest in management discourse that this thesis pursues is based on an assumption that management discourse can tell us about the relationship between the economy and migration management. The analysis of management discourse therefore requires an understanding of the context in which managers act and make sense of their relationship with migrant labour. This context, as defined in my research design described in Chapter 4, comprises the economy of the wild berry industry and the economy of the IT services industry. In the next chapter I discuss theories that will help conceptualise the economy of those two industries in which migrant labour plays a large role. These concepts and definitions will provide contact points to the overall background of how migration and citizenship affect membership and moral evaluations of the role of migrant labour in the larger society. 



\section{Theorising the moral economy of international production}

In the previous chapter, which outlined the background for this thesis, I argued for the significance of studying the moral dimensions of migration management - the selection of migrants who are worthy of entry, as well as the mediations of membership and citizenship. Migration research attributes great importance to the economy of capitalist production when it comes to mechanisms of managing which migrants are worthy of entry and membership, and which migrants are not. The economy is, however, left without scrutiny and tends to be treated as a conditioning factor (Bauder 2006). The practices of entrepreneurs, employers, and managers can be conceptualised as important aspects of the economy, and these economic actors can furthermore be understood as intermediaries of both migration and transnational relations of production. Against this background, I will consider the moral dimensions of an international economy of migrant labour in this theoretical chapter. I will discuss differences between how the movement of capital and the movement of people have been evaluated in public and academic discourse. I will also situate migrant labour within a theoretical framework of global and transnational production in order to provide a platform from which management, and its effects on how workers are valued within specific industries, can be studied.

The chapter begins with a discussion about how migration and economic globalisation have been treated as separate phenomena, and the implications this has had on theorisation, concepts, and research. I then present theoretical discussions that help frame the interconnectedness that characterises the economy. Furthermore, these theoretical discussions provide analytical tools that specify and delimit the main material of this thesis: managers, management talk, and how they describe their relations with migrant labour. These analytical tools specifically draw attention to supply chain relations, differentiation, and discourse. Towards the end of the chapter I focus the discussion on how moral dimensions of the economy can be understood in relation to the language and emotions that are enacted as people evaluate certain arrangements of labour. 


\section{Migration: being mobile in a global economy}

In the introduction to this thesis I mentioned the conceptual 'messiness' of studying migrant labour in particular industries and economies. The conceptualisation of migrant workers and temporary foreign labour can refer to the same groups of people, but directs our attention to very different theories.

Part of the explanation for this messiness is that debates about labour migration challenge us to think about two dominant discourses of freedom of mobility: the migration of people that is restricted through national and EU policy, and the mobility of business activities that is encouraged by economic globalisation. Geographer Doreen Massey argues that, contrary to the mobility of people, globalisation is seen as an aspatial and inevitable phenomenon:

The dominant institutions and governments that clamour most strongly
in favour of globalisation argue for it in terms of free trade. And they
argue for 'free trade' in terms of which in turn suggest that there is some
self-evident right to global mobility. The very term 'free' immediately
implies something good, something to be aimed at. It is self-evidently
right that space should be unbounded. Yet, come a debate on immigra-
tion, and they immediately have to recourse to another geographical
imagination altogether, another vision of global space which is equally
powerful, equally - apparently - incontrovertible (Massey 2005: 86).

Massey illustrates how self-evident truths about spatial freedom or containment, where she contrasts debates on globalisation and migration, are presented separately and are only explicitly negotiated in distinct situations. The appeal to 'an imagination of pure boundlessness or pure flow as self-evident foundation is neither possible in principle nor open to political debate', Massey (2005: 86) continues. While notions of pure boundlessness, or instead, the belief in the right to maintain impermeable borders, may act as moral foundations to some arguments, such discourses are not necessarily practised as principles. Labour migration presents an empirical case in point, where the notions of economic freedom of mobility and the spatial rootedness of people are negotiated; a case where neither total freedom nor containment is claimed in the public debates presented in the previous chapter. Migrant workers in similar regimes of managed migration, are seen as mobile, yet their mobility is controlled and managed. These migrant workers are differentiated from other categories of migrants as they are allowed entry, and their right to stay and to move are negotiated when their terms and conditions of social rights, visas, and employment are determined. According to Massey (2005), such 
practices bring the abstract principles of the rights of movement and containment into politics. I argue that it is also by analysing these practices that the moral dimensions of the rights of movement and containment become visible.

Addressing social science studies of globalisation rather than the public debate of economy, sociologist Saskia Sassen argues that academic discourse tends to reproduce a false separation of the processes that are considered to constitute globalisation and their local 'outcomes'. Rather than understanding the flows of transnational capital as disembedded processes of abstract macro-globalisation, and the migration of people and expressions of multiculturalism as 'local' phenomena, Sassen explains how:

[...] the capabilities for global operation, coordination and control contained in the new information technologies and in the power of transnational corporations need to be produced. By focusing on the production of these capabilities we add a neglected dimension to the familiar issue of the power of large corporations and the new technologies. The emphasis shifts to the practices that constitute what we call economic globalization and global control: the work of producing and reproducing the organization and management of a global production system and a global marketplace for finance, both under conditions of economic concentration. (Sassen 2000:81)

To conceptualise the economy of capitalist production in relation to migrant labour requires that the problem of an analytical separation of globalisation and migration in social theory is addressed. I take the approach that capabilities, coordination and control, and practices that constitute globalisation, are also articulated in the management of foreign labour in Sweden in ways that are not separated from the production processes. Although the management of migrant labour with regards to its international mobility and membership in national or transnational settings is central, it cannot be separated from the more general management of labour in the production processes. This directs our attention to the practices of management and the local contexts in which they act. Social theories on global production have addressed these issues and help us break down an abstract phenomenon such as the 'global economy'.

\section{Production in global chains - locating the actors}

The introduction to the two case studies in Chapter 2 - the IT services and the wild berry industries - indicated that production is not exclusively composed of 'Swedish' business and ‘foreign' workers. Globalisation 
has created an economy in which actors are increasingly interconnected, and different aspects of production are outsourced to other firms and businesses. The reason why these aspects of the economy are important to frame theoretically in this chapter is because they affect the ways in which we can understand the management of foreign workers in Swedish industries.

Although the concrete practices involved in the processes of global interconnectedness may not have been thoroughly explored in the sociological research of globalisation (Sassen 2001), the academic literature on business and management has taken an increasing interest in the governance of such international relations (Starosta 2010: 433). The literature on global commodity chains, global value chains, and global production networks, which represent the related fields of research that I present below, investigates the networks of the production processes by engaging tools derived from a world-systems perspective on the interconnectedness of global capital (Bair 2005). The framework of a world-system, developed by Wallerstein (1983), engages with the rise of 'the West' and the persistence of global inequalities through the organisation of production and exchange. Hopkins and Wallerstein (1977) introduced the concept of the 'commodity chain', defined as the 'network[s] of labor and production processes whose end result is a finished commodity' (Hopkins and Wallerstein, 1986: 158). ${ }^{5}$ This theoretical approach questioned assumptions of globalisation as the progression of national markets into an increasingly international market. Rather than analysing one-dimensional developments of markets, commodity chains conceptualise the differentiation of the globalisation processes by placing the global division of labour and unequal distribution at the centre of the analysis. This theoretical approach also looks at the processes of exchange, production, distribution, and investment, and therefore expands the analysis by incorporating the complex relationships of state and capital. These theoretical perspectives mainly help me to analyse the capitalist actors in relation to the different roles and positions that they have, because of the margins and profits of their particular businesses and their relations to particular states, regions and to global economy.

In her review of the literature on commodity chains, Bair (2005) argues that following later theoretical developments of commodity chains, researchers have shifted their focus to other aspects than those generally studied in the world-systems literature. While the world-systems framework is mostly concerned with how a stratified and hierarchical world-sys-

5 Referenced in Bair (2005:155). 
tem is structured and reproduced by commodity chains (Bair 2005: 156), later literature takes an interest in inter-firm networks or the upgrading of individual firms within a global commodity chain. A particular focus has also been put on the governance structures and the distribution of value among the different firms (ibid: 159). A partial explanation for this shift is how these later studies avoid a holistic view of global capitalism, and how they tend to focus either on a meso-level analysis of countries, in what Gereffi (2005) calls the 'institutional focus', or of organisations, in which an organisational perspective takes firms as the study object.

None of these developments, however, correspond to the research problems that I have identified in this thesis. First, I do not map the value added or track the production process along the chains. Therefore, neither the effects on stratification among world regions, nor the effects on organisations and firms within these networks can be analysed. Instead, I am interested in how these complex relations affect the ways in which managers in Sweden value labour and justify workers' conditions. In this thesis, I have chosen to work with a conceptualisation of supply-chain capitalism, inspired mainly by the anthropologist Anna Tsing's discussions on 'commodity chains based on subcontracting, outsourcing, and allied arrangements' (Tsing 2012: 148). Tsing has traced the global entanglements of production and labour in different research projects (2015, 2012, 2005) and uses the term 'supply-chain capitalism' in a theoretical article (Tsing 2012) to address what she considers to be a reorganisation of the global economy. As a new global standard, supply-chain capitalism identifies how leading firms around the world outsource just about everything, and certainly everything involving the ordinary, long-established risks of labour recruitment, training, and discipline' (Tsing 2012: 52).

The concept of supply chains is useful in this thesis for several reasons. I argue that Tsing successfully accounts for the importance of representation and discourse in the capitalist relations that construct, reproduce, or manage difference between groups of workers, through her conceptualisation of supply chains. These links between the theories of global economy and the analytical tools that can be used in order to study how managers talk about labour, and how this affects the construction of migrant labour in a larger perspective, are important to the ways in which I can approach my material. Later in this chapter I will elaborate on these links, and on how the construction of difference can be theorised. I also argue that by focusing on the term 'supply', rather than on the terms 'commodity', 'value', or 'production', the managers that feature in my material can be situated in relation to specific arrangements of outsourced labour and subcontracting, which are central to both of the case studies. 
The management practices of supplying labour to other companies, or of negotiating terms and conditions of labour supply within their respective industries, can be understood as practices that manage migration, although not directly related to state police. This facilitates an analysis that situates the role of employers and managers within the discussions on national or transnational memberships, and explores how such memberships are negotiated. With respect to the negotiation of membership, recent discussions within the literature on global production are useful in order to connect the role of the nation to the processes of global production. I will discuss how nations and national belonging can be ascribed importance in the processes of global production in the next section.

\section{The nation and the transnational - institutions and identities}

Criticisms directed at the different approaches to research on the chains of production have observed a lack of detail on institutional factors (Bair 2005), as well as on labour (Selwyn 2012). I have discussed how the regimes of managed migration can contribute to a segmentation of the labour market by decoupling labour and citizenship, resulting in cases where some workers have no social rights to fall back on. A migration regime can be understood as an institutional dimension that affects the value of labour for producers. The reproduction and regulation of labour can for instance impact why a firm locates to a particular place, or adds a particular value to a commodity. Bair, however, argues that current research on commodity chains suffers from a lack of incorporated institutional factors, and suggests that the social and institutional contexts in which commodity chains 'touch down' should be more elaborated in these studies (Bair 2005: 169). The combination of the perspectives on global production and migration regimes that this thesis pursues can therefore contribute to the theoretical discussions within this field. Although I do not study the material effects of institutional factors, such as the consequences of profit or salaries within particular industries following the reforms of the labour migration regulations, the arguments among businesses are important to investigate. By studying these arguments the influence of different capital interests on the development of migration policies in different countries can be revealed.

National and transnational contexts that affect production in an international network or chain may also depend on less 'tangible' factors, such as national identity. In a study on the importance of Mexican nationalism and national identity for the production and value of tequila, Bowen and Gaytán (2012) integrate analyses of culture into the framework of commodity chains. Transnational identities and relations can also be studied 
from this perspective. A study by Freidberg (2004) on two transnational networks of green bean production highlighted the cultural context of the global economy. Freidberg's focus on exporters and importers provides an interesting focus in relation to this thesis since it centres on how the work of these two intermediaries incorporates culture in production and in transnational economic relationships. Both transnational networks, French and British, were colonial in their governance of commodity production. The networks guided by French values projected preferences for traditional presentations and peasant production on the commodities. These values had very different effects on the ethnic and racial notions of African exporters compared with the British norms of universalistic health standards, and a consumer desire for industrial production and clean packaging. These studies are examples of how national identity and the history of transnational relationships affect both the value of the commodity and the value of labour. By studying management discourse, I investigate how managers talk about, define, and attribute importance to national and transnational aspects of production within their industries. My analytical focus is on the effects that these definitions have on how labour is situated, how different workers are valued, and how their conditions are justified.

\section{Locating the worker in theories of production}

The anthropologist and geographer David Harvey argues that labour and the working body are fundamental to globalisation and to the spatial expansion of capital (Harvey 2000). Making use of Karl Marx's separation of workers from their labour power, which is appropriated as a commodity under capitalism, Harvey argues that the circulation of capital through exchange and consumption is a dimension in which the working body is present (2000: 103). As capital defines a specific purpose of labour power, Harvey argues, it mobilises 'sexual drives, affective feelings, and creative powers of labour', and also shapes the labour force and the working body to particular practices (ibid.). As an example, a mother may be a Christian, born in Iraq, and fluent in English, and these aspects of 'the working body' will influence the ways in which capital is likely to mobilise, or not mobilise, her labour power. The Marxist understanding of workers put forward by Harvey inspires the analysis in this thesis in which the different ways that management discourse situates workers - for instance as migrants, as members or non-members of particular communities - are crucial to how migrant labour is mobilised. This gives rise to questions concerning whether the managers' accounts in this thesis, as far as man- 
agers are representative of 'capital', may constitute an important dimension of such mobilisation. I will return to this theme later in the chapter.

Selwyn has criticised the literature on commodity chains for lacking a theoretical integration of labour that allows for analyses of both the agency of workers and the role of the labour process to add value to commodities (2012). ${ }^{6}$ The most recent attempts to integrate labour have been initiated under the theoretical stream of Global Production Networks (Coe et al. 2008) and these studies, especially, point out how the economic upgrading of firms does not necessarily imply a social upgrading for workers (Barrientos et al. 2011). These are important points on the role of labour, and my approach acknowledges that workers are also agents who negotiate and affect arrangements within the global economy, though the main focus is on management practice and discourse. Being concerned with the mobilisation of labour, this thesis mainly discusses how managers account for the social dimensions of workers' lives, and how this affects the legitimation of certain arrangements of labour mobility in management discourse. The agency and the potential of workers' practices and discourses are not the focus, although the perspective on the managers' accounts also allows for observations of conflicts and ambivalence.

The management discourses reveal constructions both of labour as integrated practices in the economy and in the market, and of workers as a subject position and as 'bodies' with particular attributes and dispositions. Tsing argues that supply-chain capitalism both creates and reinforces existing niche structures of the economy through subcontracting practices of specialisation (Tsing 2009: 151). Niche structures of the economy have also been researched as labour market segmentation within migration studies which mainly reference how racialisation and citizenship affect the segments that particular workers 'fit' into (Bauder 2006; Anderson 2000). In relation to a theoretical framework of supply-chain capitalism, Tsing describes how suppliers drive corporate and managerial cultures through which workers learn to perform 'difference', in order to mark their labour competence in a certain niche. For example, a 'day labourer must perform brawn and availability; a prostitute must perform sexual charm' (Tsing 2009: 159). These arguments are based on Marxist conceptualisations of labour, referenced for instance by Harvey (2000).

\footnotetext{
6 Selwyn (2012) also adds to the critique of current research on commodity chains by arguing that the lack of a comprehensive inclusion of labour is not only the result of a retreat to meso-level analyses, but can be found also in world systems' analyses that favour studies on exchange rather than on production.
} 
Theorising these niches in the supply-chain economy, Tsing uses the concept of 'non-work tropes' (2009). These are tropes that represent labour as something else. For instance, within supply chains labour is increasingly defined in relation to entrepreneurship, consumption, or management. Tsing illustrates non-work tropes by referencing terms such as 'servant leader' - a figure that the leading retail corporation Walmart introduced in relation to labour along their supply chain. The servant leader depicts workers as managers by using references to Christian values and family loyalty (Tsing, 2009: 159ff). These constructions of labour as practices and identities that are not related to work and wage labour can act both as features of labour that may be preferred by workers, and as a capitalist super-exploitation of cultural values. Although the word 'exploitation' carries, in lay terms, the connotations of moral evaluation, in a Marxist framework the exploitation of labour is what brings about surplus value (Fine and Saad-Filho 2004: 39). Some researchers refer to 'hyper-exploitation' or 'super-exploitation', often in relation to migrant workers with particularly precarious lives (cf unfree labour; Miles 1987), to mark a difference to business, or labour, 'as usual' (Balibar, 1991: 224). There are therefore moral dimensions to these conceptualisations: When is exploitation particularly immoral? And are worker preferences valued? In this thesis I investigate moral legitimations by looking at how labour is constructed in the management discourses that mobilise labour, and whether labour is also constructed as an identity and a practice other than wage work. This does not answer the questions concerning how much exploitation, but rather how the specific exploitation within the industries that I have studied is legitimised.

\section{Differences between workers}

Feminist studies of labour have criticised theories that depict class and economy as homogenous, and have shown how gender affects the ways in which labour is exploited (Acker 2006a). Intersectional feminist scholars have critiqued the notion of gender as an experience or a social relation that can be understood apart from the relations of race, ethnicity, nationality, or citizenship (Collins 1998; hooks 1989; Mulinari and de Los Reyes 2005). Poststructuralist critique has challenged static understandings of social categories using intersectionality both as a critical tool and as a theoretical perspective that takes the transformations and instability of social constructions seriously (Bredström 2008: 93ff). In the case of research on labour, intersectionality contributes to ways of understanding a plurality of gendered or racialised practices (Mulinari and Selberg 2011). 
The great majority of feminist studies on labour can be found in the literature on domestic work, and often applies an intersectional perspective to analyse the social relations engaged in this type of work (Hondagneu-Sotelo 2001; Lutz 2008; Parreñas 2001). Using studies of domestic work as an example, intersectional analyses are visible not least in the terminology of 'care chains', defined by Arlie Russel Hochschild to illustrate how women from the global south leave their own children for others to care for children of women in the global north (Hochschild 2000, 2002). Domestic work literature has also contributed to filling a knowledge gap in migration studies that largely lack analyses of those who employ migrant workers. Research into domestic work has shown how migrant subjects are shaped in relation to the desires of those who manage and control labour, buy services, and sometimes also have the formal role of employers (Anderson 2000; Hondagneu-Sotelo 2001; Lundström 2013). The domestic work literature characterises these relations as intimate (Hochschild 2000, 2002), and debates the effects of such intimacies, for example, on the emotional labour it requires (Hochschild 1983) or the feelings of transnational families (Parreñas 2005). The global structure of domestic work is also coloured by policies on reproduction, for instance the structure of tax reductions on household services (RUT) in Sweden (Gavanas 2010), and Italian policies on private family lives (Näre 2011). From this research we know much about how Western women with nannies from developing countries negotiate their privileges of race, gender, and class through the labour of 'other' women. This scholarship also shows how such desires are related to changing welfare regimes and care regimes (Lutz 2011).

Rather than understanding feminist or intersectional studies of the economy as particularistic, Tsing argues that such interventions should be understood as an argument in favour of understanding capitalism as constituted by diversity (Tsing 2009). It is not an anomaly that non-economic aspects of peoples' life situations and identities are incorporated into arrangements of production. I see the body of literature on domestic work, parts of which are referenced here, as contributions to our understanding of how differences, along the lines of gender, race, or nationality, are mobilised in the arrangements of labour. The structures of labour and employment in the industries that are the focus of this thesis are very different from those in domestic work, and the constructions of differences between groups of workers may not correspond to what has been described in the domestic work literature. However, the ways in which analyses of domestic work has incorporated difference is central to this research on management discourse, as analyses of economic life need to resist notions of capitalist homogeneity, and instead theorise the patchy 
multiplicity of production and work (Tsing 2015: 5). Although Tsing affirms that supply chains are not essentially more diverse than other types of capitalist production, she argues that since they constitute links between very dissimilar firms they 'worry' about diversity (Tsing 2009: 150). Such self-consciousness offers analytical grounds for understanding why gender, race, ethnicity, nationality, citizenship status, age, sexuality, and other aspects of labour diversity are central to the structure of the global economy (ibid.). To me, these aspects of labour diversity constitute a strong argument in favour of studying what this thesis sets out to explore: the management discourses within supply chains and the ways in which managers talk about differences among labour and within the production processes.

\section{Moral economy - grand theory and situated management discourse}

In Chapter 2, I illustrated some of the moral issues that seem particularly difficult for migration management to navigate. Examples of such moral issues concerned the freedom of migrants, vis-à-vis the value of unity and memberships, such as national belonging or citizenship. Rather than arguing that these constitute mutually exclusive moral positions, I argue that these issues can be theoretically captured by maintaining a focus on the enactment of different values as actors put forward arguments in debates on migration policy. So far in this chapter I have discussed how I define structures of the economy and the relationships between capital and labour for the purpose of this thesis.

Moral economy could be viewed as a research field, yet studies in this field are loosely tied together and mark not a coherent theoretical approach but rather an empirical interest in how economic practices are also cultural, social, and moral. The most significant body of research concerns the moral dimensions of class relations: protests and compliance of the peasant (Scott 1976), the values and consciousness of the 18th century English working class (Thompson 1971), or present-day British class relations (Sayer 2005a, 2005b, 2004). The types of relational economic morals that are investigated in this thesis encompass class relations or labour relations, but in the specific context of transnational supply chains. In their extensive work, The New Spirit of Capitalism, Boltanski and Chiapello (2005) studied how exploitation in capitalism has changed forms in the last decades, following a social critique that demands more freedom and greater worker autonomy. In some respects their work provides a useful platform for discussions on moral economy in this thesis. 
The relevance of Boltanski and Chiapello's work to this thesis especially concerns the interest in managerial discourse that they pursue, and an interest in social critique and its impact on the economy, thus adding a moral dimension to theories of global capitalism. The authors argue that management discourse today 'constitutes the form par excellence in which the spirit of capitalism is incorporated and received' (Boltanski and Chiapello 2005: 14). The organisation of a network economy introduced more sophisticated types of exploitation, emphasising worker autonomy and flexibility. New forms of capitalism, the authors argue, must incorporate a moral dimension in order to mobilise people, and the values need to appeal to a more-than-one-dimensional human being: a homo economicus (Boltanski and Chiapello 2005: 487). Examples of such values are the changing conceptions of exploitation in a 'connexionist world'. The essence of exploitation is its invisible contribution to value - the labour that, unacknowledged, gives profit for 'great men'. According to Boltanski and Chiapello, it is the links in a network economy- mobility and flexibility - that make up value. Therefore, it is the lack of mobility of 'the little people' that legitimises how highly valued the mobility of multinationals and financial markets are (Boltanski and Chiapello 2005: 360ff). Boltanski and Chiapello have been criticised for their unclear position in relation to recent critical theories on management (Willmott 2013), and for their lack of an empirical focus on how management discourse affects management practices - a focus that requires an ethnographic perspective (Ekman 2013). I am inspired by the connections between social critique and capitalism that Boltanski and Chiapello construct through their focus on management discourse, though I am also interested in understanding more ambiguous practices of labour and migration management and the situated discourses among managers.

So, how can we think more specifically about management practices in relation to migrant workers? In their book How the Other Half Works: Immigration and the Social Organization of Labor the sociologists Roger Waldinger and Michael I. Lichter provide a rich empirical foundation for discussing the labour market processes for hiring, valuing, and replacing labour in ethnically diverse and segmented societies (Waldinger and Lichter 2003). The authors start out by arguing against an economist perspective that tends to view the labour market as an 'open bazaar' in which 'buyers and sellers encounter each other freely and, after a bit of squeezing the merchandize and kicking the tires, haggle out a deal' (2003: 43). By approaching the ethnic labour market through a sociological perspective, Waldinger and Lichter argue that they recognise an increasing 'compartmentalization' of the labour market that managers relate to in their decisions. They show how shifts into a new economy have brought 
about new ideals of workers, where newcomers are generally preferred to other groups of workers since they accept other conditions. Managers also argue that new immigrant workers cause less conflict between staff and managers than US workers. Following new flows of migration and ethnic segregation, employers come to prefer certain ethnified labour, and these choices are legitimised with references to the cultural or social and material contexts of these ethnic communities. It is however not only at the point of recruitment that the ethnification and racialisation of the workforce is constituted, but also through the managerial practices at the workplace, and the coding and sorting of different tasks and organisational hierarchies. Previous studies (e.g. Jenkins 1986; Waldinger and Lichter 2003) show how managers express a desire for certain features among their workforce in terms of ethnicity, culture, or race because they argue for a relation between these aspects of the workforce and the efficiency of social processes at the workplace. Feminist work on organisational inequality (Acker 2006b) and the feminisation of production (Salzinger 2003) have pointed out how gender and race are constructed through the labour process and through organisational and managerial practices, where, for example, certain class-coded femininities are preferred for certain work in service (Mulinari 2007) or in industry (Räthzel et al. 2014; Salzinger 2003; Tornhill 2010).

In these studies on management practice and ethnic or racial segmentation, researchers pay attention both to language - how managers talk about, describe, and argue in relation to how they manage labour - and to the effects of how managers act. In the chapter on methodology that follows I will elaborate on how these dimensions of management can be studied with regards to this research project. This approach, however, raises theoretical questions about the role of discourse in specific management practices, as well as with regards to global capitalism. Boltanski and Chiapello investigated the nature of ideology and the role of social critique in a grander perspective on capitalist developments (2005). At this 'grander level', moral economy can reference theories such as Marxist understandings of ideology and superstructure (Marx 1954 [1867]), or Weberian history of the emergence of a capitalist ethic (Weber 1992 [1976]), which has very different implications for how the role of politics and the potential of social transformation are understood. Most discussions on moral economy engage in the dilemma of social theory to, very simply, place too much or too little importance on agency and social change. The critique is either that economic or ideological structures are ignored in favour of an emphasis on change and agency of particular social actors, or that discourse or relations of production are treated as absolute. In their version of these theoretical conflicts, Boltanski and Chiapello present 
contrasts between theories of force, where 'moral exigencies, modes of justification, and institutional forms are treated as veils concealing reality' (Boltanski and Chiapello 2005: xxiv), and a paradigm in which political institutions and law carry particular weight in the classification, categorisation, and normative judgements (ibid.). The theoretical dilemmas give rise to questions such as: How much do the practices and discourses of individual managers really matter in the context of grand capitalist logics and market processes? However, rather than investigating these debates in grand theory, I aim to conceptualise the moral economy expressed in specific settings.

In contrast to how migrant practices are analysed as dynamic and creative, migration studies often neglect to analyse also the economy as comprised of practices that are multifaceted and unstable (Bauder 2006). Other academic settings have however engaged in discussions on how economic institutions and practices are also governed by habits, emotions, and normative evaluations of right and wrong (Chapman et al. 2009; Sayer 2005a; Zelizer 2011). In particular, the academic interpretations of Karl Polanyi's influential work The Great Transformation (Polanyi 1944), in which he argued that state and economy are co-constituted and are not separate spheres, act as a foundation for debates about the conceptualisation of the embedded economy. The social theorist Andrew Sayer argues that it is essential to understand market-oriented practices and capitalist processes as morally embedded (Sayer 2004, 2005, 2007). Rather than representing 'normal capitalism' these practices constitute variations of capitalism in different social and cultural settings. Sayer argues that the concept of moral economy may, however, be preferred to the concept of embeddedness:
In practice, it is hard to use the metaphor of embedding without im- plying that it refers to economic activities being externally enabled and constrained by phenomena such as traditions, norms and social rela- tions. The problem is not that there are no such external influences, but that this overlooks the norms that are internal to economic practices themselves. (Sayer 2005a: 5)

The popular focus on 'embeddedness' in social studies of economy is problematic because it tends to focus the social relations that constitute this embeddedness, yet leaves choices, negotiations, and processes that underlie the economy without critical scrutiny (Zelizer 2011). Analytically, this leads to a reification of 'economic rationality'. Inspired by this debate, I intend to analyse management discourse as necessarily producing different types of positions, locations, alliances, and values. I will therefore not approach the managers I have interviewed as 'representatives of 
global capital' who are merely embedded in national sentiments, Swedish values, dominant discourses on the community of value, cosmopolitan lifestyles, or other such social or cultural influences. Instead, I am interested in the potential contradictions or synergies of these moralities and values, for instance when notions of the economic value of migration are affected by whether or not migrants are also ascribed a cultural value (for the nation or for a particular community).

\section{Morality as normativity and discourse}

In this thesis, moral economy will be studied with regards to management and how managers justify certain relations and conditions with respect to migrant labour. I will therefore discuss my definition of moral economy in relation to how management is conceptualised in this thesis. First, management has so far been conceptualised as diverse. This fragmented and diverse character is a basic feature of a supply chain (Tsing 2009). The analysis must therefore be able to incorporate such diversity and ambiguity as managers may construct labour in different ways, depending on both managers' and workers' position in the transnational production process. However, management is also a vehicle for controlling production. Being interested in diversity within supply chains, which also acknowledges the agency of workers or other social actors to dispute or protest certain relations of production, does not disqualify a theoretical acknowledgement of the power relations of supply chains that severely limits the autonomy of workers (Tsing 2009). I also think of the economy in which managers act as relational (Zelizer 2011). Through their practices in the supply chains, actors create new relations, confirm existing relations, negotiate shared definitions of the relations at hand, and repair damaged relations (ibid: 150). This means that although management is the focus of our analyses, the role of migrant workers, states, trade unions, and other actors cannot be 'cut off' from the analysis. The analysis must remain sensitive to the specific relations that are at stake in specific justifications of economic conditions. In particular, the analysis must take into account that the relations of which managers are a part are constructed not within a static economic context, but through the economy as an on-going process.

The ways in which managers justify the conditions under which labour is mobilised in supply chains constitute the main 'moral economy' studied in this thesis. Justification, then, is related to the social relations and positions that managers and workers inhabit, but justification is also related to the arguments and the language that is used to frame these arrangements as moral. My main empirical focus in this thesis is the man- 
agers' language. However, the organisational aspects of supply chains, as well as the political aspects of migration regimes that I have discussed and established in this theoretical chapter and in the previous background chapter, constitute important dimensions in the analysis. During the last decades in social science, the 'linguistic turn', often associated with post-structuralism, has placed language as a central dimension that structures social life (Rorty 1967). Researchers turn to text and speech to search for key features of how the world is organised and how this affects categorisations and divisions, and the operations of power. In this thesis, the discourses that structure relations of labour represent the research objective.

But what might be lost in studies that focus on language and discourse? Andrew Sayer argues that social scientists should make distinctions between normativity and discourse as they study the moral arrangements of society. In particular, Sayer advocates sociological attention to 'lay normativity' and 'what matters to people' (Sayer 2004, 2005a), in contrast to academic approaches that alienate the concept of morality and create a distance between how normativity is lived by people, and how it is conceived by scholars. He further argues:
Of course there are important respects in which our justifications are indeed influenced by our social position and by wider discourses, but reflexivity is needed not only to examine such influences, but also in the opposite direction, to examine what they do not explain, that is how everyday situations often require us to make decisions and justify what we do. (Sayer 2004: 3).

Social constructionism, Sayer argues, fails to recognise how 'cultural discourses are usually rich enough to question their own beliefs' (Sayer 2004: 14). I agree with this point, and in the analyses in the following chapters I will present the choices that are made, and the active justifications that appear in managers' accounts, rather than seeing their morality as one-dimensional extensions of the global economy or expressions of big discourse. I will, however, do this through an analysis of discourse as the main empirical focus. Sayer argues against 'strong versions of social constructivism', which he claims 'always successfully construct the world as they imagine, and [that] social wishful thinking always works' (ibid. 16). I agree that not all analyses of all aspects of our social life are productively analysed through deconstruction of their social meaning. In relation to my material, however, I do not see a contradiction in studying the social constructions of economic relations and understanding the justifications and feelings of right and wrong that guide people's actions in the management of labour, mobility, and supply chain production. Instead, I 
intend to study the discursive dimension of justification and morality by situating the discourse in economic and social contexts.

Furthermore, discourse analysis does not need to imply the search for 'big discourse'. The everyday normativity of people is rarely consistent (Sayer 2004: 5) and we can think about discourse in a similar way by applying interventions in discourse analyses made within discourse psychology, which emphasises how different versions of the self and the world are articulated in different contexts. The social psychology researchers Margaret Wetherell and Jonathan Potter, who demonstrated the situated justifications and language of racism by analysing interviews with the white population in New Zealand (Wetherell and Potter 1992), have inspired my approach to discourse analysis in this thesis. From a perspective of discourse psychology, the authors argue that investigations of racism must also focus on institutional practices, on discriminatory actions and on social structures and social divisions. But the study of these things is intertwined with the study of discourse' (ibid. 1992: 3). Wetherell and Potter also use the concept of 'interpretative repertoires' instead of discourse to emphasise the ambiguous and contradictory character of language, and I will discuss this further in the chapter on methodology.

Although I do not see a necessary conflict between the sociological perspective and the poststructuralist engagement with language and discourse, there is a difference in terms of focus. I intend to focus on the social constructions and the discursive language of managers as they speak about the economy, labour, and migration. This represents a delimited focus and also implies that I cannot, through my analysis, evaluate the level of exploitation in, or the impact of migration on, for instance, particular industries. With this said, moral economy as a conceptual framework obliges a focus on the relations between discourse and practice. In this thesis, such analyses can be made by connecting discourses that are expressed during my interviews with managers to the theoretical framework of global economic processes, as well as to the discussions of migrant labour that I have presented so far. Inspired by the theoretical approaches, the language that I study is mainly analysed in an institutional economic context of supply chains. The conceptualisation of supply chains offers a good foundation for combining a focus on discourse, and an interest in economic arrangements and processes. Anna Tsing's analytical framework of supply chains includes conceptualisations of ephemeral assemblages and multidirectional histories, and signals a poststructuralist approach to the study of economy; 'a world without teleology' as she puts it (Tsing 2015: 20). I have previously referenced how Tsing (2009) argues that supply chain structures lead to an awareness of diversity and difference within the economic system. This diversity becomes 
the subject of translation within the supply chains. By analysing such processes of translation we are, according to Tsing (2015: 62), looking at the 'rhetoric of economic life' as well as looking at the practices of coordination. ${ }^{7}$ I see the practices of coordination as intrinsically linked to both the rhetoric around economic and social arrangements and to the arguments that are expressed through discourse and language, which also allows for something to be said about the moral economy.

\section{Emotions and affective practice as moral evaluation}

There is also another dimension where moral economy obliges me to extend the analysis beyond language: the role of emotions in the evaluation of moral and amoral relations - of what are the right and wrong ways to act. Andrew Sayer argues that emotions 'are crucial to how we evaluate situations, objects and others and not, as commonly assumed, antithetical to reason' (Sayer 2005a: 28). Rather than being analysed as subjective, emotions are relational; they are 'about something' (ibid.: $35 \mathrm{ff}$ ). Our emotional capability, Sayer continues, 'is crucial for any kind of social condition to affect us' (ibid.). A growing body of research has illustrated the ways in which emotions structure subjects in relation to class, race, and gender (Garner 2015; Sayer 2005a; Skeggs 2011). Class relations, for instance, give rise to particular emotions that affect how these relations are justified or challenged, yet also act in ways to align subjects with their social position and collective identities. Sayer discusses a kind of psychic economy of arrogance, pride, satisfaction, and contempt of the middle class, which is also managed through guilt, defensiveness, and empathy (Sayer 2005a). Similarly, a working class emotional structure could encompass anger or deference, pride or shame (Reay 2004). These emotional dimensions can, according to scholars inspired by the work of sociologist Pierre Bourdieu, be both reflective and unreflective, but often they seem to confirm existing social relations.

Feminist theorist Sara Ahmed (2004a) critiques two types of dominant approaches to the study of emotion in her work on the cultural politics of emotion. Ahmed argues that sociological conceptualisations of emotions propose how these are generated in a collective, in the society, and then internalised and adopted as an individual's own feelings. Psychological research, on the other hand, treats emotions as generated within a subject and then communicated or spread to the surroundings through the way we cry or clench our jaw. Both these perspectives, Ahmed argues,

7 Tsing uses the concept 'attunement'. 
reifies a division between the 'inside' and the 'outside' of subjects that cannot account for what Ahmed sees as the sociality of emotions (Ahmed 2004a: 9). Ahmed uses economy as a metaphor to illustrate this sociality. 'Economy', in Ahmed's terminology, should not be confused with the definitions of production and labour that I have presented so far. The metaphor is useful to Ahmed as she wants to illustrate how emotions are not internal - in the same way as they are perceived in everyday sentences such as 'I have a feeling' or 'this movie is sad' - but something without objective value or intensity that is given a value through its circulation between bodies and subjects.

Ahmed's notion of the sociality of emotions can be seen as part of a 'turn to affect' that is parallel to the upswing of sociological research on emotions. This turn is a critique of the limitations of deconstruction and lack of dynamic analyses in poststructuralist conceptions of the totalised power of discourse over the subject (e.g. Clough 2007). Although themes and the directions of theories on affect are diverse (Gregg and Seigworth 2010), they signify force and an interest in how people are affected and moved. This critique connotes arguments in favour of studying not only language of justification, but also what can turn such language into moral arrangements.

I choose to conceptualise emotions in relation to the material that I study. The theoretical approaches that seem most productive in relation to management evaluations and justifications are those that link up with discourse in explicit ways. The working definitions of discourse and emotion in this thesis are therefore also fundamentally methodological; words constitute the main material I have to work with. The dimension of affect that becomes accessible is therefore the social dimension and the language with which emotions are described. This requires that the analytical chapters - Chapters 5 to 8 - reveal which aspects of language or of the wider situation that are described in the ethnographic material, signify emotions. When do managers reference emotions as being important to their arguments, and when do particular discourses seem to become particularly intense and 'charged' with emotion?

Margaret Wetherell suggests the concept of affective practice as a way forward in the debates regarding social emotions and affective forces:

From an affective practice standpoint, specifying the exact relationship between affect and discourse is less interesting than investigating the range and entire patterning of affective assemblages operating in important scenes in everyday life along with their social consequences and entailments. (Wetherell 2012: 52). 
An approach to studying emotions as meaning-making can be eclectic according to Wetherell, as it attempts to understand the links between 'big discourse' and the everyday dynamics of practice. I will adopt the concept of 'affective practice' in this thesis as it allows emotions to be understood simultaneously as both structural and individual, and as situational and embodied. Affective practice will be used to support the analysis not only of how situations and relations in supply chains are represented through language, but how they are evaluated with reference to a feeling about the situation. In her conceptualisation of affective practice Wetherell argues that affective practice 'will usually be open to moral and normative assessment, and thus will be woven together in subtle ways with people's usual communal methods for describing, accounting for, and judging self and others' (2012: 116). The affective practices at the centre of this analysis are the practices that mark boundaries within the supply chains and which attempt to define what is right or wrong in relation to migrant workers. This does not, however, mean that the emotions that can be analysed are always static. In a similar way to the interpretative repertoires of discourse, affective practice can be studied in relation to diversity, intersections, and complexity (ibid: 118). Affective practice does not necessarily encompass the emotions of durable, traditional, and grand social relations, but it can help our understanding of the 'messiness' or complexity of social life, such as it may appear in the networks that structure temporary foreign labour (ibid.). As my analytical chapters will show, different emotions were mobilised in different situations and had the effect of expressing both distance and association to other groups and actors in the economy.

Before I proceed to the analysis where the central concepts of supply chains, interpretative repertoires and emotions are applied, I will describe my method. In Chapter 4 I discuss, in more depth, how I have studied management language by describing the context in which I interviewed managers, as well as the strategies through which I have analysed the material. 


\section{Talking to managers - reflections on method}

In this chapter I explain how I approached the research with two very different case industries that, at times, felt worlds apart. I aimed for a contextual understanding of the complexities of labour migration management and I therefore chose to use ethnographic methods. As is often the case, my field studies were not a straightforward process. In this chapter, I describe the process of defining and accessing each field, and then discuss how the ethnographic work of accessing and entering the wild berry and IT industries shaped the relationships with my informants and with the empirical material - mainly interviews and observations - on which I base my analysis. In this chapter I also discuss how my methods interact with leading academic theories and policy discourse on migration, and how the managers talked about their everyday lives as part of the global supply chains of IT services and forest berries. I also present my material in this chapter: the people that I have talked to as well as those I have not talked to. I describe how I prepared and carried out observations and interviews, and how the different turns that this took should be seen as part of the results.

I discuss the ethical considerations that have emerged during the research process, especially in relation to the particular ethnographic context of studying power, or studying 'up' (Nader 1974). I also consider feminist methodologies, debating whether studying power presents a specific challenge in ethnographic research, and if so, how. Furthermore, I discuss how I have analysed the material, and outline the specific approaches of discourse psychology. The chapter also includes how I analyse discourse in a systematic way, and as part of an ethnographic study of the practices and cultures of managing foreign workers in Sweden.

\section{Lingering around the 'buzz of migration talk' - and engaging with other theories}

When I was accepted for the graduate programme in Ethnicity and Migration, and began designing this project, I thought of my research project as a way of investigating the novelty of managed labour migration in Sweden. The Swedish state and its migration policies occupied my focus 
since most academic debates in this field concerned observations of a changing citizenship. I attended several policy conferences on EU debates and stakeholder cooperation, and on the Swedish implementation of the 2008 labour migration regulations that I discussed in Chapter 2. I also interviewed policymakers and experts in employer organisations and trade unions. The experts were generally enthusiastic about the topic of my research, and gladly talked to me or provided me with information. Migration clearly received much attention in the public debate and many of these experts explained the importance of mapping the patterns of labour migration to Sweden; for instance understanding whether migrants wanted to settle in Sweden, or finding ways of better defining the success and failure of different groups of migrants in terms of integration or employment. One manager at the Migration Agency told me: 'We need better tools in order to make it work here in Sweden, to get to know the different groups of labour migrants that could come here and how this can be a long-term solution for us.' During this initial part of my research it often felt like there was too perfect a match between migration management and the migration research that was expected from me. The enthusiastic quest for more knowledge among policymakers and researchers alike corresponded, according to my understanding, to a desire for more control and more sophisticated migration management tools.

I carried out the initial research during 2011, at a time when the salience of migration was increasing. Since then, this focus has remained strong in different areas of national policy, as well as in social science research. As migration is still topical there are challenges in doing research that does not only reproduce concepts generated by this political enthusiasm. A critical position is essential for reflecting on the social relations that research aligns with. The mapping of migration and the policing of borders can also be understood as being connected to a global history of population control, with severe consequences for different groups of people (Connelly 2008). During the early phase of my research, academic debates on labour migration, as well as Sweden's political focus, especially seemed to encourage the mapping of migration patterns and migrant trajectories. The point is not to argue that investigating such issues necessarily implies an alignment with regimes and practices of managed migration. However, engaging with the topic of migration, as thesis does, requires a reflexivity in regards to theories and concepts, as well as a certain distance to policy design.

I also encountered other problems as I tried to pose relevant questions within the field of managed migration and define cases that could shed light on the labour migration regimes in Sweden. Thai berry pickers stood out in statistics on nationality and work permits and were by far the 
most numerous of migrant workers. Yet several experts argued that berry pickers were not a good group of workers to study if I wanted to investigate labour migration in Sweden. They suggested that Thai berry pickers were a passing phenomenon of the Swedish labour market. 'I think berry pickers are just a parenthesis. In a few years it will not be around', a state policymaker said, thus disqualifying the need to engage in issues of Thai migrants' trajectories and rights any deeper. Furthermore, the Thai berry pickers did not represent a novelty in labour migration. One representative of an employer organisation argued: 'If you are interested in the new regulations you should definitely not look at berry pickers. Thai people have been picking berries in Sweden for decades'. The classification of berry pickers as migrants was also met with opposition. As I asked him about social rights following the new regulations of labour migration in Sweden, a representative from a municipality told me: 'They don't need anything from Sweden; the temporary work permits are not a problem [to them]. They are just here for a few months, and issues of social rights would not be very interesting to study.'

Similar arguments were made in relation to the IT workers from India, who represented the second largest national group within an industry in the labour migration statistics. Prior to the reform, computer specialists had already been able to work in Sweden on specific expert visas, and although the volume of applications for these visas had increased they did not represent a novelty. Within the IT industry it was also more difficult to map the patterns of migration, and which types of employment Indian developers held in Sweden. During an interview, when I asked a representative of an employer organisation about companies that applied for work permits for groups of programmers from India, he said: 'Well, but they aren't migrants then. They aren't recruited - they probably work there temporarily as consultants.' Furthermore, some experts related to the IT industry argued that it would be difficult to do any research based on nationality. One trade union representative said that no manager in the industry cared 'where a person is from when they apply for a job. An engineer is an engineer.' It seemed, as I was starting my fieldwork, that neither of my cases fitted the ideal type of labour migration. Thus, during the first years of my research, and as I started interviewing managers in the wild berry industry and the IT industry, I struggled to understand which concepts of citizenship and migration were most accurate, and what types of migration in these industries these cases represented. It took a long time before I realised that I wasn't struggling with the cases so much as struggling with theory. I was trying to find cases that matched the debates on managed migration in the academic literature and in policy, although the category of 'labour migrant' was foremost a worker once 
he or she was part of a particular industry. As I started integrating theories of international production, which are presented in the theoretical chapter (Chapter 3), the case studies started to 'speak' to debates about citizenship and migration.

The methodological reflexivity - how a researcher creates analyses together with the world around her through interviews and observations is crucial to how I understand the production of knowledge. This is also a central point in feminist research, which has informed how I have contextualised and defined the field that I am researching, as well informing my own social position in relation to my informants (Acker et al. 1983; Esseveld 1997; Mulinari 2005). In addition, the sociologist Michael Burawoy discusses the possibility of practising reflexive research that embraces engagement rather than detachment (Burawoy 1998: 5). The intersubjectivity of fieldwork, Burawoy argues, 'enjoins what positive science separates', for instance researcher and researched, or knowledge and social situation, but also folk theory and academic theory' (1998: 14). In this sense, Burawoy makes the reflexivity of theory explicit. When studying documents, debates, and reports on managed migration in Sweden, I found little difference between the discourses of migrant categories by policymakers, and those that were debated in the migration literature. The experts at the state agencies used the same theoretical concepts and analyses as the academic scholars and aimed to think beyond the taken-for-granted perspectives on migrants and migration, illustrated for instance by the arguments in favour of circular migration and labour migration that are inspired by transnationalist theories (see SOU 2011:28 and Chapter 2 of this thesis). Therefore, I could not just take one aspect of theory (the researchers') to analyse the other (the policymakers').

My own process of observing and struggling with the intense interest in migration in the public debate, helped me to engage reflexively with theory and avoid parts of the research aims that I had drawn from migration research. Through reflexive research, the 'cognitive maps through which we apprehend the world' (Burawoy 1998: 5) can be embraced and disclosed rather than rejected as biased. The part of the research process during which I reconsidered my concepts was, in fact, the most time consuming. In his book The Art of Listening, sociologist Les Back writes that 'the compression of time and space, the relationship between the far and the near in the era of globalization, has left also sociology in a state of obsessively searching for the spectacular' (Back 2007: 7). I also searched for a spectacular narrative of fundamental transformations in my attempts to find the perfect example of new migration regimes. The public interest in migration generally, and labour migration specifically, during the time when I started my research, seemed to have blocked my view of what was 
going on with foreign workers in the wild berry industry and in the IT industry. Writing a sociological dissertation is the practice of listening for a story (Back 2007) and I needed to set aside some of my concepts in order to listen in a different way.

\section{An ethnography of management}

Mapping the policies of labour migration in Sweden is an important aspect when writing an ethnography of migration management. Since there has been relatively little research on the role of employers in Sweden or in other EU countries regarding migration, my research interviews have contributed important descriptions of the relations that managers in Sweden engage in as they manage foreign workers. Such 'thick descriptions' (Geertz 1983) are an important dimension of the analyses. The empirical material deals with migration management in specific industries and is not an ethnography of migration but of management in the sense that it pays attention to the 'ordinary' practices of managing - of recruiting, administering, controlling, or disciplining workers. The ethnographic method allows for detailed descriptions of these practices where accounts or observations are available. Foremost, however, it is a study of the everyday language of management because interviews, rather than observations, constitute the source for most of the material that I analyse.

The main material, which I have analysed through discourse analysis, consists of interviews and conversations with six Sweden-based managers in the wild berry industry, and interviews with twelve Sweden-based managers in the IT industry. The research process differed substantially between the two case studies. I spent three weeks doing participatory observations and ethnographic fieldwork at two different companies in the wild berry industry. Several follow-up interviews with managers in the berry industry were then done over the 'phone, and two of the managers were only interviewed over the 'phone. Although I transcribed thirteen longer interviews with the managers, much of the material is drawn from shorter conversations during the ethnographic fieldwork. During the three weeks of observations I also talked to about 50 berry pickers, as well as Thai staff at the recruitment agencies. Although these conversations and interviews are not included in the main material that I analyse, they give the managers' accounts of the wild berry industry an ethnographic context because these accounts often refer to a situation or to a person in the field.

In contrast, my observations in the IT industry were limited to the actual interview situation, where I was sometimes introduced to other 
staff and given a tour of the offices. All interviews were transcribed and lasted between one-and-a-half and two-and-a-half hours. The differences between the two case studies are, for instance, reflected in the length and structures of the quotes that are presented in the analytical chapters chapters 5 - 8. In the longer interviews, the informants often presented their arguments in greater detail than in conversations during observations when themes shifted more often or were interrupted.

Part of the ethnographic work in my research has been to understand my informants' roles as managers, which is a prerequisite for contextualising the discourses that they develop and talk through. I asked all my informants, from both industries, many questions about their careers and what their work as managers included. I also researched websites and observed interactions between managers and other actors in the field. Although detailed accounts of the role of managers are not presented for every informant mentioned in the analytical chapters, these descriptions have been analysed as part of the material to provide a discussion about the type of economy the managers work in. The conceptualisation of supply chains and commodity chains (Tsing 2009, 2012; Bair 2005) has been helpful for clarifying how the main informants in both case studies are situated in relation to labour and workers and to the other actors in the industries that they represent. Some of my informants in the berry industry are business owners and the formal employers of migrant workers, but most of them would say that they work with the organisation of berry production rather than that they manage Thai berry pickers. In the IT industry, the managers I interviewed represented employers because they are CEOs of particular companies, or because they have the formal staff responsibility for specific teams. However, two of the informants were not responsible for teams of software developers or testers, and their influence over workers can instead be understood in relation to their positions as managers of outsourcing strategies. These diverse standpoints of the informants require me to ask the questions: What do the supply chain and the organisation look like? What do managers do, and what are their positions in these transnational industries?

\section{Studying 'up' - access to managers}

Ethnographic studies of migration are dominated by a focus on the experiences of migrants. There is an increased interest in studying mediators of labour migration (Tshabalala forthcoming; Xiang \& Lindquist 2014), and it could also be argued that there is a gap in migration studies concerning knowledge on how migration movements and mobilities are structured from powerful positions within the economy. This requires researchers 
to study power, for instance the role of employers. In her famous text, $U p$ the Anthropologist - Perspectives Gained From Studying Up, anthropologist Laura Nader encouraged scholars to complement the perspectives of science 'from below' with an increased interest of studying 'up'. She called for more attention to 'study the colonizers rather than the colonized, the culture of power rather than the culture of the powerless, the culture of affluence rather than the culture of poverty' (Nader 1974: 289). Central to this call for a re-direction of our scientific focus is the interest in power. However, anthropologists and sociologists still study the underprivileged more than they study the powerful (Becker and Aiello 2013).

Power is often a concern in the ethnographic research process both when the researcher attempts to get access to the field and in the interview situation (Becker and Aiello 2013: 65). The powerful have more control over access to their spheres (Welch et al. 2002), though during my research process I experienced this differently in relation to different groups of managers. In contrast to state officials who manage migration and citizenship through policy and implementation, employer representatives from the private sector do not have the same public responsibility to be accessible to researchers who are interested in social issues. This difficulty of gaining access was most apparent to me in the Swedish IT industry. In 2011, when I began my research, finding a company in Sweden that worked with IT solutions or software development was not a problem, but finding informants who were willing to participate in this study was more difficult. For the reader who is as unfamiliar with the organisation of IT services in Sweden as I was at the beginning of this project, I can confirm that the industry encompasses many people, many companies, and many websites. The statistics on labour migration permits showed that computer specialists from India dominated the work permit applications (the Swedish Migration Agency 2014) - but who were their managers? Despite the many interviews with policy makers and experts in this field I could not find the gatekeepers who could give me access to managers in the IT industry. One reason for this was the difficulty of defining the phenomenon I wanted to study. When I told an acquaintance, a young Swedish engineer, that I wanted to know more about the international work environment in computing she immediately replied: 'I was shocked you know, when I started working after getting my engineer degree, how much you work with people from India. They were everywhere at my workplace. But I never talked to anyone of them so I don't know much.' Other people responded to my research interests with an immediate association. 'Right next to where I live there is a whole house for them Ericson Indians. They live there with their families, but you don't see them much...', one friend told me. Another person said that 
she lives close to an office park and that she sees them 'at the bus stop every day; they all have very similar clothes on. You know, very proper.' It is apparent that 'the Indian computer specialist' is a recognisable figure, though not as easily categorised or defined in relation to the workplace as the Thai berry picker. It took several months before I understood that to the managers and experts, the phenomenon I wanted to study was related to outsourcing, rather than to the recruitment of labour migrants. When I talked to a friend who works for a large company, he said: 'You know, we have outsourced IT [at the company where I work]. But there are always a group of Indians here at the office. In our building we have a bright hall, a large office space, and behind this hall in a tight and dark room; that's where they put the Indians.' Specific information about which managers were responsible for the mobility or recruitment of these Indian computer specialists was still difficult to come by. This difficulty corresponds with observations by other ethnographic researchers on how elite groups are often difficult to access if one is not part of their network (Welch et al. 2002).

About 25 managers that I had heard about or read about on websites such as LinkedIn, or in industry magazines and blogs, and who had worked with third country nationals, turned down my requests for interviews. According to Burawoy (1998) these difficulties of access need to be understood as part of power relationships that can be uncovered through ethnographic reflexive practices. Those who gave a reason for not giving an interview said that they had nothing to contribute, or that they had no time to participate. Eventually, twelve managers agreed to participate. Reflections about this access to some informants are as important as the transparency regarding the lack of access to others. I discuss this further in the analytical chapter on the supply chain structures in the IT industry. In summary, however, the participation of some managers often reflected their interests with regards to the phenomena of offshoring and outsourcing. This aspect of the research illustrates how, although there may be specific challenges of studying 'up', the managers should not be regarded only as 'elites', but also as occupying diverse institutional spaces (Conti and O'Neil 2007: 80).

The general observations of studying 'up' in previous ethnographic literature were not as obvious with respect to my research in the wild berry industry. First, compared to managers in the IT industry, the managers of berry companies do not generally represent a group that perceives itself to have much influence or status in the Swedish economy or in its social or cultural spheres. Some of the managers were reluctant to participate in my research, and expressed how they were wary of the possibility of my 'twisting their words' or 'painting a false image' of the wild berry industry, 
in the end, however, they contributed with open-hearted interviews. This outcome reflects a more general ethnographic situation than a specific case of studying 'up'. Two gatekeepers, who I met early into the process and who introduced me to the field and gave me contacts to other people, also affected the research process in the wild berry industry. I was surprised by the willingness of several of the berry companies to participate in the research. In the following analytical chapters on the wild berry industry I have analysed this openness in relation to the specific moral economy in which my informants operated. For my first visit to a berry company in the summer of 2011, which was also the longest visit, I drove my car for two days, from Malmö to the northern parts of Sweden. I was welcomed and generously hosted by the managers, who gave me access to work sites for my research. They never declined to answer questions and the atmosphere was generally friendly.

The lack of access to those with more power did however appear as a concern in relation to other actors in the wild berry industry. For instance, I did not interview any representatives from the distributor companies although they are important actors in the industry. I contacted five representatives of distributing companies who all declined participation or did not get back to me. At the time of my main fieldwork, these distributing companies distanced themselves from the harvesting of berries and any responsibility for the pickers. The absence of these voices in the analysis is used as a way of critically engaging with those discourses that are highlighted in my material. I also use secondary sources such as web sites and statements in the media in order to address the distributers' role in the supply chains. Yet the presence of certain managers, namely those working in the berry companies, constitutes a delimitation of this study.

Although I felt that I was at times studying 'up', ethnographic researchers have argued that studying 'up' represents a terminology that obscures the complexity of how power operates (Conti and O'Neil 2007: 79). Becker and Aiello (2013) discuss how ethnographers who are schooled in feminist methodologies can apply their knowledge and training in reflexivity in order to study power as a complex phenomenon, rather than as an expression of 'high' or 'low' status. One specific challenge in the research process, they argue, concerns complicity with power (Becker and Aiello 2013: 65), which I will discuss after presenting the managers and the interview context. 
Interviewing managers - the informants, ethics and complicity

I spent several full days, as well as many shorter visits, with four of the managers from the berry industry. Two of the managers I only met with or interviewed on one occasion. Sometimes I talked to the managers at their office, or on the phone, but many of the conversations also took place in cars, driving the long distances between different sites where berry pickers were hosted. Due to the structure of the fieldwork, the interviews with these managers were very varied. Sometimes a conversation started on one day and continued on the next day. Most topics were covered, although I asked very few questions that I thought the managers could interpret as sensitive, as I experienced that would affect my access. Conversations about compensation or the work environment, for instance, were mostly initiated by the managers, and I would ask follow-up questions for clarification. The interviews did however include many examples, with references to specific situations and specific workers, as well as descriptions of the work that the berry pickers performed. The informants often asked me what I thought my results would show, and why I had become interested in this topic. Describing how I was doing my research in migration studies often initiated conversations about the workers' trajectories, histories, and social situations.

In the IT industry I interviewed twelve managers - five women and seven men - who worked in four different Swedish cities. The interviews with these managers were all performed in their office buildings, in their personal office or in a room they had booked for the interview. All the interviews were done in private, although we were often interrupted by short 'phone calls or questions from employees. All except one of the participants worked for businesses that provided 'solutions' for other businesses, including providing staff, for instance from India. ${ }^{8}$ Some managers were India 'specialists', most notably two who were hired by India-based corporations and were both trained engineers from India. Most of my informants were however Swedish nationals and they had all been working 'towards India' for between two and seven years. In contrast to the berry industry, it was more difficult to get the informants in the IT industry to talk about the workers and the everyday activities of managing workers. I found the arrangement of outsourcing and international mobility difficult to grasp through desk research, and in these cases it was difficult for me to steer the interviews. Some interviews were like pres-

8 One of the participants was the project manager at a large company that had recently put services out on procurement that was won by a company that used outsourcing to India. 
entations in which the interviewee had prepared slides and drew figures on a whiteboard. These interviews were a challenge because the Indian programmers were very rarely mentioned, and again this required me to come up with specific themes or topics. Some participants did however show an interest in understanding my research problem and asked me for specific questions that they could answer. This was also a challenge, considering the limited background knowledge I had of the common ways of working with staff from India. With every interview, I learned successively more valuable information about what a situation could look like for Indian programmers in Sweden who were not recruited for long-term positions. This allowed me to ask better questions as my research proceeded and towards the end of my fieldwork interviews there was more detailed 'talk' about the workplace and the workers. I learned not to fall silent when an informant talked about internationalisation, and instead tried to ask follow-up questions on the implications of internationalisation on the workers' locations - Sweden or India - and the reasons for their answers. In most interviews I asked questions about how housing was arranged for temporary Indian workers in Sweden, since this was a way to get the informants to speak less abstractly about the processes of offshoring. It required them to speak of numbers and sometimes these questions triggered anecdotes and more colourful descriptions of everyday practices. The interviews often included a tour of the offices where I was introduced to other managers and programmers. This sometimes had the effect that managers would also speak more freely about specific circumstances in the workplace.

One difficulty of studying 'up', with regards to my fieldwork, was present in the way that I felt less in control of defining the questions in the interviews, and in the way that managers often questioned the relevance of my research into temporary migrant workers. Complicity with power can be understood in relation to the identity of the researcher (Becker and Aiello 2013: 65). Female managers who spoke about 'Swedish' gender equality in contrast to less equal cultures (for example, India or Thailand), may, for instance, have felt that I was an ally in regards to their perspective. These are, however, situations that every ethnographic researcher needs to negotiate in the field. Regardless of whether we study powerful people or not, what they tell us and how much they let us in, depends on how they identify with you. There are, however, aspects of complicity in my fieldwork that may have effects on the analysis. One such aspect concerns the effects of race on the two industries that I studied. I will illustrate this through an example from the wild berry industry. My fondness for some managers in the field, and our warm relations, gave me access to information about the structures and how berry companies 
operate. Yet these relations also caused uncomfortable feelings of sharing the privileges of my informants (Lundström 2010) in relation to the Thai berry pickers. The ethnographic work in the field helped me define some aspects of this privilege, for instance by listening to voices other than those of white entrepreneurs. T was a manager from Thailand who I spent a lot of time with during my fieldwork. He was older than me, and we talked much about different social and cultural phenomena. One day $\mathrm{T}$ came back in, after we had paused our interview, to take care of a straggler car with five berry pickers whose berries needed to be weighed and stocked. 'They are very shy to talk to you, you know' he said. 'Yes I know. Why is that?' I asked. 'Because you are farang', 'But why? Is it only that?' I persisted. 'Yes, we are shy to farang', $\mathrm{T}$ said smiling. 'But are you also shy when you talk to me?' 'Yes, of course I am', T answered. This passage illustrates the importance of whiteness in the structuring of power relations in this field. It was my privilege, as a white person, to not see how $\mathrm{T}$ and my relationship was affected by feelings generated from colonial relations of power. Where I felt comfortable, $\mathrm{T}$ felt 'shy'. My privilege, and T's shyness, could be made visible during this conversation, and although it is difficult to account for the full extent of the consequences that these power relations have had on the research results, the conversation provides a certain 'setting' for the manager discourse in the analysis.

Katherine E. Smith questions whether there is something intrinsically different about interviewing 'up'. She argues that a poststructuralist conceptualisation of the complexities of power must necessarily remain critical towards such differentiations (Smith 2006b). The complex entanglements and diverse situations during my fieldwork makes me inclined to agree that studying 'up' does not necessarily pose different challenges in the research process, since difficulty of access and complicity, or the inability of the researcher to distance herself from the field, are always present in ethnographic fieldwork. Some of the specific situations of interviewing elites, especially in corporations, have not been sufficiently described and reflected upon in the methodological literature (see e.g. Welch et al. 2002) and deserve increased attention. In the analysis I do not define the managers that I interviewed as people who have appropriated power that looks the same in the interview situation, as it does in their working life. Further, they do not hold a one-dimensional position of privilege within their organisations and in the larger context of international production. The framework of discourse analysis, which I will elaborate on in the next section of this chapter, allows for a poststruc-

9 Name used in Thailand for Caucasian/white/Western foreigners. 
turalist approach in which a situational understanding of power relations can emerge in the analysis (Smith 2006b: 652).

Although there were times during several of the interviews when managers spoke at length and freely on certain topics, my initial mapping of discourses relating to labour migration also guided parts of the interviews. Performing the interviews in an active manner (Holstein and Gubrium 1995), I consistently reacted and responded, as well as added input from my observations and readings. The ways in which managers constructed the world in our conversations is related to this interaction between myself as an interviewer, and to them as participants. Yet this does not mean that I disclosed everything during the interview - for instance, I actively tried not to show whether I agreed or disagreed, and I did not oppose or counter what they said. I remained relatively 'value neutral'. These issues on how to act in an interview are not only epistemological but also ethical. If researchers do not react, interviewees are left without any chance of elaborating, clarifying, or defending a position (Wetherell 2003). This method of interviewing may also lead to a normalisation of attitudes that are perceived as problematic, such as racist or misogynous accounts. On the other hand, researchers have to be careful not to silence participants, or make them feel uncomfortable. This will not only affect the ability to collect research material but will also raise an ethical issue because it may fail to show respect for those who have taken the time, and the emotional engagement, to commit to an interview. Though I have actively (Holstein and Gubrium 1995) asked for elaborations and clarifications, I have worked mostly with 'friendly interviewing' (Wetherell 2003), leaving the content of what managers have said to be evaluated later, and picking up mostly on key aspects for clarification.

Smith (2006b) argues that the conceptualisation of power as structural has caused researchers to be less concerned with ethical conduct when studying 'up'. There is a notion that in order to access power there needs to be manipulation at some level, which Smith considers to be an ethically problematic approach (ibid.). Although I have attempted to think about how my research can be presented in a way that is interesting to the informants, I have tried to remain transparent with the research objectives throughout the process. Another ethical issue concerns how much weight is placed on the analysis of the informants' individual characteristics. Many managers have told me personal anecdotes that have not been directly related to their profession, and are therefore not relevant to the role of managing migrant workers. As a researcher is already in the field, it may be difficult for informants to resist giving information (Gruber 2007: 45), which constitutes an ethical dilemma whether these informants are managers or not. I have been careful not to ask follow-up questions that 
may cause the informants to feel that they have said more than they are comfortable with after the interview is finished, and I have not included such accounts in the analyses. Sometimes, however, these boundaries are not easily drawn. All managers featured in this thesis have been given fictitious names in order to protect their anonymity. The berry industry, being a very small industry with few actors, also required me to be less specific than is customary about facts when informants and quotes are presented. In writing this thesis, I am consciously vague about the gender of some of the informants and I disclose very little information about the berry companies themselves since they would be easy to identify. In the second case study, on the other hand - the IT services industry - the gender and sometimes the nationality of the managers are mentioned. The IT industry in Sweden is so large that it is unlikely that the informants or the companies involved could be identified.

\section{The interview as discourse}

Ethnographic observations contextualise 'management talk' in my study. Such ethnographic observations and reflections could for instance be concerned with how the talk of a manager in the berry industry also addressed a situation from earlier that day, or referenced a previous conversation between us. Ethnographic data could be concerned with how certain messages from the managers in the IT industry were supported by reports or PowerPoint presentations, which affected the message that was communicated. Much discursive psychology has focused on the logic of a particular piece of speech, text, or conversation (Wetherell 2003). So, how compatible is the analysis of ethnographic context with the discourse analysis of management talk? According to Wetherell and Potter (1992: 102) ethnographic understandings are always part of discourse analysis - we need some kind of common understanding in order to talk about certain phenomena. In this study, I extend the ethnographic data to include more than just the basic communication necessities. The research questions that motivate this study require us to map the links between how managers talk and the processes of international production. Therefore, understanding how a supply chain is constituted in relation to international labour is central to the task of researching and analysing that supply chain.

An interview, no matter how staged or structured, is also a type of ethnographic situation (Pinsky 2015) that allows certain interpretations to be made, while preventing other interpretations. Researchers can, however, have different strategies for approaching interviews. The inter- 
views that I have done with managers have not been intended to find true accounts of how migrant labour is organised and mobilised in Sweden. This does not, however, rule out that what managers say can be used as a contextual description to make sense of a situation, such as a description of certain supply chain relations. Yet, much material in the interviews tell us 'crucial things about a segment of a society's conversation with itself, about the ways in which a world is typically legitimated, organized and justified' (Wetherell 2003: 13). Wetherell understands interviews as situations that 'tell us about the cultural resources people have available for telling their patch of the world' (ibid.).

The managers that I interviewed spoke back at discourses on migration and globalisation, yet they also constructed their own logic, and organised accounts about themselves and others. Some of the managers were very actively engaged in issues of state policy on labour migration, for instance through lobbying work. They would use discourses of migration policy as resources (Wetherell 2003) in the ways they spoke about migrant workers in their sectors. Paying attention to these ways of speaking can also be done through the analytical concept of intertextuality, used in Norman Fairclough's critical discourse analysis (Fairclough 1995), to point out the ways in which discursive structures set the frames of what can, and cannot, be articulated at different times. Taking an interest in social change, Fairclough also recognised that other social practices and structures are dialectically interrelated with discourse, meaning that they are mutually constitutive, and may limit the effects of language. In this thesis, the structures of global production and economic practice are particularly interesting to study in relation to what can, and cannot, be articulated. Marianne Winther Jørgensen and Louise Phillips point out that analysing intertextuality is a common approach in discursive psychology and that it requires that researchers have a good knowledge of discourses from the fields that are referenced (Jørgensen and Phillips 2002: 134). They suggest that researchers should be strategic in the ways they map the field and make the analytic links explicit (ibid.). My research process, which was partly affected by what I have already described as 'the buzz of migration talk', represents the work of mapping the resonance of other discourses in management talk.

Critical research commits to referencing competing discourses or alternative perspectives rather than those of hegemonic accounts. I sometimes make use of migrant workers' voices from previous research or from the ethnography of this thesis in order to present alternative ways of evaluating a situation and the interpretative repertoires through which managers speak. Presenting these accounts is not the same as questioning the truth in the managers' accounts, but instead they allow me to an- 
alyse how the managers' repertoires fit with particular ways of describing the world, but not with others. In my research on the berry industry, my knowledge of the practices and perspectives of Thai pickers are present in the choices I have made and the questions I have asked managers during the fieldwork. I spent several days with the berry pickers and worked with them in the forest. I recorded shorter interviews with 25 of the Thai workers, and I talked to maybe 50 pickers about their work and about their travels. These interviews, together with reports and studies by other researchers, have added a deeper understanding of the supply chain. Yet these accounts do not provide a complete picture. First, I did not ask the berry pickers critical questions, such as how much money they make, or whether they thought their boss treated them fairly. The main reason for this is ethical; it would be difficult to guarantee that their participation in my research would not have negative effects on their life situation. ${ }^{10}$ Some of the berry pickers did describe negative aspects of their lives as migrant berry pickers, but my main purpose with the analysis was not to track these specific narratives and prove whether these experiences could be supported by other observations. Instead, I wanted to understand if there were other ways to construct and build up the story of Thai berry pickers in Sweden, and use that understanding to engage with management discourses.

Material corresponding to the interviews and conversations with berry pickers is not included in the case study of the IT industry. I did however record four interviews ${ }^{11}$ with IT workers from India who were working temporarily at a Swedish office. We talked about commuting in Stockholm, eating vegetarian food in Sweden, holidays, traditions, weather, and the school systems in the different countries. These interviews, because they were so few, and revealed very little about the experiences of working life, have not been used in the analysis. In the interviews with these Indian computer specialists, for instance, we did not talk about what they did during their working day, and in many ways this mirrored the challenges of interviewing managers in the IT industry. The concrete tasks of an everyday workday were difficult to include as interview questions due to business confidentiality, and the work situation - for instance, colleagues, feelings etc. - both of which were uncomfortable topics. The

10 Most berry pickers did not speak English and the interpreter would often be someone from the kitchen, a driver, or sometimes a work leader. Even in the situations that did not involve obvious power relations, complete privacy was rarely found. Furthermore, people who spoke to me were almost always questioned by their colleagues about what I had said, who I was, and what I had asked.

11 These lasted between one and two hours and were done at three different companies. 
precarity of working life, and perhaps even more so of migrant working life, furthermore prevented me from asking questions about salaries or working conditions. The research field of working life needs to take into account how surveillance, the culture of company loyalty, and the precarity of employment needs very innovative and safe settings in order to be made explicit in an interview. There is much left to investigate about the lives of seasonal workers and temporary high-skilled workers, globally and in Sweden. This is however beyond the scope of this dissertation.

\section{Analytical strategies}

I have transcribed field notes and interviews and have read the managers' accounts over and over again. I then selected excerpts from these transcripts and sorted them according to different themes: manifest themes and underlying themes (Saldana 2011: 108). These excerpts were selected in different ways and those that stuck with me were often coded according to a wide range of themes that I tried out. Something that stuck with a quote or a piece of conversation was usually not related to an immediate analysis of what was meant, but rather a feeling that something was 'going on' in the material that I couldn't quite grasp at first. Thus, by reading, rereading, and situating these excerpts in a wider context, I developed a more precise understanding of them.

The manifest themes were defined in relation to what managers had explicitly talked about, for instance working conditions, state regulations, or cultural differences. These manifest themes often helped me identify theoretical themes, and they sometimes provided important descriptions that are presented as part of the results of this study. The underlying themes were sometimes defined in relation to theories, and sometimes through the analytical strategies provided by discourse psychology. The thematic analysis of theoretical concepts can be illustrated with the example of supply chains. One theme that emerged from the managers' accounts was the descriptions of a fragmentation in relation to production and labour. After I incorporated theoretical conceptualisations of supply chains into the analyses, I was able to search more systematically for parts of the empirical material in which other economic actors were mentioned, or where the informants talked about international production. I developed questions that could guide this analysis, such as: How do managers describe their professional role and their work? Which aspects of management are missing from the interview material, and what effect will that have on the analysis? How do the ways in which managers position themselves in a supply chain affect their characterisation of migrant 
labour in their accounts? In the analysis I have chosen to present quotes and field notes that represent the theme that I have analysed, although there are often similar quotes that I could also have chosen. However, I also worked with analytical strategies that are suggested in discourse psychology and are located more closely to the language that managers use.

\section{Analysing discourse and interpretative repertoires}

The main data that I have analysed does not consist of long-term observations of the daily routines of managers, but of interviews with managers. The material is made up of management talk about working as managers and about workers and employees. By referring to talk I particularly want to point out that most practices and relations that I analysed were not observed and described by me, but instead they were communicated by the managers through their talk. The talk is however part of a research process, which I, as a researcher, am able to reflect upon. In the theoretical chapter I discussed different ways of thinking about supply chain relations, as well as the morality and legitimacy of these relations. I take the view that in the supply chain translations (Tsing 2009) language is an important aspect of how the economy functions. Long-term and indepth observations of the material aspects of labour and supply chain organisations would give us insights into other types of power relations, such as the dynamics and interactions between managers and workers. Working with talk as a material is, in this sense, both an opportunity and a limitation.

Discourse analysis has received criticism for its focus on the abstract and on big discourse (see e.g. Tsing 2005), and this is also one of the criticisms directed at the work of Boltanski and Chiapello (2005) discussed in Chapter 3. Critical management researcher Susanne Ekman argues that by not engaging with any ethnographic material, Boltanski and Chiapello are open to criticism for only mirroring a small segment of management designers in their claims. 'Do we not need to pursue the reception of these texts in the everyday practices, and do we not also need to look for other discursive trends than simply those of a certain line of management texts?', she asks (Ekman 2013: 298). I consider managers' talk about migrant labour to be part of such ethnographic material, which tells us something about how big discourse on migration or globalisation is received, and how it lands in an organisation. I am, however, also interested in how management talk tells us something about how the meaning of migrant labour in a supply chain is translated and affected, or altered, through the managers' active use of language. 
Discursive psychologists have debated the ways in which a researcher can think about language and discourse as resources that are not only passively received, but also used by people in the ways in which they talk and act (Whetherell and Potter 1992). As already mentioned, much of my inspiration with regards to knowledge claims and analytic strategies comes from work in this field. By using discursive psychology as a perspective on my analyses, I can avoid to treat discourse as something that lands in an organisation from the outside but also refrain from reducing the managers' ways of talking about migrant labour to something that only mirrors their voiced attitudes and prejudices. In the study on management practices and logic of hiring migrant workers by Waldinger and Lichter (2003), the researchers interviewed managers and employers in an ethnically segmented city (Los Angeles) and labour market. Waldinger and Lichter argued that, in sociological research, discrimination and prejudice are often addressed empirically through surveys and associated questions such as 'Who do I want as my neighbour, friend, colleague, or spouse?'. The authors argue, however, that this does not explain the labour market situations in which 'the employer is not looking for friends, [but] just hired hands' (ibid.). This is also the reason why I will not analyse management talk as the expression of individuals' attitudes, but instead pay attention to the organisational and economic context in which attitudes on moral and amoral arrangements are voiced. Also, discursive psychology critiques the dominant notion of attitudes in psychological research, arguing that people's beliefs and biases are neither static, nor consistent (Edley 2001; Potter and Wetherell 1992). It is not necessarily so that the managers I interviewed speak about Thai culture or Indian engineers during an interview in the same way as they do, for instance, at the dinner table. Furthermore, it is unlikely that in their conversations with me, managers establish one coherent discourse, comprised of consistent views on migrant labour. The managers did, for instance, talk differently about migrant workers depending on whether they focused economy or culture in their accounts. Wetherell and Potter argue that 'interpretative repertoire' is an analytical term that allows researchers to analyse the social and established practices of discourse in its everyday use (Wetherell and Potter 1992: 90). Their focus is on how discourse is used and how people deal with compatibilities and ambivalences when going about their daily business, rather than a focus on evaluating how discourse works in the abstract. Analysing management talk can therefore give us an insight into the content of certain discourses of migrant labour in Sweden, and how this content is organised. In order to analyse management talk as neither the result of 'big discourse', nor as individual views on migrant workers, I have sometimes studied quotes and language 
in more detail by asking: Who is addressed in the managers' accounts? Are there any colourful expressions, metaphors or ambivalences in how managers speak that are particularly interesting to analyse?

Studying certain constructions of talk as interpretative repertoires suggests that 'there is an available choreography of interpretative moves - like the moves of an ice dancer, say - from which particular ones can be selected in a way that fits most effectively in the context' (Wetherell \& Potter 1992: 92). This description highlights the active use of language and allows us to see that the interpretative moves an informant makes are chosen in relation to alternative moves that could have been used when speaking about migrant labour in Sweden. In the subsequent chapters of this thesis I will analyse discourse as a flexible resource that is used by managers as they construct notions of workers, global mobility, and production. I use 'interpretative repertoire' as a term in the analysis of management talk where there is a need to specifically mark this type of active use of language, as well as the alternative repertoires and interpretative moves that a manager could have used. I do, however, find that interpretative repertoire represents a rather technical terminology that does not always work fluently in the ethnographic analysis of management practices. Researchers in discourse psychology themselves use discourse as an alternative to interpretative repertoires (see e.g. Wetherell and Potter 1992: 92) and argue that it is not the term itself that is problematic, but rather the assumptions of how a discourse is supposed to be constituted. I use the terminology of both interpretative repertoires and discourse.

In some analyses I have particularly searched for recurring descriptions that several different managers returned to. Yet I do not identify specific interpretative repertoires only by evaluating how frequently recurring descriptions are used by different managers. Looking for interpretative repertoires, we can search especially for 'broadly discernible clusters of terms, descriptions and figures of speech often assembled around metaphors or vivid images' (Wetherell and Potter 1992: 90). Although I did not start my analysis by systematically searching for any specific type of language, it eventually became clear that this was the best approach, especially for the excerpts from the interviews with managers in the IT industry, since these interviews were more consistent than the wild berry case interviews. I also used ethnographic parameters for this selection; situations where the atmosphere was particularly energetic or, in contrast, particularly uncomfortable or ambivalent. These feelings were more commonly the reason why particular quotes or situations from the wild berry industry were analysed. This was the natural result of using participatory observations in this field that differed from the way I collected material for the IT case study. Emotions, and the affective practice 
of management that I discussed in chapter 3 , has however also been observed in relation to how they are expressed through language.

Furthermore, the absence of certain possible constructions can be just as revealing as the frequency of others (Billig 1991). These absences can include those managers who did not talk to me at all, but they could also include the silences in an interview, or the subject positions that were not mentioned or not made possible. This thesis particularly raises questions about how migrant labour is articulated, and in relation to what. It also raises questions about the possible subject position of managers and migrant workers in these accounts (Edley 2001). While managers speak about many different topics in the interviews, the research focus is on their construction of migrant workers. This does not mean that managers always explicitly addressed migrant workers in the accounts that I chose to analyse. In the analysis I have therefore worked with the questions: Is there anything in the ethnographic data, or in alternative discourses on migration, that makes certain interpretative repertoires particularly significant to analyse? Which subject positions do migrant workers need to occupy in the managers' accounts of legitimate supply chain relations?

In this chapter I have clarified how I view the managers: as informants who speak about migrant workers in specific interview situations, as people who can indeed exercise power on their workers, but also as people occupying positions that cannot be reduced to that of 'privilege'. In the four analytical chapters that follow, I use the methodological reflections to achieve more nuanced analyses of how managers are situated in complex ways in relation to migrant workers, and how these relations of power are characterised both by the organisation of international production as well as by other identities. The focus on language in the discourse analysis that I apply is complemented by 'thick descriptions' of the industries, and by the relations with which production in these industries engage. 



\section{The wild berry industry \\ - seasonal work and its \\ reliance on foreign labour}

The 2008, labour migration reform received both societal and academic interest. During the years when I carried out my dissertation project the part of the wild berry industry that employs seasonal workers from Thailand, in particular, received much attention in the Swedish media, especially debating the severe vulnerability of the migrant workers. With regards to the research on managed migration that this thesis pursues, it is important to note that the seasonal structure of harvesting wild berries, similar to that in agricultural industries, corresponds to some of the main assumptions and strategies of the EU policies that address circular migration (European Commission 2007, 2014). Investigating this type of shortterm return migration, which is tied to seasonal employment in certain industries, is a growing field of research internationally (Triandafyllidou et al. 2013). In Sweden, the situation of the Thai berry pickers has been debated in relation to Swedish labour market policies and migrant rights (Eriksson \& Tollefsen 2013, 2015; Hedberg 2013; Vogiazides \& Hedberg 2013; Wingborg 2011, 2013; Woolfson et al. 2012), and studied with a particular focus on its effect on gendered relations (Hedberg 2015; Sörensson 2015). Although several of these studies include analyses of the structure of the industry, the specific focus on employers and mediators in the industry has not been pursued as an independent area of research. The literature on the growing research field of labour in the Nordic wild berry industry is an important background for the empirical analysis in this chapter and in the next chapter, since these studies position the industry and the migrant workers in institutional and social contexts that my interviews with the managers do not necessarily address.

In this chapter, I analyse the ways in which managers in the berry companies talk about the international composition of labour in the Swedish wild berry industry, and in doing so I especially explore these accounts through the conceptual framework of supply chain capitalism. In studying the managers' accounts I also present other important actors in the industry and how the economy of foreign labour is constructed in relation to the influence, institutional positions, and motives of these actors. 


\section{Explaining supply chain relations - the development of a wild berry industry}

In the previous chapter, I introduced the theories of commodity chains and global production that I use in this chapter in order to analyse the wild berry industry. One benefit is that these perspectives challenge the idea of a homogenous industry in which migrant workers occupy certain positions and their labour can only be valued in one particular way, and instead they emphasise a diverse industry in which different moral positions may gain influence. By thinking through the conceptualisation of supply chain capitalism (Tsing 2009, 2012) the diversity of interests and discourses concerning wild berry production is placed at the centre of the analysis. The focus on how managers talk about the supply chain framework of the wild berry industry allows me to discuss how migrant workers and their labour are situated in relation to the activities of selling, marketing, distributing, and consuming wild berries. In the Swedish wild berry industry, the organisation of production and labour has changed significantly over the years. I discuss how discourses about these changes define actors and events as being of greater or lesser importance to the present-day industry and its organisation. This chapter therefore starts out with an assessment of the different positions that berry entrepreneurs take in relation to aspects of change and production.

History, change, and development were recurring themes in my interviews with the Swedish berry entrepreneurs. One representative example of how the evolution of the wild berry industry was described is a longer conversation with Rene, an entrepreneur who has worked in the berry industry for 20 years. Rene, like most managers that feature in my material, represents what I call a 'berry company': a Sweden-based corporation that acts as a middle-man in the supply chain, being neither the formal employer of berry pickers nor the final destination for berry refinement and marketing. In 2011, I called Rene to talk about the situation of Thai berry pickers in Sweden and explained my research interests to him. His descriptions and engaged interventions in the interview are the basis of the excerpt below. This excerpt reveals some of the interpretative resources that managers used when they talk about workers and about the business they are in. It is a useful introduction to the industry, as this quote by Rene presents and positions most of the central supply chain actors that are analysed in this thesis, focusing on migrant work in the wild berry industry.

Karin: So I have been talking to people at the Migration Agency about that. The office is in Norrköping, where I also work, you know. We 
talked about the routines of work permits now, how there are many aspects to consider that they have to discuss and ...

Rene: Do you know about the berry industry in Sweden, how it started? No? Well, before we started our business there were only retired people who picked berries, on the weekends. And holiday pickers who made some extra money. Back then, in the late 80 it was very controversial with Polish people who started coming here, living in camping areas and picking berries. There was even a bus company $[\mathrm{A}]^{12}$ that arranged bus trips from Poland.

Karin: A bus company?

Rene: Yes, they advertised in Poland about the trips. And then, in the 90s, a new group started picking: Thai women who met Swedish men. They started inviting relatives over and this business just kept on growing. I have heard that there are more than 25,000 Thai women in Sweden now. In the gos they invited large groups of people - they lived under really bad conditions; there were no rules. They were here on tourist visas and lived in farms and stables. Some summers were very cold and the conditions were horrible really. And the Migration Agency reacted on this!

Karin: Okay ...

Rene: And in 2000 the distributors $[\mathrm{X} \text { and } \mathrm{Y}]^{13}$ they wanted to ensure the access of berries every season. But nobody took responsibility for the Thai pickers. So then the interest organisation was formed and made an agreement with the Migration Agency. The agreement was that the berry industry should take responsibility. So companies were appointed, companies that were allowed to invite people from abroad. So they were called 'inviting companies', right. They needed to take a social and economic responsibility. This was working pretty good, but then the Tax Agency decided to check if this was in fact organised wage labour. There was a national revision then that led to the Begab sentence, which was about some Ukrainians. 'We claim that the pickers are hired for picking', said the Tax Agency. This was all the way up to the Supreme Administrative Court. Then, in 2006, you didn't know what would happen. It was a very turbulent year. $[\mathrm{B}]^{14}$ took in berry pickers on tax, right. And this one company [C] hired a Cypriot manpower company. It was very chaotic. They were charged with this and had to pay a bunch of money in missing employer fees. So then there was this email sent out, where they [the Tax Agency] told us that we should hire foreign companies to be the formal employers of the pickers because they wouldn't have to pay tax and employer fees. So they were all in on finding a solution to this. Imagine. Headline: financial department plans taxation for berry industry.

12 The name of bus company

13 Name of companies

14 Name of company 
In this quote, Rene first explains that the history of changing supply chains is central to understanding the current composition of labour. Then Rene introduces the relations between several central actors in the industry: the Thai pickers who arrived in Sweden before the distributors and the berry companies had organised production according to a supply chain structure, and the recruitment companies that entered the industry to meet both the new requirements of the state authorities as well as the moral dimensions of responsibility in the industry.

At the beginning of the interview, I try to define our conversation as being about labour migration in Sweden by referring to the practices of the Migration Agency. Rene interrupts, and instead tells me the history of berry picking in a manner that seems to follow a rehearsed storyline. It feels like a story that Rene has told many times before. The Migration Agency, which I used as a starting point, does not return in Rene's account. Instead, other actors are centred. The way that Rene tells this history resembles the accounts that other managers and entrepreneurs in the Swedish berry companies provided during my fieldwork. I had expected that migration and the international composition of labour would be central to the main issues of the industry, in contrast to Rene's focus on the business structures within the supply chain of the wild berry industry. Rene's account presents migrant labour as a phenomenon that needs to be defined in relation to the current and the past regulation of the production of wild berries. The logic of the business structures and networks define the boundaries for how Rene can talk about labour, and consequently the workers. Thus, in this chapter I discuss how these management discourses can be understood as expressions of supply chain logic.

Rene represents one of the inviting companies mentioned in the quote above. Today, Rene's company, like most berry companies, does not invite berry pickers in the same way as prior to 2006. Instead, Thai recruitment companies are the formal employers, and companies such as Rene's organise the picking in Sweden. In Rene's account on how the industry has developed, the Sweden-based berry companies are not presented as the most important actors. The strategies of Rene's own company are in fact not present at all in the quote above, and the company's role remains somewhat vague in relation to the production of wild berries. Instead, Rene's account consistently emphasises the relations within a supply chain, the instability of these relations, and the importance of the institutional settings constituted by the tax regulations and migration policy that affect these relations.

The relations between recruitment companies, berry companies, and distributing companies that Rene describes, can be understood as comprising the economy of wild berries. In analyses of the economy, the so- 
ciologist Viviana Zelizer (2012) suggests that researchers should focus on relational work performed by different actors - relational work that extends beyond risk reduction or economic performance. The analyses of such relational work, Zelizer argues, can reveal content, variation, and change, and 'the effort people make establishing, maintaining, negotiating, transforming, and terminating' these relations (Zelizer 2012: 149). The economic relations of the wild berry industry are established and are transformed through management discourse and the possible subject positions that key actors and their relations can occupy. In this initial analysis, I focus on how Rene performs relational work through the ways in which different actors are represented in the excerpt from his history of wild berry production.

At the beginning of Rene's account, Thai berry pickers were said to be recruited by Thai women in Sweden. Rene makes a point of emphasising how many Thai women there are living in Sweden, which signifies that this diaspora is important to the industry. The Thai women as a subject position in these management discourses can be observed in several manager accounts and I will discuss this theme in more depth later in this chapter. For now, it can be noted that in Rene's account the Thai women treated berry pickers so badly that a change was inevitable. The Thai women are characterised as dysfunctional in relation to the wellbeing of berry pickers and in relation to production.

In the context of worker wellbeing, another supply chain actor, the distributors, enters Rene's historical overview. According to this description, the distributors, who carry a desire for more predictable production and profit, wanted a more structured industry. However, according to Rene, the distributors did not take responsibility for the pickers. The distributors represent a significant supply chain actor and by pointing out the difference between the berry companies and the distributers Rene differentiates two subject positions: those who care about labour conditions, and those who don't. I will return to how the distributors are constructed in these discourses later in this chapter. In the narrative, companies such as Rene's invited migrant berry pickers to Sweden and were 'economically and socially responsible'. Rene makes explicit the image of a caring and responsible subject position in the supply chain; a position occupied by the berry companies. Social responsibility, in fact, becomes a key resource in positioning the berry companies as the moral subjects of the berry industry.

Rene describes how the arrangement in which berry companies had authority, worked well until the state agencies changed the game. Rene uses quotations and vividly illustrates their statements when referring to state agencies, thus creating the effect of exposing their control and in- 
fluence. In the next section, I continue the analysis of these descriptions of the state, focusing on how the wild berry industry is represented as marginalised and geographically peripheral.

This initial analysis of Rene's abbreviated history of berry picking in Sweden discloses the deconstruction of supply chain relations as an essential aspect of analysing management discourse. It acknowledges that translations across and between these different suppliers constitute the ways in which accountability, responsibility, and what is good and fair are defined (Sayer 2005a). In Rene's account, the actors in the supply chain are described in relation to their economic interests, as well as in relation to their moral positions and their geographic locations, for instance being in Sweden, Cyprus, or Thailand.

\section{A northern business}

A central construction of space in the material I collected about the wild berry industry referred to the marginalised position of the northern parts of Sweden. Literature on commodity chains open up thought about the spatial contexts of production, and from looking at the commodity chain of wild berries it is clear that it includes a wide range of places (Hedberg 2013). The berries grow in the forests of northern Sweden, they are picked by workers from Thailand, stored in warehouses across Europe, refined for beauty products in Japan, or consumed as jam in Scandinavia (Hedberg 2013; Wingborg 2011). The spatial aspects of wild berry production also concern institutional and national contexts; for instance the conditions determined by Swedish politics, law, and public debate. Tax regulations, labour laws, and migration control all affect the ways in which the networks of global production are structured (Gereffi 2005). These regulations and laws, and the ways in which they have dictated events, are a dominant theme in Rene's description of the industry's transformation and changing composition, referred to at the beginning of this chapter. Rene describes how the changing regulations allowed new actors to enter the industry, for instance the recruitment companies in Thailand, and made other actors, like Thai female entrepreneurs, disappear from it.

State agencies can be thought of as representatives of the commodity chain's institutional context. In the quote presented earlier in this chapter, Rene presented the authority of agencies such as the Tax Agency as rigid and imperative. He uses a quotation: "We claim that pickers are hired for picking", said the Tax Agency', and through a description of its consequences he presents the state as being guided by a bureaucratic logic that has inefficient and malign side effects. A different berry entrepre- 
neur, John, also explained the tax revision of 2006, which was thought at the time to threaten the wild berry industry:

\begin{abstract}
John: We had people on our side. They lobbied in Almedalen and even wrote letters to Maud Olofsson [the Swedish Minister of Industry]. We need rules and regulations but the worst thing that could happen is that they would pull the rug from under this whole industry in the north. As an entrepreneur you create jobs for people here. The blueberries and lingonberries are a great natural resource and we need to take care of it.
\end{abstract}

John illustrated the wild berry industry as being part of the northern regions of Sweden and the success of the industry as a shared interest in those regions. ${ }^{15}$ The majority of the owners and managers at the berry companies were entrepreneurs who had been, or were still, engaged in a wide range of businesses, from tourism and other services, to real estate and production (see also Jonsson \& Uddstål 2002: 18). Much of the berry picking is located in depopulated parts of the northern regions of Sweden, Norrland, and the berry entrepreneurs, who host hundreds of berry pickers every season, can buy old abandoned buildings as accommodation for their workers. These buildings are the physical components of the organisation of berry picking. Most of the stops and stays during the time I spent in the field were in old abandoned schools that could no longer be filled with children in the depopulated northern areas where there were few job opportunities. These areas are where the berry industry is mostly located. Therefore, John's statement that you 'create jobs for people here', is important in this context. This argument constructs an 'us' and a common interest in relation to the northern parts of Sweden, and at the same time it differentiates between the spatial context of wild berry production and the national Swedish space that is represented by state agencies. In the light of neoliberal globalisation, the north of Sweden, Norrland, is often represented in the media and in political discourse as obsolete and as the unmodern 'other' to modern urban Sweden (Eriksson 2010). Both Rene and John talk about an industry that is not acknowledged, and not understood in its own terms.

In relation to the state agencies, the problem of unpredictability was also highlighted in the management talk, and the managers described how the wild berry industry was difficult for them to navigate. Some of the managers I interviewed addressed the topic of unpredictability in a direct way. Kim, the chief executive officer (CEO) of a berry company, explained the risks and the marginalisation:

15 See e.g. public statement in the parliament, Grönlund Krantz 2005 
Kim: They ask me why we don't just quit. I like this business and it is fun to meet new people. And this is an important industry. But we invest in more than 300 cars and buildings for more than 1200 people. This is like putting the investments in a game of roulette - we don't know if this is all illegal next year.

Like John, Kim emphasised that the wild berry industry is an important business. This emphasis in Kim's statement counters the influential discourse that proposes the logic that economics alone is the sole determining factor of success or failure. According to Kim and John, it is not the lack of the economic value of wild berries that causes a marginalisation of the industry. Their argument is that the berry industry is culturally and morally de-valued and is viewed by others as insignificant. In these managers' accounts, the value of 300 cars and the buildings for more than 1200 people is determined by the prejudices of others.

By deconstructing the interpretative resources (Wetherell and Potter 1992) that the managers use when speaking about the wild berry industry, the analysis can therefore reveal discourses of the economy. In the context of a marginalised industry in a forgotten northern region of Sweden, managers in the wild berry industry view the economy as inseparable from cultural evaluating practices. The managers argue that the cultural notion of the berry industry is presented as lacking value to the nation, and thus affects the economic risks and profits for them. The berry company managers describe the state agencies and their attitudes towards the industry, and argue that the institutional setting of Swedish regulations and authorities adds to the burden of the berry actors. In the quotes that I have presented, Rene, John, and Kim present their argument by referring to the economics of investment, employment, and profits. In their descriptions, however, the managers also establish the relations between the berry companies and the Swedish state within a countering discourse of a struggling, hard-working, and moral berry industry in the north of Sweden. In this management discourse, the regulations and the interference of the Swedish state should be understood as disregarding the value of the berry industry.

The managers, however, spoke in different terms about their relations with the Thai authorities. John, who spent a significant amount of time in Thailand, and had hosted Thai state authorities in Sweden, said that: 'When the representatives of the Department of Finance in Bangkok were here they thanked us for all the work we did for Thai berry pickers'. John described the gratitude of the Thai authorities as being in sharp contrast to the attitudes of the corresponding Swedish state actors. These descriptions highlight the transnational space as important for understanding 
the wild berry industry. In relation to different nation states, John can describe the industry as being both wanted and unwanted, as valuable and without value. The attitude of the Thai state agencies is also used as an interpretative resource to highlight the irrationality of the Swedish state. The managers actively engaged with different institutional spaces in the interpretative repertoire of a valuable wild berry industry, emphasising Norrland, Thailand, and Sweden in different contexts.

\section{Bargaining over berries - distributors in Sweden}

During the time of my fieldwork, the risks and responsibilities of the wild forest berry supply chain were debated intensively. These debates took place within a larger discourse of accountability where non-governmental organisations (NGOs), researchers, and policymakers called for more responsibility from companies at the top of the commodity chain: the buyers and the distributors. There are only a few large distributors of wild berries in Sweden. These distributors are sometimes producers of food products, but they mainly stock and deliver berries to other producers in a global commodity chain of, for example, health or beauty products, where antioxidants from Nordic blueberries are especially in demand.

In recent years, actions have been taken within the industry to improve both the rights of migrant workers and the transparency of the supply chain. The buyers who have been involved in the work to increase social responsibility in the industry are mostly the national food corporations (Wingborg 2013). Also, distributors have increasingly adapted their practices in terms of monitoring the conditions under which berries are harvested. In 2011, however, when my main fieldwork was carried out, this work was not systematically in place. The berry company representatives that I interviewed described the position of the distributors within the industry as lacking engagement in how the industry was portrayed. In Rene's account, at the beginning of this chapter, the distributors, in their quest for more predictable and structured harvests, were unwilling to take responsibility for the wellbeing of the migrant berry pickers. Other representatives of the berry companies talked about the distributors and their responsibilities in similar ways:

John: There should be a system where we can know that distributors won't buy berries that have been picked by anyone who is not working under legal conditions. If we don't have rules we will not survive as a business, that's for sure. 
Kim: I welcome regulations from the Migration Agency - it is important that there are guarantees that salaries can be paid. But then again, distributors should take a much bigger responsibility for that.

Rene: They would say that it is not their responsibility, that they buy berries from those who have it.

Kim: Some distributors say that they don't buy berries from free pickers. But they don't have any controls on that. They just say that to the media.

John, Rene, and Kim express their opinions and debate different solutions to the problems of the industry. These suggestions of rules and regulations for the supply chain actors specifically address the distributors, and the management talk about coherency and transparency is directed towards the distributing companies who are portrayed as not being engaged enough. In the context of regulations, the berry company managers actively establish connections between the berry distributors and the conditions of labour, for instance by highlighting how they promote informal conditions when they buy from pickers with no formal employment. This serves to project the image of a coherent industry rather than a fragmented supply chain, to push responsibility in the direction of the distributors, and to include them as accountable agents. The berry entrepreneurs' arguments are an attempt to draw the distributors into the orderliness and transparency that 'regulation' and 'system' signify, and into the industry of producing or picking berries - not only distributing them. I argue that this is one aspect of constructing a notion of what a moral economy would look like according to the berry companies.

In 2011 and 2012, I contacted five people at three different distributor companies to ask them to participate in my study. They all declined, stating similar reasons, namely that the working conditions in the berry forests were not their responsibility. In 2015, this might very well have been different, considering the increased visibility of the distributors in the public debate about the industry. In the material that I analyse here, however, the distributors represent a silence. This silence can be productively included in the analyses, for instance through the ways in which managers in the berry companies attempt to draw the distributors in, closer to the heart of the moral conflicts, in their way of talking about the industry. The absence of the berry distributors' voices is not only a matter of speech and discourse, but it reflects differences of interests, or conflicts, within the supply chain and over the mobilisation of labour. In the next section, I discuss how managers of the berry companies talked about accountability and responsibility in relation to the recruitment companies. 


\section{Down the supply chain - working on the relations with partners in Thailand}

The responsibility for labour in supply chain capitalism is outsourced, which causes an increased fragmentation of labour and of management accountability (Tsing 2012). So far, the ways in which the berry companies talk about distributors has illustrated these points. Rene's initial account, which I have referred to throughout this chapter, makes clear that the responsibility for labour does not sit permanently in the hands of the berry companies. Recruitment companies, for the most part based in Thailand, are also central supply chain actors, and Rene explained that they entered the wild berry industry following the tax reforms of 2006 . After 2006, Asian recruitment agencies, or staffing companies, entered the wild berry industry on a large scale. Swedish berry companies engaged in contracts with the recruitment agencies in Thailand in order to avoid employers' fees and to avoid the taxation of the berry pickers. This type of cooperation has changed frequently from year to year, and while recruitment companies in other Asian countries have been active in some years, Thai recruitment companies dominate the berry picking industry. The relations also differ between companies. Some Swedish berry companies explained to me that they had worked closely with the same recruitment company for several years, while others had changed company almost every year, or had worked with several recruitment companies at the same time.

Returning to Rene's description of how recruitment companies entered the industry, we can see how the state is ascribed an important role in relation to changing events:

Rene: $[. .$.$] So then there was this email sent out, where they told us that$ we should hire foreign companies to be the formal employers of the pickers because they wouldn't have to pay tax and employer fees. So they were all in on finding a solution to this. Imagine: 'Headline: financial department plans taxation for berry industry'.

Inspired by the analytical strategies of discourse psychology to pay particular attention to talk that seems colourful and where something 'happens', I note how this excerpt is told in an animated manner where Rene re-enacts a debate and an event. In this quote, Rene talks about the Tax Agency, or about specific officials who work there, in contrast to the construction of state interventions as rigid, bureaucratic, and static, which I observed earlier in the analysis of this chapter. This part of the quote signifies an ambivalence towards state practices. 'Imagine', Rene says, that the department of finance would help the berry industry by coming up 
with such a controversial solution. Rene constructs the state as ambivalent, and yet actively involved in the development of the wild berry industry, which resulted in the entry of foreign recruitment companies. The ambivalence that Rene describes constructs a state subject that does not exclude the possibility that Thai companies, and by extension Thai workers, actually belong to the Swedish economy of wild berry production. In the first chapter of this thesis, I discussed this type of migration management in which specific economic conditions directly affect how government authorities change their policies to grant access to labour markets across international borders. The ambivalence of the state is therefore important to an interpretative repertoire in which the supply chain structure of the wild berry industry, and the central and important position of the Swedish berry companies in this supply chain, can be established as moral and right. The selective access of Thai workers to Swedish berry picking, mediated in part through seemingly technocratic practices, namely serves to establish the economic role of berry companies. Berry companies are described as survivors in the interpretative repertoire of their importance to the wild berry production. In Rene's account, berry companies recreate and transform their businesses according to state politics, and remain flexible and adaptive to new conditions, for instance in the ways that they cooperate in the supply chains. Hence, the existence of berry companies in an industry where Thai recruitment companies carry the formal responsibility for labour, is legitimised in part by how the state regulates the labour market in ambivalent and unreliable ways, and by the need for a supply chain actor to navigate these state practices.

Although berry companies in my material usually claimed that they felt a responsibility for the berry pickers, in contrast to how they depicted distributing companies as lacking notions of such responsibility, some of my informants instead emphasised the role of recruitment agencies as accountable for any abuse of migrant berry pickers. I talked to the berry entrepreneur John in the early summer before berry pickers had yet arrived in Sweden, and when new rules had been announced but were still not in place.

\footnotetext{
Karin: But right now, are the pickers, have they bought the tickets? John: We don't buy the tickets; [the recruitment company] does. I don't know who paid now, the deposition. I mean, I think they do it in their way. They will buy the tickets and make sure that the pickers are fit, that they can go.
}

This represented one of the more sensitive types of topics during the interviews I carried out. Talking about specific agreements between different parties in the supply chain often created uncomfortable feel- 
ings. Most of the managers I interviewed talked about these topics in an avoiding, hesitant, or distanced manner. One reason could be that the arrangements would be morally controversial, or perhaps because these issues were, in fact, handled by the Thai recruitment agencies without any deeper insight on the part of berry companies. By emphasising the role of the state in extending the supply chain of wild berry production, John establishes a legitimacy for the arrangements of the recruitment companies. Hence, the extended supply chain structure is not talked about as a strategy for outsourcing the responsibility for labour.

The relational processes in the supply chain were made explicit in the managers' talk about the development of the berry industry. Rene and Kim both described the early stages of the formation of new networks and their relations with recruitment companies in the supply chain.

Rene: It took some time to know how to work in the new system. And now we have recruitment companies that we can trust - and they understand that they have to send the same staff, that we need people here who understand the industry.

\begin{abstract}
Karin: So how did that change it, when you started working with the recruitment company?

Kim: Well [name of entrepreneur] - they had big big problems. They hired a recruitment company in Vietnam, and when their pickers came here they thought blueberries were as big as golf balls. They thought it was just to come and pick them up. So they were angry, protested; it was all over the media and that's the type of situation that is, uhm, not good.
\end{abstract}

Kim described an incident that concerned a different berry company. This company had a contract with a recruitment company that gave false information to the prospective berry pickers. There were many news items about similar events in the Swedish media in 2009 and 2010, revealing how some recruitment companies systematically cheated migrants by hiding the costs that berry pickers needed to pay, or by giving false information about the working conditions, or about the amount of berries they were likely to pick. When talking about problems or controversial topics, most of the managers I interviewed referred to other companies and their problems, which created a distance between their particular business and these more general problems. In the event that Kim describes, the pickers' belief about blueberries being 'as big as golf balls' emerged from somewhere in the communication between the recruitment company and the migrant workers, although the protests, according to Kim, became the problem of the Swedish entrepreneurs. Both Kim and Rene's statements indicate that there is much at stake in the relations between supply chain actors. 
Rene, when talking about staff sent to Sweden by the recruitment company to organise the lives of the berry pickers, emphasises that knowledge and trust are important for production to be efficient. Rene also describes the relation with the recruitment company as requiring continuity and understanding, which, according to the account, builds a mutuality and intimacy in relation to the different positions in the supply chain. This contrasts with the ways in which supply chain actors were differentiated in other management talk, and how labour responsibility was 'passed over' to the recruitment companies. The distance and differentiation, as well as the mutuality and intimacy in the supply chain, were consistently negotiated in the management talk. Rene, for instance, described the supply chain relations as supportive:

Rene: With us, we are lucky, because our distributor that we work with - they have said that they will help out with the expenses for tickets that are paid in advance. They don't think that the recruitment company should have to do that. That is too much money at once.

In Rene's description, the berry company, the distributor, and the recruitment company distribute responsibility and financial risk among themselves in the supply chain. The berry pickers are the responsibility of the recruitment company, yet there can be help and support from within the supply chain. At other times, however, the berry pickers were represented as being much closer to the Swedish berry company. Later in the interview, Rene describes how his company evaluates its recruitment partners in Thailand:

Rene: If we switched recruitment company now, the pickers would choose to come with us. They have been coming with us for many years now and they like the way we work. We give them a lot of freedom also, and we know that they value that.

This quote from Rene reveals the ambivalence of formal employment in supply chain capitalism. Rene argues that the pickers would be loyal to the Swedish berry company if the contracts changed, and in his account this creates a strong link and identification directly between the Thai pickers and the Swedish company. The Asian recruitment company, on the other hand, is presented as being replaceable.

In 2011, when I started my fieldwork, the largest debate in the wild berry industry concerned new directives that would require the employers of berry pickers, usually the Asian recruitment companies, to have a formal base in Sweden (Wingborg 2011, 2013). These directives may again put the issue of taxation on the berry pickers' income back on the table. 
The berry entrepreneurs all agreed that such taxation would make it impossible for berry picking to be profitable.

John: It's a big problem with all the costs now that we don't know what is going on with the new rules. If they have to pay tax and employer fees, no one would want to go to Sweden this year. But it is just one month left and the tickets need to be paid. And the visas - that will cost money to speed it up.

When John talks about the tax regulations, the supply chain is not positioned as being interconnected to costs - the taxation of berry pickers and the employer fees that would be a burden on the recruitment companies is not represented as something that is potentially shared with the berry companies or the distributors. However, most entrepreneurs talked about the potential taxation being the certain 'death' of the industry.

This tells us something about the ways in which money and earnings are talked about in relation to the supply chain. The taxation on these seasonal migrant workers, and the estimations and evaluations of reasonable earnings for a Thai berry picker, are central to the supply chain in an absolute sense; the recruitment companies and the berry companies are completely dependent on a situation where it is worthwhile for Thai workers to travel to Sweden. In the next chapter, I will present how migrant workers are represented in the management discourse on situations that make it 'worthwhile' for them to work in Sweden. Before presenting these discussions, however, I will analyse material where managers in the berry companies argue that there is a division between a formal and an informal wild berry industry, and how this serves as a way of establishing moral legitimacy for some actors rather than others.

\section{The other side of the industry - madams, Bulgarians, and tourist pickers}

Painting the picture of the berry picking history in Sweden in the quote that introduced this chapter, Rene describes how 'Thai women with Swedish men' started picking berries and later invited family and friends to Sweden. There is an ambiguity about the importance of these women in the development of the berry industry. Rene explains that in the early 2000 s the industry was in need of more structure and responsibility, and this required the exclusion of Thai women. Yet in Rene's and other berry company managers' talk about the industry these female entrepreneurs continued to return. Several of the informants talked about Thai wom- 
en who were, or had been, working with berries. The Thai women were sometimes referred to as 'madams'.

Karin: What is a madam? I mean, who is a madam?

Kim: A madam is a Thai woman who married a Swedish man and moved up in the world. She controls her fellow countrymen, they split half-half on the earnings. They have connections too, used to work as interpreters for [name of municipality]. So you know that, if you need an interpreter. They say what is good for them and we heard later that the translation was not fair. From the pickers, we heard that. The pickers who went with madams are afraid of them and they all say that they are much better off now with [name of recruitment company]. They have someone who speaks their language and listens to them.

The 'madam' is discussed as being obsolete, especially now that the recruitment companies themselves have Thai staff who can do the translating. Madams, however, are also characterised as occupying a central position in the wild berry supply chain, controlling the cultural brokering between Thailand and Sweden, and influencing and translating for important actors such as the municipalities. Other berry entrepreneurs told me that the madams also lobbied policymakers and other influential actors in Thailand.

Cultural geographer Charlotta Hedberg has studied the masculinisation of the wild berry industry in Sweden, arguing that the position of Thai women have changed from being active participants, both as entrepreneurs and as workers, to working under native men (Hedberg 2015). Hedberg's research shows the complexity of how Thai women are positioned within the Swedish wild berry industry. In some regions, there are still many pickers who arrive on tourist visas and work with, or under, Thai women with no registered berry companies. Former Thai female entrepreneurs also work closely with some recruitment companies in Thailand and act as cultural brokers or translators. Kim's description of the madam depicts her as a threat to the berry pickers, and Kim argues that many pickers are afraid of the madams that they previously had agreements with. Several other berry entrepreneurs talked about threats and severe exploitation of berry pickers in the former system, which was unregulated and not controlled by berry companies but by individual entrepreneurs.

On the wall of an office at one berry company I visited, there was a photograph showing a stop sign with a crossed out shape of a person. The sign read: 'No Thai Madam'. I asked John about the sign. He replied:

John: They will try to contact the pickers and they have 'phone numbers to many of them, so that they can decide places to meet up. Just the oth- 
er day some pickers told [name of manager] that they were contacted by a madam who wanted to buy their berries.

Following the labour migration reform, berry pickers, like other groups of labour migrants, were obliged to show that they would earn the equivalent of the minimum salary in line with the corresponding collective agreements for their profession. Berry picking was assigned to the $\mathrm{Mu}-$ nicipal Workers' Union as included in their field of responsibility at the labour market, and the minimum salary needed to be $22000 \mathrm{sek} / \mathrm{month}$ for migrants to be granted a work permit. By 2011, the regulations had become tougher and employers needed to show that they could cover such expenses before workers would be issued work permits to work for them in Sweden. The recruitment company that John works with would need to pay the minimum salary even though 'their' pickers sold their berries to someone else. The notion of the madam as a threat should therefore not only be analysed as a threat towards the berry picker, but also as a threat towards the main berry companies. In the interviews, the berry companies often returned to descriptions of an unfair dual system: one regulated, formal system, and one unregulated, informal system. In this context, the construction of the Thai madam as ruthless and oppressive serves to differentiate between moral and amoral subject positions in the wild berry industry.

In her research, Sörensson (2015) presents narratives of Thai women who live permanently in Sweden and pick berries with family and relatives from Thailand who travel to Sweden on a seasonal basis. These narratives are in sharp contrast to the ways in which Swedish entrepreneurs in my material talk about madams. In Sörensson's study, Thai women see berry picking as part of family interdependence and as a possibility to travel between Sweden and Thailand to maintain close family ties. Such empathy and kinship in the relational work within the informal industry also blurs the boundaries between what is moral and what is amoral.

The complexity that Hedberg's (2015) and Sörensson's (2015) research provide us with puts the discourses of Swedish entrepreneurs in perspective. In the entrepreneurs' talk, the Thai women are presented in a manner that allows only certain roles and positions - those of oppressive and greedy madams. In research that centres on the Thai women's stories (Hedberg 2015; Sörensson 2015) motives of caring, intimacy, and transnational solidarity are expressed in relation to the recruitment of family and friends through transnational networks. Thai women in the Swedish berry industry are likely to hold very diverse positions, and present their situations with very different emotional and economic rationales. The focus of this dissertation is the role that the madams are 
ascribed in the Swedish managers' talk about the industry and about migrant workers. By referring to female Thai entrepreneurs as madams, a specific role in the wild berry industry is produced. This construction of madams carries connotations of complex relations of power in which, according to the Swedish managers, the berry pickers suffer. The madams are also seen as actors in the supply chain who are in opposition to how the Swedish berry companies present themselves as subjects associated with regulated and transparent businesses. Race is a central aspect of these interpretative repertoires in which the madam is constructed as 'other' to the white Swedish entrepreneurs. In the managers' accounts, for instance Kim's quote at the beginning of this section, the madam is racialised through references to how the term is defined: as a woman who marries a white Swedish man to move up in the world. The madam does not marry a man 'in Sweden', but according to this discourse she marries into a racialised hierarchy that allows her to 'control her fellow countrymen', as Kim phrased it. In the entrepreneurial context, the madam is also defined in relation to her racialised kinship to other Thai people. This necessarily rules out the possibility that she can be associated with the regulated transparency of modern white business.

The conflict between the different sides of the industry that managers talked about, between free pickers and organised pickers, was one of their main themes and did not only address Thai women in the industry.

Kim: The new regulations are good, I really think so. But what's needed now is better controls on the free movers who don't provide any kind of security for their pickers.

John: The problem now is that [name of distributor] buys berries from free pickers. They don't have any kind of rules to follow.

The notion of the Thai madam as a threat to berry pickers has a function in relation to another dimension of the berry industry that the berry entrepreneurs consistently pointed out during the fieldwork: the new regulations in the industry that require employers to pay migrant berry pickers a minimum wage meant that it became more lucrative to buy berries from other companies' pickers. Entrepreneurs who are 'free movers', as Kim and several other managers called them, buy berries from pickers with whom they do not have any contracts. Free movers buy berries from pickers employed by other companies, or from so called 'free pickers'. According to the berry companies, free pickers are not affiliated with or employed by companies, and are mostly Thai people who are in Sweden on a tourist visa, or people from Eastern European countries who are allowed to stay in Sweden in line with the EU's policy of free movement. 
It is perfectly legal to pick berries in Sweden after entering on a tourist visa, in the same way that the common right of access to land in Sweden makes it possible for all Swedish residents to pick berries and sell them tax-free up to a value of $€_{1300}$. The entrepreneurs, however, emphasise that free movers systematise such picking and that they buy berries from free pickers for much higher amounts. The interpretative resources used by these entrepreneurs, again, mainly refer to exploitation and the lack of responsibility towards the wellbeing of the workers.

Rene: It is absolutely horrible, the situation with those Bulgarians.

There have been many complaints on littering and damages also. They came to Sweden more than a month before the berry season started, and we have our suspicions...but they are also tricked into coming here.

Rene's account describes how the Bulgarian pickers are causing problems with littering and causing damage, yet he suggests that these pickers are not acting on their own. The separation between the pickers and those who he suggests, or suspects, organise their work, is vague in his quote. In Rene's account, the articulations of migrant workers and migrant exploiters are absorbed in a homogenous construction of a segment of the industry that is violent and criminal.

Mešić and Woolfson (2015) have described the abuse of Roma people who, after escaping poverty, unemployment, and austerity in Bulgaria, have attempted to find a way to make a living in the Swedish berry picking industry. Most of these migrants had their dreams of getting out of poverty dashed when they arrived to poor conditions and few opportunities for making money from picking berries. Some of them even experienced abuse and threats from 'patrons' who had organised their travel. Parts of the local Swedish communities where Roma berry pickers lived responded to their presence with fear and contempt and raised complaints about damage to property and threats to safety. Several civil community initiatives, however, grew large, and included temporary, yet important, solutions to the problems of the many berry pickers who were without the basic humanitarian needs of food, shelter, and the opportunity to return home (Mešić 2016).

In the areas where I did my fieldwork, the issue of Roma or 'East European' pickers was a minor theme in the interviews. Although my informants occasionally talked about these incidents, like Rene above, the free movers or free pickers most often referred to the Thai people.

Rene: [The East European pickers] are occupying the south more. Up here the free pickers are Thai folks. Some of them have been coming here a long time. Some of them come with a madam or with relatives. 
In contrast to this quote, the free pickers were rarely talked about as independent berry pickers who had come to Sweden for many years and knew their way around. When my informants talked about free pickers, they more often used interpretative resources referring to the unfair system in which these pickers could be exploited and in which buyers and distributors did not need to take any responsibility. In general, the interpretative repertoire of a dual industry prevailed in the material. This produced an image of a clear-cut division between the formal part of the industry, where my informants worked, and the informal, unregulated, and dubious part of the industry, where madams, free pickers, and Bulgarian pickers and their patrons all worked. Despite the multifaceted characteristics of the 'other side' of the industry, this dualism is important in order to legitimise a moral subject as an actor who agrees on regulations set by the state, within a proper supply chain structure. Race again is an important resource in the articulations of these divisions, as the amoral and dubious dimensions of the industry are associated with that which is not white and Swedish.

Using quotes that illustrate how managers in the berry companies talk about other supply chain actors, as well as using the institutional context in which berry production takes place, I have analysed how the informants construct their own subject position within the economy. I have also shown how this subject position is ascribed a moral character. In the next chapter I discuss in more depth how migrant workers from Thailand are situated within the interpretative repertoire of a moral and functioning wild berry industry. 


\section{Representations of labour \\ - legitimising conditions in the wild berry industry}

In the previous chapter my focus was on the industry of wild berries and how managers talked about the various supply chain actors. In this chapter I shift focus and address the interpretative repertoires that managers make use of when they speak about migrant labour in Sweden. I discuss the public discourses that managers refer to by aligning with, or objecting to, as they speak about the moral legitimacy of arrangements within the industry. The chapter analyses how managers talk about the work that goes into harvesting wild berries and how Thai berry pickers are situated in relation to aspects of this work such as autonomy and competition. I discuss how labour in the wild berry industry is structured in relation to notions of a fair economy, for instance paying attention to how managers talk about prices and relations of power in the negotiations. Furthermore, I discuss the ways in which the migrant worker is viewed as a moral subject in management discourse, and under what conditions. In these analyses, I draw on the descriptions of migration and mobility that managers use as they define the transnational lives of temporary, or circular, Thai berry pickers. Towards the end of the chapter I discuss how we can understand the role of a moral economy in the wild berry industry more generally, and what public opinion and images of social responsibility mean to the industry.

\section{Speaking back - responsibility as a defence against discourses of exploitation}

In the interviews, when berry company managers talked about a lack of responsibility from other actors in the supply chain, they addressed a dominant public image in which the wild berry industry is depicted as oppressive and exploitative in relation to migrant berry pickers. This image of a deeply problematic industry has characterised the debates about the wild berry production in the media and in research, and is particularly associated with several scandals over the years, revealing situations where berry pickers have been cheated and mistreated. In some instances, these 
situations have caused many conflicts between pickers and companies, and protests or other types of clashes have occurred since the early 2000 s (Vogiazides and Hedberg 2013). Several conflicts have been reported, and detailed journalistic reports have revealed criminal employers, cases of false information by recruitment agencies in Thailand, and even forced labour and trafficking within the industry (see also Wingborg 2011). In 2010, one conflict was played out with tragic consequences in Asele, a small northern municipality. The owners of a berry company emptied their bank account and left more than 150 berry pickers from Thailand stranded in Sweden without salaries and with large debts from fees that had been charged by their Thai agency. Reporting from the situation in Assele, the leader of the Migrant Workers Union in Thailand, Junya Yimprasert, argued that it is necessary to recognise:

$[\ldots .$.$] that between the 'wild-berry processing industry' [in the north] and$ the 'labour trafficking business' [in the south] there exists, under all the smiles, a slave economy. As one picker said at the end of the 2010 season: 'We paid ourselves to be enslaved here.' (Yimprasert 2010)

This image of a slave economy articulates morally unacceptable relations of force and violence. When speaking about responsibility, the berry company managers use interpretative resources such as references to systems, regulations, and transparency to counter this image. Therefore, established discourses are important to point out in the analysis in order to understand the interpretative resources that managers use when they talk about the wild berry industry. The repertoires that insist on a possibility of moral arrangements of foreign labour in the industry have some recurring interpretative resources. As I have shown in the previous chapter, these resources that managers use counter the notions of an altogether amoral industry by differentiating between moral and amoral actors - those who are responsible and those who are not. Another important aspect of constructing the moral industry, which I observed during the interviews with managers, were their descriptions of what it was like to pick berries, and how this kind of labour could be understood as being fair for the Thai pickers.

\section{Picking berries - the natural law of risks and freedom}

The ways in which managers describe supply chain relations and responsibilities can be understood as a negotiation of how risks, profits, and costs should be distributed. Some risks are considered illegitimate, for instance when the manager Kim, who I mentioned in the last chapter, 
explained that the ambivalence of state policy made the berry companies' investments resemble 'a game of roulette'. The risks that have been the subject of public debate, however, are that migrant berry pickers will be left broke or exposed to abusive conditions. Most of the entrepreneurs I interviewed attempted to counter this image by emphasising their responsible position and transparency in relation to migrant labour in the supply chain. At times, however, managers' talk revealed inconsistencies and conflicts in relation to risks.

Mannie: I'm fed up, I'm really sick of having a situation where we are
all the time seen as one and the same. Our pickers know what they are
doing, they have the information and they return year after year. They
would never do that if they were all cheated, of course. To be honest,
they wouldn't come here if they only earned the minimum salary. They
are hoping for more.

This quote portrays migrant berry pickers as different from their public image, by describing the pickers as knowledgeable and rational concerning risks and costs in relation to their trips to Sweden. There is however an ambiguity about the knowledgeable and rational migrant subject in the quote: the migrant pickers know what they get, but they are hoping for more. When I interviewed Mannie, the regulations that guaranteed pickers a minimum wage of approximately $€ 2200$ per month was already in place. The entrepreneurs frequently called my attention to this minimum wage in our conversations, which provided an image of a situation where migrant berry pickers were facing very few risks. There was, however, ambivalence in relation to how this minimum wage was talked about, since the managers also described how it did not correspond to what berry pickers dreamed of.

In order to understand these inconsistencies I address a silence in the managers' talk about different types of costs and deductions. The berry companies often avoided my questions about the cost of visas and tickets, and sometimes also accommodation, gas, and other expenses in Sweden, and referred to the recruitment companies as the parties responsible for these issues. Although none of the managers specified these costs in any detail, they agreed that such costs take up significant parts of the migrants' earnings. Mannie's statement that pickers 'wouldn't come here if they only earned the minimum salary' should be understood against this background. Reports have shown that costs and deductions that are not specifically related to salaries have been the main source of conflicts in recent years between the berry pickers and the Swedish berry companies or Thai recruitment companies (Wingborg 2014). 
The ways in which managers avoided the topic of costs in their talk about conditions for the berry pickers reveals a process of a moral evaluation of acceptable or unacceptable levels of effort and reward, and also reveals how these negotiations in management discourse were perhaps not settled. The minimum salary guarantees that the pickers can escape indebtedness, and constitutes an arrangement that is established as being moral, in contrast to the previous unregulated system, or the system of free berry picking. Yet salary deductions and the effects these have on migrant earnings cause uncertainties and inconsistencies in the managers' arguments. In an alternative discourse, the lack of transparency regarding the relations between earnings and costs could be established as an illegitimate risk for berry pickers in the supply chain. However, the managers of the berry companies consistently argued that as long as berry pickers had all the information, then risks could not be considered as illegitimate.

Instead of talking about the risks that workers were facing, the managers that I interviewed talked about the freedom of berry pickers to roam the land and to become skilled in their ways of working the berry bushes.

Rene: They choose to come with us year after year because we give them a lot of freedom. That is also, when they ask me about their working time. Yes, they don't work 8 hours a day. They would never accept that. Some of them take breaks, maybe they sleep a bit in the middle of the day. No one would go with [our company] if I was poking around in that. As far as I know we are the only company that allows our pickers to go to other areas to pick, to travel as far as they want to if there are not enough berries by their camp. Within reasonable boundaries that is.

The volume of production of wild berries is difficult to predict, though the larger berry companies I followed and interviewed spent much of their time mapping areas and testing or measuring the different types of berries. Groups of Thai berry pickers were sometimes frustrated about not being able to pick enough berries in the areas they had been assigned, and could request to be moved. This is the type of situation Rene was referring to. Rene is saying that the company cannot interfere with the ways in which berry pickers work and spend their days. This quote addresses a discussion initiated by public critics who, during the time I interviewed him, opposed berry pickers' working hours that by far exceeded those of the trade union collective agreements. According to the observations I did during my fieldwork, most berry pickers seemed to leave their camp in the early hours of the morning and return late at night. These long hours seemed to be the normal way of working. Rene was aware that I had observed these long hours and conditions, and addressed my assumed 
moral evaluation of this situation in the quote above; only the berry pickers themselves can control their working hours.

I had heard from other berry pickers, and from the media, about migrant workers who had collapsed from exhaustion, and who were afraid and lonely for long periods on the desolate mountains. None of the managers, however, addressed these issues in the interviews. My point here is not to make any claims regarding how common such situations are, but which types of problems the managers address and counter in their talk about working conditions. The limit of the berry pickers' freedom constituted a moral debate, while the health of the berry pickers represented another silence in the management discourse.

However, the berry pickers' freedom to decide how long their working days should be can only be morally acceptable within certain limits and only within the managers' particular discourse of freedom. In order for this freedom not to resemble 'slave-like conditions', or other unacceptable situations, some mediation of the working hours is necessary. In his account, Rene achieves moral legitimacy for his definition of freedom by adding that they 'maybe sleep a bit in the middle of the day', creating ambiguity in case the listener calculates the morally acceptable amount of working hours differently. The main analytical point here is not to establish whether or not the hours for migrant berry pickers are too long, but to describe how managers' interpretative resources rest on uncertainties and non-specific descriptions in their talk about morally legitimate working conditions.

These types of negotiations, positioned between being morally acceptable and morally unacceptable, were frequently mentioned in my interviews with managers. In a more public arena, the constructions of risk could be more specifically politicised. In a press release titled 'Berry picking - a national affair', the CEO of a berry company expressed how:

[p]eople have always taken risks when making use of what the nature has to offer. These risks are a natural part of picking berries, fishing, hunting and making use of other natural resources. We shouldn't think that these risks can be taken over by an industry.

This press release is part of a debate about changes to the regulations in the sector, which several of my other informants supported. The description in this quote of picking berries associates the berry picking performed by Thai migrant workers with pre-capitalist practices of surviving on what nature has to offer. Nature is seen as the constant, and the production of wild berries is decoupled from the social relations that are invoked and affected through changes in the harvesting, valuation, and distribution of the berries. Because the risks of temporary migration be- 
tween Thailand and Sweden involve engagement with nature, they are therefore represented as natural and unavoidable.

Although none of the entrepreneurs that I interviewed dismissed the idea of an industry with at least some responsibilities of taking on risks, their understanding of the risks was inconsistent. The managers spoke through an interpretative repertoire that positioned risks as being inherent in the practice of picking berries in nature and on uncultivated lands, and therefore the risks were naturally located among the migrant berry pickers. In the accounts of managers, the freedom of pickers to work long hours or to move freely across the forests was associated with individual achievement and competition, and with making use of what nature has to offer.

After returning from a working day with a group of Thai migrant workers I had a conversation with one of the work leaders at a berry company. She described this competition:

Jane: I am really surprised actually that they let you come out with them like that. They normally want to secure their spots - they would not let people follow them. They know the mountains and the forests much better than people who have lived here their whole lives.

This quote characterises the competition between groups of pickers as a natural part of the practice of picking berries. Competition is constructed as fair because it rests upon merits and highly valued knowledge as the key to success. In a similar way to Rene, who in the quote above talked about the importance of giving pickers their autonomy, Jane views the risks of berry picking as natural. These natural risks are framed within a discourse of the workers' freedom and the competitive success of some to collect large amounts of berries. In other contexts, however, the managers used other interpretative resources when they talked about the competition between pickers. This way of talking presented competition as more problematic in relation to the moral arrangements of harvesting 'what nature has to offer'.

\section{Negotiating the morals of competition}

The managers' view of competition as a natural aspect of 'working with nature' dominated the descriptions when they talked about the migrants' freedom to choose to work long hours, for instance. In contrast, the competitive freedom was at other times articulated as a symptom of the recent supply chain capitalism of the wild berry industry. Mannie described the discussions between the berry company and the recruitment company they had contracted: 
Mannie: They want to recruit too many berry pickers, so we have to say that these are too many. We have to hold them back all the time. Like [name of entrepreneur], they took in too many. He was new to the business, he doesn't understand what happens if there are too many pickers and too little berries.

Mannie felt that it was difficult to explain to the recruitment company the importance of limiting the number of migrant pickers when the recruitment company was focused on increasing the harvest by recruiting more workers. Besides pointing out the effects of supply chain fragmentation and how interests may differ in relation to the location in these networks, Mannie's description of competition relates to how migrant labour is mobilised within the industry. In this context, competition is part of production rather than part of nature. Since companies in the wild berry industry do not control the forest areas, competition comes from other berry companies, as well as from free pickers.

\footnotetext{
Rene: I am very worried about how quickly the industry...I mean if we no longer have control of how many pickers... The Migration Agency can't do that, they say, the competition is free. But the conflicts, if there aren't enough berries to go around.
}

Like Mannie, Rene described how too many pickers may create problems in the berry industry. This competition is viewed as problematic, in contrast to the competition that is described as being based on traditional ways of working with nature. Using interpretative resources such as admitting to worry and anxiety about the future, and warning about conflict and lack of control, depicts the competition as something that is not natural or benign. Talking about competition and the number of pickers, Rene specifically referred to changes in the organisation of the industry following the closing of the interest group Skogsbranschens Intresseförening (SBIF) in 2011. SBIF, an association of berry companies, was formed in the year 2000 with the purpose of representing the Swedish berry industry. The association held a unique position in relation to the Swedish Migration Agency, as only companies that were members of the association could apply for work permits for foreign berry pickers. The role of SBIF was debated within the berry industry, but maintained its legitimacy in relation to central actors such as the Migration Agency.

The reform of the labour immigration laws in 2008 did not change the possibility of recruiting migrant berry pickers to Sweden to work within the wild berry industry, but it did change the control systems that were enforced. The Swedish Migration Agency was given a more central position in this process. In 2011, SBIF closed because it no longer had 
'influence over the number of berry pickers that are allowed to come to Sweden', according to the CEO of the association at the time (SVT 2011). According to an official at the Migration Agency who I interviewed, the Swedish Migration Agency argued that berry pickers had to be treated like other groups of migrant workers in Sweden and that it therefore had no authority to issue caps on entries for migrant berry pickers.

The continuous negotiations over the boundaries between positive and negative competition in the management talk illustrate how a moral economy is an on-going process (Sayer 2005a). Within the interpretative repertoire of autonomy in the natural harvesting of berries, migration, migrant status, and labour migration policy represent silences in how berry companies talk about competition. Yet migration is at the centre of how competition - which in management discourse is a core aspect of the practice of picking berries - is articulated in the interpretative repertoire of the control and formalisation of the wild berry industry. In this context, competition is seen as illegitimate when the employers express moral expectations of how the supply of migrant workers should be controlled by migration regimes and the Swedish Migration Agency. Managers use interpretative resources from two sets of repertoires: one emphasises the natural logic of how risks and profits are distributed, and the other engages with a critique of the social or institutional embeddedness of production, such as current migration policies.

\section{Discourses of economy - pricing, valuation, and moral evaluations}

So far in this chapter I have discussed how managers relate to working conditions in the wild berry industry, which I then analyse as a central aspect of how the economy of wild berries operates. Working conditions need to be included as part of the analysis of the economy in order to understand how labour is situated at the centre of production (Harvey 2000; Selwyn 2012). In the following section, I explore how managers talk about the way the economy is made up with regards to pricing and the valuation of the product. I discuss how managers describe the processes of pricing, and which dimensions of such practices of evaluation they include in their descriptions (Sayer 2005a). 
Is the price right? Nature and supply chain compromise

The salaries that migrant pickers make, beyond what is stated in collective agreements, is dependent on how much they are paid for every kilogram of berries they deliver to the berry companies. The berry companies, in their turn, get a set price from the distributor. Talking to Jane about the worries of uncontrolled migration in the berry industry, I asked how this affected the prices:

Karin: And prices, if there are too many pickers...

Jane: Can go down, but that's not for sure. It also depends on the weather and the growth, and how much is already in the supplies.

Jane confirmed that the price of berries was related to the supply of workers, but also to forces such as the weather and how much harvest was left in the distributor's storehouses from previous years. Temperatures and rainfall were very common topics of conversations with managers before the berry season started and they all had access to predictions on what the year would deliver. The prices of the berries go up and down during a season and between the years. Cloudberries flower until late June, which marks the beginning of the harvest season in the north of Sweden for many migrant berry pickers. There is often an overlap with the season for blueberries, which has a start date that can vary from mid-July to the end of August. The flowers of cloudberries and blueberries are sensitive to frost, and temperatures below freezing often decrease the production substantially. Lingonberry flowers are also sensitive to low temperatures, but the berries ripen in late August and survive low temperatures during September, when some pickers remain in Sweden. The normal stay for Thai berry pickers is around two months.

During my fieldwork I followed the managers as they planned for the different outcomes of nature's production of berries: How much for a kilogram of blueberries in the late weeks of July? What about prices if the south had a very small volume of blueberries due to a dry summer, but the weather had been particularly good in the north? How bad was the harvest of cloudberries and could it be compensated for by the rich growth of lingonberries later in the summer and thus prevent berry companies from losing money?

The free movers painted their prices on large signs by the stands that they set up by the gravel roads or in the villages. The berry companies instead communicated prices to the pickers through staff at the different camps, or by word of mouth. Although nature was sometimes blamed as the main agent in terms of pricing berries, depending on growth in the forests, the pricing was also talked about as an important practice 
of negotiation, of relational work within the supply chain (Zelizer 2011). I visited John's berry company during my fieldwork and sat on a chair in the corner of John's small office, where there was wooden panelling on the wall, no windows, and shelves crammed with boxes. While John was on the "phone he walked around the room and pulled out maps and folders from the shelves. The documents were notes about prices and the amount of berries different groups of pickers had managed to collect during the first three weeks of the season. The decisions that John needed to make concerned information from his staff that some pickers in an area $300 \mathrm{~km}$ south of where we were now sitting had heard that another berry company had raised their prices. John said that he would get right to it and called his old partners at a distributor company. They confirmed that the blueberry harvest was not looking as good as they had hoped, and that they had raised prices by one krona, and would probably raise it more within the following days. 'That's what I've been saying all along', John said out after hanging up the 'phone. The berries were turning out to be very small in most parts of the northern berry region and it wouldn't work out to keep the prices at such a low level. John picked up the "phone again to call his current distributor company and they agreed to follow the price. After he hung up, John told me that he was very happy to have an agreement to sell the berries to this specific company. 'They try to understand', he said. His pickers needed to get reasonably paid for the berries they picked or they might lose their motivation so early in the season, he explained to me. 'But there are a lot of pickers in the area this year', he said. 'That makes it more difficult than it should be to ask for raised prices'.

Although John uses resources that concern nature in his argument, such as set facts about the forests' berry production, the price is also determined within the social and cultural framework of how the industry is organised, including the particular supply chain his company is part of. In John's account, as well as in my interviews with other berry entrepreneurs, there is however a silence regarding how berry companies, and their profits and margins, may affect the workers' economic compensation. Speaking generally about the distributing companies, John said:

John: They should just pay more for the berries, perhaps prices have to be raised [for consumers], if that's how it needs to be. Look at what happened when the prices of lingonberries went down and people stopped picking them for other than their own needs. It didn't work out for them anymore. If we can't pick the berries here, they take berries from the Ukraine. It is not the same though, the northern berries are very desirable. But it has to do with supply and demand. 
John explained that the low prices of berries might demotivate migrant berry pickers to do a good job, and in this later quote the low prices are also presented as a problem in relation to the threat of losing workers. The references to history that John uses act as a way of emphasising how there is a limit to the price of labour and what migrant workers consider legitimate. The interpretative resources John used serve as a way of ascribing the berries a higher value by referring to what would be considered a fair and just price from the perspective of the berry pickers. There is a conflict between setting the price of berries in relation to nature or setting it in relation to the power of distributors in the supply chain, and valuating the berries in relation to the value the work invested in harvesting them. This relational aspect is interesting to analyse, and in the next section I thus discuss how the migrant worker is positioned as a part of the economy of wild berries.

\title{
Migrants' bargaining power and transnational practices
}

The times when distributing companies raised prices often seemed to follow a bargaining process within the supply chain. In the situation described above, when John was on the 'phone with different actors, the bargaining started with complaints from Thai berry pickers. In John's account, the bargaining power of the migrant pickers is strengthened by their potential boycott of berry picking and indicates a potential critical point at which the pickers might decide that travelling to Sweden for two months would not be worthwhile. The migrants were talked about as active agents in the bargaining over working conditions and berry prices. In this interpretative repertoire, the workers' compliance with the economy of berries was at the centre of management's setting of reasonable, or moral, prices.

\begin{abstract}
Kim: Well, you know, the information travels. Suddenly the pickers are saying that [name of other berry company]'s pickers are getting more for their berries. So then they heard this from their relatives who met the families of the other pickers at a market place in Chaiaphum. And they tell each other how much they get for berries and they pass on the information over the 'phone.
\end{abstract}

Describing how information travels invokes the notion of berry picking as an activity that is in fact not only located in Sweden but connects with activities elsewhere. In this quote, Kim talks about the transnational space that migrants are in, with the community being split between Thailand and Sweden for a few months, as an important dimension of how, and why, they might act on their conviction that prices are too low. 
Kim identifies the point at which workers' move from adhering to the conditions to actively disputing them as being dependent on the relations between Thai workers. Kim argues that the workers consider the price unfair if others get more. John explains it in a similar way in relation to the potential introduction of taxation on berry income:
John: This year again, we are talking about the demands of having a wing ${ }^{16}$ in Sweden.
Karin: Yes, what we talked about earlier...
John: This would mean that they all have to pay tax. If this happened no one would come, not with [name of recruitment company]. The pickers would protest. They would get less money than the people from the neighbouring village that go with tourist visas. But we don't know what is going to happen.

The description of protests among berry pickers as being triggered by the difference between Thai migrant workers can be analysed using the managers' perceptions of what matters to the workers. These perceptions of how migrant workers think and feel are crucial to the discourse of a moral economy in which migrants receive what is reasonable, and are constructed as an objective measure. In managers' talk, workers do not need to intervene in the process of pricing because of any moral failures of the industry, but because of their desire to be equal to people in neighbouring Thai villages.

In John's quote, consider also the bargaining power the migrant workers are said to inhabit if they were to protest. Beside the threat of leaving the transnational wild berry industry altogether, migrant protests were central to management discourses on compliance and non-adherence. The berry company manager B-G, whom I interviewed over the 'phone in 2011, addressed the changing regulations of the industry:

B-G: The pickers have a lot of power on how the whole industry is portrayed...

Karin: How do you mean?

B-G: They have a protest culture. You know what you do when there is something you aren't satisfied about in Thailand? You draw a sign and head out to the streets.

During the years prior to 2011, Sweden had seen several protests among groups of Thai berry pickers; marching, occupying company buildings, or gathering outside municipal headquarters. In these situations, protests

16 A corporate office in Sweden that may oblige them to pay employer fees and taxes 
are likely to be used as a strategy to change working conditions and the status quo. Talking about the protests as part of a culture gives these acts a meaning relative to that culture. The protests need to be considered in a Thai cultural context where they would perhaps not be as acute and critical as they are in the Swedish culture. B-G uses interpretative resources of cultures as being inherently different to describe the transnational space of the berry industry. As Thai workers' actions need to be understood in a specific cultural context, the Swedish reactions to their protests reflect an inadequate translation between the Thai culture and a Swedish culture that views the protests as disproportionate and illegitimate. In other words, according to B-G's construction of a cultural context, the migrant feelings of injustice are not as severe as they might seem.

Emotions were important in the managers' descriptions of how fair and unfair conditions could be evaluated. During the interview with Kim we talked about price of berries:

Kim: The price for lingonberries was 10 krona - that's not much at all. I feel awful; really, it's not reasonable that they should be picking for this little money. The distributors set the price. And I can't look [the pickers] in the eye.

In this quote, the emotional dimension of a moral economy is brought to the fore. Price, in this quote, entails something else than just the discursive notions of right and wrong in relation to market logic or to supply and demand. Kim explains how the low price of lingonberries brings about a particular way of feeling: awful. These emotions are not directed towards the berry company or the business, but generated in relation to the migrants' situation. Unable to look them in the eye, Kim expresses shame or guilt in relation to the price that migrant berry pickers are paid for the berries they have collected. In this quote, Kim does not mention the weather conditions or the size of berries as explanations of the logic to pricing, and instead addresses an embodied feeling of right and wrong in relation to how prices are established in the industry. The price, 10 krona for the lingonberries, is evaluated in relation to an empathy with the migrant pickers, although Kim's quote does not reveal exactly which aspects are considered when the boundary between the legitimate and the shameful is drawn. Yet Kim's feelings of shame and guilt also indicate a distancing from the responsibility for both the situation and the price. These complex dimensions of how an amoral situation is portrayed can be understood as an affective practice (Wetherell 2012: 52) in which complex notions of empathy and understanding of migrant situations, as well as the distancing from responsibility, are established. The ways in which Kim describes a moral boundary that has been crossed is important for 
how we can understand the negotiations in management discourse and the justification of certain conditions in the berry industry.

\section{Management constructions of migrants and their morals}

So far, I have discussed how managers talk about themselves and their practices in relation to the supply chain structure of the berry industry, and how they position themselves as moral and responsible subjects by describing their consideration for the wellbeing of Thai berry pickers. I have also discussed how managers talk about the practice of picking berries in relation to nature, or in relation to the organisation of an industry, and how this kind of talk positions migrant workers differently in relation to freedom, autonomy, and competition. In the following sections I analyse management talk that specifically addresses migrants and the morals that guide their practices. I also discuss how we can think critically about the managers' perceptions of migrants, and which migrant voices and alternative discourses provide the basis for such analyses.

\section{Respectability and fortune}

In the interviews, managers often addressed what they saw as a dominant public image of Thai berry pickers as (over) exploited and oppressed, arguing that this image gave a false impression of the actual conditions. Central to the interpretative resources they used to counter these images were the migrant berry pickers' agency, freedom, and compliance. One interpretative repertoire of Thai migrants and their relation to picking berries in Sweden represented the migrants as moral subjects with respectable trajectories.

Rene: When we go to visit them, sometimes they come running with big smiles saying that they want to go [to Sweden again] - that they were able buy land or a combine harvester. One man built a house and put the horns of a moose from Skellefteå outside. You get moved by that. We want people who contribute with something.

A sense of intimate affection between the berry company and the migrant berry picker is conveyed in Rene's account. The horns of a moose from Skellefteå, a town in the north of Sweden, are talked about as a symbol of pride, which the berry picker in the story associates with the place where he achieved his success and saved the capital to build a house. This pride touches Rene who, in this quote, expresses the transnational intercon- 
nectedness as warm and rewarding. The migrants who 'contribute with something' are acknowledged as deserving in terms of the upward mobility that the seasonal work in Sweden has given them.

The interpretative resources of deserving and respectable migrant subjects have changed from managers' everyday experiences to being published in public arenas. I have read these types of accounts in newspaper articles and on websites. As mentioned in the previous chapter, the distributor companies have accepted greater social responsibility in the industry during recent years. As I researched their websites in 2014, I observed how one berry distributor had published an article titled 'Our Pickers', in which migrant incentives were described:

They often use the money they earn in Sweden to invest in their farms and expand their livelihood, to pay for their children's school or to build a house.

The image of Thai berry pickers who travel abroad to build better lives for themselves and their families at home aligns itself with discourses of migration and development and the win-win-win situation of circular migration that benefits the migrants, the sending state, and the receiving state (Triandafyllidou et al. 2013). This image also serves as a way of cultivating a rational migrant subject who invests in hard seasonal labour in Sweden to gain more for their own future or for their children's future. This lends the organisation of the berry industry, with its dependency on seasonal migrants, a moral framework in which all parties experience gains in knowledge, predictability, and control in relation to the choices they make. In political terms, the notion of the deserving migrant therefore addresses a perceived threat of increased burdens of state regulation on the industry. Within the interpretative repertoire of rational and deserving migrant workers such regulations would be disqualified and seen instead as government actions intended to wipe out their opportunities for gaining a better life.

The managers often talked about the rationality of the migrant berry pickers in relation to their return to Sweden. On their website, one berry company described how the industry had been characterised by tragic incidents of exploitation in previous years, but added: 'But to be fair many return year after year'. Similarly, Mannie said during our interview:

And about people getting cheated - they don't get cheated every year! You don't return if you were cheated. That doesn't get through in the media. 
The almost exact phrase recurred in the interviews with several of the managers, illustrating a dominant interpretative repertoire of migrant choice. What is most interesting here is not how representative these incentives for investment are to the whole group of berry pickers, or whether the choice of many berry pickers to return is really indicative of free choice and rational decisions. Indeed, many Thai berry pickers say that they have experienced an upward social mobility (Hedberg 2013: 70). The analytical focus here is on why the articulation of the migrant workers as rational agents appears to be so dominant in management discourse, and whether we can think about their decisions and freedom in other ways.

Management discourse does not convey any other incentives and trajectories other than the investment in education, houses, or farming equipment, and there was a general silence in the management talk that I collected about any variations. However, in my conversations with berry pickers during the fieldwork, they described a variety of life situations. One older man had just gone through a divorce that had 'cost him many things', and another man wanted to repay his gambling debts. These motives do not fit into the interpretative repertoire of seasonal migration as thoughtful calculations of future investments, and these men would not be likely to fit into the discourse of respectable migrant subjects. The interpretative repertoire of migrants' rationality rests upon the selection of certain migrant subjects as representative in a management discourse.

When we analyse the economic context when people in Thailand apply for, or accept, a place at one of the recruitment agencies, the expectations of economic transactions are also part of a relational package (Zelizer 2011). When calculations of actual profits are not available, these expectations leave room for social aspirations to weigh heavily on the decisions of migrants (de Haas 2014). When managers use the return migration as an interpretative resource that proves the moral character of the industry, they also construct experience as factual and as unquestionable knowledge on which to base rational decisions. The conceptual framework of a moral economy, however, allows for an analysis of economic choices, behaviour, and feelings that are not rational in any one-dimensional sense. The choice to return to Sweden each year may not be indicative of an experience from previous seasons that proves the value of seasonal labour. This is mirrored by some migrant voices from my fieldwork, like Pam who explained what she thought about coming to Sweden to pick berries:

Pam: I was here last year with big company. But then I didn't make money. So now I try again. It is hard, very small berries. I don't know if I get money this year.

Karin: So what about next year? Will you be back?

Pam: Yes. [laughs] And all years after that. 
Success stories also build up a social fantasy around berry picking in Scandinavia. I interviewed Pravat who had himself picked berries in Sweden every year for 20 years, until a couple of years ago when he was employed as a work leader.

Pravat: Berry picking changed my life.

Karin: What did it change?

Pravat: Everything. Before I was nobody but after I started going to

Sweden everybody knows me and everybody wants to be my relative.

Pravat's story is representative of an elite group of pickers, although most pickers do not leave Sweden with life-changing sums of money. Because of the minimum salary there is now less risk for the berry pickers to return home in debt. However, the minimum salary does not leave much after all expenses have been paid, and to return home with a profit is far from given. The profit depends on the ability to pick more berries than the minimum requirement (Hedberg 2013: 67). The fantasies and social aspirations for an experience like Pravat's are likely to affect the economic calculations of whether it is worth going to Sweden during the berry season. Most berry company managers that I interviewed declared how they wanted the correct information about the difficulties of picking berries to be communicated to the migrant pickers before they signed up. Pravat is now the work leader at a Thai recruitment company. The power of his story is likely to affect how information is perceived among potential migrant pickers in Thailand.

The managers' perceptions of migrant experience as a guarantee of rationality aligns with expert discourse on transnational migration. In her study of the role of labour in the global commodity chain of the berry industry, Hedberg makes a point about discussions on migrant opportunities vis-à-vis hyper-exploitation:
Also, if we reject the idea of berry pickers as ignorant and poorly edu- cated and instead think of them as knowledgeable subjects, it appears unreasonable that they would return year after year without profiting from berry picking. This is supported by the ILO (2008:4), which states that even though the workers suffer 'labour exploitation ... most regulat- ed migrant returnees do not have negative experiences of their overseas employment in Europe. (Hedberg, 2013: 70)

Although I am not questioning the conclusions of Hedberg in this quote, the question of consent between the actors of transnational labour relations does not necessarily contribute to an understanding of how this consent is constituted. Unlike ethnographic research on migrant experiences, I have not mapped how migrants express their motivations. In- 
stead, I study the representations of migrant workers' rationalities and intentions, and I argue that the ways in which these are expressed in the dominant management discourses are important in order to understand the establishment of labour conditions and economic compensation as legitimate. The one-dimensional perspective on consent and migrant choice lends the seasonal berry industry a moral character, which is also supported through migration discourse in research and expert language. The analysis of interpretative repertoires of migrant consent that managers consistently propose, and how these align with expert discourse, are central findings for understanding the political role that employers and capital may have in the design of migration policy.

These analyses illustrate that it is not only the institutional settings of labour markets and migration regulations that are subject to management. The ways in which migrant choices and motivations are represented and recur in management discourse also constitute dimensions of management practices as political acts. In this political context, the image is presented of a specific migrant subject that fits a moral arrangement of transnational migration. This image also addresses conflicts about the hard labour of picking berries and how migrant workers perceive this labour. I discuss this in the next section.

\section{Hard work as disposition}

When talking about the labour of picking berries, there were inconsistencies and contradictions in how the managers described picking berries as 'hard work'. In the context of recruiting migrant workers in Thailand, John explained why it was important to acknowledge the work as hard:

\footnotetext{
John: Some find us and we find some of them. We have to make sure that they can do the job. We try to not take a lot of new people. We had problems [two years ago] and we tried to explain to them what the work would be like, that they had to pack their lunch every day. But they didn't understand how hard work it would be.

Karin: So it is heavy work...

John: Yes, it is, it's really hard. But like, Swedish people, old people used to do it.
}

According to John, to make sure that he did not recruit people who would not be prepared for the hard labour, this acknowledgement was necessary. The hard work was however justified in relation to how old people in Sweden used to do it, thus defining it as a reasonable type of labour. Work was also described as being less hard for the Thai workers: 
Kim: It is very much like cutting sugar canes. You work bent down like this. And they are used to working hard. This is like nothing to them.

Kim describes the work of picking berries as less hard by using interpretative resources of the fundamental characteristics of Thai working bodies. The quote illustrates the intersections of race and embodied labour. Cutting sugar cane is represented as part of everyday life for the Thai workers, and working 'bent down' is considered to be an embodied asset in relation to picking berries. In the management discourse, the disposition for hard labour refers to a naturalness of this type of labour for certain types of physique.

Karin: So, why does it work better with the Thai?

Rene: Because they are used to working hard, they are hard-working people.

In this quote, the reference to 'working hard' is used by managers specifically to play down the effort of picking berries for the Thai berry pickers. This in turn justifies the tough conditions of their work in the berry forest. The social constructs of, and associations with, race, class, and labour therefore also hide the actual labour in management discourse, obscuring both the efforts and sacrifices that constitute this labour, and the specific aspects of the labour that are hard, and those that are not.

Management talk also included other interpretative resources that referred to race, as the informants talked about Thai people as particularly well-suited for berry picking:

Mannie: [...] They are short. They can pick fast from the ground. It would be difficult for a big Swedish guy to do it like that.

Hedberg (2013) noted similar racialised representations in her research on the Swedish berry industry. Racialisation of Thai migrant berry pickers in employers' descriptions also mirror processes that have been documented in previous research on migrant work in agriculture and other manual labour. In a study on agricultural work in Canada, Kelly Preibisch (2010: 420) shows how employers portray Thai workers as hard-working people with a respect for authority that makes them compliant workers. Preibisch connects such characterisation with how temporary migrant worker programs open up possibilities for employers to make more differentiated choices, often with references to ethnicity or nationality, and regarding characteristics and behaviour of their workers (2010). With regards to interpretative repertoires among Swedish managers in berry companies, the context of temporary transnational work seemed to legit- 
imise interpretative resources that reference race, such as the notions of embodied labour and essentialised characteristics of Thai workers. The managers talked about these racial aspects of Thai labour in relation to their explanations of why Thai workers perform this type of job in Sweden. The interpretative repertoire constructed hard work as a disposition that felt different to different groups of people and, particularly, felt less hard for the Thai berry pickers. In the next section I continue this discussion, but shift focus and explore alternative accounts that allow us to discuss the ways in which managers talked about berry picking and the disposition of hard-working Thai migrants.

\section{Analysing the legitimacy of hard work}

The moral economy of the very hard physical labour of berry picking, which most managers acknowledged and justified using interpretative resources of race or embodied labour and class, can be analysed in relation to different interpretations of hard work that I encountered on the field. The experience of hard work was evaluated by how it was felt subjectively by those who performed it. I will not prove that the management justifications of the hard labour and the compensation are wrong by invoking accounts that are 'more true'. I will instead discuss how these evaluations can be critically analysed without passing a normative judgement on the experience. By pointing out alternative interpretative resources that could be used in order to explain how picking berries feels, my aim is to show how the interpretative repertoire, in which the hard labour of picking berries is legitimate, is composed. The ethnographic fieldwork and the field notes of this study are key for me to provide such alternative discourses in this section.

During my fieldwork I was invited by a group of pickers to join them in the forest the following day. It was already $11 \mathrm{pm}$ and I needed to drive almost an hour to fill up with fuel to be sure that I would have enough to get there with my own car, since their truck, like all the trucks, was already filled. I met up with the group at the camp at $4 \mathrm{am}$. They had asked me the night before if this time would suit me, and I tried my best to emphasise that anything was fine with me. One of the people at the camp translated our arrangement, since none of the pickers who invited me spoke much English, although they all knew a little. We drove for an hour before we reached the mountains and continued to drive for at least another half an hour. I was afraid that my old car was going to break down as the chassis constantly hit rocks and branches on the gravel roads that sometimes seemed to disappear in the undergrowth in front of me, only to appear again after a few meters. I lost sight of their truck a number of times, even 
though I knew that Thep, the work leader who was also the driver, slowed down for my sake. I was stressed about taking a wrong turn since my 'phone and GPS did not work up there, and I had no idea how to get back, but I was even more stressed about slowing the others down. We stopped, and Thep, who had been to Sweden for many summers, walked into the forest to look for berries. After about four stops he found a good spot by a clear-felled area on a deep slope. The group made a fire and heated a stew they brought with them from the camp. After some coffee we all walked up the slope. I felt confused about the directions and I was concentrating so hard to pick berries that I continually lost track of the others. But they seemed to keep track of me and there was always someone calling me when the group changed direction. As the blueberry bushes became sparser we carried the heavy sacks back to the car to continue to another part of the forest nearby. By lunchtime I was so tired that I could no longer see any blueberries. I tried to pretend that I was still picking and I sat down on rocks and tree trunks that were out of sight of the others.

The group decided to go back at about $6 \mathrm{pm}$. I was later told by a person back at the camp that they had actually finished earlier for my sake, which made me feel guilty. Whan, the only female picker in the group, asked if she could travel back with me in my car and I was happy that she wanted to. Whan knew a little English and asked me if I was tired. I told her that I was. With the help of body language and some key words in English Whan wanted to explain to me what she did back in Thailand - she cleaned fish, she worked in the fields, and she worked in a kitchen. After some time in the car, she borrowed my 'phone and called up a relative who lived in Stockholm. The relative knew good Swedish and wanted to translate some things. 'Whan wants you to know that she works very hard in Thailand', she said.

An analysis of these field notes should not be understood as an attempt to describe and account for the labour process. Yet my apparent exhaustion in the forest after picking berries for just half a day, trying to keep up with the others, opened up a situation in which the feelings of hard labour could be addressed. Whan made an effort to tell me that she was used to working hard and that the conditions of work here in Sweden were not exceptional to her. Whan did not say that picking berries in Sweden was easy, but she did point out that working hard during the season in Sweden could not be understood in isolation from her everyday struggles in Thailand. Rather than using interpretative resources emphasising that it was easy in Sweden, the emphasis was on the overall difficulty.

Although Whan, like the Swedish managers I interviewed, described the continuity of hard work between Thailand and Sweden, which also explained why Whan handled the work better than I, there are also dif- 
ferences in how the legitimacy of this hard work is constructed. Whan's intervention to explain the continuity of hard labour was not expressed within an interpretative repertoire of justification in relation to why Thai workers should do this job. Whan's intervention instead implicitly used interpretative resources of global inequality in order to define the meaning of hard work in Sweden. Both her work in Thailand and Sweden felt hard. A different quote by a woman returning to the camp to weigh her berries illustrates the continuity of hard work: 'Work, work, work in Sweden. Work, work, work in Thailand.' she said as she gave me a tired smile. The management discourse expresses the feelings of picking berries experienced by Thai berry pickers as something that cannot be compared to what they, or I, or any other Swedish person would feel. The legitimacy of how berry picking is organised is based on this differentiation, which, in the interpretative repertoires pointed out in this chapter, rest upon the notions of race and embodied transnational inequalities. The moral economy of wild berries in Sweden, therefore, rests upon the premise that the differences between Thai and Swedish experiences cannot be compared.

\section{Thai culture in the camps}

Describing the 'Moral Economy of the Peasant' in his classic study of protests and rebellion in South-East Asia, James Scott emphasises how 'exploitation and rebellion are not just a problem of calories and income but of peasant conceptions of social justice, of rights and obligations, of reciprocity.' (Scott 1976: vii). Scott's approach to the study of moral economy differs from this study, since my aim is not to understand what matters most to temporary migrant workers in Sweden. However, the Swedish managers often talked about the importance of understanding the culture of their Thai pickers and thus avoid the possibility of them protesting in public or abandoning the industry. Therefore, this recognition of the migrants' cultural considerations is important.

Managers emphasised the importance to have Thai staff present in Sweden to take care of administration, communication between the pickers and the berry company, cooking, and other services that were necessary in the camp areas.

Kim: We need people who can interpret...but not just the language, also what the pickers really want.

Kim's quote suggests that it is difficult for the Swedish berry companies to understand what Thai pickers really want and how they become dependent on cultural brokers. To keep the pickers content could entail 
many different things. Rene explained to me that the recruitment company had evaluated whether their pickers liked the food and the living arrangements in Sweden.
Rene: They are very picky about what they eat, this is what we have discovered after so many years in the business. The kitchen staff is very important. This is another reason why so many pickers choose to go with us every year, because we have a good reputation with the food.

Rene explained that groceries and ingredients were often brought from Thailand in order to meet the pickers' requests for local food. Thai culture was talked about as foreign and separate from the Swedish way of thinking and acting. Thai culture was not portrayed as inferior to Swedish culture; the differences were instead identified in practical terms in relation to the problems of production and efficiency that needed to be overcome by intercultural competencies within the supply chain. When talking about health issues, however, the managers presented the culture of the Thai pickers as problematic.

Kim: They always go to the doctors, for everything, they trust doctors but they want to go too often. I mean, we don't have that kind of system in Sweden.

Mannie: They get nervous and they want a pill. In Thailand the doctor is.... well, it's an authority and they want to go even if they have a small cold.

The managers described the culture of their Thai workers with confidence and with expertise.

Kim: Have you been to Thailand?

Karin: No.

Kim: No? Well, we go there every year, sometimes twice. We have been travelling everywhere and we have many friends there now that we visit - it's like a second home.

John: Well, I have a house there. We have a lot of business meetings and prepare for the season. Last year we invited the distributors, showed them around and visited our old pickers.

The interpretative resources of describing what it is like being in Thailand, knowing the country, and spending time there acts as a way for managers to place themselves as insiders to the Thai culture. This experience creates an interpretative repertoire of intimacy and understanding between themselves and the Thai pickers. Although the managers talk about how they need cultural brokers and other staff, they present their positions as managers as having an overview of the cultural differences and the po- 
tential effects of those differences. The managers also used interpretative resources when they emphasised how they had gained their knowledge of Thai culture. This served as an important component for how they talked about transnational arrangements in the berry industry and the justification of these arrangements. I discuss their notions of cultural knowledge in the following section.

\section{Migration control and circularity - constructing the perfect match}

In this section I analyse how managers talk about the transnational dimensions of berry picking. This has consequences for the dimensions of the moral economy that concern belonging, and how the Thai workers are situated in relation to the Swedish labour market and in relation to their national identity. I discuss how the workers' activities in Thailand and Sweden are connected in the interpretative repertoires of managers, and how the boundaries of their visits to Sweden are not seen as problematic. The image of these visits is however complicated through an analysis of how managers also talk about monitoring and controlling access to territory, which targets berry pickers as workers who do not belong without conditions. Furthermore, I discuss how managers talk about the practices of regulating workers' mobility, and how these regulations have a gendered dimension.

\section{What migrants do - continuity of farming}

The image of the Thai migrant worker as being a farmer in Thailand represents a central node in the interpretative repertoire of a moral economy of circular migration and temporary work. In arenas where a background to the phenomenon of Thai migrant work in the Swedish berry industry is needed, for instance on berry companies' and distributors' websites, in media interviews and newspaper articles, as well as in scientific reports and research, the group is almost exclusively presented as rice farmers from the northern regions of Thailand. Despite the lack of any larger surveys it seems fair to assume that rice farmers represent the majority of Thai berry pickers who arrive in Sweden. During my research, I came across many alternative ways of describing how people made a living in Thailand, like Whan, whom I quoted earlier, with no main profession or occupation but with a strong work identity. Several of the pickers I talked to worked in a broad range of occupations, from professional Thai boxing to manufacturing. When describing individual pickers, newspaper arti- 
cles have also one few occasions presented alternative economic identities such as small shop owners or service workers. Being interested in how managers talk about the migrant workers, the silence about these alternative identities in the generalised presentations could have a value of interest in its own right. However, in this analysis this silence has mainly acted as a starting point for thinking about why the image of the Thai farmer represents such an important resource in the explanation of why Thai people pick berries in Swedish forests during the summer. There are good reasons not to account for every kind of phenomenon when wanting to create a comprehensible image of the group of Thai berry pickers for a Swedish audience or for the media or for scientific reports. However, the critical analysis is not dependent on observing and accounting for these variations. The image of Thai migrant farmers is expressed within an interpretative repertoire of how their labour, work, and lifestyle in Thailand is connected to, and justifies, certain labour and lifestyles in Sweden. In the descriptions of transnational work between Thailand and Sweden, the seasons of farming are used in order to define the natural flow and rhythm of this migration. Presenting 'our pickers' on the website, a distributor company wrote: 'Many of the pickers would be unemployed this time of year'. Kim explained a similar system:

Kim: It's perfect for the pickers to come here now [during the summer]. Because they have sown the crop and now they just have to wait for the harvest season to begin.

The image of farmers who 'just have to wait for the harvest season to begin' identifies the time they spend in Sweden as the alternative to a period in Thailand without an income and with nothing to do. This develops an interpretative repertoire of a perfect match between the Swedish berry industry and the Thai migrant who has little to lose when choosing to join a recruitment company and travel to Sweden. This perfect match also makes an argument for the important role of Thai workers in Sweden. Discussing the ways in which the industry is not valued by the Swedish state and the threats to the current arrangements of temporary Thai labour, Rene said:

Rene: You can see a fantastic natural resource rotting away in the forests when you fly above them in a helicopter. And the Thai people are just waiting to be allowed to pick it up.

Picking berries in Sweden is represented as an activity that fills a void in the working year for the Thai berry pickers and provides them with continuity for 'making a living'- the Thai people are just waiting to be allowed 
to pick the berries. I understand these descriptions as part of the moral negotiations on both the value of berry picking and what the berry pickers are economically compensated for. The strategies to find seasonal work in relation to sowing and harvesting may be a traditional part of the livelihood in the northern regions of Thailand, similar to Vertovec's observations of circular migration as a common transnational strategy (2007). These traditions are referred to by managers and used as interpretative resources to develop an account of the supply chain capitalism of wild berries in Sweden. Rather than representing the supply chain in terms of recent arrangements between corporations to mobilise labour through recruitment, administration, control, and discipline, the arrangement is characterised as natural and traditional. The moral economy of circular migration in the berry industry, and the value of the labour of berry picking, is therefore determined with reference to the migrants' lifestyles and traditions rather than through discussions of the systems of production, distribution, and compensation in supply chain capitalism.

\section{The boundaries of temporary migration}

The work visas issued by the Swedish Migration Agency correspond to the length of the berry season - the Thai pickers stay in Sweden for two to three months. Although the majority of the pickers are men, it is not uncommon that their partners and families travel together to pick berries in the same work teams. The relatively short periods of working abroad allows many households to make arrangements for taking care of children in Thailand, which is a factor in the evaluation of their mobility as being sustainable (Hedberg 2013). The temporary migration of berry pickers to Sweden does not include the same violent border controls that characterise some other programs internationally (see e.g. Hahamovitch 2011). With the exception of a few media reports (SR 2011) there have been very few discussions in the media about migrant berry pickers who have overstayed their visas or have been deported from Sweden. When talking about the reform of labour migration policy, and the discussions this generated in Sweden concerning migrant rights, several managers argued that the berry industry was not representative of such debates.

Rene: They are not really labour migrants. I mean, they want to get back. They miss Thailand and they have their families back home.

The managers talked about the length of stays in Sweden as naturally restricted by the life back home in Thailand, rather than by the migration regimes of Sweden. There were however also times when managers 
expressed a more complex image around migrants' compliance and the consensus on the boundaries of migration and settlement:

Kim: We want pickers who are here to pick berries, nothing else. That's important for us, to know that. So we need to have more information [from the recruitment companies] that is clear. Because sometimes they bring people who shouldn't be here.

Rene: Sometimes we can suspect that they did not choose to come here to pick berries, that has happened.

John: Last year we had five of them pickers escaped from Arlanda airport when they arrived.

These accounts refer to situations when managers need to acknowledge the lack of compliance of the arrangements for seasonal migration and short-term visas. The managers describe how the match between migrant practices and the season for picking berries requires active management by them or by the recruitment companies. Their descriptions contradict the presentations of complete compliance to, and consensus on, workers' migration. These accounts further indicate a suspicion, which is grounded in the separation of the 'right' and 'wrong' reasons that migrants can have in relation to their trip to Sweden. These suspicions legitimise the practices of control and surveillance among the managers.

In these accounts of right and wrong reasons, the managers also present the image of an agreement between themselves and the workers concerning the motives and intentions for travelling to Sweden; an agreement that extends beyond what the actual labour of picking berries includes. According to the quotes above, the pickers need to have the right reasons for coming to Sweden. Hence, managing temporary migrant workers rather than worker-citizens, extends the role of employers to monitor not only the labour process but also the workers' motives for being in a country, and to establish these aspects of management as legitimate.

The managers also talk with confidence about the legitimacy of an agreement for the workers to be in Sweden for 'the right reasons', because of a migration regulation that corresponds to this temporary, limited time during which Thai pickers are allowed to stay in Sweden. While managers do not explicitly refer to the length of the visas or to the role of the Migration Agency, the description of migrants who escape from the airport for instance, as John described above, suggests a highly limited right for them to be in Sweden and a legitimacy to control the length of their stay. This institutional context of the temporary right to stay is however not used as an interpretative resource in the managers' accounts. Instead, these institutional arrangements are played down, as managers such as Rene 
object to labelling the Thai pickers as 'labour migrants'. Applying tools from discourse psychology allows an analysis of the ambivalence in these constructions. The managers do not describe the berry pickers as a problematic group of migrants who need to be regulated by the state, although they draw on the legitimacy of such regulation in their own practices.

In accounts of the pickers, the temporary character of the their stay in Sweden is repeatedly presented as an independent and free choice relating to their everyday life in Thailand and to the practical, mutually beneficial limits of the season. In relation to situations where control and surveillance is needed, the managers do not use interpretative resources of migration regimes and the institutional context of citizenship, they propose right and wrong reasons for the workers to be in Sweden based on production, where the right reason to be in Sweden is to 'pick berries and nothing else'. Alternative ways of thinking about the institutional context of migration regimes and production can be found in the conversations I had with the berry pickers. Several of the pickers I talked to said that they wished the berry season in Sweden was longer, so they could earn more money before it was time to return home. These accounts, although reflecting a 'less than perfect' image of the match between their time in Thailand and their time in Sweden, align with the notion of the seasons as the natural limits of the workers' mobility.

The idea of the perfect match is a powerful example of the win-winwin situation of circular migration as a dominant public discourse (Vertovec 2007) and lends a moral aura of consensus to the arrangements of the Swedish wild berry industry. Can we think about interpretative resources that may complicate the ideal of a perfect match? Which types of institutional or economic situations must be imagined in order for the justifications of the arrangements to be analysed critically? Most of the male berry pickers I talked to had been working as guest workers in other countries, such as Dubai or Taiwan, for long periods of their lives. To them, the seasonal work in Sweden would perhaps not be the only alternative to filling a void in their labour in Thailand. Others also dreamed of working for a longer period of time in Sweden or in another European country:

Chati: My dream is to work in a factory here. But there are no factories. Only trees.

Pam: Perhaps if there was a bus I could get a job somewhere else...

Chati and Pam do not think of obstacles to working in Sweden around a migration regime with short-term work permits. These quotes instead refer to a spatial segregation of the berry pickers, which prevents them 
from entering other labour markets in Sweden. This spatial segregation represents an exclusion that seems insurmountable when there is no transportation and there are long distances to travel.

The critical analysis of the managers' interpretative resources allows us to see how the migration regimes provide a stable backdrop to the interpretative repertoires of mutuality and moral arrangements. The regimes of citizenship and temporary permits do not need to be legitimised or addressed explicitly as they are important institutional dimensions of the arrangements in the industry. In this light, it becomes clear how dreams and hopes of alternative arrangements become difficult to express, or even imagine, in a way that challenges the image of a perfect match and mutuality between Thai workers and Swedish industry. The segregation of berry pickers in Sweden, which is partly addressed in the managers' talk about the cultural differences and long working hours presented earlier in this chapter, constitutes a material aspect of the production, and explains why certain interpretative repertoires become more prominent than others. Parreñas (2010) argues that questions generated by recent migration theories have not been adapted to explain the return regimes of circular labour migrants who have no intention of settling. 'Perhaps a more suitable analytic framework for documenting the settlement of temporary migrants would be to look not at the extent of their integration but instead at their segregation in the host society', Parreñas (2010:320) suggests. The analysis of management discourses gives rise to new sets of questions concerning voluntary circularity, such as how migration is managed, not only in relation to migration policy and working conditions, but also in relation to migrants' desires, and the delimitation of imagining other trajectories.

\section{Surveillance offemininities}

As the managers discuss how they need more information from the recruitment companies in order to prevent migrants who do not have the right intentions from coming, they view the potential disharmony between the migrants' trajectories and the berry season as a flaw that can be corrected through more efficient selection, and through monitoring and control. In her research, Hedberg $(2013,2015)$ has also observed comprehensive strategies of surveillance among certain businesses in the berry industry. There was a gendered dimension to how the pickers were observed, in relation to how they acted and dressed, which was mentioned by several managers and work leaders during my fieldwork. The surveillance required managers to speak about which characteristics would in- 
crease their suspicions, and they identified certain feminine characteristics as especially important:

Mannie: Certain women, all they want is a man. We had one who stood by the side of the road with a sign saying 'I want Swedish man'. Then we had another one who was working the night shift if you know what I mean.

Feminist sociologist Nira Yuval-Davis has elaborated on intersectional understandings of how social categories such as gender, race, and class are mediated in relation to inclusion and exclusion from notions of national belonging. She argues that racialised notions of female sexuality and reproduction are central to the strategies and politics of such a belonging (Yuval-Davis 2011). The idea of Thai women as potential subjects, through marriage, of everyday life in Sweden, positions Thai female sexuality as something that needs to be policed, in this case by the employers. This also represents a common trope that has historically regulated gendered relations where working women are suspected of also selling sex (Scott 1988). Despite the silence about migration regimes in the management discourse on labour control, the imagined niche (Tsing 2012) of racialised femininity raises the possible threat of un-matching the harmony between migrant trajectories to return to Thailand and employers' interests in labour discipline.

\section{The moral economy and public opinion}

In summing up the analysis of how Swedish managers talk about Thai migrant workers, I want to redirect attention towards the political context in which the specific discourses that I have presented so far are produced. I discuss who the managers address in the interpretative repertoires of fair conditions, the correct evaluation of hard labour, and the perfect matches of transnational contexts in the arrangements of circular migration. I also analyse how managers position themselves in the political context of migration management in relation to migrants.

\section{Talking to the media}

So far in the analyses of management talk, I have described how managers often speak back at an image of the wild berry industry using interpretative resources of freedom and independence to counter the descriptions of slave-labour or illegitimate exploitation of the migrant berry pickers. The moral economy that managers construct references these images, 
and despite justifying an economy that others condemn as amoral, they use interpretative resources that address these images rhetorically.

\begin{abstract}
Rene: Swedish people want to feel sorry for the Thai people. It's this connection, after the tsunami and everything. But when it comes to Bulgarians or Ukrainians who were starving, then no one cared. That's hypocrisy, I think. And the media portrays the Thai pickers as if they can't take care of themselves. But they choose to come here year after year because it gives them a better life and because they are very good at picking berries.
\end{abstract}

Rene is approaching the public interest in the Thai pickers as an expression of a public emotion in Sweden; a feeling of connection to and empathy with Thai people. Rene presents this public emotion as misleading, causing Swedish people to want to feel sorry for the Thai pickers, and to actively look for certain kinds of stories. Others' emotions of empathy are also presented as resting on illegitimate grounds, considering the lack of care and empathy for other nationalities such as Bulgarians and Ukrainians. The interpretative resources that are used in this particular example reflect not only the manager's personal convictions or their economic interests, but also a broader discourse of the morality of temporary migrant labour in Sweden.

I begin by discussing the presence of the media in relation to how managers talked to me and represented the migrant workers. In this regard, the ethnographic context in which managers' accounts were collected matters. One day during my fieldwork, at one of the camps where I had stayed, I was in the kitchen helping the cook to clean the dishes from breakfast. We were alone in the camp, which was located in an old closeddown school. In the late morning, a car drove into the overgrown schoolyard and two young Swedish men knocked on the door and stepped into the empty dining area. They introduced themselves as journalists from a local newspaper and they wanted to know more about the working and living conditions of the Thai berry pickers. I tried to step into the background behind the counter and continue with the dishes. When the cook didn't understand their questions in English, the journalists turn to me and I felt awkward about my sudden 'insider' position. I told them that the English-speaking work leader was not around but that they could call the company headquarters. But at the headquarters people were busy. Apparently there had been a meeting with union representatives and municipal authorities, and two interviews with media were already scheduled for that same afternoon.

The berry pickers started arriving back at around $7 \mathrm{pm}$ and the journalists returned. The Thai work leader asked around but no pickers want- 
ed to be interviewed. They ran back and forth from their cars with boxes of berries to be weighed. They looked down and didn't want to meet the eyes of the journalist. The work leader told me that the pickers were afraid that their words would be twisted if they gave an interview. Apparently there was a rumour that an interview with local media had caused extra controls to be imposed in another camp by the authorities. The journalist asked me for an interview and after declining several times I agreed, on the condition that the interview would be about being a PhD student rather than about the berry industry, since I felt uneasy about passing judgement in either direction in the polarised debate about 'perfectly content' or 'severely oppressed' berry pickers. Still, I did describe one anecdote that some of the Thai staff had told me about an older couple in a village close by who had become their friends over the years, inviting them to eat pie and stew, or bringing them cake.

The article was published in the local newspaper the next day and in one section it mentioned how local people brought food to the pickers. That same day I talked to the berry company manager, Lore:

Karin: Did you see that, what it said about the food? I said to [the journalist] that people bring food to the pickers... I could read how that sounds now. I didn't mean, or, the pickers told me that they had been making friends in the area, an older couple.

Lore: Yes, I read that. I thought about that. Now people are going to think that they don't have enough food, that's what I thought.

Lore wasn't upset, but I felt like I had said too much to the journalists. In the conversation above, Lore and I read the same interpretation into the article, seeing my quote in the text through the eyes of what we together constructed as a dominant image of migrant exploitation. Some days earlier, Lore and I had been talking about the relationship between the media and the berry pickers in a different area, following a 'phone call Lore had just received.

Lore: Now they called and the berry pickers were really worked up... Karin: Why, what happened?

Lore: Some journalists were there - they wanted to see how they lived. They have been at this before. But this time they walked around everywhere - they walked into their showers! Their showers! That's really private. Who would do that kind of thing?!

In this conversation, Lore talked about the intrusion of journalists and the ways in which the media counters the interests of the migrant workers. Lore expressed agitation on behalf of the pickers and talked with an emotion that indicated a feeling of alliance with the pickers and support 
for their wellbeing. The polarisation of two conflicting interpretative repertoires, portraying the Thai migrant worker as either independent or oppressed, were made visible through the ways in which the managers addressed journalists and the media in their talk about the industry and the migrant workers. Several of the employers I met during my fieldwork also spent much of their time before and during the berry season talking to journalists. In a quote that mirrors an earlier statement from Kim, the media coverage and the public image of the berry industry was addressed:

Kim: Because we are an important industry for Sweden and even though there are dodgy entrepreneurs in this business it's not fair on us who try to do everything in the best possible way for everyone. But it's good too that they come here and see what we really do, that they won't find any of that here.

Despite the objections to the intense media coverage managers also talked about the media as a way of gaining legitimacy and countering a negative public image of the wild berry industry.

When I did my main fieldwork in 2011 and 2012, the distributor companies often argued in the media that they had no way of controlling how the berries were picked and delivered. In 2015, most of the larger berry distributors had sections on their websites that were dedicated to their responsibilities as social actors, their work towards 'fair berry production', and in many instances, detailed descriptions of controls and practical engagements in the recruitment processes in Thailand. There have been changes to how the industry and the distributors, as well as larger Swedish food corporations, have been involved in work to increase social responsibility in the industry (Wingborg $2013 \mathrm{~b}$ ).

The interpretative repertoires that dominate the management talk in my material are not addressing other supply chain actors but the media and the Swedish public. This has implications for how we should analyse a moral economy, not just as the negotiations between those who are actors in a specific economic context, such as the supply chain, but also as justifications in relation to a larger social context, indicating the effects of social criticism to forms of capitalism (Boltanski and Chiapello 2005).

\section{Knowing the migrants and sharing their interests}

So far in this chapter, I have analysed how the notions of mutuality and shared interests, and the perfect match between Thai workers and the Swedish wild berry industry, are important components in the repertoires that justify the conditions of migrant labour. I have also shown how the managers address negative images of the berry industry in their accounts 
by explaining, for instance, what hard labour feels like to the Thai pickers, or why they want to work long hours. Knowing the migrants, and explaining their preferences to others, constitutes a central dimension of how the managers talked. During my interviews, several managers argued that they lacked support and acknowledgement from the state and from local authorities, and that the industry and the pickers were misunderstood. Visiting the manager John's company, I was told that there had just been a local inspection of the facilities that hosted about 50 berry pickers. When the inspection was finished, John had met with the controller from the local authorities. He now arrived back at the office and was frustrated as he informed his colleague and me about the report:

\begin{abstract}
John: He was this new - wanted to show off. They made remarks about the curtains. Can you imagine! There must be more important things than that! Last year they had all these little things that they complained about, like how the cook prepared the food. And we tried to talk to them, what could be acceptable? We understand that they couldn't just fry up a whole animal in the front, of course. We changed everything and bought new pans. Because they are used to cooking in their own way you know. But he didn't want to listen.
\end{abstract}

John argues that the inspection was unreasonable because it focused on small details that concerned the pickers' own cultural preferences of how to eat and sleep. By referring to the complaints about curtains, John ridicules a bureaucracy that guides the controller's evaluations. John also positions himself and his company as mediators between the Thai pickers' way of doing things and what the authorities consider as acceptable. The role of the mediator, with a neutral position and no vested interests of his own, assumes a clear position of the 'Thai way' that opposes the local Swedish authorities. The role of the manager as mediator therefore rests upon interpretative resources of Thai preferences as being independent of, rather than interrelated with, how the conditions of life in Sweden are structured by the supply chain and by the berry companies. These interpretative resources rest on the same notions of independence and freedom that managers used when they talked about the long working days and the hard labour of picking berries, as described earlier in this chapter.

The manners of the bureaucratic controller from a local authority that John describes, and ridicules, are illustrative of how these interpretative repertoires constructed the notion of unknowing Swedes from outside the industry. Feeling sentimental and sorry for berry pickers for the most irrational reasons, or feeling uncomfortable and awkward in relation to their cultural preferences, were aspects of these accounts about 'Swedes' in general. Actors from outside the industry were positioned as awkward 
because they had neither the pickers' consent to 'help' nor any legitimate role in relation to the pickers' situation. This was also reflected in the ways that managers spoke about trade unions. The Municipal Workers' Union was reluctant to be assigned responsibility for collective agreements and controls, following the reform of labour migration regulations that required employers to have collective agreements. The union, however, continued to work with collective agreements in the berry industry and gave immediate help in some of the cases when migrant berry pickers were left stranded in Sweden (see e.g. Woolfson et al. 2012).

Lore: They [the trade union] were there at the camp but no one wanted to talk to them, no one at all.

John: I can imagine that the members of Kommunal [The Municipal Workers Union] would be thinking; 'why are they taking my money to do all this for the Thai berry pickers?

Kim: Well, it's interesting to see if any pickers would even talk to them when they go out on their visits. They are just interested in making as much money as possible before they go home.

The managers view the engagement of the Swedish authorities and the trade unions as unwelcome in relation to the berry pickers' wishes to make as much money as possible in Sweden and then leave. The engagement of authorities, trade unions, the media, and the Swedes who feel sorry for the migrant workers is also considered as illegitimate because of the transnational situation that Thai berry pickers are in. The managers consistently treat the Thai berry pickers as exceptions, whose labour and lives are not only inaccessible from outside the specific conditions of production in the wild berry industry, but also impossible to evaluate from the perspective of Swedish standards.

The alliance that my informants describe between themselves, as employer representatives, and the migrant workers, corresponds to Zoran Slavnic's analyses of the dynamic forces of informalisation (Slavnic 2007). In his research, Slavnic observed how informalisation is initiated both from above, by employers, and from below as migrants intend to establish their position in the Swedish labour market (ibid.). I have not studied the processes of informalisation, but I have analysed how labour conditions that are below the 'normal' standards of the Swedish labour market are justified. The analyses show that representing these labour conditions as consensual, in the interests of both the employers and the migrant workers, constitutes an important component of these justifications. 


\section{Summarising the case for the wild berry industry}

In this chapter I analysed how migrant labour in the wild berry industry is part of a specific moral economy, characterised by notions of transnational space, worker identities that reference race and gender, and temporary migration. I also discussed how the interpretative resources used by managers within the industry define this moral economy, align with broader discourses on the positive effects of circular migration, as well as introducing notions of consent among migrant workers in the international migration debates.

The supply chain structure of the wild berry industry in Sweden has been important to map in this case study, since it has provided an analysis of the fragmentation of arguments among the actors. Knowledge about these arguments and the diverse standpoints contribute to future migration research, since they help us to locate and define the subject of 'the employer' in the growing research field that focuses on the infrastructures of migration (Xiang \& Lindquist 2014). The managers in the berry companies do not represent a homogenous group of employers. Instead, they represent a subject position that is differentiated from other actors through their acceptance of responsibility and accountability within the industry. I also discussed how the acceptance of these moral subject positions by roles within the industry or within international capitalist production, need to be understood in relation to broader political debates and migration discourse which are characterised by notions of selection, management, and circularity. These links are not obvious in the explicit arguments that managers put forward as they make their case, but the links can be detected and defined through the analysis of situated management discourse that allows for ambiguities to be brought to the fore. By making these connections in the analyses I also discussed how the construction of 'the migrant' and the construction of 'the worker' are consistently interrelated in management discourse.

As outlined in the introduction and the background of this thesis, there are two groups of migrant workers linked to the labour migration reform that stands out in the statistics. In this and the preceding chapter the analysis focused on the moral economy of the management of Thai temporary migrant workers. In the following chapters, I shift the focus to the second group, Indian temporary workers in the IT industry, and explore the moral economy in a setting where public notions of migrant workers are not characterised by images of exploitation and vulnerability. 


\section{Swedish management discourse in an international IT industry}

In the next two chapters I analyse management discourse in an industry very different from the previous case study of the Swedish wild berry industry. The IT industry is not focused on one product, but rather on a multitude of services. Businesses that sell IT services furthermore employ 'knowledge workers', whose skills are generally considered highly desired in 'the New Economy' (McCall 2001) in contrast to the kind of work that dominates the wild berry sector, which is increasingly devalued and considered as being unskilled. As I showed in the previous two chapters, managers in the wild berry industry often addressed public discourse on vulnerability and exploitation as they defined a moral economy around the arrangements of migrant labour in Sweden. In policy and research, highly skilled migrants have not been associated with vulnerability but rather with privilege. Workers who are employed in the diverse and internationally segmented IT industry do however work under very different conditions and have a different status in relation to citizenship or visas. This chapter begins by presenting the central debates on highly skilled migration that managers in this study talked about in order to contextualise this group of workers, generally referred to in the statistics as 'computer specialists'.

Thereafter, the chapter analyses how Swedish managers conceptualise international supply chains in their work with computer specialists from India. Internationalisation emerged as a theme in the interviews with managers, and can be analysed in relation to the theories of globalisation presented in Chapter 3: Theorising the Moral Economy of International Production. I will refer to internationalisation as an empirical theme that I analyse as a way of contextualising the production of knowledge among managers; internationalisation provides a setting in which they talk about the moral arrangements of the economy and labour. I discuss how internationalisation in supply chains, which managers usually refer to as 'offshoring', may contrast to an outsourcing process that has been a significant aspect of the IT industry's development within Sweden for several decades. Drawing on the interviews with managers, the main theme in the analysis concerns the links between the processes of offshoring and the 
mobility of Indian workers. I present how managers talk about their own work in these supply chains, with a particular emphasis on their role of selling and marketing international services as well as Indian workers. By analysing the discourses of internationalisation, I argue that the issues of both labour and migration are obscured when managers talk about international IT services. In the face of recent and quickly expanding internationalisation, management strategies gain legitimacy from technocratic language, expert knowledge about markets, and technology advances. I therefore argue that the discourses of internationalisation that emerge from the analysis of how managers talk about recent changes towards offshoring, never define or specify labour, but rather present it as abstract, flexible, and always changing. In chapter 8 , this observation affects how I analyse the justifications for temporary worker migration from India to Sweden.

\section{Studying highly skilled mobility: temporary workers and expatriate privilege}

Highly skilled migration gives rise to different sets of questions in academic literature than labour migration, which is generally characterised by precarious conditions in low-skilled, low-paid jobs. Against the background of the managed migration of berry pickers that I analysed in the previous two chapters, it might be asked: What similarities and differences in the moral justifications may be discerned in relation to highly skilled migration? In this chapter, I analyse the moral justifications for migration that appears to be aligned with current policies on managed migration, as high-skilled migrants can be understood as potential members of communities of value in the receiving countries (Anderson 2013). Migration scholar Eleonore Kofman argues that many regimes of managed migration have been designed with the model of a cosmopolitan IT worker in mind (Kofman 2013). This system, Kofman continues, gives priority to the transferability of skills and lifestyles of privileged male workers, in contrast to groups of skilled women workers in other occupations (ibid.). I investigate how this association is constituted in relation to management practice, and whether there are ambiguities in management's perceptions of the Indian IT worker in Sweden.

As the analyses in this chapter will show, it is challenging to grasp more specifically who the workers, i.e. who receive work permits in the Swedish IT industry, for instance in terms of their career status and their job descriptions. Most of the Indian IT workers that the managers talk about in my interviews are however not part of a global elite of entrepreneurs, 
at least not in the stages of their careers when they work temporarily in Sweden for large consultant agencies and suppliers. The Indian workers who are the subjects of my interviews are mainly employed in large multinational corporations. Their temporary work in Sweden is arranged within an organisational structure rather than by the migrants themselves through individual entrepreneurial decisions. With few exceptions, most of the Indian IT workers referred to in the interviews belong to the category 'computer specialists' in the migration statistics (the Swedish Migration Agency 2014). In 2014, five per cent of all computer specialists in Sweden were non-EU citizens, and approximately 80 per cent of the more than 3000 computer specialists who were granted a work permit in 2015 were from India (the Swedish Migration Agency 2016).

Compared to other groups such as 'engineers and technicians', statistics show that computer specialists earn significantly less than Swedish citizens employed in the same occupation (Emilsson and Magnusson 2015: 91). The image of the privileged male expatriate that is put forward in the migration debate can be complicated by research that accounts for social categories other than gender, nationality, ethnicity, and race. In a qualitative study of the segmentation of work in high-technology industries, Xiang Biao (2007) describes how, by the turn of the millennium, the majority of Indian IT workers were hired as consultants through a practice named 'global body-shopping', and were performing monotonous tasks such as programming or testing in Western countries.

Like seasonal workers in the wild berry industry, IT workers from India represent a case of temporary, or short-term, migration. In discussions following the labour migration reform in Sweden, the potential of permanent residence permits and settlement have been prominent themes. Permanent residency is seen as supporting migrant rights and attracting highly skilled workers (Magnusson \& Osanami Törngren 2014). Migration in the IT industry, however, appears to be closely linked to intra-corporate transfers and short-term migration (OECD 2011). In fact, less than 10 per cent of computer specialists with work permits stay in Sweden for more than one year (Emilsson and Magnusson 2015: 92).

\section{Indian workers in Sweden - or services performed in India?}

Short-term stays characterise the migration of Indian computer specialists to Sweden. Although no studies specifically map the reasons for these short-term contracts they are generally understood as being related to the temporary needs of development projects, training of staff in other 
international branches, or facilitation of communication between offices in different countries (OECD 2011; Emilsson \& Magnusson 2015:92). In order to introduce the analysis of how managers talk about work permits, and how they explain the structures of foreign labour in the industry, I turn to a conversation with one of my informants, Erik, whose thoughts illustrate the complexities of defining labour migration, internationalisation, and mobility in the IT industry. Erik had been involved in general strategic work on the development of recruitment in the Swedish IT industry for a few years. I described my interest in labour migration reform to him:
Karin: So in terms of labour migration, this is the largest group, Indian citizens who get a work permit for less than a year...
Erik: Labour migration is very good and important for the industry. We have a big challenge in the whole industry when it comes to diversity, that people rather hire someone named Johan than someone named Ahmed. So we can also look at that - what people do we have here, in Sweden, who can be important. We are working together with some of the largest universities in Sweden, because it needs to start at that level. We have been doing work of getting girls to be interested in technical educations, uhm, like that. The competitive power of Sweden depends on the kind of work force that we can have in the future.

In this quote, Erik associates the phenomenon of increased labour migration with the challenge of re-defining the workforce of the Swedish IT industry. Situating labour migrants within the Swedish labour market, Erik argues that there is a risk they will not be fully accepted or included in the general image of who is considered a proper worker in the Swedish IT industry; namely white, Swedish-born men with names like Johan. Economy and economic value are important resources in the interpretative repertoire of the illegitimate exclusion of labour migrants in the account above. According to Erik, it is economically irrational not to include labour migrants, and the reluctance to hire 'an Ahmed', or hire girls and women, will counteract Sweden's competitive position in the global economy. Highly skilled 'Ahmeds' in Sweden, or Indian labour migrants, are not primarily talked about as a group of workers whose needs depend on being included - Sweden needs them. Hence, inclusion is not a moral claim in its own right nor in relation to the recognition of non-citizens or discriminated migrants - inclusion is justified through an economic argument. Yet analysing Erik's quote, the interpretative repertoire in which inclusion is justified on economic terms is also dependent on the nation as an interpretative resource. The moral purpose, to increase competitive power, points back to what is good for Sweden as a nation. Despite the lack of specifics regarding who is really included in the notion of Sweden, 
and how this may be different for 'Ahmed' than for 'Johan' or an Indian citizen, the nation can justify strategies for increasing competitive power through labour migration. Through this framing, managed labour migration is turned into a competitive resource that can, in line with theories of the competition state, be regarded as adding to the state's attractiveness for transnational capital circulation (Cerny 1997; Menz 2008).

Later in the interview, Erik showed me a report that his organisation was working on, describing the future of the IT labour market in Sweden. One of the diagrams illustrated the different demands for labour that were likely to grow, and those that were likely to decrease. Erik pointed to one of the smaller circles and said:

\footnotetext{
So, as you can see there will not be so much demand for the more, well, the routine labour, coding. This type of work will increasingly be done in India, in low-cost countries. But there is an increased demand for architects [in Sweden], so there is a large need for labour in the future, which we need to address when we watch education issues.
}

In the earlier quote, Erik positioned labour migrants within the Swedish labour market by arguing that it is important to expand the workforce and include more people - referring to Indian workers in the Swedish IT industry. In the later quote, Erik talked about changes in the Swedish labour market through which certain types of jobs would decrease. On the diagram in the report, circles of various sizes represented the number of future Swedish jobs in the IT industry. Erik, in contrast to the earlier quote, described Swedish labour as including what the Indian workforce does not offer; Swedish labour will supply architects, innovation, and design, whereas Indian labour supplies manual work and coding.

The ways in which Erik aligns with the composition of the Swedish workforce as being both comprised of, and in opposition to, Indian workers connotes ambivalence and conflict between different interpretative repertoires. Speaking about workers in Sweden, Erik argues in favour of an expansion of the Swedish workforce and identifies labour migrants as subjects that should be included. Within the domain of global economic restructuring, however, Erik positions Indian workers as different from the Swedish workforce. So, how are temporary Indian IT workers in Sweden situated in relation to these different ways of talking about migration and internationalisation: as potential subjects of the Swedish labour market, or as 'Other' in relation to Swedish labour? 


\section{Management work - supplying Indian labour}

The managers I interviewed worked on different kinds of projects, in which labour was differently located across Sweden and India. Four of the managers who participated in the interviews either held central positions at the Swedish offices of multinational companies, or in Swedish firms in international corporate groups where the job description explicitly included managing offshoring and the mobility of workers. These managers often talked about the bigger picture, the general strategies of internationalisation, and the consequences of labour mobility. The other managers who participated in this study worked on specific projects that fully, or partly, hired Indian workers. The majority of these Indian workers were located in India, but the projects always included temporary migration to Sweden for some of them during specific periods. These managers used their specific project and management strategies as examples in the interviews, and they made fewer statements about the general development of the internationalisation of the industry. Their roles as managers in the supplying companies, and the ways in which these roles structured their relations to labour, are important for how we can interpret the perception of Indian labour in management discourse.

The supply chain structure of IT services performed for companies located in Sweden is not new. Large corporations mobilise IT workers who are permanently employed, as well as those who are recruited by supplying companies.

Lars: Using consultants, using them from staffing companies, well we have done that since the 8 os and maybe even earlier than that. So that's not new. But it is relatively new to look for engineers outside of the Swedish borders. You didn't do that in the 8os.

The managers agreed that during the last five years, prior to 2013 , when most interviews were carried out, international recruitment and offshoring had grown in Sweden and that this process had still only just begun:

Benji: In Sweden there is a lot more services left, services that were offshored in the US maybe ten years ago or in Britain and other European countries after that. And now this is really taking off here.

As suppliers of labour, the managers I talked to would rarely say that they recruited Indian programmers for Swedish projects. The concepts that recurred in the interviews included the idea that companies transferred staff from an Indian office to a Swedish client, or delivered a service by using workers in both Sweden and India. These concepts identify temporary situations and flexibility, not with regards to the location of workers, but 
as an attribute of production itself - a characteristic feature of supply chain capitalism (Tsing 2012). Some of the informants also worked on projects where they had agreements with other staffing companies located in India, indicating even longer supply chains. All the managers, however, represented suppliers of labour for customers in Sweden; they supplied client companies with labour from Sweden or from India.

When talking about how suppliers needed to work towards larger clients, Sarah, a manager at a multinational staffing and service corporation in the IT industry, explained:

Sarah: If you look at these large global corporations, the procurement of IT, it is more and more....they used to have IT competence but now it becomes more of a purchasing organisation. An outsourcing organisation. Where they ensure that they have a competence to procure and purchase services. So then you can choose to go single sourcing, which is one supplier, or if you should go multi sourcing, with several [suppliers]. And that depends on how big your company is and how much volume of IT you are buying, what is reasonable and what strategy you have. To only have one supplier, that's a risk, but you can also get a better deal. There are so many factors that determine which way you go.

According to Sarah's description, understanding, analysing, and participating in the organisation of supply chains is an expertise in itself that is practiced by organisations within the global corporations. In other words, the fragmentation of production through outsourcing requires new kinds of knowledge creation within and across organisations. Several social constructionist perspectives have approached the relations between language and structures in the economy as part of this production of knowledge and power. In Peter Miller and Nicholas Rose's theoretical elaboration on the Foucauldian notion of governmentality, they stress the importance of paying attention to the technologies of governing (Miller and Rose 2008). For instance, they argue that an individual manager can be understood as a resource for governing the economic discourse of an enterprise (ibid: 42). However, the role of the individual manager in relation to foreign workers and the Swedish labour market is difficult to evaluate in this study due to the complexity of networks and the system of suppliers that Sarah describes. It seems as though outsourcing IT services has become such a dominant material-discursive practice (Bridgman and Willmot 2006) that some managers, for instance those who supply Indian labour, are likely to define labour in relation to complex procurement processes rather than in relation to the work that these computer specialists perform. In this context, the supply chain is also difficult to analyse through a relational approach; the actors in an IT supply chain that Sa- 
rah describes are not connected through clear-cut, two-way negotiations. Instead, they are connected through the type of complex information networks that have been frequently emphasised as a central feature of late capitalism in the literature on globalisation (see e.g. Castells 1996). Boltanski and Chiapello (2005) argue that social capital, diversity, and sharing information become moral values to the international enterprise or supply chain due to the celebration of a 'connexionist world', in which the ability to create links sets down the foundations for being free. Managers who adapt to 'connexionist values' (Boltanski and Chiapello 2005), because of their role of supervising the flexibility of labour within these new types of enterprises, also need to believe in their own ambitions to create connections and to participate in the complex networks.

In this study, I have located supplying managers as actors who are interesting to analyse because of the positions they occupy. They provide one point of several connections between offices in Sweden and workers in India. However, I do not primarily analyse these managers as resources that govern one big economic discourse of globalisation. Although they are clearly part of an interconnected global economy of procurement and transnational enterprises, their arguments are also likely to be specific to their positions within the supply chains, and specific to the motivations and justifications that they need to work with in their day-to-day-life as they meet clients or co-workers. By reflecting upon these different positions - adopting values that may be both representative of a general management discourse and of their daily moral justifications - the informants in this study provide a key to the processes of how Indian workers are positioned in relation to the Swedish labour market. In the next section, I discuss one such dimension of how managers in the supplying companies position Indian workers.

\section{Selling workers - management talk as marketing practice}

A central aspect of how the managers talked during our interviews can be analysed in relation to the specific practices of sales and marketing that characterise the supplier position. The managers that I interviewed explained how one of their main tasks was to sell offshoring services to their clients. Jonas explained to me how he negotiates with a potential client, and after finding out the client's needs and how much they are willing to pay, he may suggest offshoring:

Jonas: So then I get into talking about costs. That is the reason for going offshore. That is for a longer project, the costs increase in the beginning of a project but can be saved in a certain period of time. I have expe- 
rienced several projects when we have brought people here, and how long they stay here - that's economy too. After 90 days they will cost more for the company. Sometimes there is travelling, including family relations when we might allow people to go home for a while. So that is an investment because it takes extra costs. So [a project that lasts] less than a year, then I wouldn't say that it is worth it to go offshore.

During the initial phase of a procurement process, when the supplying companies compete with each other for contracts, calculating the costs of offshoring is one of the main tasks for managers like Jonas. The mobility of Indian workers is described as part of the offshoring process, although it is also represented as an extra cost at the beginning of a project. Similarly to Jonas, all managers that I interviewed acknowledged that lower costs represented the main reason for suggesting offshoring services to clients, and that the lower cost of Indian workers was mainly associated with their labour in India. As I have elaborated in the method chapter of this thesis, asking specific questions about salaries and costs was not a successful approach during my fieldwork, since they were sensitive topics that informants either declined to answer or that could potentially make me lose access to the field. Rather than talking about salaries, the lower costs of labour are implicit in the managers' accounts of lower costs in general. No manager mentioned any specific numbers relating to the salaries of computer specialists.

Jonas, however, also argued that besides costs, the short supply of workers in Sweden was another significant reason for offshoring:
Jonas: I mean, the reason why offshoring is used in my business is because in periods of economic recession companies start looking for ways to save money. They want to outsource. So they come to us and others and ask; 'can you do this?' That's when we start looking at how long these projects are. But then there are drivers within the market that drive [the development]; they want lower prices, they expect it. And the drivers in the line of business where I work are often to increase turnover; deliver more, have a higher capacity. There are not that many people left in Sweden to recruit - that's the market. We cannot grow organically in Sweden and then it is much easier to grow offshore-wise.

In Jonas' explanation, internationalisation and offshoring are connected to the market, and the market is ascribed different characteristics. At first, Jonas explains how, once the alternative of offshoring is available on the market, other actors in the industry start expecting lower prices. In this part of his quote, the market is made up of the relations and expectations of those who handle procurement and supply chain relations. Here, the supplier is given the active role of developing offshoring busi- 
ness and negotiating reasonable prices. However, the market is also characterised as having its own natural logic - the need to expand organically outside Sweden and the drive to grow and to achieve higher turnover. In this interpretative repertoire of internationalisation, offshoring is no longer presented as the decision of specific actors within the industry who engage in economic relational work (Zelizer 2011). Instead, internationalisation is presented as a phenomenon that mirrors Marxist geographer David Harvey's (Harvey 2000) explanation that globalisation is an inevitable process of capitalism's destructive competition over land and resources. The managers are positioned as both the architects behind internationalisation in Sweden and as the mediators of an inevitable process of competitive expansion.

Although the managers view internationalisation as a process that they actively engage in, selling offshoring is not only about selling the geographical expansion of service production. The managers also described their work as that of selling labour and selling workers:

Emil: So this transformation that we do, from an all-Swedish delivery to a global one, I am in charge of that. I am in charge of making everything work; everything from convincing our customers and co-workers that this is a good thing, and all that this entails.

Jenny: This is a pretty tough situation with much extra work on me; on the managers who bring them here and for those in sales who need to learn how to sell these people.

Managers at supplying companies talk about Indian computer specialists in terms of how they are sold to client companies. Within this domain of selling and marketing, interpretative resources of cost-efficiency and other positive judgements prevailed in the characterisation of Indian workers. It is therefore important to once again emphasise how the specific position in a supply chain affects the interpretative repertoires of management. 'Sales talk' dominated the management rhetoric in my interviews and can be understood as the main domain in which managers talked about workers. The practice of selling migrant workers through ways of speaking can be understood as one aspect of how a moral economy is perceived. In this particular moral economy, the positive qualities of Indian workers are brought to the fore when my informants speak, not least in order to legitimise the role of these managers in the supply chain. The managers are sales people and labour is their commodity, therefore in these contexts they tend to ascribe a high value to labour.

Jenny addressed how many positive dimensions there were to introducing Indian workers to Sweden: 
Jenny: It has been really important for us to have these people here; to see that they are not scary but rather super good, and nice, and much more well-educated than we are. Which is amazing. They have fantastic IT skills in India. Much better than we do! Straight from school they come out at a much higher level.

The enthusiasm and the rhetoric of selling and convincing can be observed in the way that Jenny describes Indian IT workers in this quote. Her enthusiastic and colourful language can be thought of as a way of talking that matches the position of managers in the supplying companies who are invested in the positive image of the Indian IT worker. They also need clients to value Indian workers in order to be able to sell them. At the beginning of this chapter I presented a quote by Erik in which he explained how manual jobs in the global IT industry would increasingly be located in places like India. Offshoring was associated with the preservation of high-quality jobs in Sweden and was established as a process that would not necessarily have a negative impact on the Swedish nation. Jenny, however, describes Indian IT workers as having better IT skills than Swedish IT workers. According to my analysis of Jenny's account, bringing Indian people to Sweden is therefore a way of countering a misperception of Indian workers as being lower skilled.

Erik and Jenny's views of offshoring and Indian workers would potentially have different consequences should they be incorporated into political arguments. Neither of them argues for any type of regulation regarding offshoring or labour mobility. However, while Erik emphasises the differences between workers in India and in Sweden, Jenny views workers in India as more like 'us'. While Erik uses the nation as a resource in his understanding of the differences, Jenny uses the individual corporations as a resource in her understanding of the similarities. There is a consistent tension in how managers treat Indian workers either as being representative of 'quantity' and as opportunities to cut prices, as described by Jonas in a previous section of this chapter, or representative of the skills and standards that Swedish workers cannot live up to. This rhetoric is addressed to clients, but it can also be thought of as affecting a general political discourse about the role of high-skilled migration or the offshoring of services that affect the public notion of what it means when so many work permits are issued to Indian computer specialists in Sweden.

In the next section I analyse how the informants speak about the effects that processes of internationalisation have on organisations in Sweden, and on their role as managers in terms of managing these effects. 


\title{
Internationalising Swedish industry - a management task
}

One main theme that emerged from internationalisation, which all managers that I interviewed identified as the main process relating to Indian workers, was how working in transnational organisations constituted a challenge in terms of maintaining trust and efficiency. This theme concerned the specific context of Sweden in a perspective of the internationalisation of businesses. Westermark (2013) investigated the strategies of creating proximity between offices in Sweden and offices in India in those Swedish firms that have chosen to internationalise. Her results show that individuals, particularly in the role of being 'cultural brokers', are often important for these processes to be successful. Culture was also a prominent theme in my material, as managers talked at length about the particularities of the Swedish and Indian organisational contexts in the offshoring processes. This theme is analysed in more depth in the next chapter. Here, I wish to address how managers described their work in terms of administering and managing the internationalisation of an organisation.

Often, the managers described the task of selling Indian labour as a challenge:

\begin{abstract}
Angelica: It has been, with the language, that a lot of organisations have staff that want to work in Swedish [language]. And then it can be a challenge. But the tools for integrating and working hard on creating teams between India and Sweden are paying off.

Jenny: We have seen that the language barrier is a really big issue. Many of the customers are not at all interested in having anything to do with Indian people, because they might suck at English themselves or they see it as a cultural clash of some kind.
\end{abstract}

Both Angelica and Jenny centre language in their explanations of why internationalisation has been difficult and slow in Sweden. However, in analysing these quotes further, language is closely tied to notions of culture. Angelica, who only explicitly talks about language, describes strategies for integration that I understand as connoting other dimensions of culture as well. At the beginning of the quote, Jenny establishes the challenges and barriers as being about language, but then she suggests that the reluctance of Swedes to work with Indians is based both on their lack of knowledge of English and on their general attitudes towards other cultures.

Angelica and Jenny describe the attitudes and reactions of customers, an understanding and knowledge that they can be expected to have as suppliers who cater for the desires of client companies. This does not, 
however, mean that Angelica and Jenny morally legitimise their clients' attitudes. Instead, the reluctance to work with Indians is perceived as illegitimate and narrow-minded in the quotes above. The management work that my informants do includes understanding as well as mediating the attitudes of clients. In this case, the managers identify negative attitudes towards foreign cultures as a challenge to the internationalisation process that they manage. This supports the theoretical interventions in the Global Commodity Chain and Global Value Chain literature that emphasise the importance of nation and culture in networks and chains of production (Bowen and Gaytan 2012). In relation to the analysis of a moral economy that this thesis pursues, it is possible to observe how important the tasks that the managers describe here are for making arrangements within the industry more morally legitimate; for instance by eliminating illegitimate prejudice.

The importance of national and cultural contexts to the supply chain structure is also relevant in order to understand the character of how offshoring is sold by the managers in Sweden. The managers described the international structures of their organisations as an important reason why internationalisation took on, despite the challenges.

\begin{abstract}
Jonas: So then two years ago we were bought by [large multinational corporation] and now we have the head office in the US. They wanted us to be more aggressive with offshoring, to sell it better.

Lars: It has been, the office in the Netherlands has done better than us [in the Swedish branch], for example, when they cooperate with India. So we have to show now that we can sell this also to Swedish clients and we have to be better and tighter when we integrate offshoring. That involves also that we have to show that the Indians know their job and that they are extremely competent at what they do.'
\end{abstract}

Both Jonas and Lars talked about the changing identities of the Swedish companies that they work for. As suppliers, their corporate identity was increasingly internationalised, which provided new opportunities to sell internationalisation, or offshoring. Similar to Jenny's arguments about the qualities of Indian workers, Lars says that the sales managers at the supplying companies need to be convinced about the qualities of Indian workers in order to sell them. Such a conviction was, in part, facilitated by a corporate identity, and sales managers were assigned the role of not only administering internationalisation, but also of envisioning and facilitating a moral arrangement of international labour. There is a parallel between the connexionist values that Boltanski and Chiapello (2005) emphasise and the active management of identification and affective and 
moral commitment to the project of internationalisation that the managers describe.

\section{The abstract language about labour - workers as bodies and resources}

During their interviews, the managers' talk centred more on issues of offshoring than labour migration. This had the effect of shifting focus from labour and workers to the internationalisation of services and production in my material. So far, I have mainly analysed managers' accounts of internationalisation and their own role in these processes. In this section I point to some aspects of how managers talked about labour in relation to a global structure of the supply chains. As a concept, offshoring associates changing spatial relations strongly with practices of selecting locations that can contribute to cutting prices or choosing places in the world where more value can be added to a service commodity (Hopkins and Wallerstein 1977, 1986). By analysing the managers' accounts it is apparent that the marketing of offshoring is also related to the introduction of a specific group of workers to the Swedish market, namely Indian computer specialists.

Some of my informants described the increasing complexities of outsourcing in the supply chains, which had effects on how labour was talked about. In an interview with the manager Sandra, I asked:

Karin: So, then, when you recruit Indian workers to work here in...

Sandra: But we don't recruit. It's on a project basis, so we decide on the composition in order to deliver the service to the price and quality that our customer wants.

When being asked about recruiting Indian workers to the Swedish office, Sandra immediately corrected me. The interpretative resources that Sandra used in this conversation place workers, who Sandra refers to as 'composition', as secondary to the design of a service. This short interaction serves as a way of shifting focus from the workers to the production, although the composition of workers is one of the main aspects of how price and quality is calculated. Although Sandra corrects me because officially there is no recruitment of workers, the shift in our conversation is also indicative of a management discourse in which the place where potential workers are located is not given, but is rather seen as a flexible variable in the production design. The delivery of a service is considered the priority, and the location and distribution of labour, as well as the 
components of the supply chain, are treated as flexible and dependent variables.

The manager Emma explained the background to supply chain complexities to me in greater detail. Emma's title was 'GD lead', short for global delivery lead. She seemed to be used to talking about processes of internationalisation and filled the large whiteboard on the wall with complicated abbreviations and arrows to show its development over time and across continents.

\begin{abstract}
Emma: Now, this is not exact, but first you have body-shopping staff [writes on the whiteboard]. That is, you choose, I need a consultant in this field and then I buy, sounds awful when I write it down [laughs], but body-shopping. Buy individual persons. But then, for the next generation, I don't remember exactly but basically we look at how we can buy a full service. We want you to maintain this whole system for us, that it works, that you can take on full projects. So more towards service [writes on the whiteboard] and less about just the persons. And that requires that we cooperate, that we have a little better...methods. In generation 3 you develop even better process tools [writes on whiteboard]. You find even better tools, so ok we need the same standard methods in order to work together and deliver this service. With individual people it doesn't really matter what processes and methods you have. And then in generation 4 then we look at, ok, so we want to deliver a service where we are available 24 hours a day, 7 days a week. Should we really only have consultants in India who sit there and work in shifts? Or could we think about having...let's start with the Philippines who deliver the first hours of the day, and then you go over to India, then you have one hub in Europe and then one hub in Brazil. So there are better working conditions and you find a balance. Between different units to cooperate and it becomes this global integrated enterprise [writes on whiteboard] or something nice like that.
\end{abstract}

In this quote, internationalisation is described in a chronological, linear manner where generations of arrangements succeed each other, seemingly in close connection to the evolution of management discourse. Emma describes how words have shifted; from body-shopping of individual workers to the complex integration of enterprises. Body-shopping is described as out-dated an unmodern, belonging to the first generation. In my interpretation, what Emma thinks 'sounds awful' about the terminology of body-shopping is the thought of human bodies that can be bought and sold. Indeed, the concept has the effect of decoupling people from their labour. Bodies, in this case the Indian computer specialists who are part of the offshoring processes, are furthermore defined without any geographical, social, or cultural context when managers shop for bodies. Still, when Emma says that it 'sounds awful' she is not necessarily react- 
ing to the arrangements of production but rather to language that sounds amoral in relation to workers.

Although Emma's argument about integration within international supply chains especially suggested positive effects on efficiency and economy, she also emphasised how the later generation models of offshoring acknowledge the specific geographic locations of workers and are more attentive to their needs. Emma uses interpretative resources that refer to harmony, integration, and balance to describe the changes that become finalised in a 'global integrated enterprise'. However, the increasingly advanced practices of integration, cooperation, standardisation, and spatial expansion that the later generational models of production design require, seem to represent advanced management rather than advanced IT work. In fact, Emma does not speak explicitly about labour at all. In Emma's description of development and advanced internationalisation there are, for instance, no references to the upgrading of jobs for individual programmers or testers.

I do not address changing work processes in international information technology in this analysis, and my point here is not to claim that nothing changes for workers and their conditions as the processes of internationalisation develop. The interesting changes that I engage with concern those of management discourse that Emma makes use of as she constructs the progress of internationalisation. While Emma explicitly addressed workers in her description of the first generation model of body-shopping, if only as 'bodies', she defined labour by its relations to specific 'hubs' in her descriptions of the final stage of integration. Yet this does not necessarily tell us anything about the value that labour and individual workers are given. Because the specific everyday context of workers is rarely made explicit in the material, it is through the managers' talk about integration, distance management, and technology advancement that I can analyse how workers are situated in management discourse.

The managers I interviewed generally talked very differently about themes such as integration or distance.

Karin: So how do you find them, when they are coming over to the Swedish office?

Sarah: We have databases, and then you can find resources in there. Fill out level of seniority and the skills that they should have. Basically it's a worldwide database. So you tick boxes, maybe there is a particular environment that you want them to be familiar with. And then how much they cost.

Sarah's description of labour mobilisation in the supply chain does not reflect the later generations of internationalisation that Emma described 
in her quote above. This indicates that generational progress may not be linear, and may mirror management discourse rather than the succession of practice in Swedish organisations. Sarah, like most other managers that I interviewed, uses the concept of a 'resource' when talking about workers. The concept of a resource is interchangeable with any type of skill, in any type of body, and connotes the abstract and generalised system of the supply chain. The desire for a resource can indicate the desire for any type of labour. It is difficult to say anything about the substantive aspects of work processes or labour conditions from the interviews with these Swedish managers in the supply chain. In fact, there is a striking silence around these substantive dimensions of labour - what computer specialists do during the day, or how they are differentiated and selected. The managers talked in a distant manner about resources rather than about workers, which indicates a dominance of this abstracted notion of labour. This does not mean that labour is always abstracted; those who design technical solutions or code software are likely to talk about labour in very different ways. However, among the informants that feature in this thesis, the structure of the supply chain, and the flexible system of finding a skill or a body, constitute the main domain that they manage. Because of the central position of these managers to translate the need for specific workers or specific types of internationalisation in the Swedish market, my analyses correspond to observations on how supply chain capitalism represents a fragmentation of labour (Tsing 2012). This fragmentation is not morally without problems, as most clearly illustrated in the way Emma makes excuses for using abstract language - body-shopping - for workers that 'sounds awful'. In the next section I discuss how the abstract language that managers use as they speak about workers can be understood in relation to their perceptions of identity and space in the IT industry. They describe how they re-model the identity of the Swedish corporation to become more international, as well as re-model their own attitudes as sales managers, or the attitudes of clients, towards Indian workers. How do they speak more specifically about their opportunities for affecting such identifications within the international supply chain?

\section{The identity of workplace and employment}

Anna Tsing $(2009,2012)$ argues that as the supervision and organisation of labour is outsourced, identity of workers is decoupled from labour relations. The focus on the role of management discourse in this thesis raises the question of how this may be related to the managers' processes of identification. The ways in which managers talk about temporary workers in transnational or Swedish projects, for instance, give rise to questions 
concerning how much the location of workers, or their employment contract, matter in times of advanced communication technologies and flexible employment in supply chains.

Computer specialist and managers' workplaces were described in a variety of ways in my material. Some of the managers I interviewed handled just one large client, and their workplace was often located at the client office in order to communicate more closely about the service. Some of the managers worked for different clients and had their main workplace at the office of the supplying company. While in Sweden, temporary Indian workers often worked at the client office in order to become familiar with their needs:

Emil: So in the beginning we need to have quite a few [people here]. We have team leaders, programmers, testers; those who will be key persons after part of the delivery moves to India. So the customer gets to know some of them and it will be much easier to communicate.

Other temporary Indian workers were stationed in Sweden in order to be 'shown off' to Swedish clients:

Lisa: When we started offering offshoring we needed to have some of our Indian consultants stationed here. We showed them off and they worked at different clients before they even had a set mission that we could get paid for.

Compared to the international supply chains in which the labour of workers across the world is cut off from the client companies, the managers in my material often described how the Indian workers should instead be made to feel familiar and close to the clients. Managing the recognition of temporary workers represents a link between offshoring and labour migration in the IT industry.

Identification also emerged as a theme with other supply chain actors who are not featured in this study. During the phase of my fieldwork where I researched the IT industry, I contacted several client companies where I knew that temporary Indian computer specialists were working. These companies all declined to participate in my study, often referring to how they merely ordered a particular service and did not have an overview of the people working on the projects. Lars, the manager of a supplying company, described the situation like this:

Lars: The order-maker or the final customer, they might not want to talk about it or they might not know. They buy a service and expect to have it delivered at the time that has been agreed. They don't care who is doing it. It's like buying a loaf of bread in the store and caring about who drove the loaf there. Their interest stops at what gives them value. 
Supply chain capitalism is characterised by an eroded transparency and dispersed responsibility among different actors (Tsing 2012). The lack of interest among the client companies, and the lack of identification with their workers, can be analysed as the result of these processes. This type of fragmentation of responsibility also seemed to lead to complexities and insecurities among different actors with regard to how labour mobility should be talked about. Several of the managers I talked to, as well as several of those who declined to be interviewed, presented staffing issues, and more specifically the mobilisation of labour within supply chains, as sensitive business information. The mobilisation of labour was considered as requiring knowledge, expertise, and trust that would be vulnerable to exposure outside the immediate supply chain negotiations.

As described earlier in this chapter, labelling these labour topics as sensitive not only influenced managers to decline participation in the study, but also contributed to a general silence around the specifics of the foreign computer specialists and their employment. The division of responsibility among managers in the supply chain is important for understanding management discourse, since the resources that my informants drew on as they talked about temporary Indian workers and their role in Sweden, partly represent these organisational codes of appropriate, and inappropriate, talk. From the discussion in the next chapter on the specifics of how Indian labour is positioned in Sweden, the effects of more general outsourcing are also worth noting, since they seem to lead to a dis-identification of labour from some positions in the supply chain.

\section{Speaking through globalisation discourse - silencing the role of labour}

So far, I have discussed how the informants talk with very few references to the specifics of labour and the working conditions in the IT industry. I have discussed how the silence about labour in management discourse is related to outsourcing, which creates a distance between the managers and the labour processes for programmers and testers. I have also discussed how this silence is related to the accumulation of complex management knowledge about how production can be integrated using concepts such as 'global delivery' rather than references to the mobility of workers. In this section, I attempt to position these silences in relation to the theoretical discussions on globalisation.

The abstraction of labour, and the ways in which workers are not mentioned in the dominant narrative of the industry's economic development, also reflects criticism of the literature on globalisation. Research 
on global value chains, for instance, tends to leave out the analysis of labour by favouring the business and managerial perspectives (Barrientos 2004). In the theoretical chapter of this thesis, I argued that it is important to understand globalisation as made up of practices rather than as the abstract processes of capital (Sassen 2001). In a number of different ways in this analysis of managers' descriptions of their facilitation of internationalisation, we can see how the silence about the role of workers in the globalisation processes reflects both management discourse and a larger discourse on capital in a connexionist world. When the managers talk about global delivery they talk using the discourses of globalisation. As social geographers have critiqued discourses of globalisation are aspatial and inattentive towards the concrete practices that constitute globalisation processes (Massey 2005; Sassen 2000), such as the actual movements of people in the IT projects and the 'deliveries'. The silence about labour in management discourse reflects a silence about what we can call the mobility of workers, since the computer specialists' travel to Sweden is an aspect of their work.

In the next chapter I analyse how workers can be positioned within the interpretative repertoires of managers as they talk about the differences between Swedish and Indian culture within an organisation. Before moving on to the next chapter, however, I want to contrast the silences about labour when managers talked about internationalisation, and point out the contexts in which workers did become visible in the management discourse. It is possible to understand how workers are situated in relation to the globalisation processes by analysing how managers talk about the administration of mobility that they themselves perform. Sarah, for instance, explained how selling offshoring required new types of tasks and assignments for management and the support functions at the Swedish company.
Sarah: So because of these developments in the larger company, we started a centre [also at the Swedish office] that used resources in India, mainly. Because it is pretty complicated with how you cooperate, where you are supposed to be located, what kind of visas and permits will you need, methodology, how we take care of people when they come here, where they are supposed to live, a lot of practical stuff like that. So we had this centre [...] with the purpose that this should be business as usual, that it works and everyone knows it eventually. So the plan is that it should be smaller and smaller and eventually only a few people have to work with these issues.

Sarah's description indicates that managing internationalisation and managing mobility are in fact aspects of the same processes. To establish 
offshoring at Swedish companies required the mobility of Indian workers to come to Sweden. Although the offshoring process from Sweden to India was framed as the main process, the mobility of Indian workers required knowledge and routines about visas, living arrangements, and other aspects of the workers' everyday lives. These practices were also described by Hanna:

\begin{abstract}
Hanna: Continuity is very important. We can't have people who resign because the job is boring, or because they want to do something else. One way for a colleague in India to boost their career is to work in Sweden. So we have a rotation schedule. We make sure that at one time or another every person in this delivery will have been in Sweden during three months. We have tech leads and [people in] similar positions who will be in Sweden more than that. But we have a process when everyone gets to work in Sweden. And that is for two reasons. It contributes to continuity. Both by meeting our clients and talking to them every day, and forming a relation to the company. [...] Continuity is important, so we make sure they come here. Three months is the easiest, from a migration perspective.
\end{abstract}

Hanna describes how mobility is important in India, and how opportunities to go abroad are an institutionalised aspect of the professions and careers in the Indian IT industry. We can partly understand the silence from the managers in this study about the social and cultural contexts of migration by acknowledging how the informants are located in Sweden. By referring to what mobility means to 'a colleague in India', Hanna is indicating that migration does not carry the same meaning to her, as a manager in Sweden. From an Indian perspective then, a moral economy may be framed differently. For instance, critical researchers have argued that in relation to highly skilled migration, global inequalities persist and affect whether global arrangements can be considered moral or not. The persistence of social and economic divisions can be related to both a precarisation of cheap and flexible labour and to the outsourcing and offshoring of innovation systems, to the disadvantage of the global south (Delgado Wise 2015: 27).

When Hanna accounts for the administration of mobility concerning visas or career opportunities, the mobility of Indian workers is not portrayed as a problem. This reflects how research on managed migration portrays highly skilled migrants, such as Indian computer specialists, as subjects who are supposed to fit the migration regimes (Anderson 2013; Menz 2008). The reason why the administration of migration is not framed as an issue, and generally was not a theme in the interviews with the managers, can also be connected to how labour is included as a component of a complex, interconnected global economy, as shown in 
previous sections of this chapter. Most literature on highly skilled migration in the IT industry applies economic or neoclassic migration theories (Kofman 2013). These theoretical frameworks reinforce the notions of a cosmopolitan male subject who is cut off from the social and emotional contexts of migration (ibid.). However, the way in which managers position workers as economic components and as flexible resources, also constitutes a barrier to talking about these computer specialists as migrants with social or emotional needs that are regulated through migration management.

In the interpretative repertoires that managers use, Indian workers in Sweden are seen as workers who are mobile within the boundaries of their general work description, rather than just seen as migrant workers. It seems as though foreign workers are classified as migrants only if they become the subject of migration control. Hanna refers to the role of the state in the quote above. 'Three months is easiest from a migration perspective', she says. Similarly, Jonas, whom I referenced earlier in this chapter, argued that for tax reasons 90 days was a preference for the company to keep Indian workers in Sweden. Hence, state regulations do seem to play some role in the design of the strategies of internationalisation and mobility.

However, most of the managers described that they had already started working with offshoring prior to the change in Swedish regulations on labour migration in 2009. Jessica described the early phases of offshoring in her company:

Jessica: At first we wanted twenty people to come here to Sweden. Back then the rules were much worse at the Migration Agency. You were required to place an ad to all of the EU, to make sure no one in the EU wanted the job. It was extremely bureaucratic and administrative bullshit, frankly. We didn't want anyone from the EU, we wouldn't...I mean that's not where the competence was. At that time one really felt disgust about how things were handled. But of course you do it anyway.

Jessica described the irritation she felt about the difficulties of recruiting Indian workers to Sweden. Through her affective language, Jessica criticises the Migration Agency's bureaucracy and administration as evidently and obviously illegitimate. She expresses her criticism of the illegitimate character of the migration regime, especially the state regulations prior to 2009 , by referring to how the regulations prevented the recruitment of 'competence' rather than migrants. Jessica also described the changes after 2009:

Jessica: We have been forced to use the services of the Migration Agency much more now, after working with Indian resources caught 
speed. And after the changed regulations in 2009 , well it was very slow at first. The authorities didn't keep up. And after a while the turnaround time started increasing enormously. And then this thing that we needed signatures from the trade union. Why do they need to get involved? We have a collective agreement. We had to have one of our co-workers, who was a union representative, have a fax machine at his desk where he worked so that the applications could be signed faster. In the beginning we always applied for six months, but it was always a mess so we stopped caring and now we always apply for the maximum. Two years is what you can put the application out for, so you do that.

Jessica describes the current system as being much better at facilitating the mobility of Indian workers. Despite the liberalisation, however, migration controls are not perceived as illegitimate functions of the state in relation to Indian computer specialists. Instead, the state practices are portrayed as petty bureaucratic requirements. In management discourse, the temporary migration of Indian workers is not constructed as a migration phenomenon, but as aspects of internationalisation, in which the control of individual people appears superfluous. In the interpretative repertoires of the managers, a moral arrangement of migrant labour in the IT industry would therefore not treat Indian computer specialists as migrants at all. When managers describe a moral economy of internationalisation they dismiss the state's practices of migration control as illegitimate.

This chapter has engaged with the specific language and knowledge creation of Swedish managers in the IT industry. In their interpretative repertoires, they mostly avoid entering into discussions about migration. In this chapter, I have analysed how this specific management language reflects both connexionist values of global capitalism and the changing supply-chain structure of the industry. I have also described how the working conditions of computer specialists are dismissed as a possible moral topic in the discourse of economic integration. This type of rhetorical silence that affects what can and cannot be said, should be seen as a research finding in its own right (Billig 1991).

In the next chapter, rather than discussing how managers talk about internationalisation and offshoring in general, I analyse situations in which managers talk about their own changing organisations, and then analyse how interpretative repertoires in these contexts describe Indian workers in terms of their economic and cultural value. 



\section{The moral concerns about difference between IT workers}

The previous chapter put management talk in an organisational and economic context, more specifically within supply chains of labour. I presented how the internationalisation of production was considered as the main process that explained the presence of Indian workers in Sweden. I also presented how interpretative repertoires were based on a very specific type of management and a terminology that reflected business strategies for administering and facilitating internationalisation.

As the informants described how they managed these processes of internationalisation, the most dominant theme that emerged from the analyses of how labour was talked about concerned cultural differences. In this chapter, I analyse the ways in which managers talked about cultural difference, and how Indian labour was defined within these discourses. The moral negotiations of how Indian labour should be recruited, supervised, as well as valued and evaluated within the organisation, are the themes that resulted from the analyses of management talk about cultural differences. Furthermore, I discuss how the managers' descriptions of the differences between Indian workers and Swedish workers use interpretative resources that refer to both transnational economic inequalities as well as race. I also consider how the interpretative repertoires reflect the moral ambiguities of these descriptions of difference, and how these ambivalent notions of Indian workers in Swedish industries represent an unresolved moral dimension of the arrangements of temporary foreign labour.

\section{Constructions of cultural differences from a supply-chain perspective}

In this section, I discuss the characteristics of cultural difference and why it was identified as a dominant theme when managers talked about Indian workers in Sweden. When the managers talked about Indian culture, or the cultural differences between Sweden and India, they sometimes used interpretative resources that referred to 'common knowledge' - an- 
ecdotes from their travels, references to TV-programmes, or everyday life - and not the specific knowledge that they had acquired in their roles as managers. Discourses about culture affect attitudes for most of us in our daily lives, for instance attitudes towards citizenship, national belonging, ethnicity or race, and they contribute to the political categorisation and separation of groups of people. However, in this analysis I attempt to understand how the interpretative resources that these managers used as they established how being Indian is different from being Swedish, may also be specific to their roles as managers in supply chain capitalism and as mediators of labour migration. The analysis is concerned with how we can understand why cultural difference preoccupies management discourse.

Culture was brought up as a theme in my interview with Jan:

Jan: So you can work with offshore, but then maybe sometimes you need to be closer. Then you can work with nearshore, maybe that's Estonia or Latvia or Ukraine.

Karin: So, close is...

Jan: Well, it's about how long it takes to fly but also culture, that there is not as much translation as with the Indian.

Jan portrayed nearshoring as an alternative to offshoring when a manager like himself chooses internationalisation strategies. In the context of the internationalisation that Jan talks about, cultures can be different to a greater or lesser extent. Furthermore, Jan describes how cultures can be compared in relation to a scale of cultural proximity and distance. In this interpretative repertoire of cultural differences, India is acknowledged as being substantially different from Sweden, and further away on the imagined scale of cultural differences than other locations such as Estonia or Latvia. This interpretative repertoire of cultural differences as possible to evaluate and grade in relation to proximity and distance - the ways in which 'shores' are located 'near' or 'off' - requires a subject who performs these evaluations. Managers who design and suggest strategies of internationalisation need information about the culture of these locations, as well as information about the needs and desires of customers and in the evaluation of cultural difference; the managers' creation of knowledge is key. Discourse psychology provides a productive analytical framework to analyse the active production of knowledge by managers, for whom cultural difference appears to be a central aspect of their work of internationalising organisations.

Returning to Jan's explanations, the calculation of cultural difference reappears: 
Karin: So how do you choose, I mean who wants nearshoring? Jan: Well, nearshore, that could be the Czech Republic. So if you work with a project there, the developers could come to Sweden much more often. Well, and it is a mind-set that is closer to our culture. It's a light version. So we might offer that as a kind of first step.

In this quote the importance of worker mobility is mentioned as one important aspect of successfully executed internationalisation. I will return to how managers portray geographical distance, mobility, and communication technologies later in this chapter, but will now discuss Jan's notion of cultural difference as distance that he puts forward in this quote. This notion is inherent in the very concepts that define the services of nearshoring or offshoring, and therefore uses resources from established discourses of internationalisation practices. The centrality of cultural difference must therefore be understood as a fundamental aspect of business rhetoric in the IT supply chains. However, the meaning of 'near' and 'off' is also the result of individual managers' active descriptions. In the quote above, Jan described the different strategies of outsourcing as dependent on the managers' knowledge about cultures and distance of suppliers. Managers in supplying companies know about cultures, for instance in the Baltic states, the Czech Republic, and India, and they know how to offer their clients the type of difference that they can handle. The authority with which Jan explains how categorisations and calculations are made rests on references to his expertise as a manager. Within the interpretative repertoire of cultural difference as something that can be calculated is also a legitimisation of the importance of management practice. This practice includes the responsibility of knowing about cultures and presenting this knowledge to the client when selling the service of internationalisation.

I analyse the managers' active use of language (Wetherell and Potter 1992) and the interpretative repertoires as expressions of both the general discourses of culture that are transmitted in everyday life for most of us, as well as the expression of particular interests that are located within a capitalist organisation. This analysis brings to the fore how difference, or diversity (Tsing 2009), is shaped by relations in a global economy and not only through abstract ideologies and cultural values (Sayer 2005a). In this sense, the organisation of outsourcing, offshoring, and nearshoring provides a framework that morally justifies the construction of cultural difference within the IT industry.

In Jan's description, which I referred to earlier, he presented India as a location that required much 'translation'. I will return to what this type of translation could entail according to my informants. However, the man- 
agers that I interviewed also engaged in the task of selling Indian workers, including the cultural context in which their labour was marketed:

Sarah: [The Indians] work very hard and have that mentality, because it's a very competitive culture.

Emma: So, India is like, the Chinese they are very good also, they are coming on strong now, but they are generally not as good at speaking English, they don't work as well in English as the Indians do. Also they [the Chinese] are maybe more difficult in groups, I think. So that is why, I think.

In the previous chapter I presented the role of management in the supplying companies as being characterised by the task of selling internationalisation and selling workers. How was the notion of cultural difference transmitted within this framework of positive enforcement? Sarah and Emma, in the quotes above, did not talk about Indian culture in relation to its relative distance from Swedish culture. Instead, they see culture in terms of its value to the supply chain and to service production. Economic value is portrayed as something that can be extracted from the efficiency, competitiveness, and productivity of Indian workers, which are presented as being dependent on their culture. In the same line of argument, aspects of Chinese culture are represented as obstacles to the extraction of economic value. These perceptions of culture are representative of a niche structure of supply chain capitalism (Tsing 2009) in which aspects of workers' lives, such as their culture, determine the ways in which they fit into a system of global production. According to Emma, the Chinese may be 'very good', but in certain ways they do not fit quite as smoothly into the system of cross-cultural cooperation as Indian workers.

Apart from showing how managers talk about cultural difference, a central contribution here is the analysis of how the management of labour in a supply chain changes the meaning of cultural difference. When managers talk about cultural difference, they articulate these differences in specific economic and organisational contexts that affect the ways in which culture is defined and valued. The ways in which the managers interpret the meaning of cultural difference is affected by their work, which includes deciding how foreign workers can best be sold to Swedish companies, and how difficult and costly cultural differences will turn out to be in a nearshoring/offshoring process. They also reinforce these interpretations of culture through their work as managers.

By taking into account the investments in internationalisation that these managers have made, as presented in the previous chapter, the interpretative repertoires of cultural difference can be analysed in the context of both economy and culture. These discursive practices cause cul- 
tural differences to take on new meanings, and to be ascribed new types of value through the specific creation of knowledge within the supply chain.

\section{Production of management knowledge - mapping cultures and nationalities}

After analysing how managers view cultural difference in a supply chain context, I now illustrate how manifest the theme of cultural difference was in the creation of management knowledge. Before I met Lars, a project manager at a supplying company, I had read one of his reports that presented strategies for companies to successfully manage 'blended delivery'. Among the managers I interviewed, blended delivery was the most common flag under which labour was mobilised, and meant that they were managing a team of workers in both India and Sweden. My informants explained that such management involved varying degrees of exchange across locations, as well as different strategies in terms of integrating the work processes. Since writing this particular report, Lars had moved on to manage new accounts that involved various kinds of offshoring, and he advised both clients and other managers within his own organisation on how to think about these processes.

During the interview, Lars showed me a slide presentation that he normally gave to his co-workers, management, or to clients when he informed them about the offshoring processes. One part of the slide presentation illustrated the differences between Indian and Swedish culture; the caption read: 'Model of cross-cultural differences between India and Sweden'. Lars' presentation included theoretical definitions of culture at four levels: individual, group, national, and universal. His presentation was based on a popular model of cultural differences widely used in business management. The use of such theories in the managers' talk illustrates the importance of taking intertextuality into account in discourse analysis (Wetherell and Potter 1992; Winther Jørgensen and Phillips 2001) to acknowledge how talk about cultural difference is not necessarily the invention of individual managers, nor the reflections of individual attitudes towards culture. Cultural difference is also defined in relation to public discourse and institutionalised understandings. I am therefore not reviewing the popular model of cultural difference, but analysing the ways in which Lars makes use of these interpretative resources in his presentation of managing offshoring processes.

According to Lars, the definitions and comparisons of culture that he presented should be 'used as tools, to get people thinking, maybe reflecting on their own behaviour and how that is interpreted by others'. A 
diagram in one of the slides compared five cultural aspects. The differences were illustrated through the scale 'high' or 'low'. For instance, as illustrated in the diagram, Sweden scored higher than India on 'individualism', and lower on 'uncertainty avoidance' and 'power distance'. Lars explained what this meant:

Lars: Swedes are more comfortable with differences of opinion and lack of rules. Indians, they want clear hierarchies and communication. This is one of the things that can stir up controversies in a project. And I, as a manager, need to know how to be clear when I speak to Indian programmers.

The greatest differences, according to the model, related to the themes of 'masculinity' and 'monochromic time'. India had a high score on masculinity, implying 'assertive and competitive values'. On the other hand, according to the explanations on the slides, Sweden's low scores on 'uncertainty avoidance' and 'power distance' implied 'modest and caring values' or 'quality of life'. According to Lars, the title 'monochromic time' referred to how different cultures related to time:

Lars: Yes, this often causes misunderstandings. It says here that Sweden is future-oriented, that we want to overcome obstacles over time. India has more of a here-and-now-attitude.

I return to some of the themes later since there are similar descriptions in other managers' accounts. An interesting aspect of Lars' presentation is how it reveals the systematic production of knowledge about cultural difference in management discourse. The cultural aspects categorised as individualism, masculinity, and monochromic time, are reinforced through charts and diagrams that also lend these models a scientific legitimacy. The interpretative repertoire of cultural difference as being able to calculate is furthermore translated into organisational relevance in Lars' presentation: people will work differently depending on how they understand time, social relations, and careers. Again, cultural difference is not articulated in relation to a decontextualized notion of cultures everywhere, but rather as a work-related culture of production or organisation. Hence, although the theoretical model sets out to map cultures as 'Indian' or 'Swedish', cultural difference is in fact defined as the differences in terms of how people act as workers.

The interpretative repertoire of cultural difference, illustrated through Lars' presentation, is relativistic in the sense that no cultures are perceived as being neutral. Everyone, including supply chain managers, lives in a culture and may, as Lars puts it, benefit from 'reflecting on their own behaviour'. The consistent differentiation between what is 'Swedish' and 
what is 'Indian' is morally justified not only because it serves a purpose in the economy when organisations become international, but also because it is justified with references to increased reflexivity and tolerance that constitute positive values. In the next section I analyse how these cultural differences were presented in other contexts during the interviews with managers.

\section{Discourses of the nation and Indian culture as 'Other'}

The theoretical model that Lars presented proposes a notion of neutral categorisations and classifications of cultures. Potential differences in terms of efficiency are portrayed as dependent on how cultural contexts are managed and on an organisation's ability to take cultural aspects into consideration. In contrast, however, Sarah and Emma in the previous section expressed how one culture could be more productive than another; for instance the competitive culture of India that makes Indians work harder, and the cultural traits of Chinese people that make them a little less desirable as workers. In the interpretative repertoires that present certain cultures as more productive than others, there is a notion of difference that disregards the neutral and scientific language of charts and diagrams. The interpretative repertoires in which cultures are compared in relation to productivity do, however, make use of the same type of interpretative resources in which cultural boundaries are seen as fixed and as tied to nationalities.

At the beginning of the interview with Lars, as he explained his work with cultural difference, he addressed the generalisations in terms of how cultures were represented:

Lars: Have you ever been to India? No? I mean, it so big. They have so many languages and dialects and cultures. Eating in Bangalore is not the same as eating in Chennai or in Delhi. When I am in Bangalore, I eat the same burgers that I would in the US. But it is important that we talk to people here about the things that can go wrong so that we can have an efficient process.

In the quote above, Lars acknowledged that Indian culture is diverse. However, presenting the cultural differences between India and Sweden is still important, he continued. Although Lars does not argue for an understanding of the nation as a collection of homogenous cultures, the division between national cultures is perceived as the only effective and coherent way of presenting differences to clients or to co-workers. Michael Billig (1995) has analysed how ideologies of the nation are reproduced in everyday practice and speech, rather than through explicit confessions to 
nationalist agendas. Therefore, studying how the constructions of cultural difference in management discourse align with ideologies of the nation (ibid.) can contribute to an understanding of how Indian workers and Swedish workers may be situated differently in terms of the nation they are thought to belong to; where their culture 'fits' and where it doesn't.

Although marketing and selling the attractive features of Indian labour constituted a main resource in the managers' interpretative repertoires of Indian culture, the managers also argued that Indian culture could be a problem in a Swedish context. I have not observed any patterns regarding when Indian culture was seen as a problem or as an advantage to the organisation. Instead, managers described these negative representations of Indian workers just like the celebration of their culture, using the same interpretative resources of cultures as a national difference. An illustrative example of a negative evaluation of Indian culture was Sarah's description of problems in the offshoring processes:

Sarah: Well, Indians don't communicate enough. In Sweden we expect more independence, a better plan. But for them everything needs to go through the hierarchies, and that is not the most effective.

The problematic aspects of Indian culture that Sarah described reflect some of the themes, such as 'monochromic time' and 'individualism', in Lars' presentation of cultural difference presented in the previous section. Another aspect of difference that returned in Lars' presentation, and in several of the interviews, concerned 'masculinity':

Jenny: I was a little worried. I mean, being a female manager when perhaps the man in India has a higher status and many women, after they have kids, they become housewives. But I am so proud to be in a company that takes gender equality seriously.

Gender scholars have observed how discourse in Sweden ascribes the Nordic welfare state an exceptional position of morality in terms of gender equality. Sweden is constructed as a nation in which women have a strong position, where gender equality characterises the society, and where gender inequality and misogyny are ascribed to ethnic others (see e.g. Carbin 2010). In the quote above, Jenny aligns with gender equality as a mark of difference between her (Swedish) context and India, and she challenges the stability of these perceived differences by pointing out how her company, which spans cultures, takes gender equality seriously. In the context of international business, the transnational mobilisation of labour is ascribed a potential of overcoming national cultural difference. Still, cultural difference is seen as being connected to nationality, and the 
problems of gender inequality are positioned in the national context from which labour is recruited.

Notions of cultural difference were present in most of the managers' accounts, and management discourse often felt remarkably homogenous as I was going through my notes and transcribed the interviews. Cultural difference was repeatedly described in similar ways, although the value judgement that was attached to these differences varied. One characteristic feature of the management discourse, however, was how it lacked descriptions of conflicts or problems. This can be interpreted as reflecting the interests of these managers, who had invested in the future of internationalisation, to emphasise opportunities rather than to acknowledge conflicts or problems. However, even in the management talk that avoided conflict, the construction of cultural difference can be analysed in relation to asymmetries in terms of how difference is valued.

\section{Cultural difference and constructions of race}

Rohit, one of the Indian managers I interviewed, talked about the asymmetric valuations of differences. After finishing his degree in engineering in India, he was trained at a large centre in Bangalore. During his training he was taught specific cultural manners that were considered useful for working in Western countries. He explained that he was now in charge of Indian workers at Swedish offices and found it important to instruct them on how to behave:

Rohit: They should try to blend in, to look like those employees here who never wear formal clothes. And some find it uncomfortable with smells, and you know Indian food - so I tell them to bring other food that doesn't smell so much.

Rohit's account of the importance of 'blending in' illustrates an imbalance when Indian developers work in Sweden. The importance of clothes and smells indicates that for Indian computer specialists to work without problems at a Swedish office depends on toning down certain Indian characteristics. In her book Space invaders (2004), Nirmal Puwar studies how women and racialised minorities enter spaces, or domains, that are traditionally dominated by white male professionals. Puwar argues that as 'bodies out of place', racialised minorities are defined through a white male gaze, and their positions are compromised by subtle practices and by the language of exclusion in the workplace. Implicit in how Rohit talks about the strategies that Indian workers need to adopt, are the potential consequences that seemingly negligible cultural differences may have in the workplace. Implicit in the need to blend in, for instance, is the 
threat of being the subject of negative attitudes or uncomfortable feelings among Swedish staff. Theories about race highlight how the asymmetric power relations of colonial histories (Fanon 1986; Said 1995) are implicit in the definitions of difference, resulting in uneven social relations where 'whiteness' is the norm. The interpretations of cultural difference in management discourse, therefore, may not be as neutral and free of value judgement in their effect in the workplace and in the organisation as they are presented in manager accounts. In his research on Indian IT workers, Xiang Biao unveils a critical dimension to the political economy of a global IT industry (2007). He describes a systematic differentiation in the way Indian, Chinese, and South American IT workers are labelled differently in relation to their technological and social skills when they are marketed and placed in Western countries. This is a result not only of cultural stereotypes but also of a global political economy that Indian programmers need to navigate in complex ways. Cultural stereotyping of employees is also documented in previous studies of the US IT industry. Indian IT workers in the US experience recruitment practices based on racial discrimination, where secure or senior jobs are given to 'whites' or 'US citizens' (Banerjee and Ridzi 2008; Varma 2002). Furthermore, Indian migrants on $\mathrm{H}-1 \mathrm{~B}$ visas earn US\$13,000 less than their US counterparts (Banerjee and Ridzi 2008: 103) and are more often employed as contract workers.

When analysing the notion of difference, it is also important to consider how the situation in which the managers' accounts were generated may have affected how boundaries and subject positions were named and differentiated. To some extent, the category of 'the Indian' preceded the interviews. I told the managers who I was about interview that I was interested in Indian migration to Sweden, and asked them questions specifically about this group of workers. The category of 'the Indian' was, however, also determined through management talk, and these are the aspects I focus on in the analysis. For instance, in the workplace, Indian appearance marked one difference according to some managers' descriptions:

Karin: So, are there any Indian programmers in your project now? Jan: No, there are some working at another project in the building I think. At least I have seen a group of them in the lunchroom.

Lars: I mean, you often see them eating lunch together. Even those who are here more long term, they don't learn Swedish either. But well, it is safe [for them] of course - to be in a group.

In passing, both Jan and Lars described how they recognised Indian computer specialists in the lunchroom. When they are seen in a group, 
through the managers' eyes, their appearance makes them identifiable as Indian in the organisation. Therefore, associations with cultural differences are projected onto brown bodies at the workplace. This type of visibility can be understood as the basic assumption from which Rohit instructed Indian workers to blend in, presumably to avoid negative visibility. During their interviews, the white Swedish managers never talked about how Indian workers were taught how to blend in. Among these white Swedish managers, the reflexive position of cultural difference, and the emphasis on observing themselves in the global context of cultural difference, represented a morally legitimate way of talking about differences between Indian and Swedish cultures and people. Issues of race and the social relations of power, however, were not used as resources to construct an image of the arrangements of foreign labour in the Swedish industry. This silence around race and difference can therefore be understood as a dimension of what constitutes a moral economy in the (white) Swedish IT industry.

Feminist poststructuralist theories have described how indicators of race often cannot be understood as being stable or 'fixed' (see e.g. Ahmed 2000). The contextual understanding of the constructions of race is essential for analysing Indian computer specialists; a group of highly skilled migrants who are described as desirable by the Swedish industry. In the case described by Rohit, the associations of smells, texture, and place identified workers as Indian. In other words, food and clothes made Indian workers visible and constructed them as different from Swedish workers. In other contexts, difference may not be racialised in the same ways.

\section{Those who overcome difference - being cosmopolitan}

As presented in the previous section, racialisation can be observed in the managers' accounts by the ways in which Indian workers were described as being different from Swedish workers in the workplace in Sweden. The 'on site' presence of Indian computer specialists was described as important for internationalisation to work:

Lars: It is important, so that people get to know them. It is easier to work together after that, even if it is perhaps not the same people.

According to the managers, transferring knowledge to specific members of an Indian team was one reason why mobility from India to Sweden was important. However, getting to know them, in Lars' quote above, seems to relate to a general idea of Indian culture rather than to notions of friendship with individual Indian workers. The Indian specialists who came to 
Sweden were seen as representatives of Indian workers, and although they might not be the same people who continued to work on the project after returning to India, the meeting was described as essential for successful internationalisation. Some Indian programmers and managers were described as better representatives than others:

Jan: When you have been to Europe a few times, then it is likely that you become labelled as more senior. Because you know how to deal with different kinds of people, you have developed the soft skills.

Hanna: I work really well with him. He has been to Europe many times and has adapted to, you know, Western culture.

The ability to work together and make a good impression on Swedish colleagues and customers was associated with the international experience of the Indian IT workers. They were seen as being able to transcend cultural differences and act as interpreters between the Indian and the Swedish teams. The 'soft skills' of an Indian computer specialist who has been to Europe many times can be interpreted as 'cosmopolitan skills' the ability to transcend cultural difference. The academic literature on cosmopolitanism has received criticism for not fully problematising the interconnections between Eurocentric or 'Western' definitions and the understanding of processes such as modernity, globalisation, and cosmopolitanism. The sociologist Gurminder Bhambra points out the differences, especially between postcolonial perspectives and cosmopolitan scholarship:

What appears striking in not just the sociological, but also the wider academic literature on cosmopolitanism, is the extent to which 'being cosmopolitan' (as a practice) is associated with being in the West, and cosmopolitanism (as an idea) is seen as being of the West.

(Bhambra 2011:314)

According to the Swedish managers, the Indian colleagues they described as Westernised had adopted these manners through working abroad, and although the Western qualities were not defined specifically, the 'Western experience' was central to how the managers talked about recruitment and collaboration in projects. Hence, there is an ambivalence in terms of how managers legitimise the focus on cultural difference that their work entails. On the one hand, the managers argue that everyone in the industry needs to be cosmopolitan, and on the other hand being 'in the West' is considered an important experience that grants access to cosmopolitan manners. 


\section{Mobility and careers - explaining the social context of Indian workers}

The managers did not describe mobility as something that was demanded by Indian workers in the process of internationalisation. Instead, mobility was described as something that had a value to the Indian workers. The managers presented the opportunity to work abroad as a benefit that they could offer in order to find more competent developers, or to make sure that Indian workers did not leave a project for a job with more opportunities.

Sara: We try to shift so that everyone in the team gets to travel to Sweden. And it doesn't always work like that. But that would be fair. That everyone gets to go.

Hanna: For these people, well, if you have done a mission abroad you climb the hierarchy enormously when you return to India. It means that you can climb several steps on the ladder of your career. But then, after a while, they become picky. So we have to make an effort as a hosting nation. They do have very good experiences here, as it is now, but we can always get better. So that's what we are working on now, that they should feel like part of our ordinary employees.

The managers represented 'being abroad', and what it meant to Indian developers, as both an ordinary part of the job in a transnational organisation, and as an opportunity that individual computer specialists invested greatly in. They described how they needed to understand, and relate to, the meaning that Indian workers ascribed to migration and mobility. In Hanna's quote, this understanding was necessary for the internationalisation process to run smoothly without a high turnover rate of staff in the projects. Still, mobility was seen as part of a professional career rather than as a process with social and emotional consequences. In my interview with Jonas, however, he touched upon other aspects of migration:

Jonas: It is about the career. Perhaps you are more senior if you are chosen. There are good economic benefits for those who go, too. They get allowances and we try to fix them up with their own household [in Sweden] so that they don't have to go out to eat all the time. They can cook and save some money on that. So, that's why it is attractive. It's just like with people from the Philippines who send money home to the family, perhaps from the US. But with the older generation [in India], when they [the Indian computer specialists] come here for only three months and then return - they say; did you fail or what? They might expect more money. 
Jonas associated the mobility of Indian computer specialists with other types of migrant worker situations, for instance between the Philippines and the US. In this quote, the social and emotional context of mobility among Indian IT workers classifies them as migrants, although they are only in Sweden for a short period of time. By addressing Indian workers as migrants, other types of vulnerabilities emerge in Jonas' account; more than in most of the other managers' descriptions. The importance of the personal and immediate economic context of mobility, for instance Swedish food costs, as well as the more long-term social expectations and emotional consequences of mobility, are examples of such vulnerabilities. By acknowledging these dimensions of mobility, Jonas incorporates these aspects in management's responsibilities. The moral economy that Jonas constructs requires the Swedish managers' empathy and their identification with the migrants' situation.

Some social aspects of Indian IT workers' mobility were also highlighted in other interviews, and concerned the practical arrangements within the company:
Hanna: Well, our housing market is awful. But it's still cheaper than hotels. And they have company even if they are only here temporarily, they get friends so they don't feel isolated and lonely. And they also get to choose if they want to bring family members. That's part of the deal. Some have their wife and kids with them.
Karin: Even if it's only for a few months?
Hanna: Yes, exactly. They don't want to be without them. Someone actually brought their mother. I think that's hilarious, we laughed so hard when we saw that application. The mother! So they get to do that, they have to make room of course, our apartments are not that big but it works when they are not here for that long.

In this quote, the social and emotional aspects of mobility relate to the organisation, and to how the Swedish management and administration can accommodate the preferences of Indian workers. It is of course not surprising that managers talk about how they work with the social aspects of mobility in a work situation, rather than about the wider structural dimensions. The consequences of this organisational context, however, are interesting. When Hanna frames the Indian workers' visits to Sweden as professional experiences, she also finds it funny, and perhaps a little ridiculous, for a worker to bring a mother. Hanna views the migrant situation in relation to organisational relocation, rather than imagining the migrants' social relations, economic arrangements, and emotional strategies in relation to their temporary migration. Hanna describes how Swedish management strives to understand the needs of the Indian workers, and she presents this as a moral dimension of the company's 
arrangements. However, the organisation and the supply chain structure of production define the economic and normative boundaries for these needs. A situation in which personal relationships, eating habits, housing arrangements, and other aspects of personal life are arranged on behalf of an employer is also likely to affect how social and emotional needs can be expressed. The managers presented their acts of caring for the needs of the temporary Indian workers as being important, and they described how these needs should be defined by the Indian co-workers. The managers did not, however, talk about their own position as associated with influence and power. In this sense, the moral economy was constructed in relation to the migrants' expectations that naturally matched the expectations of the organisation, which, as Hanna's account indicated, may not always be the case.

\section{Mediating intimacy, and the discipline of mobility}

So far, the main focus of the analysis in this chapter has been to illustrate how managers viewed the presence of Indian workers in Swedish workplaces in relation to managing cultural difference, and how conflicts or uncomfortable feelings were talked about as something that can be avoided through the right managerial strategies. Yet, the management of difference that my informants talked about did not only concern immediate workplace interactions. Some of the managers, like Hanna in the previous section, described how managers gained insights into the personal lives of Indian computer specialists in Sweden while managing their mobility. Participant observations or in-depth interviews with Indian workers could give us more knowledge about the social consequences of mobility and about personal lives when these are arranged within a supply chain. In this study, by focusing on the ways in which managers make sense of their relations with temporary foreign workers, it is possible to look more closely at how the boundaries between work life and private life are drawn. My material did not contain many such accounts, but Hanna talked about a situation in which her company defined such a boundary:

Hanna: A fun example. Or it's a horrible example. There was a woman and two guys who were here at the same time. A little misogynous you could say, these guys. They treated her worse than could be expected. They wanted her to cook and clean and all that. They had separate accommodation. They were not married. But she would do the worst tasks on the project as well. But then we discovered this, and moreover, we saw that she was the one who did a good job. So then we sent the guys home and kept the girl. Prematurely. Because they simply did not act in a good way. And it's a true story ... and she was better [at the work]. But 
it was this, this ugly gender thing, as well. Indeed it still exists in Sweden, but it is perhaps even more evident in India. When they showed it off this clearly as well, how they think and feel, then it was quite nice to put a foot down.

The ways in which housing and personal relations are arranged through the organisation provides a setting in which managers gain access to and knowledge about other aspects of the employees' lives. Although this is not the point of Hanna's anecdote, this knowledge about who cooks and cleans is what led her to relate to the Indian workers in new ways; the men's private lives establish proof of the misogynous ways in which they think and feel. Earlier in this chapter, I discussed how gender equality provided a value in management discourse; a value that was normally associated with Swedish culture. Although Hanna expresses how misogynous attitudes are not exclusive to Indian men, culture is brought into the argument as an interpretative resource to explain what happened, why it happened, and why it was important for her to react. In this sense, evaluations of which differences are legitimate and which differences are not, become part of the management practices of mapping and defining cultural distinctions.

Emotions are important to the ways that Hanna described how she evaluated the situation. Hanna described how it felt good to put her foot down in the face of the ' $u g l y$ gender thing'. It may very well be that similar actions by white Swedish male workers would have generated the same emotions in Hanna, causing her to take measures. Perhaps it would be more difficult to do so, and that the main difference in relation to sending the Indian employees home was the practical aspect of mobility: that it was possible to send 'the guys home'. Taken together, however, the constructions of cultural difference - the temporary presence of Indian workers and the managers' access to spaces outside the workplace - generate a situation where surveillance and discipline seem to take other forms, and seem to be morally justified in different ways for Indian workers than for Swedish employees.

\section{Indian labour in economic terms}

So far in this chapter, I have discussed how cultural difference is constructed as an essential aspect of the internationalisation that dominated the management talk and, more specifically, the management of labour in international supply chains. Indian workers were positioned within the Swedish IT industry in a number of different ways: through repertoires of scientific models of national cultures, through racialised notions of be- 
longing, and through the control and discipline of mobile labour. Furthermore, I discussed how these perceptions of Indian workers in relation to cultural difference were expressed within specific positions of a supply chain, and how they therefore rest on specific economic relations. In this section, I extend this discussion and illustrate the interrelations of cultural and economic notions of Indian workers.

In management discourse, cultural difference was often referred to in relation to management's desire for efficiency and productivity. Cultural difference was therefore categorised in relation to those aspects that were expected to bring value to the organisation, and to those aspects of culture that were considered to be problematic. However, these evaluations of cultural difference were also described as depending directly on the supply chain structure.

Jan: But with conflicts and problems in these projects, or with the clients, it's like this: it's always our fault. I mean, I'm sure it's like this in most situations where there is a supplier. If someone is responsible for a specific task it is much easier to put the blame downwards, or away, to wherever you rent your services from. [pause]

Karin: Yes. So you mean. It's not only about India but it's about the chain of production. That when it's outsourced it also creates a certain relationship between the client and...

Jan: Exactly. And a lot of the time, if we are close to a customer, and we have a lot of meetings with the customer, and we get all the information... if we don't communicate all that information [to the Indian team] so that everyone knows what's going on, then it turns into that they, as people, they are like this...

In this quote, Jan positions himself as part of the supplier and described how blame, if a project doesn't progress in a desirable way, is passed on 'downwards, or away' in a supply chain. According to Jan, this position in the supply chain coincides with the position that Indians usually take as part of the supplier, and may have the effect of portraying Indians as people who 'are like this'. Highlighting the asymmetric organisational relations rather than the cultural relations, Jan also differentiated between himself as a supplier, and the Indian team as a supplier. Jan explains that a lack of information between a Swedish team that is 'close' to the customer, and an Indian team that is further away, contributes to a situation where Indian workers are portrayed as the problem. In this quote, Jan describes how being Indian therefore coincides with inhabiting a position 'downwards, or away' in a supply chain, both in relation to customers and Swedish teams, which reinforces notions of difference. The main consequence of this co-constitution of organisation and internationalisation is how the position of Indian workers in the IT industry systematically coin- 
cides with a distant position in the supply chain, mirroring Wallerstein's conceptualisation of a periphery (Wallerstein 2000). These relations cannot be understood as the result of either the cultural construction of the group 'Indians', or an organisational differentiation and asymmetry they need to be understood as integrated processes of culture and economy. Here, there is a loyalty between the manager of a supplying company and the Indian workers regarding any unfair evaluations that he observes. From his position in the supply chain, Jan criticises the amoral relations of responsibility and blame that characterise the economic relations between clients and their Indian teams.

The organisational differentiation within a supply chain is one aspect of the economy that I analyse in this thesis; an analysis that is centred on the managers' accounts. When interpretative resources that concerned aspects of the economy were used, this pointed to a more complex way of understanding differences and similarities between economic regions and groups of workers than in those situations when managers only referred to national cultures. While Lars, whom I have referred to earlier in this chapter, explained the model of cultural difference to me, he elaborated on how the difference between 'live to work' or 'work to live' should be understood.

Lars: I would explain it like this, that the Indians live much more competitive lives. They want to show off, or show to colleagues that they are good. And in societies that are a little more insecure, with employment that...where it is easier to lose one's job, then you have to show that you can do it. This is one of the reasons that they work long hours. You should be at the office before the boss comes, and leave after the boss leaves and this kind of thinking. And us Swedes, we don't think like that. We are more laid back - we have the trade union and everything, MBL, [the Swedish co-determination act for working life]. It is almost difficult for companies to get rid of people, the way it is today, you could say. Well compared to India anyway. And we are not at all as driven [as the Indians] - that's the difference too, what it says there: live to work work to live. Then we are more work to live.

As the social and economic contexts in which Indian IT workers are recruited are brought into the repertoire of national cultural difference, cultural traits such as competitiveness are no longer considered natural and stable aspects of culture. Lars highlights the insecurity of Indian labour markets, and the expectations of long working hours and the tough demands on the individual worker point at how the dominant interpretative repertoires of cultural difference cloud the potential recognition of inequalities. The celebration of Indian working culture that dominates the management discourse and is said to bring value to the service pro- 
duction, is also a reflection of economic global differentiation. Although there are many organisational processes in which managers manage difference - for instance as they attempt to overcome difference, mediate difference, discipline difference, or reproduce difference - the wider social context of the differences between India and Sweden presents difference as a structural prerequisite for the organisation of the industry. I return to this theme in the next section.

The presence of Indian workers in the Swedish IT industry can be constructed around cultural difference and can represent a moral economy as long as political or economic power relations are excluded from the interpretative repertoires. In this sense, cultural difference can be used as a resource to indicate tolerance and economic efficiency in IT companies, rather than indicating transnational inequalities.

\section{Economic spaces - negotiating the differences between Sweden and India}

The theoretical framework of global chains of production, or supply chains that link up labour from India to companies in Sweden, includes notions of space in the analyses. It does so by focusing not only on how Swedish and Indian labour is presented in management discourse, but also how this relates to the ways in which Sweden and India are positioned in these discourses. Several of the managers I talked to discussed how India was becoming expensive, and how the difference in terms of costs between Sweden and India was decreasing.

Jan: My company is right now looking into the Philippines. We are also looking at China and so on.

Karin: Mm...

Jan: That's in order to meet competition. All our competitors use offshore in their business design. If you have a large customer, a procurement, then, well it depends on the business, but you might need at least $70 \%$ offshoring. $70 \%$ of your workforce offshore. And the price tag, it increases also offshore. So you will have to start looking long term at other places. Inflation in India is calculated at 6\%. Well, we take that into account.

Karin: Yes, that's a lot...

Jan: Yes. And many deals, like one we are working on right now, that's a five-year agreement. $6 \%$ in five years, that hits pretty hard.

Jan described how his company is searching for new offshore territories because India is becoming too expensive. According to Jan, there needs to be a significant difference in costs between Sweden and an offshore location, and inflation seems to threaten this difference with India. These 
descriptions mirror David Harvey's (2001) analyses of how a capitalist search for new locations generates the global expansion of production; the time-space compression of globalisation.

Managing a supplier's business strategies also includes the work of finding, defining, and marketing the places where labour is available. Prior to my interview with the manager Andréas, I looked for information on his company's website and found a notice about clients who visited a city in India that is well-known for its IT industry. On the website, I also found the names of representatives from the Swedish branch of the supplying company that Andréas worked for.

Karin: These trips. Is this something that you normally do, that you offer...

Andréas: Yes, just like I said before. To take it down from being about all these people to being about real people. See them, talk to them, touch them, listen to what they have accomplished. See Indians, see their inspiration and their passion. I mean, we have a 100\% conversion if we take a customer to India, we sell.

Andréas described the customers' trips to India as an experience of getting to know India and the Indian workers. He described these processes in rather intimate language, and argued that the trips were an opportunity for customers to understand the emotional aspects of the Indian workers' work - their inspiration and passion. Getting to know Indians as 'real' people, which Andréas emphasises as an opportunity for Swedish clients visiting India, aligns with the understanding of cultural difference, and the possibilities of overcoming difference, presented earlier in this chapter. However, in Andréas' account, visiting India was not only about meeting specific people who were engaged in the project:

Karin: But, how are these trips organised. I mean ...

Andréas: Well, I might be a control freak. But it should, this kind of trip should be a one hundred percent altogether positive experience. Everything. So I'm extremely detailed about that. But I believe in that, so I do it. If the car is supposed to come at 11.15 it should be there at 11.15 sharp. This could be a bit of an exaggeration, ok, but this is really dangerous, right! Because if you go there and you get the impression that nothing works... everything should work! And well, it's a country where the car might not show up at 11.15, but at 11.45, and that's just something that happens, with traffic and all. But that's not an option. The clients need to get the impression that everything works.

To Andréas, the practice of marketing Indian labour involves an active representation of space; for instance by presenting the Indian city as reliable, and by managing that impression in relation to the prospective cli- 
ents. Andréas describes his own work during these customer trips as that of controlling and creating a spatial context that produces the client's imaginations of labour as being reliable and functional. The importance of perceptions and fantasies about labour has been documented in previous studies about service work (see e.g. Mulinari 2007) and does not mean that these images are false, but rather that they are aspects of how workers are valued for specific types of jobs. In relation to a supply chain analysis, the imaginations that Andréas sells can also be understood as a more specific type of management practice than that of influencing the consumption of services. As a supplier of labour, Andréas' representation of India affects the mobilisation of labour within the supply chains. This is particularly interesting if we adopt a perspective on management talk as a practice (Wetherell and Potter 1992) that not only markets and sells but also manipulates and manages national and regional differences of labour. When space and workers are represented in certain ways during customer trips, these management acts are likely to affect not only the performance of labour, but also the expectations of the Indian workers, whether similar to or different from Swedish workers.

Critical theories of globalisation, space, and networks often propose the exploitation of labour as being partly related to the relative spatial fixity of workers (Harvey 2001) or of 'the little people' (Boltanski and Chiapello 2005). Whether temporary Indian labour in Sweden is perceived as being fixed or mobile in the management discourse is not obvious in the managers' accounts. Although the presence of Indian workers at Swedish offices does seem to require certain administrative actions from my informants, they consider the relocation of workers as a mere side-effect of economic integration. As Indian workers travel to Sweden they cease to contribute to the substantially lower costs that managers say the industry wants. Despite the increased presence of Indian workers in Sweden, the need for labour to remain in spaces that maintain a relative difference in terms of costs, may therefore indicate that labour is seen as being relatively 'fixed' in these supply chains, compared to the mobile and flexible companies and markets (Chiapello and Boltanski 2005).

In contrast to the importance of having Indian workers carry out the work in India to reduce the costs of production, the flexibility and mobility of companies and markets are also aspects of management discourse that have implications on how workers are valued. Sarah described how customers can think about where to locate service production:

Sarah: And I'm not saying that buying outsourcing services from India is buying a bad deal, but if you...you choose what to pay for a car and if you buy a Skoda then you can't expect a Ferrari or another car... It's con- 
nected with the price you pay, and you don't go back to Skoda and complain that this product doesn't have the capacity of a Ferrari because you know you didn't really buy...you didn't pay for it.

Although several of the managers I interviewed challenged this perspective and described how they struggled to improve the general image of Indian labour, this quote by Sarah illustrates a fixed notion of differences in terms of price and quality. The '[lower] price you pay' is presented as a feature of 'Indian services', which cannot be separated from the Indian labour that performs those services. Getting what you pay for, in this case Indian services, therefore establishes a difference between Swedish and Indian quality that is bound to 'stick' to the workers who move between different situations. At the same time, there is a discursive tension between (a slow) upgrading of Indian values relative to Swedish values, which is reflected not only in how managers are 'selling in' Indian workers, but also in the idea of Sweden as continuously developing a qualitative advantage in a spatially high position in the supply chain.

\section{Analysing absences - anxiety and the circulation of emotions}

Previously in this thesis I elaborated on the difficulties I had when I entered this field of research, for instance the large number of contacts who declined to participate in the study. So far, I have explained this 'silence' in the material as the management of labour being regarded as confidential within the supply chain. I have also analysed these silences in terms of the fragmented responsibilities of supply chain actors that cause some managers to deny that they have a role in relation to labour. In my analysis, the silences can be understood as the absence of certain possible interpretations or interpretative moves (Wetherell and Potter 1992) that are analysed in spite of some managers declining to participate in the study. Labour was also presented in abstract ways, as shown in the previous chapter, and was discussed as being secondary to the location and the design of production strategies. Most managers were reluctant to talk about specific working conditions. The topic of salaries represented a dead-end in the interviews, with the managers referring to how such information could not be discussed with outsiders, or else disregarding it as an individual issue:

Emma: No but, they are not cheaper when they are here - you have to remember that. That saves us no money. And we have collective agree- 
ments, so that should be enough I think. But it's complex with costs and we have no possibility of declaring numbers like that.

Jan: That's individual; it depends on seniority, just like for everyone else.

Early into my fieldwork, I read an article in a trade union magazine, which illustrated the phenomenon of temporary migration that I was interested in studying. The article was particularly interesting, since the temporary migration of Indian workers, and the specific conditions of their mobility, was generally difficult to address in the interviews. The article offered a point of reference that did not solely rest on managers' accounts. The journalist who wrote the article had interviewed several Indian IT specialists who worked temporarily at a large company in Sweden (Lundbäck 2010). The article concluded that information about the real compensation of Indian IT workers in Sweden is difficult to obtain, and that both companies and workers are very reluctant to talk about money (2010: 43). The avoidance of certain topics, and the absence of a certain type of talk in my material, was confirmed by this article. Yet there seemed to be more dimensions to the absence of certain topics. This is how the journalist described the interviews with some of the Indian workers:
With us is a woman from the communication department of the compa- ny. She wants to make sure that the purpose of the article is not to dis- close business secrets or depict [the company] as job thieves. Perhaps they have bad experiences from the USA where the advances of India in the IT area has caused bitterness among many Americans who have seen their jobs disappear to Indian IT cities such as Bangalore and Hydera- bad. We wouldn't want to cause a bad atmosphere, she says smiling.

This description reflects the same observations I made during the interviews concerning how my informants carefully managed their language and the topics, especially when the interviews addressed labour. The references to a potentially 'bad atmosphere', and the surveillance of information, seemed to be related to the experiences I had during my fieldwork. I interviewed the manager Anna, who was working for a large supplying corporation, and wanted to know more about what managers in the industry could not talk about:

Karin: When I ask these large companies, who I know work with a lot of people from India in the projects, they say that they don't want to talk about that in interviews...

Anna: Maybe I shouldn't be here talking to you either [laugh] [pause] No, but it's probably a bit...ugly...in a way. Still. It can very well be that we are helping to reduce the number of Swedish job opportunities, for 
sure, but on the other hand, we have even more...the market situation. You can't avoid it.

The laughter was followed by an awkward pause as Anna looked at me as though she really did hesitate about how she should continue speaking to me after what she said about offshoring and temporary labour migration being 'a bit ugly'. These associations kept recurring in my interviews, as these two quotes illustrate:

\section{Andréas: You have to be careful sometimes when it comes to offshoring,} that it is a bit of a sensitive subject to some folks.

Roger: Well we have to know how to bring it up so that we avoid stirring up any emotions unnecessarily.

The managers described a sense of threat in relation to offshoring. Yet they often ascribed the experience of such a threat to others; to those for whom this is sensitive and to those who are afraid that Swedish jobs will disappear. There was an awareness of emotions among the managers; emotions that could perhaps be best represented by a broad definition of anxiety. Andréas and Roger related to these anxious emotions in even more specific ways by acknowledging how they attempted to manage their reactions by being careful or thinking about how they talked about offshoring.

The avoidance of anxious feelings seemed to explain much of the silences in my interviews around Indian labour, and why labour migration was almost exclusively addressed in terms of internationalisation and cultural difference. Yet anxious emotions, especially as they were never described as the feelings of the person who was talking but rather the anxiety of others, was a difficult theme to analyse. How can one ask follow-up questions, or find definitions for this anxiety through interviews? Like several other theorists in the field of affect theory, feminist and postcolonial researcher Sara Ahmed is interested in what feelings do rather than what they are (Ahmed 2004a: 9). 'In my model of sociality', Ahmed writes, 'I suggest that emotions create the very effect of the surfaces and boundaries that allow us to distinguish an inside and an outside in the first place' (2004a: 10). Ahmed directs our attention towards thinking about emotion, like all action she says, as reaction. The processes she focuses on in her affective analyses are the processes that act upon, that affect, something. The subtle emotions of anxiety referred to in the managers' quotes above can be thought to further enforce the boundaries between Sweden and the outside, between Swedish jobs and other jobs, between Swedes and Indians. I experienced these boundaries during my fieldwork, 
especially as I crossed them by asking uncomfortable questions, although they were not acknowledged through discussion.

With the help of Sara Ahmed, if we think about anxiety as a feeling that circulates in the Swedish IT industry, where internationalisation is accelerating, then it is the movement - the ways in which these feelings of a vague threat pass by - that reproduces the emotion. Yet these feelings do not affect all subjects in the same way. Anxiety is likely to stick to certain subjects, to 'Indians' for instance, who come to represent the threat of economic restructuring. This perspective on the theorisation of emotions, which Sara Ahmed presents, extends a notion of a moral economy to incorporate not only the ways in which right and wrong are explicitly expressed in management talk, but also the feelings that cause certain topics to be avoided; to be left in silence.

Moral economy is a useful framework in this analysis since it points out how emotions not only circulate but are also included in management discourse as something that can be actively managed. The managers are aware of, and attempt to address, emotional reactions in their practice as managers. The moral negotiations of the economic arrangements can therefore be understood as on-going. However, the threat of a 'bad atmosphere', the fear of causing discomfort or stirring up emotions, also indicates that the internationalisation of today's Swedish IT industry is not characterised by acute or heated emotions, but rather by the latent and underlying risks of discomfort and potential negative economic effects.

\section{Managing emotions and navigating anxiety in the New Economy}

Managing emotions was a prominent theme in my interview with the Swedish manager Andréas. During the past few years, he had given a great deal of thought to how a transition towards global delivery could be handled smoothly in relation to Swedish staff:

Andréas: We have a unit in the US [...] if you look back, I have tried to learn a lot from them, if you look back five years, or maybe seven years, when they started with global delivery, much with India, then they had problems with their employees. You think, or I think, preconceived opinions [about] the US, everything there is like, they are multi global, they like other cultures. But they have huge problems with their employees. Like, 'no I DON'T want to do this, [they] will take our jobs'. What we see now is that the US is stronger than ever, they are greater in terms of numbers of American employees, and they make more money than ever. And they say themselves that without this opportunity to compete in different fields than the competitors they would have been totally over. So that is somehow, why we do this. And where do I want 
to get with this really... No, but I think this is a good foundation for our discussion...

Andréas argued that the fear that American employees felt in the face of the threat of global delivery was irrational, since only embracing internationalisation can overcome economic failure. Viewing others' fears as irrational, Andréas uses interpretative resources of the nature of the market, more specifically of competition. He also refers to the notion of a bigger picture, seeing the future of jobs rather than the potential loss of individual jobs. Emotions are seen as something that can be countered with the arguments of progress and market growth, where the boundaries are not drawn between jobs in different regions of the world, but rather between different corporations. Andréas described the same 'failing logic' in Sweden:

\begin{abstract}
Andréas: We can't say that we don't have that challenge with our consultants, just like the Americans, that they stand up and say that this is wrong. They say, when you talk to each other, but we should have the jobs here. But ok, we could manage these ten jobs that we have here until there's one left. Ok, so that's fun. And I'm not saying that my colleagues are Sweden Democrats but it's the same, the logic fails. If we don't grow, we die. And that goes for companies, people and countries.
\end{abstract}

This interpretative repertoire of internationalisation rests upon notions of the economy and of progress. In relation to these economic developments, Andréas suggests that certain mind-sets and certain emotional responses are more suitable and functional than others. He emphasised that he was not saying that his colleagues were Sweden Democrats. I interpret this statement as establishing that being labelled as a Sweden Democrat - a Swedish, xenophobic/racist, nationalist political position is an unwanted recognition. But how can we understand the characterisation of the Swedish IT worker in this quote? Chris Haylett argues that the political notions of cultural hybridity and multiculturalism are grounded in an individualist culture and neoliberal economy (Haylett 2001: 365). Multiculturalism, Haylett continues, is performed and operates as capital for the middle class, partly by cultivating liberal views of 'ethnic others' (ibid.). Although Swedish IT workers do not represent an undervalued working class, the value of a cosmopolitan position is centred in Andréas' quote - and he wishes to extend the embrace of neoliberal globalisation to his colleagues. I position Andréas' ambivalence towards his colleagues' reluctance in the face of economic globalisation within this discourse of national multiculturalism and global cosmopolitanism. Racism and the fear of economic globalisation, or 'being a Sweden Democrat', are not 
compatible with being proper and respectable in the moral economy of internationalisation that Andréas, and the other managers, represent as they manage projects of global delivery. Andréas emphasised that the middle class he speaks about - his colleagues - are not determined to take such a position, but rather they are at risk of ending up outside cosmopolitanism by not fully embracing its ideals. The logic, Andréas continues, is the same, and is based on fear and the threat of competition from outside. In my interpretation, the failing logic that Andréas refers to is the inability to adapt to globalisation, and a mind-set that is characterised as being backwards or unmodern.

Craig Calhoun has addressed how cosmopolitan values rest on material ground as part of an ideology of economic globalisation (Calhoun 2007,2008 ). Andréas' statement, 'If we don't grow, we die. And that goes for companies, people and countries', creates a connection between global capitalism, global competition of nations, and competitive individualism. Calhoun reflects critically on how these discourses of cosmopolitanism have come to dominate the ethical, political, and sociological perspectives on globalisation. Although cosmopolitanism can mean many different things, it is generally a critique of particularistic or nationalistic notions of belonging (ibid.). Yet referring to cosmopolitanism often conceals what belonging would mean in such a version of citizenship and globalisation. 'The markets, the migrations, and the media that encourage and shape cosmopolitanism are not simply responses to individual taste or morality but creatures of capitalism', Calhoun continues (2008: 434). It is within this discourse of capitalism that a cosmopolitan mind-set, which does not acknowledge that globalisation may not be equally empowering to all people, and which may rest on economic inequalities, is regarded as the only moral position to take.

The silences regarding labour conditions, and the economic differences between Indian and Swedish workers in the managers' interviews, illustrate how the cosmopolitan subject position is constructed only in relation to culture. This can be analysed in the context of there being no possible subject position in these cosmopolitan interpretative repertoires that refuses to embrace the arrangements of internationalisation in the IT industry - or at least no subject position that can still be incorporated into the interpretative repertoire of a (globalised) moral economy. So, when there are potential clients or employees who resist offshoring, who want to keep 'Swedish jobs in Sweden', this gives rise to anxiety and ambivalence in relation to the status quo of the moral economy of cosmopolitanism. This can be illustrated by how the manager Hanna related to the increasing influence of offshoring within her company, and how she 
felt that she could understand her ambivalent feelings towards offshoring:

Hanna: I mean, I don't even know where I will be in a year, if they will be happy with my results. And my job could very well be one of those jobs disappearing.

The managers do not escape anxiety and worry in the face of economic restructurings, yet the strong encouragement to manage these emotions dominated the management discourse. The managers are positioned within complex global production networks in which management and business knowledge are concerned with understanding and legitimising the arrangements of capitalism and the locations where value is added within a framework of competition (Harvey 2000). Cosmopolitan values can be understood as an interpretative resource to legitimise the economic arrangements in the supply chain. There are similarities between the notions of cosmopolitan values and connexionist values. Taking an interest in management literature, Boltanski and Chiapello (2005) argue that managers in particular need to identify with the connexionist values of today's capitalism. In order to do so, the values must fulfil the desires for both autonomy and security - seemingly contradictory desires (ibid.). Yet it is within this contradictory notion of moral arrangements that we can understand the managers' arguments in relation to cosmopolitanism: that the consistent progress of global diversity will provide stability and security, while the ability of individuals to be flexible and mobile allows them the freedom to connect to new networks and new opportunities. The ways in which Andréas presented his arguments, with much passion and emotional investment, can be thought of as reflecting how he actively manages feelings in his own organisation. The mobility of Indian workers plays a central role in this emotion management.

\footnotetext{
Andréas: So you have to show that it works and, most of all, and it's the same thing with our clients... If you talk about India, India is like twelve hundred million [people], or thirteen hundred [million]. Well, those big numbers, they have to come down to Amit here. He is sitting here. Talk to Amit about what he does during the day. That is, you have to personalise the whole experience for both our employees and for customers.
}

In this quote, Andréas presents meeting with Indian workers as a situation in which negative emotions decrease; that Indian faces in the Swedish offices personalise an experience of internationalisation and make it less threatening. Although Andréas was unusually consistent in his rhetorical support of global integration, compared to some of the other 
managers, the importance of personal face-to-face meetings with Indian workers recurred in all of my interviews.

Although the mobility of workers was often considered a by-product of internationalisation in the managers' accounts, the moral economy in which differences between groups of workers needed to be explained and 'overcome', both organisationally and emotionally, is dependent of the presence of Indian workers in Sweden. 'Amit here' is used as a projection surface that reflects a central aspect of the work that managers do. While intellectuals and social scientists have viewed good arguments as the main tool for change, which could give managers an important role in affecting migration policy, emotions more often seem to explain the rapid shifts of what 'feels right' (Wetherell 2012: 141), or the lack of influence of such arguments (Berlant 2011). The value of Indian workers not only depends on the organisational and public work of managers to influence opinions one way or the other, it also depends on the larger structures of the economy and culture, which managers actively relate to, align with, or attempt to counter as they market Indian workers in Sweden.

In this chapter, I have discussed how cultural difference between Indian and Swedish organisations and workers constitute the dominant interpretative repertoire that morally justifies how managers work with offshoring and with global delivery. Their role in the supply chain is to calculate the costs and benefits of differences between India and Sweden, both in terms of culture and in terms of salaries. I have argued that the emphasis on cultural difference in management discourse has various effects, and presents Indian workers as inferior and as being particularly productive in the international IT industry, but also presents them to Swedish organisations as 'other'. Furthermore, the focus on culture has the effect of silencing arguments and interpretations of economic inequalities, what I have referred to as 'an interpretative repertoire of cosmopolitanism'. I argued that one aspect of the moral economy of Indian labour in the Swedish IT industry concerns the anxiety that economic competition and unequal benefits of globalisation give rise to. The managers need to manage these emotions by avoiding certain topics and by 'personalising' internationalisation through presenting and representing Indian workers.

In the next chapter, I summarise the analysis of the two case studies. Presenting the main points from both the wild berry industry and the IT industry allows me to discuss some dimensions of the moral economy of current migration politics that address both low-skilled and high-skilled workers. 



\section{Moral economies of temporary migration - concluding discussion}

In this concluding chapter, I begin by providing a short overview of the thesis so far, and then discuss the similarities and differences concerning the two case studies: the wild berry industry and the IT industry. Finally, I end the chapter by drawing some more general conclusions, and setting the study in a wider context. I especially focus on the importance of employers and managers in the study of temporary migration within a context of economic globalisation.

In the first chapter, I introduced the core of the thesis, focusing in particular on how the process of selecting and managing temporary migrant workers can be seen as a characteristic feature of current migration regimes in the EU and in Sweden. I presented the main aim of this thesis: to centre employer practices with a focus on how managers talk about temporary workers, and by doing this, to theorise about the economy of temporary labour migration. Through additional research questions I defined the aim of the thesis in relation to the moral dimensions of this labour economy by asking how managers in the Swedish wild berry industry and the Swedish IT industry justify their reliance on foreign workers.

In Chapter 2, I presented previous research that addressed the nexus of migration and citizenship in relation to labour migrants in general, and to temporary or circular migrants in particular. I described how citizenship is characterised by the processes of social inclusion and social exclusion that target different migrant groups in different ways in relation to shifting notions of who can be considered to be a valuable member of the citizenship community (Anderson 2013). I argued that the role of employers has been studied in relation to earlier systems of labour migration, but that current migration research tends to focus on a debate concerning the dominance of nation states or of transnational practices for defining migrant membership.

After presenting previous research on citizenship and migration politics, I introduced my theoretical framework in Chapter 3. In this chapter, I discussed theories that could facilitate a conceptualisation of employers and managers in relation to economic globalisation. I especially discussed theories of international production, and proposed how supply-chain 
capitalism represented a particularly suitable concept for understanding the structure of the recruitment, supervision, and management of temporary foreign workers in the Swedish wild berry industry and the Swedish IT industry. In this chapter, I also introduced 'moral economy' as a central theoretical concept to capture how practices of justification, based on notions of race, ethnicity, gender, or citizenship, for instance, are integrated with economic practices. Further, I discussed how I could approach the effects of the interactions between the practices of justification and economic logic when comparing certain groups of workers with others. Towards the end of the theoretical chapter, I considered the relation between language, which I referred to as 'management talk', and management practice. I discussed this in relation to the normative nature of moral economy compared to management discourse, as well as in relation to the role of emotions when trying to make sense of which economic arrangements are to be considered fair and right.

In Chapter 4, I described the ethnographic research process that led to finding informants for this study - my sources of information for the two case study industries - as well as finding the right concepts to work with regarding both economic processes and migration policy. I discussed whether studying 'up' constituted a dilemma in the research process, and how the informants' own concepts could be understood with regard to my research questions. I also described how the interviews were performed, and the analytical strategies that I used in order to make sense of the material. I described the specific approach I used to analyse the discourses by focusing on interpretative resources and repertoires in the managers' language as they talked about their industries, the migrant workers, and their own work as managers.

In the following sections I discuss the main themes in the analytical Chapters 5 to 8 , and consider management discourse in the two case studies together.

\section{The moral economy of managing temporary migrant workers}

In exploring how managers talk about workers from Thailand in the wild berry industry and workers from India in the IT industry, this study has attempted to develop an analytical framework that centres on the role of employers in migration processes. Managers, as employer representatives, are positioned differently due to both the particularities of the industries and the specific positions in the supply chain that they represent, 
as well as how they use interpretative resources of various kinds to make sense of their activities in relation to migrant workers.

Chapters 5 and 6 analyse the moral economy of managing temporary migrant workers in the wild berry industry, and Chapters 7 and 8 analyse these practices within the Swedish IT industry. In retrospect, this strategy of selecting two very different industries for my case studies, created certain difficulties in the general theoretical framework on the one hand, as they emphasised different issues. On the other hand, the strategy provided me with material that, when analysed, not only showed differences between the industries but also certain similarities. In this final chapter, I bring together some of the points from the two case studies to demonstrate variances and convergences of the global supply chains of two different sectors. I structure the discussion in short subsections through a set of themes from the analytical chapters that became central points for my arguments.

\section{Supply chains as the economic setting}

The supply chain structures of the two industries were prominent themes among the managers of both wild berry production and IT services. In fact, in both industries, managers emphasised how the presence of Thai or Indian workers could not be explained without an understanding of an on-going process of internationalisation, based on the processes of outsourcing. The emergence of these supply chains were however described in different ways.

In the wild berry industry, as the managers described, the Thai berry pickers themselves were the starting point for how the supply chain structure developed. Because Thai pickers had entered the seasonal wild berry labour market as pickers, through kinship and transnational networks, a new industry emerged. According to the berry company managers, the ability to manage Thai workers specifically, which was described as depending on gaining legitimacy in relation to regulations and policy makers as well as for the pickers themselves, constituted the main resources of supply chain success. In terms of the proportion of work permits that are issued in Swedish industries every year, the reliance on foreign workers in the IT industry is dominated by Indian nationals almost as much as the wild berry industry is dominated by Thai workers. However, in the IT industry, the management discourse did not specifically ascribe the emergence of supply chains to the role of Indian workers. Instead, managers talked more broadly about the processes of internationalisation and offshoring. Although the specific ability to manage Indian workers was a 
prominent theme in the interviews, which I return to in the section on cultural difference below, the framing of the supply chain in the management discourse did not disclose any references to specific nationalities or ethnicities in the IT industry. I argue that this difference of emphasis on ethnicity, nationality, and race can be understood in relation to the different identities that computer specialists and berry pickers are given in relation to class. This is discussed further below.

The managers who participated in this study represented suppliers who sold berries or IT services to distributors or clients. There were many similarities in how these relations were described in the two cases. First, these managers described the distributors of wild berries, as well as the companies who bought IT services or manpower, as being detached from the moral responsibility for, or interest in, the workers. This constituted a moral theme in the wild berry industry, where berry company managers advocated the increased accountability of the distributors. In the IT industry, the managers talked less explicitly about these relations. Instead, the detachment of the clients from labour and from the working conditions was presented as a legitimate position inherent in the supply chain. These relations also defined the role of the managers in the supplying companies: they sold services and workers' labour. Managers of suppliers in both industries expressed loyalty with subcontractors both in Thailand and in India. Asymmetric relations were also made visible as the managers described the difficulties for subcontractors in Thailand or India to gain legitimacy in relation to Swedish actors. The managers further described how they were dependent on functional cooperation with their partners in Thailand or India, yet they were also dependent on the demarcation of a certain niche in the global economy. Their knowledge about the Swedish market, and their ability to sell the labour of Indian or Thai workers in a respectable manner, provided a foundation for their role in the supply chains. This also identified tensions in the material since temporary workers were portrayed as having a greater or lesser value than Swedish workers, or being more or less a 'perfect match' with the Swedish labour market, depending on which position in the supply chain managers referred to.

In relation to both these industries, it was apparent that the supplying companies had an interest in participating in a study of the presence of Thai and Indian workers in the Swedish labour market. This was in contrast to the representatives of the wild berry distributors and the IT clients who declined offers to participate. To my informants, these workers represented a commodity that needed to be marketed. The managers of the berry companies were dependent on describing Thai berry pickers as particularly suitable for labour in the Swedish wild berry industry in order 
to legitimise favourable state regulation. The managers of the supplying companies in the IT industry, on the other hand, had an interest in increasing the value of Indian workers, particularly among potential clients in order to increase their market for offshoring. Thus, the interpretative repertoires of the moral economy that I observed had, to some extent, different intended audiences in the two case studies: for wild berry managers, the audience was policymakers and the media, while for the managers in the IT industry the audience was mainly other Swedish actors in the industry.

Managers in both these industries emphasised economic transnational connections when they described their investment in functioning supply chains. In both these industries, the activities of the Thai and Indian workers matched the organisational and economic efforts of their managers. This had implications for how the mobility of the workers came to be a secondary issue for these supply chains, rather than a central component in the development of international production. In the management discourse, the emphasis on this transnational match abstracted the notions of relocation or travelling and what that meant for individual workers; neither the Thai berry pickers nor the Indian computer specialists were talked about as migrants.

\section{Constructions of mobility: circulation and possibilities of moving 'up'}

Managers avoided seeing the Thai berry pickers and the Indian computer specialists as migrants, and this was one of the strongest themes of the analysis in this thesis. I have presented how managers talked about the presence of Thai berry pickers in Sweden as a practice that filled a void for them in relation to their economic activities in Thailand. Within an interpretative repertoire that, in practice, corresponded to the discourse of circular migration, the mobility of workers was viewed as being perfectly integrated with their lives in Thailand, both in terms of breadwinning and of reproduction. In Chapter 6, I engaged critically with this perception of mobility, since it also has the effect of obscuring an understanding of migrant vulnerability. Within the IT industry, the temporary mobility of Indian IT workers was not talked about as 'circular migration' but as a symptom of increased offshoring of IT services in Sweden, which I analysed as a management focus on internationalisation, and discussed later in Chapters 7 and 8. The effect was that Indian computer specialists were not viewed as migrants but were assumed to represent Indian labour or to represent an Indian office when they were in Sweden. 
In relation to both case studies, mobility rather than migration provided a terminology that was easier to integrate with the analysis. Furthermore, the emphasis on the temporary character of this mobility had the effect of positioning both Indian and Thai workers outside the "normal' Swedish labour market. When IT managers talked about the common features of Swedish and Indian workers, the interpretative repertoire of internationalisation characterised all workers as being included in this global workforce (compare Kofman 2013). Still, when managers talked about the organisational challenges of offshoring it was clear that most of the Indian workers were seen as 'belonging' in India. Globalisation did not mainly define the workers, it also defined the identity of the supply chain network. Thai berry pickers were exclusively viewed as exceptions to the Swedish labour market and were not included in any discourse of globalisation; they were instead included as part of the specific transnational relation between Norrland (the northern part of Sweden) and the rural regions of Thailand, where most of them came from. This exception to the Swedish labour market characterised Thai berry picking as something other than a migration phenomenon linked to issues of citizenship and inclusion, and thus ruled out that this mobility might have wider social implications for Sweden. Similarly, the mobility of Indian computer specialists was viewed as a practice within organisations rather than within wider social or cultural contexts, and hence was not talked about as a phenomenon that was affected by citizenship differentiation. Thus, in both case studies, citizenship and citizenship rights were firmly connected with being Thai or Indian.

Within the discourse of circular migration, which corresponded to how the managers perceived the mobility of Thai berry pickers, there was an emphasis on the development and upward mobility of the migrant workers. Managers often pointed out how berry pickers invested the money they earned in order to have a better life. Still, their circulation was assumed to be on-going and a continuing process; there was an expectation that the berry pickers would return to Sweden year after year. In contrast, the mobility of Indian computer specialists was seen as something that was likely to change for the individual. According to the managers, IT workers' international experience leads to socio-economic mobility in terms of improved careers. Therefore, although Thai berry pickers as well as Indian computer specialists are positioned outside the 'normal' Swedish labour market, and though both groups are far removed from Swedish citizenship rights, they are situated differently in relation to mobility within the global economy. 


\section{Constitutive diversity: culture, race, gender and nations}

Anna Tsing $(2012,2015)$ argues that capitalism is constituted by diversity; the exploitation of non-work identities and the complexity of difference between workers is not an exemption from a normal system of production, but rather a prerequisite for its reproduction. In supply-chain capitalism, Tsing argues, the niche structure of the economy and of labour is enhanced (2012). This type of diversity also comprised the central themes in the interviews with managers from both the wild berry and the IT industry, as they explained the role of foreign labour in relation to the particular niche that they worked in.

The supervision and management of Thai and Indian labour was explained with references to specific aspects of their cultures. Management knowledge about these cultures was described as being prerequisite for a successful match between Thai or Indian workers and the Swedish labour market. Cultural difference in relation to Thai berry pickers was constructed as absolute, and was used to explain how inclusion in the normal Swedish labour market was not possible. Paired with the racialised notions of Thai workers being physically suited to berry picking, as well as references to the lives of Thai peasants who could not fit into Swedish life styles, these workers were consistently identified as belonging to Thailand. The focus on culture in the IT industry was a prominent theme, yet was more ambivalent in terms of difference. Through a cosmopolitan interpretative repertoire which targeted the chauvinism of all cultures in the organisational internationalisation process and supply chain cooperation, both Indian and Swedish workers were perceived as being potentially included in a global labour market. In relation to the Swedish workplace, however, the perception of race and difference in terms of gendered cultural identities constituted ways in which managers did mark a difference and did point out obstacles to the inclusion of Indian workers. Several differences between Indian and Swedish workers that the managers labelled as 'cultural' also referred to different expectations regarding work and the economies of India and Sweden. The good work ethic and long working hours, which managers ascribed to Indian workers as positive values, made visible a spatial difference and an asymmetry between expectations and standards in India compared with Sweden.

The construction of diversity did not only concern labour but also concerned the different geographical spaces involved with the supply chains. The differences between Sweden and Thailand or India were central components in the moral economy of both berry picking and IT work, although in different ways. Working groups of Thai berry pickers were talked about as having a matching, permanent life in Thailand. The con- 
dition under which they were in Sweden could only be justified as long as they were in circulation. In general, berry pickers were viewed as being so different to workers in Sweden that relatively little surveillance of their migration was needed. This was perceived as a positive value when mobilising them as labour. The social notions of where Thai workers fitted in were however made more ambivalent in relation to the gendered aspects of mobility. Female Thai berry pickers were, for instance, thought of as potential subjects of marriage or partnership in Sweden, which therefore required a particular kind of control and surveillance. The lower cost of IT services in India was the foundation of the arrangements in the IT industry. Therefore, the differences between these two geographical locations were apparent in how the managers talked about labour at a more general level. Individual Indian workers were, however, not seen as belonging permanently in India in any way comparable to the way that Thai workers belonged to Thailand. Within the cosmopolitan interpretative repertoire, the ability to overcome cultural difference was seen as a personal skill that allowed workers to transcend differences and geographical locations, for instance by building an international career or moving to the US. Managers in the Swedish IT industry did not talk about control or surveillance of the Indian workers in terms of their mobility. This can be understood in relation to how managers talked about the migration control of workers - who were only mobile within an international organisational structure - as illegitimate. They also argued that Indian workers who worked in Sweden for longer periods had earned this opportunity through a moral system of a working life meritocracy. In summary, it was possible for computer specialists from India to transcend socio-economic differences of class when working in Sweden, but it was not possible for the Thai berry pickers to overcome these differences, except, perhaps, through marriage or partnership.

The articulation of differences also generated, and was generated by, emotions when managers talked about the Thai and Indian workers. A sense of entitlement in relation to asymmetric relations between Sweden and other regions, were for instance based on the recognition of cultural difference in the IT industry where Indian workers were talked about as being less autonomous than Swedish workers. Feelings of empathy were emphasised when managers argued that what the Thai workers wanted in order to improve their lives could never be compared with what Swedish people appreciated, but that they, as managers, were able to see things from a Thai perspective. In order to analyse the role of emotions, the theoretical framework of moral economy was essential.

In contrast to studies of moral economy that found how different moral attitudes corresponded to middle or working classes within na- 
tions (Sayer 2005; Svallfors 2006), or in relation to the moral legitimacy of white privilege (Garner 2015), or attitudes towards migrants (Lamont 2000), the perspective on transnational supply chains emphasises fragmentation rather than continuity. A consequence of this is that a supply chain perspective gives rise to a certain decentralisation of a moral economy. When analysing certain themes I have observed differences based on race or colonial 'othering', for instance when IT managers talked about the workplace in a way that made visible how Indian computer specialists were made into 'others' in relation to their appearance, or how the Thai body was described as particularly suitable for hard labour. I have also observed how asymmetric socio-economic differences were constructed as static and natural, especially in relation to Thailand but also to some extent in relation to India. However, the economic transactions of labour and compensation, and the negotiations around working conditions and the value of a service, also change these relations. In both the wild berry industry and the IT industry, I observed how management discourse could not be reduced to devaluing racial or national 'others'. Several managers did, for instance, talk about India as a region that could no longer be regarded as backward and traditional compared with Western countries. With regard to Thai berry pickers, the managers argued for the support of the Thai workers' own preferences in both regulations and the supply chain arrangements, which can be thought of as an alignment with discourses of empowerment. In the IT industry, some of the managers actively worked to support the legitimacy of Indian labour in terms of gaining a more dominant position than Swedish labour in the global market.

In my material, the relational identities in the moral economy are mediated through arrangements of production and highlight themes of fragmentation and temporary conditions rather than the reproduction of class or race within a specific geographical setting. Margaret Wetherell points out how class identities today, and the emotions that structure feelings of right and wrong, cannot be reduced to stable histories: 'As mobility and globalisation have increased, it has become more evident that many social actors, even those traditionally seen as the most fixed in place such as English, white, working class [...] live within a nexus of exceedingly complicated intersections between resources, histories, futures, investments and identifications' (Wetherell 2012: 117). Temporary migration, as discussed in this thesis, is a relatively new and growing phenomenon in Sweden, and it is unlikely that the emotional structures through which citizens judge whether temporary migrants belong to, or deserve a place in, the Swedish labour market, are straightforward and unequivocal. In the same way, evaluating the compliance or non-adherence of temporary 
migrant workers is also complex, and in different situations the moral response is likely to be different.

The role of employers and capital in structuring discourses on the relations between, for instance, Swedish workers and 'temporary migrant workers' or 'foreign workers', is particularly important in order to understand how these relations are not only the result of immanent moralities among, for instance, Swedish blue collar workers or knowledge workers. In my analysis, I have observed how managers intervene in moral relations between groups of workers by justifying some differences and challenging others. The ways in which management discourse positions Swedish workers and foreign workers in relation to value and in relation to the future of the global economy, is structured around complex intersections on what is being valued: for instance, hard labour (see Chapter 6 and 7), cultures (Chapters 6 and 8), gender identities (Chapters 6 and 8), and cosmopolitan ambitions (Chapter 8).

\section{Precarity as the normal condition}

So far in this concluding discussion, I have argued that the temporary mobility of Thai berry pickers and Indian IT workers satisfies particular niches in the economy. In relation to the wild berry industry, with small economic margins along most of the supply chains, this niche of sub-standard conditions, hard work, and favourable regulations, makes it worthwhile to make a long and costly trip for a relatively short season. In relation to the computer specialists, the dominance of India in the structure of global offshoring makes it worth the organisational difficulties of merging cultures and languages. So, do these niches of temporary labour represent especially precarious labour circumstances? The outsourcing of labour in supply chains is, in itself, an indicator of a transformation towards greater informalisation - more informal ways of working - where fewer jobs are characterised by permanent contracts, full-time pay, and stable conditions. Outsourcing can also create precarious labour within the framework of citizenship. However, the arrangements of temporary migration within this supply chain structure of labour may contribute to informalisation in different and additional ways. In the wild berry industry, the temporary labour migration of Thai workers contributed to an expansion of the industry, and hence also contributed to the incorporation of these hyper-flexible systems of labour into the heart of production. Similarly, several managers that I interviewed in the IT industry described how institutional conditions of labour in India provided more flexibility - with the downside of higher turnover rates of staff - which, as 
offshoring grew as a phenomenon, affected a larger portion of the global industry. The IT industry, being large and varied, is likely to be affected in more diverse ways by transnational supply chain networks and outsourced labour.

The temporary situation of Thai and Indian workers can, although its effect on the labour market at large is ambiguous, be associated with precarious conditions for these workers. In regards to berry pickers, the supply-chain structure of temporary migration incorporates the normality of over-exploitation in the global South (Räthzel et al. 2014: 274), also within the parts of Swedish industries that in no way represent 'bad examples'. The Thai workers invested greatly in travel, and were, at least partly, dependent on their employers for all types of everyday needs in Sweden, for instance, medical needs, commuting, food, and housing. To some extent, the Indian IT workers were also vulnerable to their employers' control when they were in Sweden, for instance, because their employers arranged their housing and supervised their cultural integration at the office. Still, from a global perspective, Indian computer specialists cannot be regarded as a generally precarious group of workers. Rather than defining the absolute borders around specific groups of workers as a 'precariat' (Standing 2011), precarity can be understood as an ambivalent state that restructures relations. 'Precarity is the condition of being vulnerable to others. Unpredictable encounters transform us; we are not in control, even of ourselves', Tsing argues (2015: 16). In relation to the IT industry I analysed the emotions generated by such a precarity in relation to an anxiety in the face of global competition, and in the wild berry industry this vulnerability could be seen in the reactions towards a poverty that was not considered to be 'part of' the Swedish society.

Precarity, as a concept, can be used as a way of articulating experiences in the global economy rather than exploitation linked to specific labour markets (Bak Jørgensen 2016). Rather than simply affecting Swedish labour or the Swedish labour market, temporary labour migration in Sweden, and especially the supply chain structure of these arrangements, creates new entanglements in which more people become vulnerable to changes in different parts of the world. This precarity is also structured by how accountability and responsibility in relation to distant spaces are more difficult to define and more difficult to expect (Massey 2005). 


\section{The absence of discussions about citizenship}

In this study I have shown how managers generally do not mention citizenship or social rights, and they avoid defining Thai berry pickers and Indian computer specialists as migrants. The analytical approach of discourse psychology has been important for understanding how issues of citizenship and exclusion are removed from the relations between employers and migrant workers. In relation to both Thai berry pickers and Indian computer specialists, managers consistently emphasised the temporary character of their labour. The managers viewed this as a situation that explained and legitimised the notion that these workers could not be considered part of the Swedish labour market, and that their conditions could not be assessed in relation to the general working conditions in Sweden. These temporary workers were instead viewed as belonging to other national labour markets - in Thailand or India. Hence, these analyses allowed me to link management discourse back to how these workers were viewed as different from Swedish labour.

Because most temporary migrant workers are unlikely to be represented by Swedish trade unions (Neergaard 2015) there are very few arguments from worker representatives to counter the images of a smooth integration of worker mobility into the economy. In Chapter 6, I showed how visions of the perfect match between berry pickers' own desires and the structure of the Swedish wild berry industry were ambivalent and ambiguous, since some pickers needed to be screened and controlled for their motives to be in Sweden. This indicated that the discourse suggesting that circular migration was natural depended on the berry companies' active management and supervision of the workers. In Chapter 8, I showed how the asymmetric economic arrangements between India and Sweden were not mentioned in management discourse. This omission had the effect that these discourses were unable to explain ambivalent feelings in the face of internationalisation, for instance the fear of losing jobs to low-cost countries. In both case studies, I analysed how employer representatives are central actors in terms of describing and defining temporary labour migration, both in relation to the public and in relation to other supply chain actors.

Seemingly, employers and managers often share the standpoint of migrant workers in the face of state regulations and citizenship regimes. Exemplifying such relations, as shown in Chapter 5, the managers in the wild berry industry argue that it would be unfair to impose social fees or tax on migrant berry pickers, because the temporary workers cannot benefit from such social insurance. These exceptions are what make labour arrangements possible in the industry and they are therefore also in the 
interest of migrant workers. As another example, the work to counter the prejudices against Indian computer specialists in Sweden, which managers in the IT industry described as a central aspect of their work, is also likely to be in line with the Indian workers' interests of increasing the value of Indian services. Investigating how this potential agreement between migrants' and employers' standpoints is structured avoids reducing such results to actual shared interests. Instead, a critique of both the management arguments and their wider social and economic context points to ambivalences rather than straight alignment between the different positions. Although the commitment to cosmopolitanism, empowerment and tolerance may be convincing in the management discourses, they can be critiqued if we instead study the absence of any reference to equality. In relation to both the industries in this study, the supply chain structures in which workers are expected to be located in Thailand or India, for the most part, may not allow the seemingly compliant berry pickers and computer specialists to imagine possibilities other than temporary work under relatively precarious conditions.

As the idea of open borders often corresponded with how migrant workers expressed their interests, this alignment between positions did, in itself, lend moral legitimacy to the employers' arguments in my material. One of the central findings of this dissertation is how the management discourses, by referring to the temporary character of the migrants' work in Sweden, justified how the migrants were situated outside the real Swedish labour market, as well as outside Swedish citizenship rights. The managers in the berry industry argued that no other groups wanted to perform the work that Thai berry pickers did. The managers in the IT industry argued that the presence of Indian computer specialists in Sweden was not only good for the companies but was also good for Swedish workers as it reflected a global restructuring rather than an intervention in the Swedish labour market.

Some migration scholars have argued that migrant situations are not best represented by references to a lack of national membership, but rather by references to transnational inclusion (Soysal 1994). This perspective supports the argument that migrants' exclusion from citizenship rights is not problematic for all groups of migrants. Temporary labour migrants, in particular, may be in a situation in which transnational inclusion is central to how they go about their working lives. So, what could the role of employers be in relation to transnational inclusion, and what is the make-up of this type of transnational identification in management discourse? The Swedish managers in the wild berry industry emphasise how they account for the culture and the preferences of workers who travel from Thailand to Sweden, as described in Chapter 6. They further- 
more explain how they engage in transnational relations through their negotiations with other supply chain actors regarding terms and conditions, and through their appreciation of the Thai way of life, which their business requires from them in order to mobilise labour. The managers in the Swedish IT industry describe how their work of internationalising the industry, as described in Chapter 7 , creates the setting in which Indian computer specialists structure their careers as well as organise their visits to Sweden. In summary, the managers describe how they are involved in transnational practices within supply-chain capitalism; an arrangement where the migrants are key figures. Hence, the managers in my case studies view temporary migrant workers in relation to transnational inclusion in the economy of supply chains, thus replacing notions of citizenship.

By referring to citizenship discussions, what problems could there be in concluding that migrant and employer interests converge? If the migrants' exclusion from national citizenship, which temporary migrants experience, and which is both justified by managers and described as unproblematic because it matches the migrants' preferences, then their exclusion from social rights in the country in which they work must also be seen as unproblematic. We could imagine transnational institutions supporting this transnational alignment of industry and migrant lives, thus ensuring social and cultural rights for migrant workers in a post-national space (Soysal 1994). Yet there has been criticism directed towards the academic emphasis on the increased importance of human rights and universal values, because these cannot be ascribed to any specific, accountable actors or institutions, such as those belonging to the state.

In relation to my case studies, I furthermore find that the similarities between the transnational identities that managers describe in relation to their businesses and the migrants, are perhaps better conceptualised with reference to transnational supply-chain capitalism than to increasingly post-national spaces of universal notions of citizenship and membership. Work within supply-chain capitalism is characterised by flexibility and instability (Tsing 2012). Thus, transnational identities, which may be formed by non-work-related cultural traditions, or by the reproductive arrangements among Thai or Indian workers concerning who cares for children and households during periods spent abroad, are incorporated in the perception that these workers are especially suitable for temporary work in other countries. Through this interpretation, for instance how a focus on farming and kinship in Thai villages presents them as being inclined to travel to the Swedish berry season (Chapter 6), or how Indian culture is portrayed as convenient for international cooperation (Chapter 8), the temporary work comes to represent a certain niche, reserved for 
certain workers in the global labour force, in which insecure conditions are the norm.

The transnational identities and inclusion that managers describe cannot, however, be dismissed as false, and it does not seem controversial to think that temporary migrant workers do indeed have an interest in accessing the labour market. Understanding temporary migration as part of the labour that migrant workers need to sell, however, makes notions of compliance and shared interests appear more complex. The results of this thesis point out how studying employers in migration research requires that economic relations are clearly conceptualised and not placed at the margins of the analysis. While managers view migrant workers as being included in a global economy, migrants are not necessarily seen as subjects of universal, as opposed to national, membership. The managers in the wild berry industry situated Thai workers within a context of Thai culture and Thai working standards, during the months when they worked in Sweden. Similarly, managers in the Swedish IT industry situated most Indian workers within a fixed notion of Indian culture, rather than within a post-national identity.

My final reflection regarding how citizenship and social rights were considered as being irrelevant to the wellbeing of temporary migrant worker, places the moral position of the managers at the centre of these debates. The managers in the wild berry industry distanced themselves from an ideology of pity, which, they argued, characterised the general public's approach towards the Thai berry pickers. They argued that feeling sorry for berry pickers, and acting on this feeling, prevented the berry pickers from travelling and from creating a better life for themselves. The ways in which berry company managers embraced mobility, they argued, facilitated the empowerment of the migrant workers as well as economic development in both Sweden and Thailand. In the IT industry, the managers established their position as that of embracing globalisation rather than giving in to fear of change. By taking this as their moral position, they also defined the less moral position of suspicion towards the inevitable process of economic globalisation. These notions of moral positions raise questions about the role of employers and managers in relation to more general migration politics. In the next and final section of this thesis, I discuss the position from which managers can be understood as engaging in the design of migration regimes. 


\section{Epilogue: Employer arguments in the migration debate}

I began this thesis by illustrating how the labour migration debate references different moral positions. In the years following the 2008 reform of Sweden's labour migration policy, I observed how opposition to a liberal system of labour migration was often met with accusations of protectionist or nationalist agendas, and seen as illegitimate on moral grounds. In February 2017, the Social Democrats and the central blue collar Swedish Trade Union Confederation (LO) together announced that they intended to work towards stricter rules for labour immigration. They argued that in order to ease some of the administrative burden from highly desirable groups of highly qualified migrant workers, they wanted to leave lower qualified jobs, such as berry picking, for people who 'live in Sweden', such as newly arrived refugees (Dagens Nyheter 2017a). The announcement was met with opposition mainly on the grounds that only the internationalisation of markets can lead to economic growth in Sweden (Dagens Nyheter $2017 \mathrm{~b}, \mathrm{c}$ ). Thus, nine years later, in the spring of 2017, the debate was clearly not centred on any arguments about the wellbeing of migrant workers, nor was it centred on Swedish labour rights. The arguments along the lines of 'what is good for Sweden' positioned national economic responsibility as the central moral position. This position also corresponds to the moral position that dominated the most recent shift in migration politics towards increased control and security. In 2015, following the framing of a 'refugee crisis' (Hansen forthcoming), Sweden saw a dramatic shift in the political rhetoric of receiving refugees. Politicians went from embracing the challenge of meeting humanitarian commitments by welcoming refugees in the summer of 2015 , to enforcing stricter control systems with references to infrastructural and fiscal strains a few months later (ibid.). During those months before the increased security and increased border controls, refugees were however framed not only as a moral responsibility but also as an economic opportunity to solve the demographic deficit that Sweden is experiencing (ibid., see also Chapter 2 in this dissertation). According to Hansen, although it was finally the commitment to fiscal austerity and the inability to envision increased public spending that so abruptly changed the rhetoric, corporate actors argued that they were leading the way in terms of seeing refugee potential, and some of them accused politicians of giving in to xenophobic trends as regulations tightened (ibid.).

In migration politics that refer to the economic value of migrants, it is likely to matter how employers define the migrants that they need, both in relation to refugees and temporary migrant workers. The management discourses that I have studied in this thesis construct the control and 
regulation of temporary migrant workers as morally illegitimate on the grounds that these temporary migrants are integrated members of a global economy and work force. Private sector actors hence define who can be categorised as integrated in the economy, be it a national or a transnational economy. A position that is characterised by such inclusion is disassociated from the exclusion that generally defines the migrant, and therefore strict controls and regulations are not seen as legitimate.

Yet, analysing the managers' arguments is not the same as analysing the political influence they have and arguments in favour of stricter border controls also categorise migrants in relation to their 'usefulness' to both the economy and the national community. In the Social Democrats' and the LO's intervention in 2017 regarding stricter labour migration regulations, refugees were situated within the nation as a national economic responsibility. The labour migrants were, instead, classified as subjects who could be excluded, with references to a moral justification that other groups who were already here, such as refugees, needed these (precarious) jobs in order to become useful members of the national economy. In the announcement by the Social Democrats and the LO, labour migrants could be re-positioned as migrants who can legitimately be regulated by migration control through association and comparison with refugees. Proposing that low-qualified jobs need to go to refugees instead of to labour migrants situates these migrant categories in relation to each other, and hence avoided a debate in which anyone might be called a 'protectionist'. The debate can also be seen as a negotiation of non-citizenship, failed citizenship and membership in the community of value (Anderson 2013). The temporary migrant workers, whose comparably worse conditions at the labour market is justified by their citizenship elsewhere, are proposed to be replaced by refugees. When also refugees are expected to work with conditions that have previously been seen as belonging to labour markets outside Sweden, their conditioned belonging is made visible but also indicates that precarity is extended more generally, not only for non-citizens.

At certain times, private sector actors may be given a central position as political subjects, and empowered as agents with the crucial capacity to integrate, and make use of, different categories of migrants. From this position, capital notions of mobility and economy can be disseminated. Private sector arguments frame migration as something that needs to be defined in relation to both the economy and market demands. In the discourse on temporary labour migration, because people are more concerned with capital than they are with citizenship, the direction of the political argument changes in relation to the arguments set up by other actors. The political argument is reduced to border controls that may 
affect economic processes, rather than to the arrangements of a global economy. Countering a capitalism that has values of mobility and openness incorporated in it - a 'spirit', as Boltanski and Chiapello put it (2005) - is associated with the risk of returning to nostalgic arguments that reference the memory of a Swedish model of migration with clearly defined boundaries of national inclusion. By not sufficiently addressing transnational inequalities, and deepening the critique of how such inequalities are justified, arguments may lead to a dead-end where more and more groups are dismissed as being the problem of other nation states. This is, for instance, a dominant argument in relation to the so-called 'EU-migrants' who, when the symptoms become visible as poverty in Sweden, are often framed as the responsibility of their Eastern European home countries.

Finally, the point that I have argued in this Chapter, and ending with in these final notes, is the importance of studying the role of employers, and framing the management of migration as the management of global labour as well. On the one hand, I argue, this makes visible the importance of the role that employers (may) play on the political stage of migration policies, in ways that are not necessarily expected. On the other hand, understanding the role of employers demonstrates that variations in industry and the position of managers will shape how they understand labour supply on a global scale, and thus how they understand temporary labour migration. This thesis points out a need to investigate labour within migration processes further, and for future studies to bring migration research closer to the research on the global labour supply. 


\section{Bibliography}

Acker, Joan, Kate Barry and Joke Esseveld (1983) 'Objectivity and Truth: Problems in Doing Feminist Research', Women's Studies International Forum 6(4) pp. 423-435.

Acker, Joan (2006a) Class Questions: feminist answers, Larham: Rowman $\&$ Littlefield.

Acker, Joan (2006b) 'Inequality regimes: gender, class and race in organizations', Gender \& Society, Vol. 20(4) pp. 441-464.

Ahmed, Sara (2000) Strange Encounters: embodied others in post-coloniality, London: Routledge.

Ahmed, Sara (2004a) The Cultural Politics of Emotion, Edinburgh University Press: Edinburgh.

Ahmed, Sara (2004b) 'Affective Economies', in Social Text, Vol. 22(2), pp. 117-139.

Anderson, Bridget (2000) Doing the dirty work: the global politics of domestic labour, London: Zed.

Anderson, Bridget (2013) Us and them?: the dangerous politics of immigration control, Oxford: Oxford University Press.

Back, Les (2007) The Art of Listening, Oxford: Berg.

Bair, Jennifer (2005) 'Global Capitalism and Commodity Chains: Looking Back, Going Forward', Competition \& Change, Vol. 9(2) pp. 153-180.

Bak Jørgensen, Martin (2016) 'Precariat - what it is and what it isn't: towards an understanding of what it does', in Critical Sociology, Vol. 42(78): 959-974.

Balibar, Etienne and Immanuel Wallerstein (1991) Race, Nation, class: ambiguos identities, London: Verso.

Banerjee, Payal and Frank Ridzi (2008) 'Indian IT workers and Black TANF clients in the New Economy: a comparative analysis of the racialization of immigration and welfare policies in the U.S', in Race, Gender and Class, Vol. 15(1-2) pp. 98-114.

Barrientos, Stephanie and Andrienetta Kritzinger (2004) 'Squaring the Circle: Global Production and the Informalization of Work in South African Fruit Exports' in Journal of International Development, Vol. 16: pp. 81-92.

Barrientos, Stephanie, Gary Gereffi and Arianna Rossi (2011) 'Economic and social upgrading in global production networks: a new paradigm for a changing world', in International Labour Review, Vol. 150(3-4) pp. 319-341. 
Bauder, Harald (2006) Labor movement: how migration regulates labor markets, New York: Oxford University press.

Beck, Ulrich (2000) What is Globalization? Cambridge: Polity Press.

Beck, Ulrich and Edgar Grande (2007) Cosmopolitan Europe, Cambridge: Polity Press.

Becker, Sarah and Brittnie Aiello (2013) 'The Continuum of complicity: "Studying up"/studying power as a feminist, anti-racist, or social justice venture', in Women's Studies International Forum, Vol. 38, pp. 63-74.

Behtoui, A. and Neergaard, A. (2010) 'Social capital and wage differentials between immigrants and natives', in Work, Employment and Society, 24 (4):761-779.

Berezin, Mabel (2005) 'Economy and Emotion', in Smelser, N, and Swedberg, R. (ed.) The Handbook of Economic Sociology, Princeton: Princeton University Press.

Berlant, Lauren (2011) Cruel optimism, Durham: Duke University Press.

Bhambra, Gurminder K (2007) Re-thinking Modernity: Postcolonialism and the Sociological Imagination, Basinstoke: Palgrave MacMillan.

Bhambra, Gurminder K (2011) 'Cosmopolitanism and Postcolonial Critique' in Rovisco M. and Nowicka M. (eds) The Ashgate research companion to cosmopolitanism, Farnham: Ashgate.

Billig, Michael (1991) Ideology and opinions: studies in rhetorical psychology, London: SAGE.

Billig, Michael (1995) Banal Nationalism, London: Sage.

Boltanski, Luc and Eve Chiapello (2005) The New Spirit of Capitalism, London: Verso.

Bourdieu, Pierre (1984) Distinction: a social critique of the judgement of taste, London: Routledge.

Bowen, Sarah and Marie Sarita Gaytán (2012) 'The Paradox of Protection: National Identity, Global Commodity Chains, and the Tequila Industry, in Social Problems, Vol. 59(1) pp. 70-93.

Brah, Avtar (1996) Cartographies of Diaspora: Contesting Identities, London: Routledge.

Bredström, Anna (2008) Safe Sex, Unsafe Identities: intersections of 'race', gender, and sexuality in Swedish HIV/AIDS policy, Linköping: Linköping University.

Bridgman, Todd and Hugh Willmott (2006) 'Institutions and technology: Frameworks for understanding organizational change - the case of a major ICT outsourcing contract', in The Journal of Applied Behavioral Science, Vol. 42(1).

Burawoy, Michael (1976) 'The functions and reproductions of migrant labour', in American Journal of Sociology, 81(5) pp. 1050-1087. 
Burawoy, Michael (1998) 'The Extended Case Method', in Sociological Theory, Vol. 16(1) pp. 4-33.

Butler, Judith (2004) Undoing gender, New York: Routledge.

Calhoun, Craig (2007) Nations matter: citizenship, solidarity, and the cosmopolitan dream, Oxford: Routledge.

Calhoun, Craig (2008) 'Cosmopolitanism and Nationalism', in Nations and Nationalism, Vol. 4(3), pp. 427-448.

Calleman, Catharina and Petra Herzfeld Olsson (ed.) (2015) Arbetskraft från hela världen - hur blev det med 2008 års reform?, Demi Rapport 2015:9, Stockholm: Elanders.

Calleman, Catharina and Petra Herzfeld Olsson (2015) 'Inledning' in Calleman, C and Herzfeld Olsson, P. Arbetskraft från hela världen - hur blev det med 2008 års reform?, Demi Rapport 2015:9, Stockholm: Elanders.

Carbin, Maria (2010) Mellan Tystnad och Tal: flickor och hedersvådl i svensk offentlig politik, Stockholm: Stockholms Universitet.

Castells, Manuel (1996) The information age: economy, society and culture, The rise of the network society, Malden: Blackwell.

Castles, Stephen and Godula Kosack (1972). 'The Function of Labour Immigration in Western European Capitalism', in New Left Review, Vol. 73(May-June), pp. 3-21.

Castles, Stephen and Mark Miller (2003) The Age of Migration - International population movements in the modern world, Basingstoke: Palgrave.

Castles, Stephen (2006) 'Guestworkers in Europe: A Resurrection?', in International Migration Review 40(4), pp. 741-66.

Cerny, Phil (1995) 'Globalization and the Changing Logic of Collective Action', in International Organization Vol.49(4), pp. 595-625.

Cerny, Phil (1997) 'Paradoxes of the Competition State: The Dynamics of Political Globalization', in Government and Opposition 32 (2): pp. 251-74.

Chapman, Christopher, David Cooper and Peter Miller (2009) Accounting, Organizations, and Institutions, Oxford: Oxford University Press.

Chernilo, Daniel (2006) 'Social Theory's Methodological Nationalism Myth and Reality', in European Journal of Social Theory, Vol. 9(1) pp. 5-22.

Clough, Patricia Ticineto (2007) 'Introduction', in Clough, Patricia Ticineto and Halley, Jean O'Malley (ed.) The Affective Turn: theorizing the social, Durham: Duke University Press.

Coe, N., P. Dicken and M. Hess (2008) 'Global Production Networks: realizing the potential', in Journal of Economic geography, Vol. 8, pp 271-295.

Collins Particia Hill (1998) 'It's All in the Family: Intersections of Gender, Race and Nation', in Hypatia, 13(3): 62-82.

Connelly, Matthew (2008) Fatal Misconception: the struggle to control world population, Cambridge: Harvard University Press. 
Conti, Joseph A. and Moira O’Neil (2007) 'Studying Power: qualitative methods and the global elite', in Qualitative Research, Vol. 7(1), pp. 63-82.

Dagens Nyheter (2017a) 'Vi vill ha nya regler för arbetskraftsinvandring', DN Debatt 2017-02-13.

Dagens Nyheter (2017b) 'S och LO har fel om arbetskraftsinvandringen', DN Debatt 2017-02-15.

Dagens Nyheter (2017c) 'Gör det instället lättare att rekrytera från utlandet' DN Debatt 2017-02-15.

Daston, Lorraine (1995) 'The Moral Economy of Science', in Osiris, Vol. 10, Constructing Knowledge in the History of Science, pp. 2-24.

de Haas, Hein (2009) Mobility and Human Development, Oxford: International Migration Institute.

de Haas, Hein (2014)'What Drives Human Migration?' in B. Anderson and M. Keith (ed.) Migration: A COMPAS Anthology, Oxford: COMPAS.

Delgado Wise Raúl (2015) 'Migration and Labor under Neoliberal Globalization: key issues and challenges', in Schierup, C-U, Munck, R., Likic-Brboric, B., and Neergaard, A. (eds.) Migration, Precarity and Global Governance: challenges and opportunities for labour, Oxford: Oxford University Press.

Dunaway, Wilma (2014) 'Introduction' in Dunaway, W. (ed.) Gendered Commodity Chains: Seeing Women's Work and Household in Global Production, Stanford CA: Stanford University Press.

Edley, Nigel (2001) 'Analysing Masculinity: Interpretative Repertoires, Ideological Dilemmas and Subject Positions', in Wetherell, M., Taylor, S. and Yates, S.J. (eds.) Discourse as Data - a guide for analysis, London: Sage.

Ekman, Susanne (2013) 'Authenticity at Work: Questioning the New Spirit of Capitalism from a Micro-sociological Perspective', in Paul Du Gay \& Glenn Morgan (eds.), New Spirits of Capitalism? Crises, Justifications, and Dynamics, pp 294-316, Oxford: Oxford University Press.

Emilsson, Henrik and Karin Magnusson (2015) 'Högkvalificerad arbetskraftsinvandring till Sverige', in Calleman, C and Herzfeld Olsson, P. (eds.) Arbetskraft från hela världen - hur blev det med 2008 års reform?, Demi Rapport 2015:9, Stockholm: Elanders.

Emilsson Henrik (2016) Paper Planes: labour migration, integration and the state, Malmö: Malmö University.

Eriksson, Madeleine (2010) (Re)producing a periphery - Popular Representations of the Swedish North, Umeå: Department of Social and Economic Geography, Umeå University.

Eriksson, Madeleine and Aina Tollefsen (2013) 'Of Berries and Seasonal Work': The Swedish Berry Industry and the Disciplining of Labour Migration from Thailand', in Geiger, Martin and Pecoud, Antoine (eds.) 
Disciplining the Transnational Mobility of People, New York: Palgrave Macmillan.

Eriksson, Madeleine and Aina Tollefsen (2015) 'New figurations of labour in global circuits: migrant workers in the forest berry industry in Norrland, Sweden', in Faber S. T., Nielsen H.P. (eds.) Remapping gender, place and mobility: global confluences and local particularities in Nordic peripheries, Dorchester: Ashgate.

Esseveld, Johanna (1997) 'Att söka förändra vårt tänkande om kvinnlighet och kön/genus', in Lundqvist Å. and D. Mulinari (eds.) Sociologisk Kvinnoforskning, Lund: Studentlitteratur.

European Commission (2014) '5th Annual Report on Immigration and Asylum', $\operatorname{COM}(2014)$ 288, Brussels.

European Commission (2007) 'On circular migration and mobility partnerships between the European Union and third countries', $\operatorname{COM}(2007)$ 248, Brussels.

Fairclough, Norman (1995) Critical Discourse Analysis: the critical study of language, London: Longman.

Faist, Thomas (2000) The Volume and Dynamics of International Migration and Transnational Social Spaces, Oxford: Clarendon Press.

Fanon, Frantz (1986) Black skin, white masks, London: Pluto.

Fekete, Liz (2009) A Suitable enemy: racism, migration and Islamophobia in Europe, London: Pluto.

Fine, Ben and Alfredo Saad-Filho (2004) Marx's Capital, London: Pluto Press.

Frank, Denis (2005) Staten, företagen och arbetskraftsinvandringen, Växjö: Växjö University.

Frank, Denis (2010) 'Från statligt formad invandring till företagsdriven invandring - En jämförande studie av 2008 års regler för arbetskraftsinvandring till Sverige', in Berggren, (ed) Samhällshistoria i fokus: En festskrift till Lars olsson om arbete, migration och kultur, Lund: BigBadBooks.

Frank, Denis (2014) 'Changes in migration control during the neoliberal era: surveillance and border control in Swedish labour immigration policy', in Journal of Political Power, Vol. 7(3) pp. 413-432.

Freidberg, Susanne (2004) French Beans and Food Scares: Culture and Commerce in an Axious Age, Oxford: Oxford University Press.

Fryklund Björn and Anna Lundberg (eds.) (2010) Asylsökande $i$ Sverige: ett rättssäkert och värdigt mottagande för barn och vuxna?, Malmö: Malmö University.

Fudge, Judy (2014) 'Making claims for migrant workers: human rights and citizenship', in Citizenship Studies, Vol. 18(1) pp. 29-45. 
Garner, Steve (2015) A moral economy of whiteness: four frames of racialising discourse, Abingdon: Routledge.

Gavanas, Anna (2010) Who cleans the welfare state? Migration, informalization, social exclusion and domestic services in Stockholm, Stockholm: Institutet för Framtidsstudier Forskningsrapport.

Geertz, Clifford (1983) Local Knowledge: further essays in interpretative anthropology, New York: Basic Books.

Gereffi, Gary (2005) 'The Global Economy: Organization, Governance, and Development' in Smelser, Neil J. And Swedberg, Richard (eds.), The Handbook of Economic Sociology, 2nd ed., Princeton: Princeton University Press.

Glick Schiller, Nina, Linda Basch Linda and Cristina Szanton Blanc (1995) 'From Immigrant to Transmigrant: Theorizing Transnational Migration', in Anthropological Quarterly Vol. 68(1), pp. 48-63.

Glick Schiller, Nina, Tsyplyma Darieva and Sandra Gruner-Domic (2011) 'Defining cosmopolitan sociability in a transnational age. An introduction', in Ethnic \& Racial Studies. Vol. 34(3) pp. 399-418.

Glick Schiller Nina and Noel B. Salazar (2013) 'Regimes of Mobility Across the Globe', in Journal of Ethnic \& Migration Studies, Vol. 39(2) pp. 183200.

Glick Schiller, Nina (2015) 'Explanatory frameworks in transnational migration studies: the missing multi-scalar global perspective', in Ethnic \& Racial Studies, Vol. 38(13), pp. 2275-2282.

Gregg, Melissa, Seigworth, Gregory J. (2010) 'An Inventory of Shimmers', in Gregg, Melissa, Seigworth, Gregory J. (eds) The Affect Theory Reader, London: Duke University Press.

Gruber, Sabine (2007) Skolan gör skillnad: Etnicitet och institutionell praktik, Linköping: Linköping University.

Grönlund Krantz (2005) '[Question for the Parliament] Fråga 2005/06:887', January 302005.

Gunaratnam, Yasmin (2003) Researching race and ethnicity : methods, knowledge and power, Sage, London.

Hahamovitch, Cindy (2011) No man's land: Jamaican guestworkers in the America and the global history of deportable labor, Princeton University Press, Princeton.

Hall, Stuart (1996) 'Introduction' in Hall, Stuart \& Du Gay, Paul (ed) Questions of Cultural Identity, London, Sage.

Hammar, Tomas (ed) (1985) European Immigration Policy, Cambridge: Cambridge University Press.

Hammar, Tomas (1985) 'Sweden', in Hammar T. (ed.) , European Immigration Policy, Cambridge: Cambridge University Press. 
Hansen, Peo (2009) 'Post-national Europe, without cosmopolitan guarantees', Race \& Class, Vol. 50(4), pp. 20-37.

Hansen, Peo (2016) 'The European Unions' External Labour Migration Policy: Rationale, Objectives, Approaches and Results, 1999-2014', Paris: OECD Social, Employment and Migration Working Papers.

Hansen, Peo (forthcoming, spring 2017) 'Asylum or Austerity? The 'Refugee Crises' and the Keynesian Interlude', European Political Science

Hansen, Peo and Sandy Brian Hager (2010) The Politics of European Citizenship: deepening contradictions in social rights and migration policy, $\mathrm{Ox}-$ ford: Berghahn.

Haraway, Donna (1991) Simians, cyborgs, and women : the reinvention of nature, London: Free Association Book.

Harding, Sandra (2008) Sciences from below: Feminisms, postcolonialities, and modernities, Raleigh: Duke University Press.

Harvey, David (2000) Spaces of Hope, Edinburgh: Edinburgh University Press.

Harvey, David (2001) 'Essay: Globalization and the 'Spatial Fix', in Geographische revue, 2/2001, pp 23-30.

Haylett, Chris (2001) 'Illegitimate subjects?: abject whites, neoliberal modernisation, and middle-class multi-culturalism', in Environment and Planning Vol. 19, pp. 351-370.

Hedberg, Charlotta (2013), 'Grapes of wrath'? Power spatialities and aspects of labour in the wild berry global commodity chain'. in Competition and Change 17(1), 57-74.

Hedberg, Charlotta (2015) 'Doing Gender' in the wild berry industry: Transforming the role of Thai women in rural Sweden 1980-2012', in European Journal of Women's Studies, Vol. 23(2), pp. 169-184.

Hochschild, Arlie R. (1983) The Managed Heart: commercialization of human feeling, Berkley: Univ. of California Press.

Hochschild, Arlie R. (2000) 'The Nanny Chain', in American Prospect, Vol. 11(4), pp. 32-37.

Hochschild, Arlie R. (2002) 'Love and Gold', in B. Ehrenreich \& A. Hochschild (eds.), Global Woman, New York: Owl, pp. 15-31.

Holgersson, Helena (2011). Icke-medborgarskapets urbana geografi. Göteborg: Glänta.

Holstein James A., and Jaber F Gubrium (1995) The Active Interview, Thousand Oaks: SAGE.

Hondagneu-Sotelo, Pierrette (2001) Doméstica : immigrant workers cleaning and caring in the shadows of affluence, Berkley: University of California Press.

hooks, bell (1989) Talking Back: Thinking Feminist, Thinking Black, London: Sheba Feminist Publishers. 
Hopkins, Terence K. and Immanuel Wallerstein (1977) 'Patterns of development of the modern world-system', in Review Vol. 1(2), pp. 11-145.

Hopkins, Terence K. and Immanuel Wallerstein (1986) 'Commodity chains in the world economy prior to 1800', in Review, Vol. 10(1), pp. 157-170.

Jenkins, Richard $(1986,2010)$ Racism and recruitment : managers, organisations and equal opportunity in the labour market, Cambridge: Cambridge university Press.

Jessop, Bob (2007) State power: a strategic-relational approach. Cambridge: Polity.

Johannesson, Livia (2017) In Courts We Trust: Administrative Justice in Swedish Migration Courts, Stockholm: Stockholms Universitet.

Jonsson, Lena and Roger Uddstål (2002) 'En beskrivning av den svenska bärbranschen', Skog \& Trä, Uppsala: Sveriges Lantbruksuniversitet.

Jonsson, Stefan (2005) 'Världens centrum' in Jonsson, Stefan Världen $i$ vitögat, Stockholm: Nordstedts förlag.

Khosravi, Shahram (2010) 'An Ethnography of Migrant 'Illegality' in Sweden: Included yet Excepted? In Journal of International Political Theory, vol. 6(1), pp. 95-116.

Kjellberg, Anders (2010), 'Kollektivavtalens täckningsgrad samt organisationsgraden hos arbetsgivarförbund och fackförbund', in Working Life and Mobility Research Reports, 2010:1, Lund: Department of Sociology Lund University.

Kofman, Eleonore (2013) 'Gendered labour migrations in Europe and emblematic migratory figures', in Journal of Ethnic and Migration Studies, Vol. 39(4), pp. 579-600.

Krifors, Karin (2013) ' Entrepreneurs and Migration, the case of Sweden', in Note de l'Ifri, Paris: Ifri Center for Migration and Citizenship.

Lamont, Michele (2000) The dignity of working men: morality and the boundaries of race, class, and immigration, New York: Russell Sage Foundation.

Lamont, Michele (2012) 'Toward a Comparative Sociology of Valuation and Evaluation', in Annual Review of Sociology, Vol. 38(21), pp. 201-221.

Larsson, Jennie K. (2015) Integrationen och arbetets marknad, Falun: Atlas.

Lawler, Stephanie (2005) 'Disgusted subjects: the making of middle-class identities', The Sociological Review, Vol. 53(3), pp. 429-456.

Levitas, Ruth (1998) The Inclusive Society? Social Exclusion and New Labour, London: Macmillan.

Lister, Ruth (2003) Citizenship: feminist perspectives, New York: New York University Press.

LO (2013) Fusk och utnyttjande - om avregleringen av arbetskraftsinvandringen, LO Arbetsmarknad. 
Lundbäck, Karin (2010) 'Borta Bra men Indien Bäst', Ingenjören - Sveriges Ingenjörers Medlemstidning, 2010:1.

Lundström, Catrin (2010) 'White Ethnography: (Un)comfortable Conveniences and Shared Privileges in Field-Work with Swedish Migrant Women', in NORA: Nordic Journal of Women's Studies, Vol. 18(7), pp. 70-87.

Lundström, Catrin (2013) “Maid' sökes : “live-in-maids” och skillnadsskapande praktiker i svenska migranthem i Singapore’, in Gavanas, A. \& Calleman, C. (eds), Rena hem på smutsiga villkor? : hushållstjänster, migration och globalisering, Göteborg: Makadam.

Lutz, Helma (2008) 'Introduction' in, Lutz, Helma (ed.) Migration and domestic work; A European Perspective on a Global Theme. Aldershot: Ashgate.

Lutz, Helma (2011 The new maids : transnational women and the care economy, London: Zed.

Magnusson, Karin and Sayaka Osanami Törngren (2014) 'Migration och Integration av Högkvalificerade Arbetskraftsinvandrare' in Bevelander, P., H Emilsson, K. Magnusson och S. Osanami Törngren (eds.), Världens öppnaste land: arbetskraftsinvandring efter reformen 2008. Fores Studie 2014:1, Stockholm.

Marx, Karl (1954) [1867] Capital: a critique of political economy, Book 1. London: Lawrence \& Wishart.

Massey, Doreen B. (2005) For Space, London: SAGE.

Massey, Douglas S. (2004) International migration: prospects and policies in a global market, Oxford: Oxford University Press.

Massey, Douglas (1998) 'Introduction', in Massey, D., Worlds in Motion, Oxford: Clarendon Press.

McCall, Leslie (2001) Complex Inequality: gender, class and race in the new economy, New York: Routledge.

McDowell, L. (2009) 'Old and New European Economic Migrants: Whiteness and Managed Migration Policies', in Journal of Ethnic and Migration Studies, 35(1), pp. 19-36.

Menz, Georg (2008) The Political economy of managed Migration: nonstate actors, europeanization, and the politics of designing migration policies, Oxford: Oxford University Press.

Mešić, Nedžad and Charles Woolfson (2015) 'Roma berry pickers in Sweden - Economic crisis and new contingents of the austeriat', in European Review of Labour and Research, 21(1), pp. 37-50.

Mešić, Nedžad (2016) 'Paradoxes of European free movement in times of austerity - The role of social movement actors in framing the plight of Roma berry pickers in Sweden', in International Journal of Sociology and Social Policy, 36(5), pp. 289-303. 
Miles, Robert (1987) Capitalism and Unfree Labour: Anomaly or Necessity?, New York: Tavistock Books.

Miller Peter, Rose Nikolas (2008) Governing the present : administering economic, social and personal life, Cambridge: Polity.

Mulinari, Diana (2005) 'Forskarens biografi och situerade kunskapsproduktion', in Lunqvist, Å. Davies, K. Mulinari, D. (eds.), Att utmana vetandets gränser, Malmö: Liber.

Mulinari, Diana, de los Reyes, Paulina (2005) Intersektionalitet, Kritiska reflektioner över (o)jämlikhetens landskap, Malmö: Liber.

Mulinari, Paula and Rebecca Selberg (ed.) (2011) Arbete: intersektionella perspektiv, Malmö: Gleerup.

Mulinari, Paula (2007) Maktens fantasier \& servicearbetets praktik : arbetsvillkor inom hotell- och restaurangbranschen $i$ Malmö, Linköping: Linköpings Universitet.

Nader, Laura (1974) (1969) 'Up the Anthropologist-Perspectives Gained From Studying Up', in Dell Hymes (ed.) Reinventing Anthropology, New York : Vintage Books.

Neergaard, Anders (2015) 'Det fackliga löftet" - solidaritet, fackföreningsrörelse och arbetskraftsinvandring', in Calleman C. And Herzfeld Olsson P. (eds) Arbetskraft från hela världen - hur blev det med 2008 års reform?, Demi Rapport 2015:9, Stockholm: Elanders.

Nielsen, Amanda (2016) Challenging Rightlessness: on irregular migrants and the contestation of welfare state demarcation in Sweden, Växjö: Linnaeus University Press.

Nordling, Vanna (forthcoming 2017) Taking responsibility: Negotiating Undocumented Migrants' Access to Social Rights, dissertation, Lund University.

Näre, Lena (2011) The moral economy of domestic care and labour: Migrant workers in Naples, Italy, in Sociology, 45(3), pp. 396-412.

OECD (2011) Recruiting Immigrant Workers, Sweden, European Commission, Proposal for a Directive of the European Parliament and of the Council, 2010:0210, OECD Publishing.

Ong, Aihwa (2003) Buddha is Hiding: refugees, citizenship, the new America, Berkley: California Univ. Press.

Ong, Aihwa (2006) Neoliberalism as exception: mutations in citizenship and sovereignty, Durham: Duke University Press.

Parreñas, Rhacel Salazar (2001) Servants of Globalization: Migration and Domestic Work, Stanford: Stanford University Press.

Parreñas, Rhacel Salazar (2005) Children of Global Migration: transnational families and gendered woes, Stanford: Stanford Univ. Press. 
Parreñas, Rhacel Salazar (2010) 'Homeward bound: the circular migration of entertainers between Japan and the Philippines', Global Networks, 10:3, pp. 301-323.

Peck, Jamie (2001) Workfare states. New York: Guilford Press.

Pinsky, Dina (2015) 'The Sustained Snapshot: Incidental Ethnographic Encounters in Qualitative Interview Studies', in Qualitative Research, 15(3), pp. 281-295.

Piore, Michael J. (1979). Birds of Passage: Migrant Labor in Industrial Societies. Cambridge: Cambridge University Press.

Polanyi, Karl $(1944,2001)$ The great transformation : the political and economic origins of our time, Boston: Beacon Press.

Portes, Alejandro (1989) 'Contemporary immigration: Theoretical Perspectives on Its Determinants and Modes of Incorporation', in International Migration Review, 23(3), pp. 606-30.

Preibisch, Kerry (2010) 'Pick-Your-Own-Labour: Migrant Workers and Flexibility in Canadian Agriculture', International Migration Review, Vol. 44(2), pp. 404-441.

Puwar, Nirmal (2004) Space Invaders: race, gender and bodies out of place, Oxford: Berg.

Reay, Diane (2004) 'Gendering Bourdieu's concepts of capitals? Emotional capital, women and social class', in Adkins, Lisa and Beverly Skeggs (eds.), Feminism After Bourdieu, Oxford: Blackwell.

Rodrik, Dani (2011) The Globalization Paradox: why global markets, states, and democracy can't coexist, Oxford University Press, Oxford.

Rorty, Richard (1967) The Linguistic Turn: recent essays in philosophical method, Chicago: Univ. of Chicago Press.

Rosewarne, Stuart (2010) 'Globalisation and the Commodification of Labour: Temporary Labour Migration',in The Economic and Labour Relations Review, Vol.20(2), pp 99-110.

Ruhs, Martin (2013) The price of rights: regulating international labour migration, Princeton: Princeton University Press.

Räthzel, Nora, Diana Mulinari and Aina Tollefsen (2014) Transnational Corporations From the Standpoint of Workers, Basingstoke: Palgrave Macmillan.

Sager, Maja (2011) Everyday Clandestinity: Experiences on the Margins of Citizenship and Migration Policies, Lund: Lund University.

Said, Edward (1995) Orientalism, London: Penguin.

Saldana, Johnny, Patricia Leavy and Natasha Beretvas (2011) Fundamentals of Qualitative Research, New York: Oxford University Press.

Salzinger, Leslie (2003) Genders in production: making workers in Mexico's global factories, University of California Press, Berkley 
Sassen, Saskia (2000) 'The global city: strategic site/new frontier', in American Studies, Vol. 41(2) pp. 79-95.

Sassen, Saskia (2001) The Global City: New York, London, Tokyo, Princeton: Princeton University Press.

Saxenian, AnnaLee (2002) Local and Global Networks of Immigrant Professionals in Silicon Valley, San Francisco: Public Policy Institute of California.

Saxenian, AnnaLee (2006) The New Argonauts: regional advantage in a global economy, Cambridge MA: Harvard University Press.

Sayer, Andrew (2000) 'Moral Economy and Political Economy', in Studies in Political Economy. Vol.61, pp. 79-104.

Sayer, Andrew (2004) 'Moral Economy', Department of Sociology, Lancaster University, On-Line-Papers.

Sayer, Andrew (2005a) The Moral Significance of Class, Cambridge: Cambridge University Press.

Sayer, Andrew (2005b) 'Approaching moral economy', in Stehr, N., Henning, C., Weiler, B. (eds.) The Moralization of the Markets, New Jersey: Transaction Books.

Sayer, Andrew (2006) 'Language and significance - or the importance of import: implications for critical discourse analysis', in Journal of Language and Politics, Vol. 5(3) pp. 449-471.

Sayer, Andrew (2007) 'Moral economy as critique', in New Political Economy, Vol. 12(2) pp. 261-270.

Schierup, Carl-Ulrik, Peo Hansen and Stephen Castles (2006) Migration, Citizenship, and the European Welfare State: A European Dilemma, Oxford: Oxford University Press.

Schierup, Carl-Ulrik and Aleksandra Ålund (2011) 'The End of Swedish Exceptionalism? Citizenship, Neoliberalism and the Politics of Exclusion', in Race \& Class, Vol. 53, pp. 45-64.

Schierup, Carl-Ulrik, Aleksandra Ålund and Branka Likic-Brboric (2015) 'A global migrant precariat: Labour, Citizenship and space for civil society', in International Migration. Vol. 53(3), pp. 50-63.

Scott, James (1976) The Moral Economy of the Peasant: rebellion and subsistence in Southeast Asia, New Haven: Yale Univ. Press.

Scott, Joan Wallach (1988) Gender and the Politics of History, New York: Columbia University Press.

Selberg, Rebecca (2012) Femininity at Work - gender, labour and changing relations of power in a Swedish Hospital, Lund: Arkiv Förlag.

Selwyn, Ben (2012) 'Beyond firm-centrism: re-integrating labour and capitalism into global commodity chain analysis', in Journal of Economic Geography, Vol. 12, pp. 205-226. 
Skeggs, Beverly (2011) 'Imagining personhood differently: person value and autonomist working class value practices', in The Sociological Review, Vol. 59(3), pp. 496-513.

Slavnic, Zoran (2007), "Informalization of the Economy and the Recomodification of Labour", in Berggren, E. Likic-Brboric, B., Toksoz G. and Trimikliniotis N. (eds.), Irregular Migration, Informal Labour and Community: A Challenge for Europe, Maastricht: Shaker Publishing.

Slavnic, Zoran (2010), 'Political economy of informalization', in European Societies, Vol. 12(1), pp. 3-23.

Smelser, Neil (1998) 'The Rational and the Ambivalent in the Social Sciences', in Americal Sociological Review, Vol. 63(1), pp. 1-15.

Smith, Dorothy E. (2005) Institutional Ethnography: a Sociology for People, Walnut creek: Alta Mira Press.

Smith, Dorothy E. (2006a) Institutional Ethnography as Practice, Lanham: Rowman \& Littlefield.

Smith, Katherine E. (2006b) 'Problematising power relations in 'elite' interviews', in Geoforum, Vol. 37, pp. 643-653.

SOU 2011:28 Cirkulär migration och utveckling - förslag och framåtblick, Stockholm: Fritze.

SOU 2010:40, Cirkulär migration och utveckling - kartläggning av cirkulära rörelsemönster och diskussion om hur migrationens utvecklingspotential kan främjas, Stockholm: Fritze.

SOU 2006:87, Arbetskraftsinvandring till Sverige - förslag och konsekvenser, Stockholm: Fritze.

SOU 2005:50, Arbetskraftsinvandring till Sverige arbetsmarknad i förändring, internationell utblick befolkningsutveckling, Stockholm: Fritze.

Soysal, Yasemin (2012) 'Citizenship, immigration, and the European social project', in British Journal of Sociology, Vol. 63(1), pp. 1-21.

Soysal, Yasemin (1994) Limits of Citizenship: migrants and postnational citizenship in Europe, Chicago: Chicago University Press.

SR (2011) 'Konflikt, Bärplockarna som försvann', 2011-07-11.

Standing, Guy (2011) The Precariat: the new dangerous class, London: Bloomsbury.

Starosta, Guido (2010) 'Global Commodity Chains and the Marxian Law of Value', in Antipode, Vol 42(2), pp. 433-465.

Svallfors, Stefan (2006) The moral economy of class: class and attitudes in a comparative perspective, Stanford: Stanford University Press.

SVT (2011), 'Bärbranschen lägger ner organisation', http://www.svt.se/ nyheter/lokalt/vasterbotten/barbranschen-lagger-ner-organisation, accessed in January 2017.

Sydsvenskan (2013) 'LO förklär sitt makspel till omsorg', Ledare 201305-30. 
TheSwedishMigrationAgency 2014, 'Statistics on Labour Migration', found at; http://www.migrationsverket.se/download/18.7cood8e6143101d166ddaa/1485556207395/Beviljade+arbetstillstånd+2013+-+Work+permits+granted+2013.pdf, accessed in September 2016.

The Swedish Migration Agency 2016, 'Statistics on Labour Migration', http://www.migrationsverket.se/download/18.7cood8e6143101d166ddaa/1485556207395/Beviljade+arbetstillstånd+2015+-+Work+permits+granted+2015.pdf, accessed in February 2017.

Sörensson, Erika (2015) 'When your child gets easy money it feels good being a mom: Thai migrations and wild-berry picking in northern Sweden as a form of social reproduction', in Nordic Journal of Migration Research, vol. 5, no 4, pp. 207-214.

Tawney, Richard H. (1966) Land and Labor in China, Beacon Press: Boston. Thompson, E.P. (1971) 'The moral Economy of the English Crowd in the Eighteenth Century', in Past \& Present, Vol. 50, pp. 76-136.

Tornhill, Sofie (2010) Capital Visions: the politics of transnational production in Nicaragua, Stockholm: Stockholms Universitet.

Triandafyllidou, Anna (ed.) (2013) Circular Migration between Europe an its Neighbourhood: Choice or Necessity? Oxford: Oxford University Press.

Tshabalala, Xolani (forthcoming) Hyenas of the Limpopo - surplus movement, assisted border crossings, and social transformation across South Africa's border with Zimbabwe, Linköping University.

Tsing, Anna (2005) Friction: an ethnography of global connection, Princeton: Princeton University press.

Tsing, Anna L. (2009) 'Supply Chains and the Human Condition', in Rethinking Marxism, Vol. 21(2), pp. 148-176.

Tsing, Anna L. (2012) 'Ordinary Catastrophe: Outsourcing Risk in Supply-Chain Capitalism', in Heinlein, M. (ed) Futures of Modernity: Challenges for Cosmopolitical Thought and Practice, Bielefeld: Transcript.

Tsing, Anna L. (2015) The mushroom at the end of the world: on the possibility of life in capitalist ruins, Princeton: Princeton University Press.

Varma, Roli (2002) 'High-tech coolies: Asian immigrants in the US Science and Engineering Workforce', in Science as Culture, Vol.11(3), pp. 337-361.

Vertovec, Steven (2007) 'Circular migration: the way forward in global policy?’ Working Paper -International Migration Institute, University of Oxford.

Vesterberg, Viktor (2015) 'Ethnicized un/employability: Problematized Others and the shaping of advanced liberal subjects', in Ephemera: theory \& politics in organization, Vol. 13(4). 
Vesterberg, Viktor (2016) Ethnicizing Employability: governing the unemployed in labor market projects in Sweden, Linköping: Linköpings Universitet.

Vogiazides, Louisa and Charlotta Hedberg (2013) 'Trafficking for forced labour and labour exploitation in Sweden: Examples from the Restaurant and Berry Industries', in Ollus, Natalia et al (eds) Exploitation of migrant workers in Finland, Sweden, Estonia and Lithuania: Uncovering links between recruitment, irregular employment practices and labour trafficking, Helsinki: European Institute for Crime Prevention and Control.

Waldinger Roger and Micael Lichter (2003) How the Other Half Works: Immigration and the Social Organization of Labor, Berkley: University of California Press.

Walia, Harsha (2010) 'Transient Servitude: migrant labour in Canada and the apartheid of citizenship', in Race \& Class, Vol. 52(1), pp. 71-84.

Wallerstein, Immanuel (1983) Historical capitalism, New York: Verso.

Wallerstein, Immanuel (2000) 'Introduction to special issue on commodity chains in the world economy', 1590 to 1790, in Review, 23(1), pp. 1-13.

Weber, Max (1992) [1930] The Protestant Ethic and the Spirit of Capitalism, London: Routledge.

Welch, Catherine, Rebecca Marschan-Piekkari, Heli Penttinen and Marja Tahvanainen (2002) 'Corporate elites as informants in qualitative international business research', in International Business Review, Vol. 11, pp. 611-628.

Wernesjö, Ulrika (2014) Conditional Belonging: Listening to Unaccompanied Young Refugees' Voices, Uppsala: Uppsala University.

Westermark, Kristina (2013) Proximity and Learning in Internationalisation: Small Swedish IT Firms in India, Stockholm: Stockholm University.

Wetherell, Margaret and Jonathan Potter (1992) Mapping the language of racism : discourse and the legitimation of exploitation, Hemel Hempstead: Harvester Wheatsheaf.

Wetherell, Margaret (2003) 'Racism and the analysis of cultural resources in interviews', in ed. Wetherell, M., van den Berg, H., Houtkoop-Steenstra, H. (eds.), Analyzing Race Talk, Cambridge: Cambridge University Press.

Wetherell, Margaret (2012) Affect and emotion: a new social science understanding, London: SAGE.

White, Harrison (2002) Markets from Networks, Princeton: Princeton University Press.

Willmott, Hugh (2013) 'Spirited Away: When Political Economy Becomes Culturalized', in Du Gay, P. and Morgan G. (eds.), New Spirits of Capi- 
talism? Crises, Justifications, and Dynamics, Oxford: Oxford University Press.

Wingborg, Mats (2011) "Mors lilla Olle är en underbetald vietnames", Swedwatch.

Wingborg, Mats (2013a), Arbetsvillkor $i$ bläbärsskogen. En rapportserie om snåriga regler, utnyttjade plockare och solskenshistorier, Swedwatch.

Wingborg, Mats (2013b) Bärbranschen tar krafttag för bättre villkor $i$ blåbärsskogen, Context Swedwatch.

Wingborg, Mats (2014) 'Villkoren för utländska bärplockare säsongen 2014', Arena Idé, November 2014, Stockholm: Arena.

Winther Jørgensen, Marianne and Louise Philips (2002) Diskursanalys som teori och metod, Lund: Studentlitteratur.

Woolfson, Charles, Christer Thörnqvist and Petra Herzfeld Olsson (2012) 'Forced Labour and Migrant Berry Pickers in Sweden', The International Journal of Comparative Labour Law and Industrial Relations, Vol. 28(2), pp. 147-176.

Woolfson Charles, Judy Fudge and Christer Thörnqvist (2014) 'Migrant Precarity and Future Challenges to Labour Standards in Sweden', in Economic and Industrial Democracy, Vol.35(4), pp. 695-715.

Xiang, Biao (2007) Global "Body Shopping": an Indian labor system in the information technology industry, Princeton: Princeton University Press.

Xiang, Biao and Johan Lindquist (2014) 'Migration Infrastructure', in International Migration Review, Vol. 48(1), pp. 122 - 148.

Yimprasert, Junya (2010) 'The ongoing struggle of Thai berry pickers in Sweden, Migrant Workers' Union of Thailand', http://www.scribd. com/doc/45065606/A-report-on-The-on-going-struggle-of-Thai-berry-pickers-in-Sweden\#scribd.

Yuval-Davis, Nira (1997) Gender \& Nation, London: Sage.

Yuval-Davis, Nira (2011) The Politics of Belonging: intersectional contestations, Los Angeles: Sage.

Zelizer, Viviana (2011) Economic Lives: How Culture Shapes the Economy, Princeton: Princeton University Press.

Zelizer, Viviana (2012) 'How I became a relational sociologist and what does that mean?', in Politics \& Society, Vol. 40, pp. 145-174. 